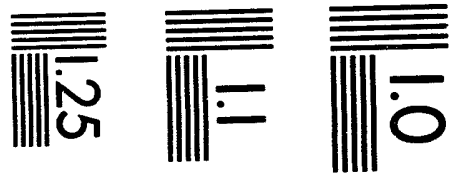

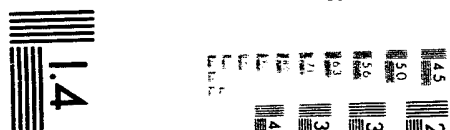

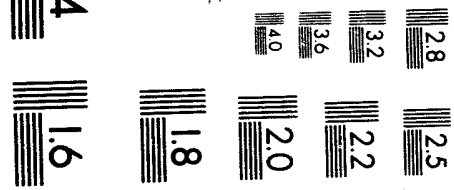



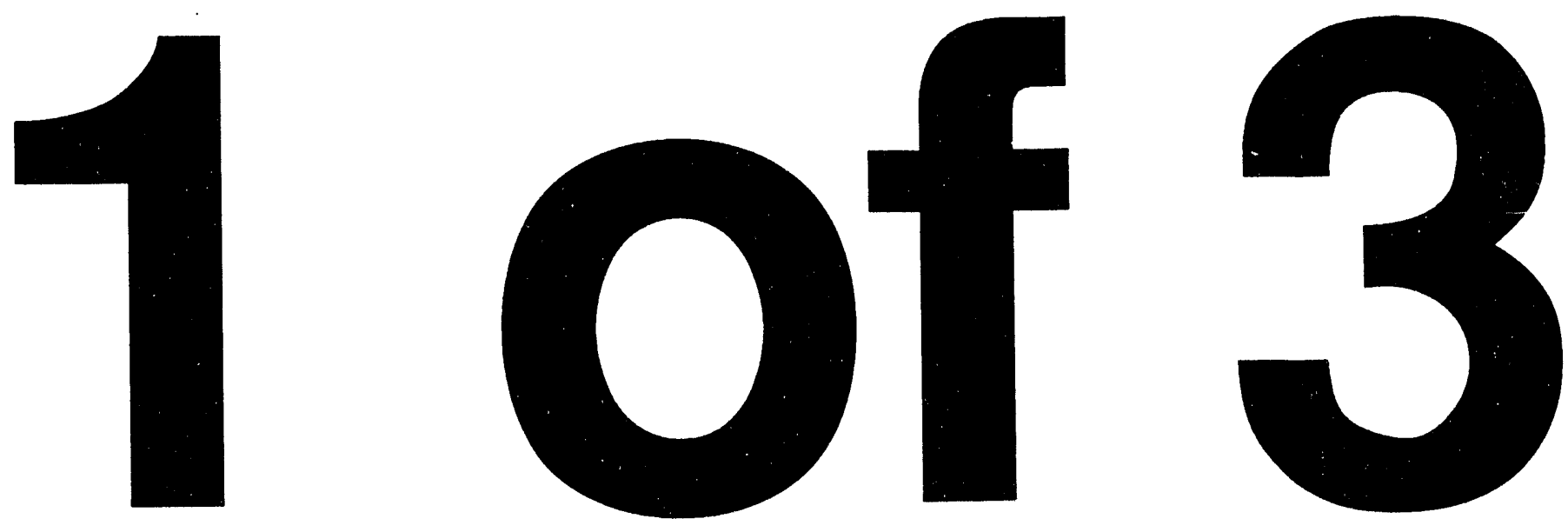


\section{(\% \\ ANALYSIS OF CONTAINMENT PERFORMANCE AND RADIOLOGICAL CONSEQUENCES UNDER SEVERE ACCIDENT CONDITIONS \\ FOR THE ADVANCED NEUTRON SOURCE REACTOR AT THE OAK RIDGE NATIONAL LABORATORY}

S. H. Kim

R. P. Taleyarkhan

January 1994

Prepared by the

Oak Ridge National Laboratory

Oak Ridge, Tennessee 37831-8057

Managed by

MARTIN MARIETTA ENERGY SYSTEMS, INC.

for the

U.S. DEPARTMENT OF ENERGY

under contract DE-ACO5-840R21400 
LIST OF FIGURES

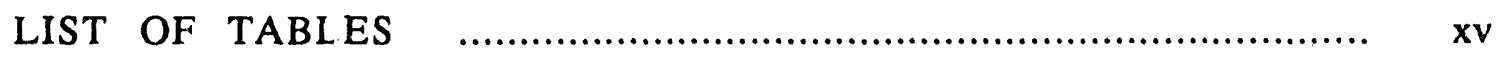

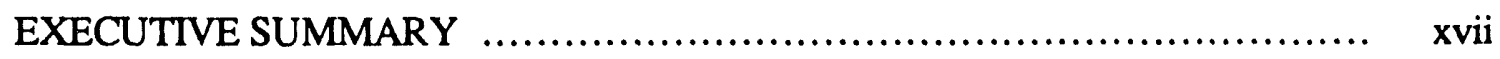

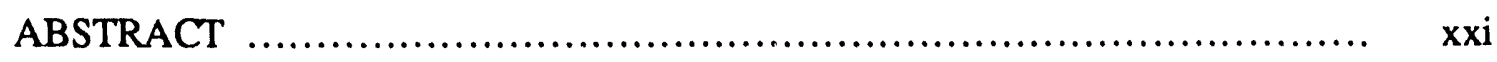

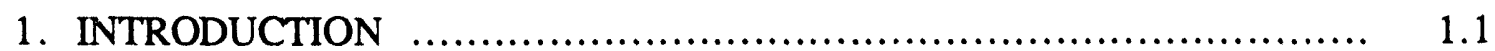

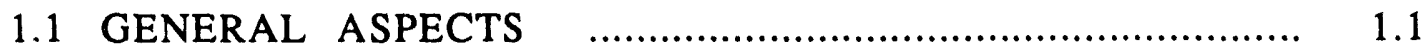

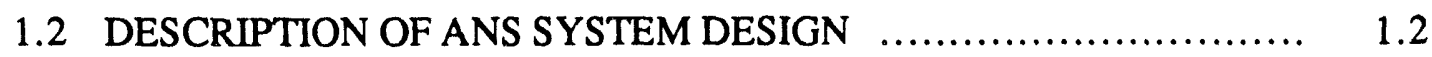

$\begin{array}{lll}1.3 & \text { PROBLEM FORMULATION FOR SOURCE TERM EVALUATION } \ldots & 1.2\end{array}$

2. SOURCE TERM EVALUATION …............................................ 2.1

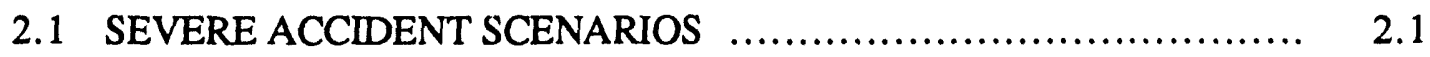

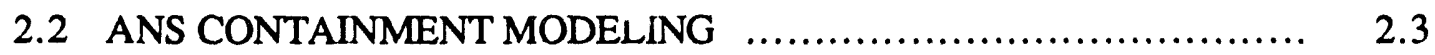

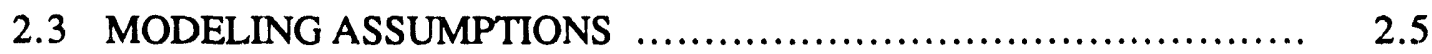

2.4 SEVERE ACCIDENT RESPONSE AND SOURCE TERM

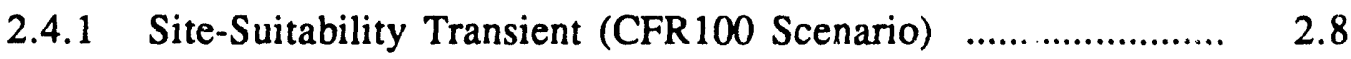

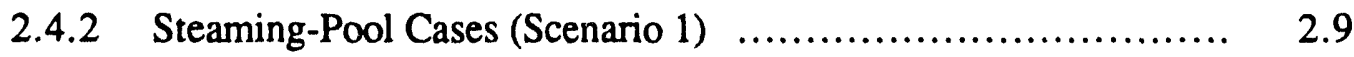

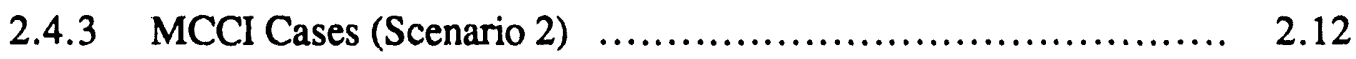

3. OFF-SITE CONSEQUENCES ................................................. 3.1

3.1 MODELING METHODOLOGY OVERVIEW ........................ 3.1

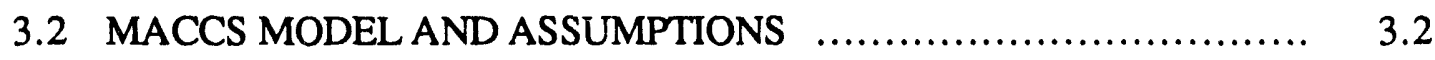

3.3 RADIOLOGICAL CONSEQUENCE RESULTS ...................... 3.5

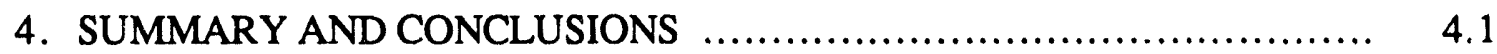

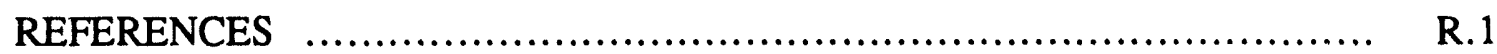

APPENDIX A Determination of Equivalent Activities for MACCS
Calculations 


\section{LIST OF FIGURES}

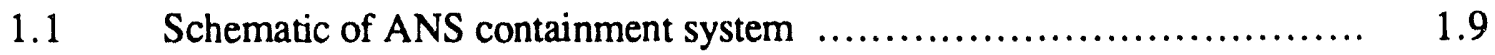

1.2 Partial core melt progression event tree for ANS CSAR $\ldots \ldots \ldots \ldots \ldots \ldots \ldots . . . . . .10$

$2.1 \quad$ ANS containment (MELCOR) representation for ANS CSAR ........... 2.25

2.2 Variation of ANS core debris end-of-cycle decay power vs time $\ldots \ldots \ldots . .26$

$2.3 \quad$ Variation of containment volume pressures vs time (Case - CFR100) $\ldots . .2 .27$

2.4 Variation of containment volume temperatures vs time

(Case - CFR100)

2.5 Variation of atmosphere aerosol masses vs time (Case - CFR100) ........ 2.29

2.6 Variation of atmosphere radionuclide vapor masses vs time (Case - SC1 - C) 2.30

2.7 Variation of total radionuclide mass deposition on heat structures vs time

(Case - CFR100)

$2.8 \quad$ Variation of radionuclide masses in reactor pool vs time (Case - SCl - B) 2.32

2.9 Variation of radionuclide masses in reactor pool vs time (Case - SC1 - B). 2.33

2.10 Variation of fractional radionuclide masses (volatile species) to the environment vs time (Case - CFR100)

2.11 Variation of fractional radionuclide masses (non-volatile species) to the environment vs time (Case - CFR100)

2.12 Variation of reactor pool water mass vs time (Case - CFR100) $\ldots . . . . . . . . .2 .36$

2.13 Variation of containment volume pressures vs time (Case - SC1-B) ..... 2.37

$2.14 \quad$ Variation of containment volume temperatures vs time (Case - SC1-B) $\ldots 2.38$

2.15 Variation of atmosphere aerosol masses vs time (Case - SC1 - B).......... 2.39

2.16 Variation of atmosphere radionuclide vapor masses vs time (Case - SC1 - B) 2.40

2.17 Variation of total radionuclide mass deposition on heat structures vs time (Case - SC1-B)

2.18 Variation of radionuclide masses in reactor pool vs time

(Case - SC1-B)

2.19 Variation of radionuclide masses in reactor pool vs time

(Case - SC1-B) 


\section{LIST OF FIGURES (continued)}

Eigure

Page

2.20 Variation of radionuclide masses (volatile species) to the environment vs time (Case - SC1-B)

2.21 Variation of fractional radionuclide masses (volatile species) to the environment vs time (Case - SC1-B)

2.22 Variation of reactor pool water mass vs time (Case -SC1 - B) .......... 2.46

2.23 Variation of containment volume pressures vs time (Case - SC1-C) ..... 2.47

2.24 Variation of containment volume temperatures vs time (Case - SC1 - C) ... 2.48

2.25 Variation of atmosphere aerosol masses vs time (Case - SC1-C) $\ldots . . . . . . .2 .49$

2.26 Variation of atmosphere radionuclide vapor masses vs time

(Case - SC1-C)

2.27 Variation of total radionuclide masses on heat structures vs time

(Case - SCl-C)

2.28 Variation of radionuclide masses in reactor pool vs time (Case - $\mathrm{SCl}-\mathrm{C}$ ).

2.29 Variation of radionuclide masses in reactor pool vs time (Case - SC1 - C).

2.30 Variation of fractional radionuclide masses (volatile species) to the environment vs time (Case - SC1-C)

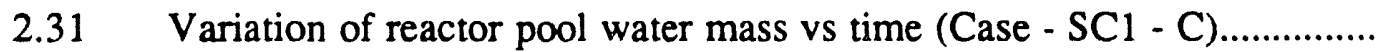

2.32 Variation of containment volume pressures vs time (Case - SC1-A) ......

2.33 Variation of containment volume temperatures vs time (Case SC1 - A)...

2.34 Variation of atrnosphere aerosol masses vs time (Case - SC1-A) ......... 2.58

2.35 Variation of atmosphere radionuclide vapor masses vs time

(Case - SC1-A)

2.36 Variation of total radionuclide masses on heat structures vs time

(Case - SC1-A)

2.37 Variation of radionuclide masses in reactor pool vs time (Case - SC1 - A). 2.61

2.38 Variation of radionuclide masses in reactor pool vs time (Case - SC1 - A). 2.62

2.39 Variation of fractional radionuclide masses (volatile species) to the environment vs time (Case - SCl-A)

2.40 Variation of reactor pool water mass vs time (Case SC1 - A) ... 


\section{LIST OF FIGURES (continued)}

Eigure

2.41a Variation of containment volume pressures vs time (Case - SC2-B) $\ldots \ldots .2 .65$

$2.41 \mathrm{~b}$ Variation of containment volume pressures vs time (Case - SC2-B) $\ldots \ldots .2 .66$

2.42a Variation of containment volume temperatures vs time (Case - SC2-B) $\ldots \quad 2.67$

$2.42 \mathrm{~b} \quad$ Variation of containment volume temperatures vs time (Case - SC2-B) $\ldots \quad 2.68$

2.43a Variation of containment volume hydrogen mole fractions vs time

(Case - SC2-B)

2.43b Variation of containment volume hydrogen mole fractions vs time

(Case - SC2-B)

2.44 Variation of containment volume gas and steam mole fractions vs time

(Case - SC2-B)

2.45 Variation of containment volume aerosol masses vs time

(Case - SC2-B)

2.46 Variation of atmosphere radionuclide vapor masses vs time (Case - SC2-B)

2.47 Variation of total deposited radionuclide masses on heat structures vs time (Case - SC2-B)

2.48 Variation of fractional radionuclide masses (volatile species) to the environment (Case - SC2-B)

2.49a Variation of containment volume pressures vs time (Case - SC2-C) $\ldots \ldots .2 .76$

$2.49 \mathrm{~b}$ Variation of containment volume pressures vs time (Case - SC2-C) $\ldots \ldots .2 .77$

2.50a Variation of containment volume temperatures vs time (Case - SC2-C) $\ldots \quad 2.78$

$2.50 \mathrm{~b}$ Variation of containment volume temperatures vs time (Case - SC2-C) $\ldots \quad 2.79$

2.51a Variation of containment volume hydrogen mole fractions vs time (Case - SC2-C)

$2.51 \mathrm{~b}$ Variation of containment volume hydrogen mole fractions vs time (Case - SC2-C)

2.52 Variation of containment volume gas and steam mole fractions vs time (Case - SC2-C)

2.53 Variation of containment volume aerosol masses vs time (Case-SC2-C) .. 2.83 


\section{LIST OF FIGURES (continued)}

Eigure

Page

2.54 Variation of atmosphere radionuclide vapor masses vs time

(Case - SC2-C)

2.55 Variation of total deposited radionuclide masses on heat structures vs time (Case - SC2-C)

2.56 Variation of fractional radionuclide masses entering the environment vs time (Case - SC2-C)

2.57a Variation of containment volume pressurss vs time (Case - SC2-A) ..... 2.87

$2.57 \mathrm{~b} \quad$ Variation of containment volume pressures vs time (Case - SC2-A) $\ldots . \ldots 2.88$

2.58a Variation of containment volume temperatures vs time (Case - SC2-A) .. 2.89

$2.58 \mathrm{~b}$ Variation of containment volume temperatures vs time (Case - SC2-A) .. 2.90

2.59a Variation of containment volume hydrogen mole fractions vs time (Case - SC2-A)

$2.59 \mathrm{~b}$ Variation of containment volume hydrogen mole fractions vs time (Case - SC2-A)

2.60 Variation of containment volume gas and steam mole fractions vs time (Case - SC2-A)

2.61 Variation of containment volume aerosol masses vs time (Case - SC2-A)

2.62 Variation of atmosphere radionuclide vapor masses vs time (Case - SC2-A)

2.63 Variation of total deposited radionuclide masses on heat structures vs time (Case - SC2-A)

2.64 Variation of fractional radionuclide masses entering the environment vs time (Case - SC2-A)

2.65a Variation of containment volume pressures vs time (Case - SC2-BF) $\ldots . .2 .98$

2.65b-1 Variation of containment volume pressures vs time (Case - SC2-BF) .... 2.99-1

2.65b-2 Variation of containment volume pressures vs time (Case - SC2-BF) predicted by MELCOR Mod 1.8.2

2.66a Variation of containment volume temperatures vs time (Case - SC2-BF) 


\section{LIST OF FIGURES (continued)}

Eigure

2.66b-1 Variation of containment volume temperatures vs time (Case - SC2-BF)

$2.66 \mathrm{~b}-2$ Variation of containment volume temperatures vs time predicted by MELCOR Mod 1.8.2

2.67a Variation of containment volume hydrogen mole fractions vs time (Case - SC2-BF)

2.67b-1 Variation of containment volume hydrogen mole fractions vs time (Case - SC2-BF)

2.67b-2 Variation of containment volume hydrogen mole fractions vs time predicted by MELCOR Mod 1.8.2

2.68 Variation of containment volume gas and steam mole fractions vs time (Case - SC2-BF)

2.69-1 Variation of containment volume atmosphere aerosol mass vs time (Case - SC2-BF)

2.69-2 Variation of containment volume atmosphere aerosol mass vs time predicted by MELCOR Mod 1.8.2

2.70-1 Variation of containment volume radionuclide vapor masses in atmosphere vs time (Case - SC2-BF)

2.70-2 Variation of containment volume radionuclide vapor masses in atmosphere vs time predicted by MELCOR Mod 1.8.2

2.71-1 Variation of total radionuclide masses deposited on heat structures vs time (Case - SC2-BF)

2.71-2 Variation of total radionuclide masses deposited on heat structures vs time predicted by MELCOR Mod 1.8.2

2.72-1 Variation of fractional radionuclide masses entering environment vs time (Case - SC2-BF)

2.72-2 Variation of fractional radionuclide masses entering environment vs time predicted by MELCOR Mod 1.8.2

2.73a Variation of containment volume pressures vs time (Case - SC2-CF) .... 2.109

2.73b-1 Variation of containment volume pressures vs time (Case - SC2-CF) ....2.110-1

$2.73 \mathrm{~b}-2$ Variation of containment volume pressures vs time predicted by MELCOR Mod 1.8.2 


\section{LIST OF FIGURES (continued)}

Figure

Page

2.74a Variation of containment volume temperatures vs time

(Case - SC2-CF)

2.74b-1 Variation of containment volume temperatures vs time

(Case - SC2-CF)

$2.74 \mathrm{~b}-2$ Variation of containment volume temperatures vs time predicted by

MELCOR Mod 1.8.2

2.75a Variation of containment volume hydrogen mole fractions vs time (Case - SC2-CF)

2.75b-1 Variation of containment volume hydrogen mole fractions vs time (Case - SC2-CF)

2.75b-2 Variation of containment volume hydrogen mole fractions vs time predicted by MELCOR Mod 1.8.2

2.76 Variation of containment volume gas and steam mole fractions vs time (Case - SC2-CF)

2.77-1 Variation of containment volume atmosphere aerosol mass vs time (Case - SC2-CF)

2.77-2 Variation of containment volume atmosphere aerosol mass vs time predicted by MELCOR Mod 1.8.2

2.78-1 Variation of containment volume radionuclide vapor masses in atmosphere vs time (Case - SC2-CF)

2.78-2 Variation of containment volume radionuclide vapor masses in atmosphere vs time predicted by MELCOR Mod 1.8.2 .

2.79-1 Variation of total radionuclide masses deposited on heat structures vs time (Case - SC2-CF)

2.79-2 Variation of total radionuclide masses deposited on heat structures vs time predicted by MELCOR Mod 1.8.2

2.80-1 Variation of fractional radionuclide masses entering environment vs time (Case - SC2-CF)

2.80-2 Variation of fractional radionuclide masses entering environment vs time predicted by MELCOR Mod 1.8.2.

2.81a Variation of containment volume pressures vs time (Case - SC2-AF) .... 2.120

2.81b-1 Variation of containment volume pressures vs time (Case - SC2-AF) ....2.121-1

2.81b-2 Variation of containment volume pressures vs time predicted by MELCOR Mod 1.8.2 


\section{LIST OF FIGURES (continued)}

Eigure

Page

2.82a Variation of containment volume temperatures vs time

(Case - SC2-AF)

2.82b-1 Variation of containment volume temperatures vs time (Case - SC2-AF)

2.82b-2 Variation of containment volume temperatures vs time predicted by MELCOR Mod 1.8.2

2.83a Variation of containment volume hydrogen mole fractions vs time (Case - SC2-AF)

2.83b-1 Variation of containment volume hydrogen mole fractions vs time (Case - SC2-AF)

2.83b-2 Variation of containment volume hydrogen mole fractions vs time predicted by MELCOR Mod 1.8.2

2.84 Variation of containment volume gas and steam mole fractions vs time (Case - SC2-AF)

2.85-1 Variation of containment volume atmosphere aerosol mass vs time (Case - SC2-AF)

2.85-2 Variation of containment volume atmosphere aerosol mass vs time predicted by MELCOR Mod 1.8.2

2.86-1 Variation of containment volume radionuclide vapor masses in atmosphere vs time (Case - SC2-AF)

2.86-2 Variation of containment volume radionuclide vapor masses in atmosphere vs time predicted by MELCOR Mod 1.8.2

2.87-1 Variation of total radionuclide masses deposited on heat structures vs time (Case - SC2-AF)

2.87-2 Variation of total radionuclide masses deposited on heat structures vs time predicted by MELCOR Mod 1.8.2

2.88-1 Variation of fractional radionuclide masses entering environment vs time (Case - SC2-AF)

2.88-2 Variation of fractional radionuclide masses entering environment vs time predicted by MELCOR Mod 1.8.2

3.1 Schematic representation for radiological consequences calculations using MACCS

3.2 Cancer fatality CCDF for the scenario CFR-100 


\section{LIST OF FIGURES (continued)}

Figure Page

3.3 Cancer injury CCDF for the scenario CFR-100 $\ldots \ldots \ldots \ldots \ldots \ldots \ldots \ldots . . . \ldots \ldots$

3.4 Population weighted risk CCDF of cancer fatality for the scenario CFR-100

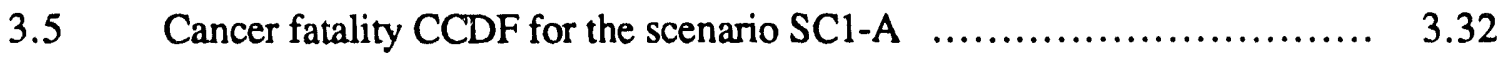

3.6 Cancer injury CCDF for the scenario SC1-A ........................ 3.33

Population weighted risk CCDF of cancer fatality for the scenario
SC1-A

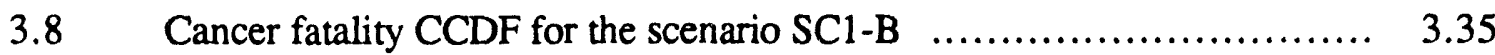

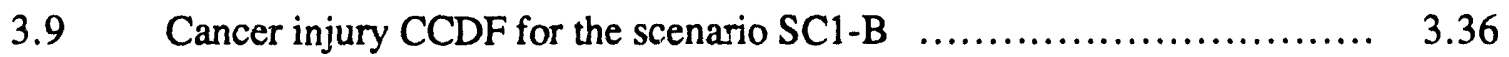

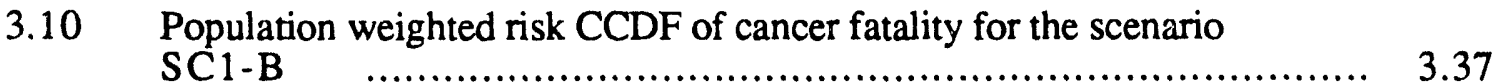

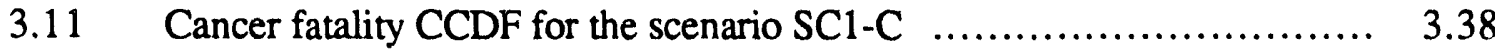

3.12 Cancer injury CCDF for the scenario SC1-C ......................... 3.39

3.13 Population weighted risk CCDF of cancer fatality for the scenario
SC1-C

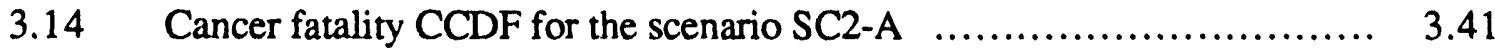

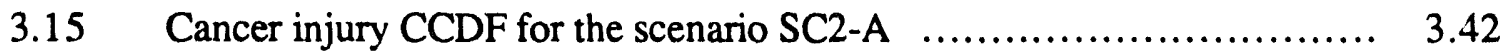

3.16 Population weighted risk CCDF of cancer fatality for the scenario

3.17 Prompt fatality CCDF for the scenario SC2-A ....................... 3.44

Population weighted risk CCDF of prompt fatality for the scenario
SC2-A

3.19 Cancer fatality CCDF for the scenario SC2-AF …............................ 3.46

3.20 Cancer injury CCDF for the scenario SC2-AF ……........................ 3.47

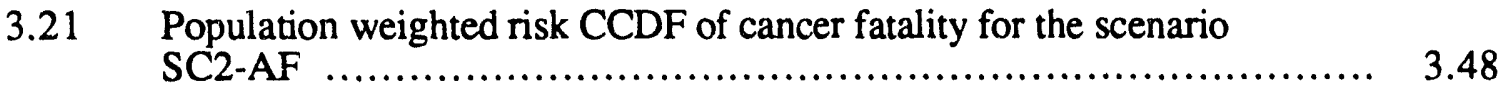

3.22 Prompt fatality CCDF for the scenario SC2-AF ...................... 3.49

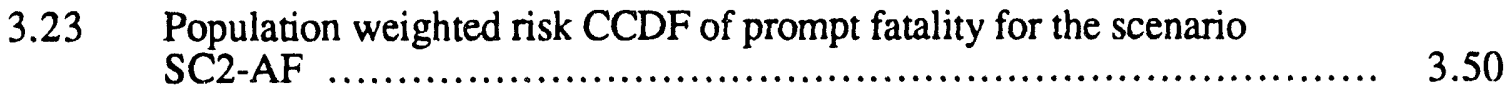




\section{LIST OF FIGURES (continued)}

Figure

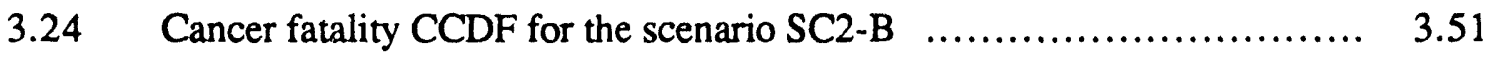

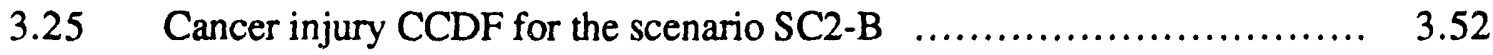

3.26 Population weighted risk CCDF of cancer fatality for the scenario

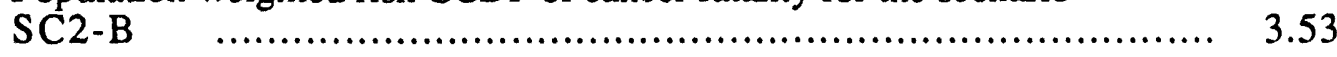

3.27 Cancer fatality CCDF for the scenario SC2-BF ……....................... 3.54

3.28 Cancer injury CCDF for the scenario SC2-BF ………................... 3.55

3.29 Population weighted risk CCDF of cancer fatality for the scenario

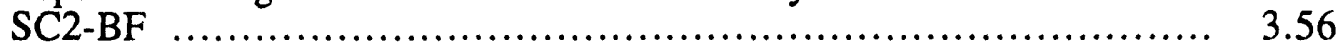

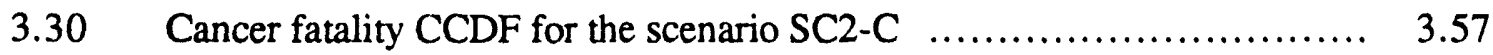

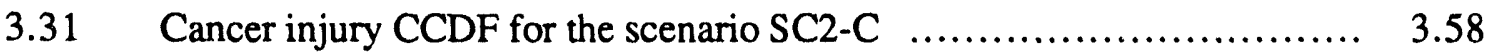

3.32 Population weighted risk CCDF of cancer fatality for the scenario

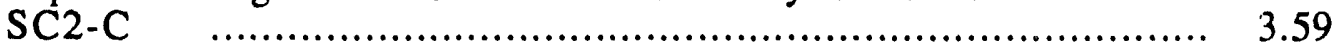

3.33 Prompt fatality CCDF for the scenario SC2-C ...................... 3.60

3.34 Population weighted risk $\mathrm{CCDF}$ of prompt fatality for the scenario

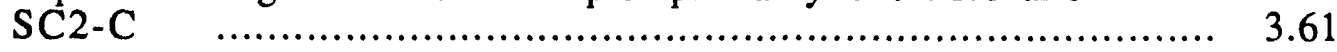

3.35 Cancer fatality CCDF for the scenario SC2-CF ……....................... 3.62

3.36 Cancer injury CCDF for the scenario SC2-CF ….......................... 3.63

3.37 Population weighted risk CCDF of cancer fatality for the scenario

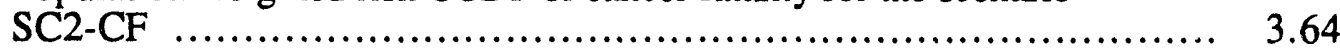




\section{LIST OF TABLES}

Table

Page

1.1 Severe Accident Characteristics of the ANS and Other Reactor

Systems

1.6

1.2 Calculation Matrix for ANS CSAR Study

1.7

1.3 Estimated Yearly Frequencies for Various Events

1.8

2.1 Radionuclide Mass Inventory Predicted by ORIGEN2 for ANS Core

(End-Of-Cycle)

2.2 Activity Levels for Important Radionuclides at End-Of-Cycle for ANS

Core

2.3 MELCOR Estimates for Fractional Fission Product Mass Released into the Environment for Various Accident Scenarios

2.4 Released Mass Fractions and Associated Rates of Energy Generation .....

3.1 Population Distribution and Emergency Response Zones for MACCS

Calculations

3.2 Population Distribution Around ANS

3.3 Mean Values for Health Consequences for Various Accident Scenarios ...

3.4 Number of People Exceeding Specified Dose of Various Organs for

Each Scenario

3.5 Population and Indiviclual Doses for the Steaming Pool Accidents

3.6 Population and Individual Doses for the Core Concrete Interaction Cases

Without Subpile Room Flooding

3.7 Population and Individual Doses for the Core Concrete Interaction Cases With Subpile Room Flooding

3.8 Variation of Average Individual Risk from the Scenario CFR-100

3.9 Variation of Average Individual Risk from the Scenario SC1-A

3.10 Variation of Average Individual Risk from the Scenario SC1-B

3.11 Variation of Average Individual Risk from the Scenario SC1-C

3.12 Variation of Average Individual Risk from the Scenario SC2-A

3.13 Variation of Average Individual Risk from the Scenario SC2-B 


\section{LIST OF TABLES (continued)}

Table Page

3.14 Variation of Average Individual Risk from the Scenario SC2-C ........... 3.23

3.15 Variation of Average Individual Risk from the Scenario SC2-AF ........ 3.24

3.16 Variation of Average Individual Risk from the Scenario SC2-BF ........ 3.25

3.17 Variation of Average Individual Risk from the Scenario SC2-CF ....... 3.26

3.18 Radiological Accident Risk Limitation Goals for the ANS ............. 3.27

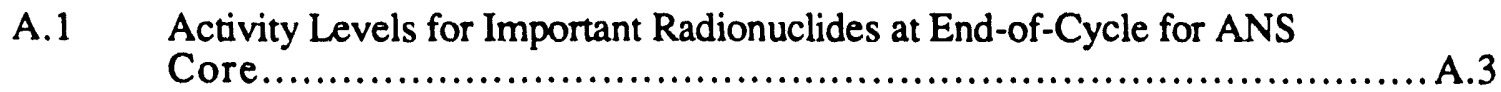

A.2 Deriving Equivalent Acitivty Levels for MACCS Radionuclides at Endof-Cycle for ANS Conditions .......................................... 5 


\section{EXECUTIVE SUMMARY}

A focused severe accident study is being conducted to evaluate conservatively scoped source terms and radiological consequences to support the Advanced Neutron Source (ANS) Conceptual Safety Analysis Report (CSAR), and to aid in the introduction of built-in design features for mitigation and management controls. This report presents the results of a conservative scoping study of potential severe accident risk associated with the ANS conceptual design. This study goes far beyond analysis of the design basis accidents andthe 10 CFR 100 prescribed fission product release typically found in Safety Analysis Reports (SARs) in that the issue of containment failure coincident with a severe fuel damage accident is addressed.

The MELCOR code (Ver. 1.8.1, Summers et al., 1991) is used to predict the transport of the fission product nuclides and their release from containment. The MACCS code (MELCOR Accident Consequence Code System - Ver. 1.5, Chanin et al., 1990) is used to determine subsequent atmospheric dispersion and radiation exposures. Approximate estimates of the frequency of the severe accident and the conditional probabilities of the various containment performance branch points are utilized to translate the cons quence numbers into estimates of risk to an individual.

Three different types of severe accident scenarios are postulated with a view of evaluating conservatively scoped source terms. The first scenario (i.e., Scenario 1) evaluates maximum possible steaming loads and associated radionuclide transport. The core debris for this case is assumed to be confined within a water volume of $100 \mathrm{~m}^{3}$. At the beginning of the MELCOR calculations, it is assumed that a partitioning of fission products has occurred. All of the noble gases and $50 \%$ of the halogen inventory escape from the water and get directly sourced into the atmosphere of the primary containment high bay area volume. The balance of the radionuclides stay behind and deposit their decay energy into the water, eventually causing steaming. The next scenario (i.e., Scenario 2) is geared towards evaluating conservative containment loads from releases of radionuclide vapors and aerosols with associated generation of combustible gases during the molten core-concrete interaction (MCCl). Due to the very high power density of the ANS fuel debris, it is postulated that during a core meltdown accident, core debris could ablate penetration seals or other structures and relocate onto the concrete floor of the subpile room. Thereafter, the core debris would spread and an $\mathrm{MCCl}$ event would begin. The containment will get challenged from the resulting loads arising from combustible gas deflagration, released radionuclides, in addition to other gases produced from the MCCI, and steaming (if flooding is employed). If flooding is employed, it is postulated that steam explosion loads, combined with aerosol suspension of nonvolatile fission products will not occur. It is not apparent that a steam 
explosion in the subpile room, or detonable quantities of combustible gases could directly threaten containment integrity. At this stage, this is difficult to state with certainty. Hence, from the standpoint of conservatism, we include the analysis of containment failure during MCCI. Several different containment configurations (including primary and/or secondary containment failure) are studied in combination with and without flooding during MCCI events. The third scenario follows the prescriptions given by the 10 CFR 100 guidelines for demonstrating ANS site suitability.

Several containment configurations are studied. These range from an intact primary and secondary containment (i.e., containment isolation), to at least partial failure of both the primary and secondary containment. The worst containment failure mode (viz., the failure of both primary and secondary containment) would occur in such a manner that a leakage path of some particular size would open to the environment.

For all the intact containment configurations including the 10 CFR 100 scenario, MELCOR predicted that only a negligible amount of radionuclides get released into the environment. The scenarios with the failure of the primary containment (with intact secondary containment) revealed that about $10 \%$ of noble gas inventory, and a few percent of volatile radionuclide inventories get released into the environment. For the cases with failure of both primary and secondary containment walls, however, the results show that about 10 to $20 \%$ of initial inventories of noble gases and volatile radionuclides are released into the environment. This source term information was used to drive MACCS for the evaluation of radiological consequences.

The results of radiological consequence calculations show that the MCCI case provides for greater fatalities than the steaming pool case (i.e., Scenario 1). Indeed, for the 10 CFR 100 case and all of Scenario 1 cases no prompt fatalities are predicted. This is because, for Scenario 1 several hours elapse before any significant amcunts of radioactivity are released to the environment, leaving sufficient time for evacuation and sheltering of all individuals on the ANS site and within the neighboring 3 rings. For a similar reason the MCCI case with flooding (viz., $\mathrm{SC2}-\mathrm{AF}$ ) gives rise to much lower values for prompt fatality in comparison to the similar case without flooding. This is despite the fact that the overall source terms (i.e., over $70 \mathrm{~h}$ ) for MCCI cases with flooding are much larger than for equivalent cases without flooding, and thus underscores the importance of providing a strategic flooding capability. The $0.25 \mathrm{~Sv}(25 \mathrm{rem})$, and $0.05 \mathrm{~Sv}$ ( $5 \mathrm{rem}$ ) PAG limits for the thyroid, and whole body dose limits are exceeded for the steaming pool scenario (i.e., scenario 1) with failure of the primary and secondary containments. For people close to the ANS site (i.e., within $2 \mathrm{~km}$ ), the non-flooding MCCI scenarios with containment failure (i.e., either failure of primary containment, or failure of both containment walls) lead to dose levels which exceed the PAG limits for the whole body and thyroid. Overall, individual risk for all cases was estimated to be substantially lower than the design goal risk. The margin of safety that has been demonstrated at this stage of development is a credit to the extremely 
low risk of core damage occurrence in the first place (i.e., ANS core damage frequency goal of less than $10^{-5}$ occurrences per year), coupled with an ANS containment failure frequency design goal of less than $10^{-2}$ per occurrence of a severe accident.

The results of this study show that the conceptual design meets the radiological risk limitation goals that have been established for the ANS Project. One of the ten sequences reported in this report adopts the radionuclide source term and containment performance assumptions prescribed by 10 CFR 100 for evaluation of site suitability. The predicted consequences for this event are very small compared to the $0.25 \mathrm{~Sv}$ ( $25 \mathrm{rem}$ ) radiation exposure guidelines in $10 \mathrm{CFR}$ 100 ; thus, the ANS design basis containment capabilities go beyond the minimum requirements of the regulations.

The calculations for six of the ten sequences investigated in this study assume partial or complete containment failure. Although the net risk attributed to these sequences is small and acceptable, the consequences would be significant, especially for personnel in the closest kilometer or two. These failures are not an inevitable consequence of the postulated core meltdown itself but rather reflect the finite possibility that containment isolation valves might not close and to a certain extent uncertainty over whether an energetic event might be able to penetrate primary and/or secondary containment with a shock wave or missile. Elimination of containment failure could yield significant risk reduction or perhaps the elimination of significant risk in a deterministic sense. This will therefore be a priority for design studies and severe accident calculations during the advanced conceptual phase planned for the ANS. 


\begin{abstract}
A severe accident study was conducted to evaluate conservatively scoped source terms and radiological consequences to support the Advanced Neutron Source (ANS) Conceptual Safety Analysis Report (CSAR).

Three different types of severe accident scenarios were postulated with a view of evaluating conservatively scoped source terms. The first scenario evaluates maximum possible steaming loads and associated radionuclide transport, whereas the next scenario is geared towards evaluating conservative containment loads from releases of radionuclide vapors and aerosols with associated generation of combustible gases. The third scenario follows the prescriptions given by the 10 CFR 100 guidelines. It was included in the CSAR for demonstrating site-suitability characteristics of the ANS. Various containment configurations are considered for the study of thermal-hydraulic and radiological behaviors of the ANS containment. Severe accident mitigative design features such as the use of rupture disks were accounted for.

This report describes the postulated severe accident scenarios, methodology for analysis, modeling assumptions, modeling of several severe accident phenomena, and evaluation of the resulting source term and radiological consequences.
\end{abstract}




\section{INTRODUCTION}

\subsection{GENERAL ASPECTS}

The Advanced Neutron Source (ANS) is to be a multipurpose neutron research center, currently in the design stage at the Oak Ridge National Laboratory (ORNL). The major purpose of the reactor will be condensed matter physics, materials science, isotope production, and fundamental physics research [C. D. West (1990) and F. J. Peretz (1991) ORNL/TM-11625]. ANS is planned to be a $330 \mathrm{MW}$ research reactor which uses $\mathrm{U}_{3} \mathrm{Si}_{2}$ Al cermet fuel in a plate-type configuration. A defence-in-depth philosophy has been adopted. In response to this commitment, ANS project management initiated severe accident analysis and related technology development early-on in the design phase itself. This was done to aid in designing a sufficientiy robust containment for retention and controlled release of radionuclides in the event of such an accident. It also provides a means for satisfying on- and off-site regulatory requirements, accident-related dose exposures, containment response, and source-term best-estimate analysis for level-2 and -3 Probabilistic Risk Analyses (PRAs) that will be produced. Moreover, it will provide the best possible understanding of the ANS under severe accident conditions and consequently provide insights for the development of strategies and design philosophies for accident mitigation, management, and emergency preparedness efforts (R. P. Taleyarkhan and S. H. Kim, 1992).

A focused severe accident study was conducted to evaluate conservatively scoped source terms and radiological consequences to support the ANS Conceptual Safety Analysis Report (CSAR), and to aid in the introduction of built-in design features for mitigation and management controls. This report describes the thermal-hydraulic and radionuclide transport modeling aspects along with analysis conducted for deriving source terms in support of the ANS CSAR. Also the methodology, assumptions, and modeling of various features related to radiation exposure, and health consequences from the source terms are presented in this report.

Due to the early stage in severe accident technology development for the ANS, relevant mechanistic tools have not been developed for evaluating core melt progression phenomena. Consequently, conservatively scoped scenarios were postulated and analyzed. To provide initial source-term estimates for the high consequence, low probability end of the severe accident risk spectrum, early containment failure cases are also evaluated for scenarios analyzed and reported in this paper. In addition, containment response for an intact containment configuration is also analyzed. 


\subsection{DESCRIPTION OF ANS SYSTEM DESIGN}

The ANS is currently in the conceptual design stage. As such, design features of the containment and reactor systems are evolving based upon insights from ongoing studies. Table 1 summarizes the current principal design features of the ANS from a severe accident perspective, in comparison with ORNL's High Flux Isotope Reactor (HFIR) ${ }^{4}$ and a commercial Light Water Reactor (LWR). Specifically, the ANS reactor will use about $15 \mathrm{~kg}$ of highly enriched (i.e., 93\% U-235 enrichment) uranium silicide fuel in an aluminum matrix with plate-type geometry, and a total core mass of $100 \mathrm{~kg}$. The power density of the ANS will be about 2 to 3 times higher than that of HFIR, and about 50 to 100 times higher than that of a large LWR. Due to such radical differences, high-powerdensity research reactors may give rise to significantly different severe accident issues. Such features have led to increased attention being given to phenomenological considerations dealing with steam explosions, recriticality, core-concrete interactions, core melt progression, and fission-product release. However, as opposed to power reactors scenarios, overall containment loads from hydrogen generation and defiagration are relatively unimportant for the ANS.

A schematic representation of the reactor and containment is given in Fig. 1. The reactor core is enclosed within a so-called core pressure boundary tube (CPBT) and enveloped in a reflector vessel. As seen in the figure, this reactor system is immersed in a large pool of water. Experiment and beam rooms for researchers are located on the first and second floors, which are connected to the third floor high-bay region through a rupture disk. The subpile room housing the control rod drive mechanisms is also connected to the third floor through lines with a rupture disk in between. The $\sim 95,000 \mathrm{~m}^{3}$ primary containment of the ANS consists of a $25 \mathrm{~mm}$ steel shell housed in a $0.8 \mathrm{~m}$ thick reinforced concrete secondary containment wall with a $1.5 \mathrm{~m}$ gap in between. The targeted design leak rate for the primary containment is $0.5 \mathrm{vol} \% /$ day (to the annulus), whereas, for the secondary containment the design leak rate is $10 \mathrm{vol} \% /$ day. Annulus flow is exhausted through vapor and aerosol filters. The containment isolation system is designed to automatically initiate closure of isolation valves on lines that penetrate the primary containment wall.

\subsection{PROBLEM FORMULATION FOR SOURCE TERM EVALUATION}

This report presents the results of a conservative scoping study of potential severe accident risk associated with the ANS conceptual design. This study goes far beyond 
analyzing for design basis accidents and the 10 CFR 100 prescribed fission product release typically found in Safety Analysis Reports (SARs) in that the issue of containment failure coincident with a severe fuel damage accident is addressed. By attacking the containment failure issue, we believe that this approach presents conservative estimates of the total potential severe accident risk posed by the ANS conceptual design.

The calculations of this report are premised upon the postulation that a severe core damage event involving melting of the reactor fuel has occurred. An event tree showing the several basically different paths along which the accident might progress is developed, and the paths that represent the greatest possibility for release of radioactivity are selected for detailed calculations. This results in the selection of ten sequences involving different combinations of assumed severe accident phenomena and containment failure modes.

The MELCOR code (Ver. 1.8.1, Summers et al., 1991) is used to predict the transport of the fission product nuclides and their release from containment. The MACCS code (MELCOR Accident Consequence Code System - Ver. 1.5, Chanin et al., 1990) is used to determine subsequent atmospheric dispersion and radiation exposures. Approximate estimates of the frequency of the severe accident and the conditional probabilities of the various containment performance branch points are utilized to translate the consequence numbers into estimates of risk to an individual.

The single most important factor in determining severe accident source terms is water - something the ANS has in abundance. The ANS reactor is located at the bottom of a $600 \mathrm{~m}^{3}$ pool of light water, and the primary coolant system has another $150 \mathrm{~m}^{3}$ of heavy water. Figure 1.2 illustrates the sequence of events between severe accident initiation and various states of debris cooling. Independent factors, such as core irradiation time, core power level at the time of the accident, etc., determine the path followed through the event tree for any given severe accident. Six end states are shown in Fig. 1.2. Three of the end states: 1,3 , and 4 involve cooled debris under a large quantity of water. In accordance with the spirit of conservatism, these end states have been temporarily neglected. Two of the end states, 2 and 5, involve debris that is dispersed in a significant but limited quantity of water $\left(100 \mathrm{~m}^{3}\right)$. End state 2 provides the beginning state for initializing the MELCOR code in Scenario 1 described in Chapter 2. End states 5 and 6 provide the MELCOR initialization point for the calculations of Scenario 2 in Chapter 2. To yield end states 5 and 6 , it must be postulated that the molten core debris melts through the primary coolant pressure boundary and drops into the subpile room. End state 5 would involve a situation whereby water would accompany the core debris relocating into the subpile room, or otherwise would be available via strategic flooding. Strategic flooding would involve proper injection of water such that a steam explosion would be avoided. Note that the 
mechanics of incorporating strategic flooding is not a part of the current ANS design. For end state 6 we postulate that somehow (e.g., possibly due to freezing of molten metals and plugging thereafter of breaches) none of the greater than $100 \mathrm{~m}^{3}$ of heavy water in the primary coolant system accompanies the debris.

The more likely containment failure modes involve excess leakage from primary containment to secondary containment (e.g., due to failure of electrical or mechanical penetrations). This sort of failure referred to as the "C" sequences (e.g., SC2-C) would be relatively benign since the uncompromised secondary containment air treatment system would still function to remove airborne radionuclides (excepting noble gases) prior to release to the environment. It is well known that severe accident phenomena can lead to containment failure under extreme conditions, but for the ANS this possibility is being minimized by design. That is, severe accident related loads are within the design basis of the ANS containment. For example, containment design pressure will be set sufficiently high to withstand static pressure loading due to fission product heating and from gases generated from severe accidents such as core-concrete interactions. There is a possibility that a severe accident initiated explosion (e.g., a steam explosion) could generate energetic missiles and/or shock waves. However, these explosive loads would have to be sufficiently energetic to breach the containment. For example, in order to cause failure of the primary and secondary containments, a missile generated from a steam explosion in the core region would have to rise through the large reactor pcol, to the top of the high bay and then penetrate both the steel primary containment, and the reinforced concrete secondary containment wall. Several such pathways are being closely examined for their damage potential, and will be designed against as warranted.

Several containment configurations are studied. These range from an intact primary and secondary containment (i.e., containment isolation), to at least partial failure of both the primary and secondary containment. The various containment configurations are shown in Table 1.2. The very worst containment failure mode (viz., the failure of primary containment and secondary containment) would occur in such a manner that a leakage path of some particular size would open to the environment. One credible way for this to happen would be for a containment ventilation line to fail to isolate upon demand. Since these lines are isolated by two valves in series, the probability of this failure mode is low less than $10^{-2}$ per demand. Other ways for this to happen could involve energetic events such as gas detonation, or steam explosions. At this stage mechanistic evaluations have not been conducted to quantify the likelihood of containment failure from such energetic events. 
The MACCS calculations reported in Chapter 3 show that significant radiation exposures are associated with the very conservative source terms posed for this report. To quantify the risks associated with the calculated radiation exposures it is necessary to consider accident and equipment failure probabilities. This was done using probability levels explained below.

Although the planned level 2 and level 3 PRAs have not been completed for the ANS, the approximate probability levels can be estimated from design goals and from the scoping PRA studies that have been completed to date. For example, the ANS design goal for limiting the risk of severe core damage is $10^{-5}$ per year, and preliminary PRA studies indicate that the goal should be achievable. Another safety-related design goal being applied during conceptual design is that the probability of containment failure should be less than $10^{-2}$ per accident initiated demand (i.e., via containment isolation). Scoping studies completed to date indicate that this goal can be achieved if special attention is paid to the design of personnel airlocks. From these considerations, it is evident that the mean frequency of severe accidents with containment failure is expected to be less than $10^{-7}$ per year assuming energetic events do not fail containment. Mechanistic analyses are needed for evaluating the effect of energetic events on containment failure. These are planned. However, from a conservatively bounding perspective if we postulate that energetic events can lead to containment failure following as many as $50 \%$ of the initiating events, the mean frequency of severe accidents with containment failure may be on the order of $5 \times 10^{-6}$. Furthermore, from consideration of the preliminary core melt progression event tree (Fig. 1.2), it is evident that Scenario 1-type outcome is representative of perhaps as much as $25 \%$ of core melt progression sequences, and Scenario 2 of a little more than $25 \%$, with the remaining $50 \%$ of possible melt progression outcomes being more favorable. These split fractions are based upon current knowledge and represent our best engineering judgment. They will be refined as best estimate tools are developed. Coupled with the different containment failure modes outlined in Table 1.2, we derive conditional probability levels for the various scenarios. Results of these probability levels are depicted in Table 1.3. These values will be used to estimate the health risks reported in Chapter 3. It is recognized that lower consequences, higher probability severe accidents will add to the overall ANS severe accident risk profile. To what extent is difficult to state at this stage of development. The work to estimate these risks is planned, and preliminary results will be reported in the Preliminary Safety Analysis Report (PSAR). Final results will be documented in the Final Safety Analysis Report (FSAR). For the present CSAR, analysis was conducted only for consequences from the ten events summarized in Table 1.2. 
Table 1.1. Severe accident characteristics of the ANS and other reactor systems

\begin{tabular}{lccc}
\hline \multicolumn{1}{c}{ Parameter } & Commercial LWR & HFIR & ANS \\
\hline Power [MW(t)] & 2600 & 85 & 300 \\
Fuel & $\mathrm{UO}_{2}$ & $\mathrm{U}_{3} \mathrm{O}_{8}-\mathrm{Al}$ & $\mathrm{U}_{3} \mathrm{Si}_{2}-\mathrm{Al}$ \\
Enrichment (m/o) & $2-5$ & 93 & 93 \\
Fuel Cladding & $\mathrm{Zircaloy}$ & $\mathrm{Al}$ & $\mathrm{Al}$ \\
Coolant/Moderator & $\mathrm{H}_{2} \mathrm{O}$ & $\mathrm{H}_{2} \mathrm{O}$ & $\mathrm{D}_{2} \mathrm{O}$ \\
Coolant Outlet Temperature $\left({ }^{\circ} \mathrm{C}\right)$ & 318 & 69 & 92 \\
Avg. Power Density $(\mathrm{MW} / \mathrm{T})$ & $<0.1$ & 1.7 & 4.5 \\
Clad Melting Temperature $\left({ }^{\circ} \mathrm{C}\right)$ & 1850 & 580 & 580 \\
Hydrogen Generation Potential $(\mathrm{kg})$ & 850 & 10 & 12 \\
\hline
\end{tabular}


Table 1.2. Calculation matrix for ANS CSAR study

\begin{tabular}{llccc}
\hline Calc 1.D. & Scenario & $\begin{array}{c}\text { Secondary } \\
\text { containment } \\
\text { failure }\end{array}$ & $\begin{array}{c}\text { Primary } \\
\text { containment } \\
\text { failure }\end{array}$ & $\begin{array}{c}\text { Subpile } \\
\text { room } \\
\text { nooding }\end{array}$ \\
\hline SC1-A & Steaming pool & Yes & Yes & No \\
SC1-B & Steaming pool & No & No & No \\
SC1-C & Steaming pool & No & Yes & No \\
SC2-A & CCI & Yes & Yes & No \\
SC2-B & CCI & No & No & No \\
SC2-C & CCI & No & Yes & No \\
SC2-AF & CCI & Yes & Yes & Yes \\
SC2-BF & CCI & No & No & Yes \\
SC2-CF & CCI & No & Yes & Yes \\
CFR100 & Steaming pool & No & No & No \\
\hline
\end{tabular}

Note:

(1) Containment failure is assumed to be 0.5 diameter hole.

(2) Flooding to a subpile room is made strategically to ensure the effectiveness of core-concre interaction (CCI) mitigation. 
Table 1.3. Estimated yearly

frequencies for various events

\begin{tabular}{lc}
\hline Event & $\begin{array}{c}\text { Net occurrence frequency } \\
\text { (occurrence per year) }\end{array}$ \\
\hline CFR $100^{b}$ & $2.5 \times 10^{-6}$ \\
SC1-A & $6.25 \times 10^{-7}$ \\
SC1-B & $2.5 \times 10^{-6}$ \\
SC1-C & $1.25 \times 10^{-6}$ \\
SC2-A & $3.125 \times 10^{-7}$ \\
SC2-B & $1.25 \times 10^{-6}$ \\
SC2-C & $6.25 \times 10^{-7}$ \\
SC2-AF & $3.125 \times 10^{-7}$ \\
SC2-BF & $1.25 \times 10^{-6}$ \\
SC2-CF & $6.25 \times 10^{-7}$ \\
\hline
\end{tabular}

$a_{\text {Frequencies are displayed only for }}$ certain branches of event tree (Fig. 15.12.1). Therefore, the sum of all frequencies for $\mathrm{SC} 1$ and $\mathrm{SC} 2$ scenarios shown above do not total to $1.0 \times 10^{-5}$.

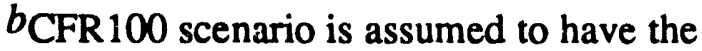
same frequency as the base case of the steaming pool scenario SC1-B. 


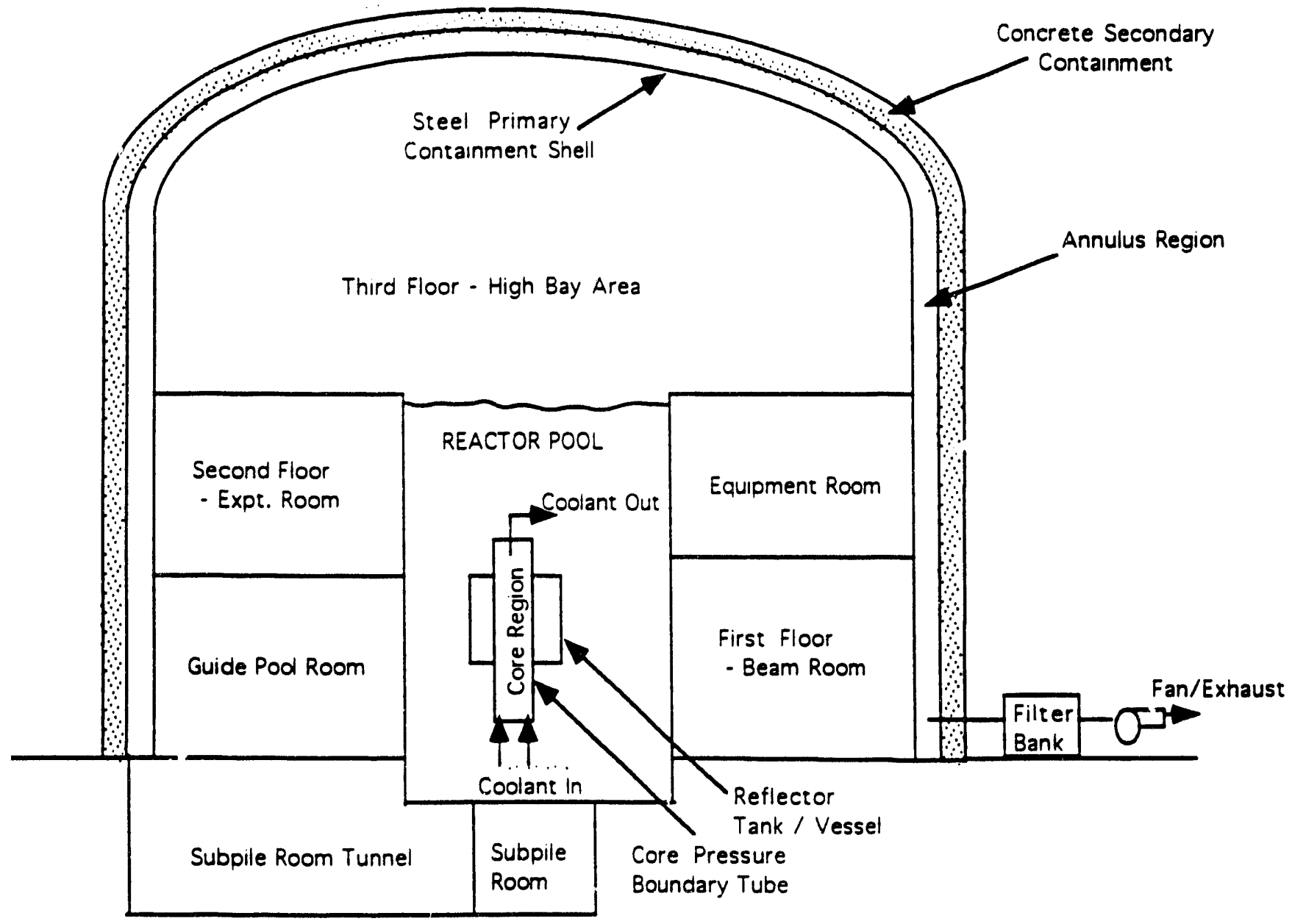

Figure 1.1 Schematics of ANS Containment System 


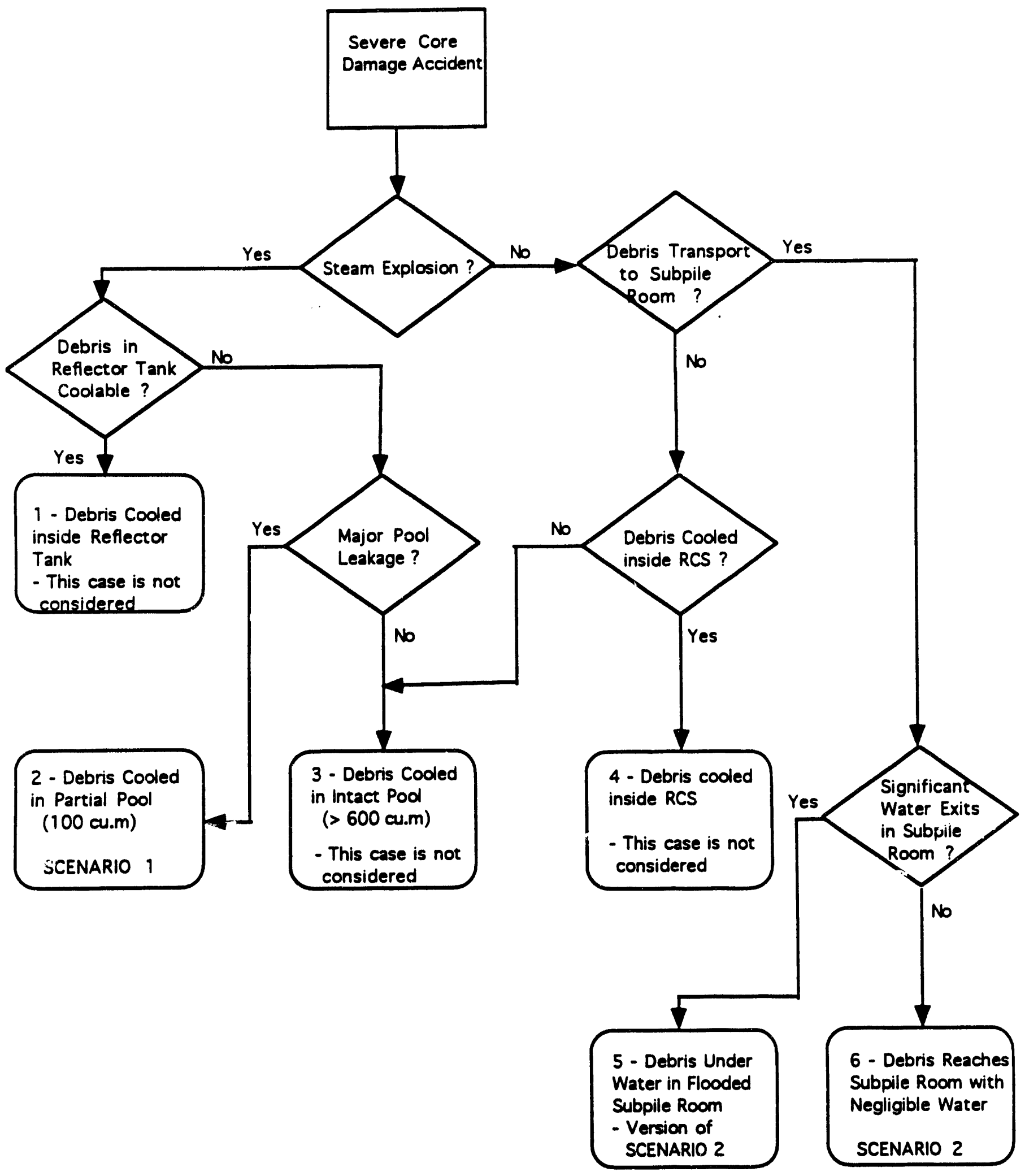

Figure 1.2 Partial Core Melt Progression Event Tree for ANS CSAR 


\section{SOURCE TERM EVALUATION}

This section describes the postulated severe accident scenarios, methodology for analysis, modeling assumptions, modeling of several severe accident phenomena, and the resulting source terms.

\subsection{SEVERE ACCIDENT SCENARIOS}

Because the severe accident analysis work 'as been initiated for the ANS at a much earlier stage than for other nuclear reactor projects, it has not been possible to develop mechanistic tools for capturing core melt progression phenomena. As explained above, three different types of severe accident scenarios are postulated with a view of evaluating conservatively scoped source terms. The first scenario (i.e., Scenario 1) evaluates maximum possible steaming loads and associated radionuclide transport, whereas the next scenario (i.e., Scenario 2) is geared towards evaluating conservative containment loads from releases of radionuclide vapors and aerosols with associated generation of combustible gases. The third scenario follows the prescriptions given by the 10 CFR 100 guidelines (J. J. DiNunno et al., TID-14844, 1963). It was included for the CSAR for evaluating the ANS containment response for a site-suitability basis transient, and is herein referred to as the CFR 100 scenario. It is similar to end states 2 and 3 of the preliminary containment event tree shown in Fig. 1.2.

Specific aspects of explosive conditions have not been modeled mechanistically, but the reader should note that we have modeled containment failure pathways (viz., primary to secondary, and secondary to environment) as flow paths with a diameter of $0.5 \mathrm{~m}$. While we have yet to conduct mechanistic analyses to evaluate the range of possible breach sizes, we presently judge this modeling feature to be a conservative (if not bounding) way to account for the possibility of primary containment failure by missiles or shock waves generated from steam-explosions or other explosive processes.

\section{Scenario 1: Severe Accident Steaming Event}

The evaluation of loads from steaming events during severe accidents is done via Scenario 1, in conjunction with various containment failure modes. The core debris for this case is assumed to be confined within a water volume of $100 \mathrm{~m}^{3}$. At the beginning of the MELCOR calculations, it is assumed that a partitioning of fission products has occurred. All of the noble gases and $50 \%$ of the halogen inventory escape from the water 
and get directly sourced into the atmosphere of the primary containment high bay area volume. The balance of the radionuclides stay behind and deposit their decay energy into the water, eventually causing steaming. This prescription is clearly conservative since it makes no allowance for core material degradation, relocation, fission product release and possible retention during the time before onset of steaming. It also does not consider iodine removal due to scrubbing as it passes through a body of water (e.g., the large reactor pool in the ANS). However, it does represent a conservative guide for evaluation of source terms in the absence of mechanistic melt progression analyses.

\section{Scenario 2: Molten-Core-Concrete-Interaction (MCCI) Event}

Based upon more than a decade of research (first discussed in the Reactor Safety Study (RSS) or WASH-1400) on severe accidents for power reactors it is now well-known that the study of MCCIs represents an important phase of any hypothetical severe accident that has progressed to the point of core debris relocation outside of the primary system onto a concrete surface. MCCI events can release large amounts of combustible gases ( $\mathrm{CO}$ and $\mathrm{H}_{2}$ ), and also release considerable radionuclides in the form of vapors and aerosols. Due to the very high power density of the ANS fuel debris it is postulated that during a core meltdown accident, core debris could ablate penetration seals or other structures and relocate onto the concrete floor of the subpile room. Thereafter, the core debris would spread and an MCCI event would begin. Details of a scoping study conducted for the ANS on MCCI are reported elsewhere (C. R. Hyman and R. P. Taleyarkhan, 1991, ORNL/ TM-11761). The scenario postulated for the current study conservatively assumes that the core debris will relocate rapidly (i.e., $75 \mathrm{~s}$ after scram) onto a dry or partially flooded (limestone common-sand) concrete floor in the subpile room: Thereafter, the containment will get challenged from the resulting loads arising from combustible gas deflagration, released radionuclides, in addition to other gases produced from the $\mathrm{MCCI}$, and steaming (if flooding is employed). If flooding is employed, it is postulated that steam explosion loads, combined with aerosol suspension of nonvolatile fission products will not occur. It is not apparent that a steam explosion in the subpile room, or detonable quantities of combustible gases could directly threaten containment integrity. At this stage, this is

difficult to state with certainty. Hence, from the standpoint of conservatism, we include the analysis of containment failure during MCCI. Several different containment configurations (including primary and/or secondary containment failure) are studied in combination with and without flooding during MCCI events. 
CFR100 scenario: Site-Suitability Basis Scenario Event

The CFR 100 scenario is analyzed based upon the prescriptions given by the 10 CFR 100 guidelines as mentioned earlier for demonstrating ANS site suitability. It has a long history of similar usage for demonstrating power reactor site licensing from a radionuclide consequence standpoint. For ANS, the CFR100 scenario is analyzed for the intact primary and secondary containment configuration with prescribed partitioning of volatiles and non-volatile fission products which tends to maximize the amount of steaming loads.

\subsection{ANS CONTAINMENT MODELING}

ANS contain wnt modeling was conducted using the MELCOR (Ver. 1.8.1) severe accident analysis code. MELCOR is a fully integrated computer code that has been primarily developed for power reactor severe accident analysis, and incorporates models for core melt progression (specific to power reactors), and generalized containment response evaluations including radionuclide transport, and engineered safety features. It has been developed by the USNRC as a second generation plant risk assessment tool. MELCOR is a control volume code that models transport of various materials between volumes via so-called flow paths. Extensive capability is available for fairly detailed representation of complex heat absorbing structures, and flow paths for various materials and radionuclides (both as vapors and aerosols).

Although general in nature, MELCOR does not have the capability of modeling specific core melt progression phenomena in the ANS associated with a radically different fuel-type, power density, materials, and geometry. Hence, as mentioned previously the three scenarios are modeled without taking into consideration the salient aspects of core melt progression. The ANS MELCOR containment representation developed for the current study is shown in Fig. 2.1. Significant additional coding was done to develop so-called control functions which enable the defining or control of various aspects of the simulation such as opening and closing of valves; specification of pump characteristics, specification of heat structure boundary conditions, controlling plot, edit, and restart frequencies, etc. As seen in Fig. 2.1, all of the major components of the ANS containment have been represented along with associated flow paths. The model consists of 11 control volumes, 15 flow paths, and 21 heat structures (which represent structural components such as walls, ceilings, shells and miscellaneous materials) of various shapes. Inleakage to the annulus is modeled assuming allowance of $0.5 \%$ (i.e., of high-bay volume) leak 
amount per day at a design pressure of $170 \mathrm{kPa}$ (10 psig). Due to the nonavailability of blower fan characteristics, the annulus-to-environment leakage flow rate of $10 \mathrm{vol} \% /$ day is modeled by conducting an inverse calculation. That is, for the case where the secondary containment is intact, the exhaust rate of $10 \mathrm{vol} \% /$ day was specified as a boundary condition, and resulting pressure distributions in the annulus were back calculated. It is stated that this preliminary representation of the ANS is based upon the best available information of the containment at the current stage, and was developed to provide a means for fulfilling the needs of the CSAR.

For Scenario 1 source term evaluations, $50 \%$ of the iodine inventory and $100 \%$ of the noble gases are sourced into the high bay volume (i.e., CV 240) along with the associated decay energy, and the remaining radionuclides are evenly distributed in the reactor pool water (CV 202). No credit is taken at all for the presence of the reactor coolant system boundary piping, reflector tank, etc.

For Scenario 2 source term evaluations the entire core inventory of fission products and fuel plate structural materials are relocated onto the subpile room floor concrete where the MCCI event is postulated to occur. This is a conservative assumption because at least some of the noble gases and halogen inventory would have been released prior to ablation and relocation to the subpile room. With $100 \%$ of the core debris and its fission products initialized on the subpile room floor (dry or flooded), we treat gas generation from MCCI to result from $50 \%$ of core debris power contributing to core-concrete interaction. This is reasonable because at the limestone common sand concrete ablation temperature of $1500 \mathrm{~K}$ most of the volatile fission products (contributing about $50 \%$ of the debris decay power) will escape the silicide fuel debris into the subpile room atmosphere (Saito et al., 1989, R. P. Taleyarkhan, 1992). Once again, the various aspects of the core melt progression and associated timing of such events leading up to this stage are not taken credit for. These aspects have not been modeled in the interests of conservatism, and also because a core melt progression capability is not yet available from conceptual design work.

For the CFR 100 site-suitability basis scenario an intact containment is analyzed with iodine and aerosol filter trains incorporated in the secondary containment (annulus) exhaust system to provide retention (of halogens and particulates) with decontamination factors of 100 and 200 , respectively. Leakage rates of $0.5 \mathrm{vol} \% /$ day from the primary containment to the annulus (under design pressure difference), and $10 \mathrm{vol} \% /$ day from the annulus to the environment are modeled as described earlier. At the start of the calculation, $100 \%$ of the noble gases and $25 \%$ of the halogen inventory were sourced into the high-bay volume atmosphere as vapors. In addition, $1 \%$ of the remaining radionuclides are sourced into the high-bay atmosphere as aerosols. The remainder of the radionuclides are forced to 
"stay" in the reactor pool volume of $100 \mathrm{~m}^{3}$ without volatilization. Such a prescription provides for the maximum possible heat generation for steaming purposes.

Containment failure configurations are modeled via specification of flow paths between various volumes. Each failure path was modeled to have a diameter of $0.5 \mathrm{~m}$.

The various modeling assumptions that have been implemented for conducting source-term calculations are given in the next section.

\subsection{MODELING ASSUMPTIONS}

Various modeling assumptions had to be made for conducting evaluations with MELCOR. These assumptions are discussed below:

1. ANS core averaged end-of-cycle (EOC) radionuclide inventory is computed using the ORIGEN2 code (A. G. Croff, 1980) assuming a 17-day fuel cycle at an operating power level of $330 \mathrm{Mw}$. Results are summarized in Tables 2.1 and 2.2.

2. Radionuclide decay of parents to daughter isotopes during the containment transport stage is negligible.

3. For the steaming-pool case (i.e., Scenario 1) all the noble gases and $50 \%$ of iodine inventory (in vapor form) are sourced into the high bay volume at the start of MELCOR evaluations for radionuclide transport. The remaining radionuclide inventory is sourced into the reactor pool water. Upon heatup of pool water to saturation, cesium and tellurium release will be initiated, and will be proportional to the steaming rate. Cesium will be in hydroxide form (i.e., as $\mathrm{CsOH}$ ). Remaining iodine release (i.e., the other $50 \%$ not released instantaneously to the atmosphere) is modeled mechanistically. Aerosol formation, deposition and transport is allowed. However, chemical interactions are neglected.

4. For Scenario 1 cases, it is assumed that due to some event (e.g., beam-tube rupture) the reactor pool water gets depleted up to the level of the beam tubes. This gives rise to a pool water volume of $100 \mathrm{~m}^{3}$. It will be further assumed that pool cooling equipment (for all pools in the high bay area) will not function.

5. For the MCCI cases (i.e., Scenario 2 events), all of the volatile fission products will be sourced into the subpile room atmosphere at start of evaluations for radionuclide transport. Iodine will be in vapor form, whereas cesium and tellurium species elements will be in aerosol form. The nonvolatile species contribute to continuation of MCCI and stay in the debris. That is, they are not allowed to volatile or form aerosols. Fifty percent of the total core decay power is assumed to be associated with nonvolatile fission products. If a water pool is present in the subpile room cavity it 
receives $50 \%$ of the nonvolatile decay power (corresponding to heat transfer from pool boiling, and radiation heat transfer. Once the pool is evaporated completely, this energy fraction gets transferred into the atmosphere. Chemical interactions between the various fission product species are neglected.

This is a conservative assumption because it does not take into account volatile fission product release into the RCS coolant prior to the core debris relocation to the subpile room. The extent of volatile fission product release prior to relocation is difficult to state since an integrated core melt progression capability has yet to be developed. However, the partitioning of volatile and nonvolatile fission products in terms of decay power splits is considered to be realistic, and based upon a combination of experimental data and ORIGEN2 code results.

6. Decay power generation in the refueling pool will be at a constant level of $0.62 \mathrm{MW}$ which represents a typical inventory of spent fuel elements.

7. ANS target elements with their transplutonium inventory will not be released to the atmosphere. Decay power from transplutonium elements is negligible.

8. Core melt progression phenomena and their associated time histories in-vessel will not be modeled.

9. ANS containment normal and emergency ventilation flow paths will not be modeled, or accounted for as being potential radionuclide release pathways. However, it should be noted that the $0.5-\mathrm{m}$ diameter containment leak path postulated for some cases is based upon the assumed failure-to-isolate of one normal containment ventilation line; it could also represent an opening created by missiles or shock waves generated during energetic events.

10. Natural circulation phenomena that may occur between interconnecting volumes will not be modeled explicitly.

11. Gas, vapor and stratification phenomena will not be modeled. That is, all control volumes will exhibit perfect mixing.

12. Containment cooling features such as pool coolers are assumed to be inoperable.

13. The subpile room is modeled as if there were functioning ignites such that if oxygen is available there, any hydrogen $\left(\mathrm{H}_{2}\right)$ and carbon monoxide $(\mathrm{CO})$ gas will be allowed to deflagrate (but not detonate). The basemat of the subpile room is modeled as being made of limestone common sand concrete. For cases with flooding, it is assumed that only half of the $101.4 \mathrm{~m}^{3}$ subpile room gets filled up. Once this water mass is evaporated, it does not get replenished. 
14. Explicit modeling of highly energetic events such as steam explosions, recriticality, and detonation of combustible gases is not done. Containment failure from such events is represented as stated in Item 9, above.

15. For modeling cases with containment failure, upon occurrence of a severe accident, a $0.5 \mathrm{~m}$ diameter opening will become available in the high bay volume primary containment shell for release of radionuclides. Such a release will occur either directly to the environment without filtration for the case with primary and secondary containment failure, or to the annulus region alone for the containment failure cases where the secondary concrete shell is intact. The release paths will be $1-\mathrm{m}$ above the lowest level of the high bay area volume (to represent essentially ground level release). Such pathways will simulate early containment failure from the possible effects of explosive and/or external events, as well as simulate the possibility of failure of dual dampers in ventilation ducts.

16. Any steam condensation run-off from the vertical structures in the high bay area will collect in a basin and will not be allowed to drain back to the reactor pool.

17. Rupture disks will be provided to allow passage of materials between the subpile room and the high bay area, and between the high bay area volume and the first and second floor volumes (where the experimental scientists are located) respectively. These rupture disks will open if a pressure differential of $115 \mathrm{kPa}$ (2-psig) or greater is imposed. The doorway in the subpile room leading to the access tunnel will fail open if a pressure differential of $136 \mathrm{kPa}$ (5-psig) or greater is imposed.

18. The filter trains will perform with decontamination factors of 100 for iodine, and 200 for aerosols respectively (without degradation).

19. For the case of primary containment failure only (i.e., with intact secondary containment), it is assumed that if the secondary containment loses its negative pressure from pressurization loads (generated from the primary side) partial filter train bypass can occur. That is, if the annulus pressure gets high enough a portion of the volume atmosphere can flow out through the flow path which previously represented inflow to the annulus. This simulated intake line/flow path is assumed to have a diameter of $0.5 \mathrm{~m}$ which collectively represents flow from the many cracks that may be present in the large concrete shell or other leakage paths from annulus to the environment. The effect of annulus pressurization on penetration seal integrity is not modeled. 


\subsection{SEVERE ACCIDENT RESPONSE \& SOURCE TERM ESTIMATES}

A summary of the severe accident response behavior (including source-term estimates) of the ANS containment is provided in this section for the three scenarios described in earlier sections. Results are given first for the site-suitability basis transient, viz., CFR 100 scenario, followed by the Scenario 1 steaming-pool cases and thereafter for the Scenario $2 \mathrm{MCCl}$ cases. For reference purposes, the decay power history obtained from the ORIGEN2 computer code is shown in Fig. 2.2.

Due to the enormous quantities of detail generated from simulation of the ten events listed in Table 1.2, it was decided to display the results of variation in key parameters selectively, and in a certain format. That is, for each of the three scenarios we first display base case results representing variation of key parameters. The base case corresponds to the intact primary and secondary containment configuration. Thereafter, for each individual event in the three scenarios we present and discuss graphical results which indicated significant differences from the base case. Nevertheless, source term variations for each individual event will be presented graphically, and also in summary form.

\subsubsection{Site-Suitability Transient (CFR100 Scenario)}

Salient results of MELCOR calculations for this case are shown in Figs. 2.3 through 2.12. Pressurization traces for various regions of the containment are shown in Fig. 2.3. As seen therein, high-bay volume pressure rises quickly after about $4 \mathrm{~h}$ when pool steaming begins. Thereafter, rupture disks between the high bay and the experiment areas of the first and second floors provide pressure relief when a pressure difference of $115 \mathrm{kPa}$ ( $2 \mathrm{psig}$ ) is reached. Eventually, the entire containment volume pressure levels off at about $121 \mathrm{kPa}(2.75 \mathrm{psig})$.

Figure 2.4 provides results of temperature rise in various containment regions. As the figure shows, the atmospheric temperatures in the high-bay and annulus regions can rise to $335 \mathrm{~K}\left(140^{\circ} \mathrm{F}\right)$ due primarily to steam condensation and radionuclide settling on various heat structures. Figures 2.5 and 2.6 show total aerol and radionuclide vapor mass suspended in the containment atmosphere, respectively. Figure 2.7 shows the transient variation of total radionuclide mass deposition onto heat structures in the containment. As can be seen, more than $0.5 \mathrm{~kg}$ of the radionuclides that were originally deposited in the high-bay area are deposited onto heat structures within the first $15 \mathrm{~h}$ of the transient. Figures 2.8 and 2.9 show fission product mass retained in the reactor pool. 
Figures 2.10 and 2.11 show the transient variation of the radionuclide source term (after passing through filter banks). As seen from Fig. 2.10, only about $0.1 \%$ of the noble gases, and less than $0.0002 \%$ of the halogen inventory is released over $70 \mathrm{~h}$. Figure 2.11 shows that a negligible amount (i.e., about $10^{-7 \%}$ ) of the nonvolatile elements escape to the environment over $70 \mathrm{~h}$. Most of the nonvolatile release occurs soon after the high bay area volume pressure exceeds $115 \mathrm{kPa}$ ( $2 \mathrm{psig}$ ), which is close to the peak pressure rise. The balance of the radionuclides based on the present model and assumptions made remains within the containment.

The variation in water mass for the reactor pool is shown in Fig. 2.12. As seen therein, the water gets saturated in about $4 \mathrm{~h}$, and steams thereafter resulting in close to $55,000 \mathrm{~kg}(120,000 \mathrm{lb})$ of water inventory being lost in $70 \mathrm{~h}$ to steam formation.

The results presented for the CFR 100 scenario indicate that negligible amounts of radionuclide are released to the environment, and that (as will be demonstrated later on) such releases will allow the ANS to meet site suitability criteria by a good margin. The low releases are essentially due to the leak-tight nature of the containment, coupled with halogen and aerosol removal by the filter banks.

\subsubsection{Steaming-Pool Cases (Scenario 1)}

As shown in Table 1.2 three steaming pool cases were analyzed for Scenario 1. The base case is entitled SC1-B which considers the situation in which the primary and secondary containment are intact. For the SC1-C case, the steaming-pool scenario is analyzed with a breached/failed primary containment, but an intact secondary containment. For the SCl-A case, the steaming-pool scenario is analyzed for a failure in both the primary and secondary containments.

\subsubsection{Steaming-Pool Case SC1-B}

Results for case SCI-B are shown in Figs. 2.13 through 2.22. Key results of interest for the base case (viz., SC1-B) are similar to the ones obtained for the CFR 100 scenario. Hence, the details relating to containment pressurization, containment temperature rise, atmospheric radionuclide aerosol and vapor mass, and radionuclide deposition on heat structures are not discussed, but shown in Figs. 2.13 through 2.17. A key difference between the modeling of the CFR 100 scenario and Scenario 1 cases is in the treatment of volatile fission product evolution from the reactor pool. For the CFR 100 scenario, the fission products sourced into the pool at the start of the transient were not 
allowed to escape or volatile from the pool. For the Scenario 1 cases we utilize a somewhat mechanistic treatment for evaluating volatile fission product evolution upon reactor pool heatup, whereby additional releases of halogens, cesium and tellurium class inventories to the high-bay area were evaluated. This evolution is shown in Figs. 2.18 and 2.19. As seen from these figures, all of the iodines get released when the pool water reaches saturation conditions. This is because of the substantial halogen vapor pressure increase. About $40 \%$ of the cesium and tellurium inventories in the pool also get transferred to the high-bay volume. Figures 2.18 and 2.19 also provide the time history of the various radionuclide masses trapped in the reactor pool water. Note the fractional reduction of the cesium and tellurium species in the pool water due to the steaming process. An important feature from the standpoint of source-term evaluation can be seen in Fig. 2.20, where we notice that upon the reactor pool water reaching saturation conditions, almost all of the halogen inventory is released to the atmosphere. As expected, all of the nonvolatile species elements stay in the reactor pool water. The final source term variation with time is shown in Figs. 2.20 and 2.21. Overall, about $0.1 \%$ of the noble gases, $6 \times 10^{-4} \%$ of the halogens, $2 \times 10^{-5 \%}$ of the cesium and tellurium class inventories get released to the environment. No releases occur for the nonvolatile species. The balance of the radionuclides based on the present model and assumptions remains within the containment.

\subsubsection{Steaming-Pool Case SC1-C}

Results for the SC1-C case (i.e., failed primary containment), are shown in Figures 2.23 through 2.31. One major difference from the base case, which can be expected, deals with the degree of containment pressurization. As noted in Fig. 2.23, a negligible pressurization results in the various control volumes, with the plotted differences in pressure due primarily to density heads. The high bay area volume pressure does not exceed $115 \mathrm{kPa}$ (2-psig). Consequently, the first and second floor volumes do not receive radionuclide vapors or aerosols because the disk does not rupture. As seen from Figures 2.25 and 2.26, the radionuclide vapor and aerosol masses in the atmosphere of the high bay area are similar to those seen for the base case. Note the sharp increase in aerosol and vapor mass release to the atmosphere at the onset of steaming, and the leveling-off characteristic behavior. The amount of overall radionuclide mass deposition on heat structures is similar to that for the base case. However, the transient variation of the deposited radionuclides is somewhat different as seen in Fig. 2.27. It is seen from Fig. 2.27 that the rate of early deposition is much greater up to the first $30 \mathrm{hr}$. However, at about $30 \mathrm{hr}$ into the transient, the steel shell heatup causes some of the 
deposited volatile species to revolatilize. This leads to a drop in the deposited fraction, which starts building up again. As expected, the time history of the various radionuclide masses trapped in the reactor pool water is also the same as for the base case. As opposed to the base case, for the SC1-C case the primary containment breach allows the annulus to also pressurize thereby overcoming the slight overall negative pressure required for suction. This causes some of the annulus atmosphere (bearing radionuclides) to bypass the filter banks and enter the environment without filtration. The final source term variation with time is shown in Fig. 2.30. Overall, about $14 \%$ of the noble gases, $2 \%$ of the halogens, and $0.14 \%$ of the cesium and tellurium class inventories get released to the environment. As expected no releases are predicted for the nonvolatile species. The balance of the radionuclides based on the present model and assumptions remains within the containment. Note from Fig. 2.30, that breach of the primary containment causes a significant increase in the source term from the base case. However, the secondary containment also acts as a significant mechanism for reducing the overall source term. The secondary containment acts to provide structural surface for deposition of radionuclide vapors, and aerosols. In addition, the secondary containment allows channeling of a good portion of the annulus atmosphere via the filter banks since the suction fans are still operable. The annulus region also acts as a kind of retention pool which will allow for decay of the various fission products. These aspects underscore the importance of having a dual containment system. Beneficial aspects of the secondary containment will be clearly seen when we display results for the SC1-A case.

\subsubsection{Steaming-Pool Case SC1-A}

Results for the SC1-A case (i.e., Scenario 1 with early primary and secondary containment failure) are shown in Figs. 2.32 through 2.40. These results are similar to those described earlier for the SC1-C case, with the exception of the radionuclide deposition characteristics, and the magnitude of the source term. Radionuclide deposition characteristics onto heat structures is similar to that for the base case, as seen in Fig. 2.36. However, due to early containment failure the total amount deposited is about $10 \%$ lower than that seen for the base case. The principal difference of results from the cases described earlier concern the magnitude of the source term. Figure 2.39 provides the transient variation of the radionuclides leaving the containment (i.e., the source-term) and entering the environment. As seen from these figures for the steaming-pool case with early (primary and secondary) containment failure, approximately $28 \%$ of the noble gases, about $26 \%$ of the halogen inventory, and approximately $1.6 \%$ of the cesium and tellurium 
inventories get released to the environment. This is significantly larger than for the case where only the primary containment was breached (i.e., for the SC1-C case), and underscores the importance of having a secondary containment. The balance of the radionuclides based on the present model and assumptions made remains within the containment.

\subsubsection{Cases (Scenario 2)}

As done for Scenario 1 cases key results for Scenario $2 \mathrm{MCCl}$ cases will be given first for the base cases, viz., SC2-B, and SC2-BF, and then for the other related cases looking at different containment failure configurations. The MCCI cases with and without flooding are treated sequentially.

\subsubsection{MCCI Base Case SC2-B (without flooding)}

Key results of interest for case SC2-B are given in Figs. 2.41 through 2.33. As noted in Fig. 2.41a, the subpile room pressure rises rapidly due to the intensity of the $\mathrm{MCCI}$, and causes the rupture disk to open and allow passage of radionuclides, etc. to the high bay area. The pressure in the subpile room does not rise high enough to cause the door leading to the subpile room tunnel to fail. However, a direct pathway exists from the high bay area to the subpile room tunnel which causes the pressure there to rise concomitantly. As seen from Fig. $2.41 \mathrm{~b}$ pressure in the high bay area does not exceed $115 \mathrm{kPa}$ (2-psig) and hence, the first and second floor volumes are not subject to pressurization and radionuclide transport. The short spike in the subpile room pressure lasting a few seconds is due partly to hydrogen and carbon monoxide deflagration, after which the oxygen content is completely depleted. Since no ventilation flow path is available in the model to bring in a fresh supply of oxygen, hydrogen combustion stops. The traces of atmospheric temperature variations are shown in Fig. 2.42. These (temperature) traces indicate that very high temperatures can result in the subpile room due to heating from fission products, and combustion of $\mathrm{H}_{2}$ and $\mathrm{CO}$. As can be expected, such high temperatures may lead to structural damage (viz., ablation of concrete, collapse of structures) and possibly, to releases of additional gases from ablating concrete. However, the same process causing ablation and melting would also deplete the available heat sink. An integrated modeling and analyses should be used for such cases. This was not possible to do as part of the ANS CSAR workscope. However, the MELCOR2 calculated high temperatures were conservatively permitted to exist in ordet to allow the maximum possible 
gradient for transport of aerosols via thermophoresis. After the initial high temperature rise, the subpile room air begins to cool down as combustion ceases, and the heat producing radionuclides get transported to the high bay area, coupled with energy absorption in structural materials.

The variation of hydrogen mole fractions in the various system volumes is shown in Fig. 2.43. Even though relatively high $\mathrm{H}_{2}$ and $\mathrm{CO}$ mole fractions exist in the subpile room it is not possible for combustion to occur due to the unavailability of oxygen as depicted graphically in Fig. 2.44. The mole fraction of hydrogen in other system components is close to zero.

Figures 2.45 and 2.46 show the transient variation of aerosol and vapor mass distributions within the high bay area and other volumes. As seen from these figures, the amount of radioactive aerosols in the atmosphere decreases fairly significantly with time. However, the hot radioactive vapors do not display significant condensation. Therefore, as seen from Fig. 2.47, the radionuclide deposition onto heat structures is governed primarily by aerosol deposition. As can be seen a considerable amount of the radionuclides can be expected to deposit on relatively cold structures. When compared to an equivalent steaming pool case, we see that for MCCI cases, the amount of radionuclides deposited onto heat structures is roughly five times as much.

Figure 2.48 provides the transient variation of the source term. As seen, about $0.01 \%$ of the noble gas inventory, $4 \times 10^{-5 \%}$ of the halogen inventory, $6 \times 10^{-5 \%}$ of the cesium class inventory, and about $5 \times 10^{-4} \%$ of the tellurium class inventory enters the environment over $70 \mathrm{hr}$. These low values of the source term are essentially due to the leak-tight nature of the intact ANS dual-containment design. No radionuclides enter the first and second floor volumes. The balance of the radionuclides based on the present model and assumptions remains within the containment.

\subsubsection{MCCI Case SC2-C}

Results for the SC2-C case (i.e., failed primary containment) as for the base case are shown in Figs. 2.49 through 2.56. Variation of important parameters in the subpile room is similar to that seen for SC2-B. One major difference, which can be expected deals with the degree of high-bay area pressurization. As noted in Fig. 2.49, a very mild (i.e., negligible) pressurization results in the various control volumes, with the plotted differences in pressure due primarily to density heads. The high bay area volume pressure is well below $115 \mathrm{kPa}(2-\mathrm{psig})$. Consequently, the first and second floor volumes are not available to receive radionuclide vapors or aerosols. 
The radionuclide vapor and aerosol masses in the atmosphere of the high bay area are similar to those seen for the base case (Figs. 2.53 and 2.54). The amount of overall radionuclide mass deposition on heat structures is similar, but somewhat lower (i.e., by about 20\%) than that for the base case (Fig. 2.55). This can be attributed to the fact that significantly more radionuclides escape to the environment compared to the base case. As opposed to the base case, for the SC2-C case the primary containment breach allows the annulus to also pressurize thereby overcoming the slight overall negative pressure required for suction. This causes some of the annulus atmosphere (bearing radionuclides) to bypass the filter banks and enter the environment without filtration. The final source term variation with time is shown in Fig. 2.56. Overall, about $2.6 \%$ of the noble gases, $1.4 \%$ of the halogens, and $1.6 \%$ of the cesium and tellurium class inventories get released to the environment. As expected no releases are predicted for the nonvolatile species. Note from the figure, breach of the primary containment causes a significant increase in the source term from the base case. However, as noted previously for the SC1-C case, the secondary containment also acts as a significant mechanism for reducing the overall source term. Beneficial aspects of the secondary containment will be clearly seen when we compare these results with results for the SC2-A case. The balance of the radionuclides based on the present model and assumptions made remains within the containment.

\subsubsection{MCCI Case SC2-A}

Results for the SC2-A case (i.e., Scenario 2 with early primary and secondary containment failure) are shown in Figs. 2.57 through 2.64. These results are similar to those described earlier for the SC1-C case, with the exception of the magnitude of the source term and are provided here for the sake of completeness. The principal difference of results from the $\mathrm{MCCI}$ cases described earlier concern the magnitude of the source term. Figure 2.64 provides the transient variation of the radionuclides leaving the containment (i.e., the source-term) and entering the environment. As seen from these figures for this MCCI case with early (primary and secondary) containment failure, approximately $10.5 \%$ of the noble gases, about $9.9 \%$ of the halogen inventory, and approximately $10 \%$ of the cesium and tellurium inventories get released to the environment over $70 \mathrm{~h}$. This is significantly larger than for the case where only the primary containment was breached (i.e., for the SC1-C case), and underscores the importance of having a secondary containment. The balance of the radionuclides based on the present model and assumptions

made remains within the containment. No radionuclides enter the first and second floor regions. 
It should be noted, however, that for all the MCCI cases described above most of the radionuclide releases occur well within the first hour of the start of MCCI. This contrasts sharply with the steaming pool cases described earlier, where significant releases to the environment occur only after the reactor pool water reaches saturation conditions and starts steaming thereafter.

\subsubsection{MCCI Base Case SC2-BF (including flooding)}

Key results of interest for case SC2-BF are given in Figs. 2.65 through 2.72. As noted in Fig. 2.65a, the subpile room pressure rises rapidly due to the intensity of the MCCI, and causes the rupture disk to open and allow passage of radionuclides, etc. to the high bay area. The pressure in the subpile room does not rise high enough to cause the door leading to the subpile room tunnel to fail. However, a direct pathway exists from the high bay area to the subpile room tunnel which causes the pressure there to rise concomitantly. Upon saturation of the water in the subpile room steaming begins at about $7 \mathrm{~h}$ into the transient. Soon thereafter, pressure in the high bay area exceeds $115 \mathrm{kPa}$ (2 psig) after which, the first and second floor volumes become available for pressure relief and radionuclide transport. Overall containment pressure levels off at about $115 \mathrm{kPa}$ ( 2 psig), and then starts a slow decrease about $40 \mathrm{~h}$ into the transient. The short spikes in the subpile room pressure lasting a few seconds is due partly to hydrogen and carbon monoxide deflagration, after which the oxygen content is completely depleted. Since no ventilation flow path is available (via modeling) to bring in a fresh supply of oxygen, hydrogen combustion stops. Interestingly, after about $37 \mathrm{~h}$ into the transient a chuggingtype instability sets in which leads to pressure oscillations in the subpile room. Based on sensitivity studies coupled with preliminary modeling and analysis, this was thought to be not a numerical instability, but a physical one driven by the occurrence of the appropriate combination of decay power level of the fission products, pressure levels in the subpile room and high bay area, and steaming rates. For the intact containment configuration these oscillations in pressure do not introduce any significant effects on the source term. However, these oscillations turned out to be related with a numerical instability after repeating the calculation using the newer version of MELCOR (Mod 1.8.2). This new version of the code has significant improvement in physical modeling and numerics over the version used for the current study (Mod 1.8.1). Figure 2.65b-2 shows no oscillations

in pressure predicted by the new MELCOR version. The traces of atmospheric temperature variations are shown in Fig. 2.66. These temperature traces indicate that high temperatures can result in the subpile room due to heating from fission products, and combustion of $\mathrm{H}_{2}$ 
and $\mathrm{CO}$. Combustion of these gases are the cause for the significant jumps of several hundred degrees (Kelvin). After the initial high temperature rise to close to $1100 \mathrm{~K}$, the subpile room air begins to cool down as combustion ceases, and the heat producing radionuclides get transported to the high bay area, coupled with energy absorption in structural materials, and most importantly steam production. As can be seen from Fig. $2.66 \mathrm{~b}$, the subpile room temperature stabilizes to a level of about $400 \mathrm{~K}\left(261^{\circ} \mathrm{F}\right)$ soon after the water pool gets saturated, and begins to steam. This level is considerably lower (by several thousand degrees Kelvin) than for the MCCI cases without flooding, and clearly underscores the beneficial aspects of flooding (whether it occurs naturally as a result of primary coolant accompanying core debris into the subpile room after melt-through, or whether it is enforced strategically by an engineered system). It is recognized that these evaluations would need to be validated via scaled experiments.

The variation of hydrogen mole fractions in the various system volumes is shown in Fig. 2.67. Even though relatively high $\mathrm{H}_{2}$ and $\mathrm{CO}$ mole fractions exist in the subpile room it is not possible for combustion to occur due to the relative lack of oxygen as depicted graphically in Fig. 2.68. As seen from Fig. 2.68, combustion phenomena resulting in large temperature excursions in the subpile room also lead to spikes in steam formation. The mole fraction of hydrogen in other system components is close to zero.

Figures 2.69 and 2.70 show the transient variation of aerosol and vapor mass distributions within the high bay area and other volumes. As seen from these figures, the amount of radioactive aerosols in the atmosphere decreases fairly significantly with time. The amount of this decrease is greater than that seen for case SC2-B (i.e., no flooding), and can be attributed to the enhancement of agglomeration-caused settling. However, the hot radioactive vapors do not display significant condensation. Therefore, as seen from Fig. 2.71, the radionuclide deposition onto heat structures is governed primarily by aerosol deposition. As can be seen a considerable amount of the radionuclides can be expected to deposit on relatively cold structures. The dip in radionuclide deposition can be attributed to revolatilization of halogens upon increase in vapor pressure. When compared to an equivalent steaming pool case, we see that for MCCI cases, the amount of radionuclides deposited onto heat structures is roughly five times as much.

Figure 2.72 provides the transient variation of the source term. As seen, about $0.1 \%$ of the noble gas inventory, $5 \times 10^{-4} \%$ of the halogen inventory, $1 \times 10^{-4} \%$ of the cesium class inventory, and about $1 \times 10^{-4} \%$ of the tellurium class inventory enters the environment over $70 \mathrm{hr}$. The noble gas release is essentially the same as seen for the equivalent case SC2-B without flooding. The releases of the halogens, cesium and tellurium species is significantly enhanced due to larger driving pressure gradients arising 
from the steaming process. However, the release amounts are still very low. These low values of the source term are essentially due to the leak-tight nature of the intact ANS dualcontainment design. However, due to increased pressurization in the high bay area, radionuclides enter the first and second floor volumes about $7.5 \mathrm{~h}$ into the transient. The balance of the radionuclides based on the present model and assumptions made remains within the containment.

\subsubsection{MCCI Case SC2-CF}

Results for the SC2-CF case (i.e., failed primary containment) which differ sufficiently from the base case (viz., SC2-BF) are shown in Figs. 2.73 and 2.80 . Variation of important parameters in the subpile room is similar to that seen for SC2-BF. One major difference, which can be expected deals with the degree of high-bay area pressurization. As noted in Fig. 2.73, a very mild (i.e., negligible) pressurization results in the various control volumes, with the plotted differences in pressure due primarily to density heads. The high bay area volume pressure is well below $115 \mathrm{kPa}$ (2 psig). Consequently, the first and second floor volumes are not available to receive radionuclide vapors or aerosols. However, once again as seen for the SC2-BF case, a chugging-type instability sets in around $40 \mathrm{~h}$ into the transient. Unlike the previous case, the pressure oscillations do cause a noticeable increase in the rate of release of the source term as will be shown later. These pressure oscillations are not evident from the MELCOR-Mod 1.8.2 calculation (Fig. 2.73b-2).

The radionuclide vapor and aerosol masses in the atmosphere of the high bay area are similar to those seen for the base case. The amount of overall radionuclide mass deposition on heat structures is similar to that for the base case. As opposed to the base case, for the SC2-CF case the primary containment breach allows the annulus to also pressurize thereby overcoming the slight overall negative pressure required for suction. This causes some of the annulus atmosphere (bearing radionuclides) to bypass the filter banks and enter the environment without filtration. The final source term variation with time is shown in Fig. 2.80. Overall, about $10.9 \%$ of the noble gases, $4 \%$ of the halogens, and $3 \%$ of the cesium and tellurium class inventories get released to the environment. A similar result from the new version of MELCOR (Mod 1.8.2) is shown in Fig. 2.80-2. As seen in the figure, halogen release is only about $10 \%$ mainly due to no pressure oscillation in the subpile room. However, the radiological consequence study described in Section 3 is based on the results obtained from the old version of MELCOR (Mod 1.8.1). As expected no releases are predicted for the nonvolatile species. As noted from these figures, 
breach of the primary containment causes a significant increase in the source term from the base case. However, as noted previously for similar cases with an intact secondary containment, the secondary containment acts as a significant mechanism for reducing the overall source term. Once again, this underscores the importance of having a dual containment system.

\subsubsection{MCCI Case SC2-AF}

Results for the SC2-AF case (i.e., Scenario 2 with early primary and secondary containment failure) are similar to the results described earlier for the SC1-CF case, with the exception of the source term (Figs. 2.81 through 2.88). The principal difference of results from the $\mathrm{MCCI}$ cases with flooding described earlier concern the magnitude of the source term. Figure 2.88 provides the transient variation of the radionuclides leaving the containment (i.e., the source-term) and entering the environment. As seen from these figures for this $\mathrm{MCCI}$ case with early (primary and secondary) containment failure, $\sim 24 \%$ of the noble gases, about $24 \%$ of the halogen inventory, and $\sim 16 \%$ of the cesium and tellurium inventories get released to the environment over $70 \mathrm{~h}$. This is significantly larger than for the case where only the primary containment was breached (i.e., for the SC1-CF case), and underscores the importance of having a secondary containment. The balance of the radionuclides based on the present model and assumptions made remains within the containment. No radionuclides enter the first and second floor regions.

It should be noted, however, that for all the MCCI cases with flooding described above, significant releases to the environment occur in two stages. In the first stage which begins soon after the onset of MCCI, releases to the environment occur as seen for the equivalent cases without flooding. The release amounts during this time frame are somewhat lower than those predicted for the cases without flooding. The second stage of significant release occurs once the water pool in the subpile room gets saturated, and begins steaming. This steaming event increases driving pressure gradients such that over the duration of $70 \mathrm{~h}$, the overall source term is much larger in magnitude when compared to the equivalent case without flooding (viz., SC2-A). The implications of such trends on radiological consequences will become apparent in the next sections where MACCS derived results and analyses are presented.

A summary of source terms for each of the ten cases is provided in Table 2.3. Somewhat more detail is provided in Table 2.4 which shows the release of important 
radionuclides to the environment over different time segments, along with the decay energy content. This information will be utilized in performing consequence calculations with MACCS. 
Table 2.1. Radionuclide mass inventory predicted by ORIGEN2 for ANS core (end-of-cycle)

\begin{tabular}{cll}
\hline $\begin{array}{c}\text { Class } \\
\text { (MELCOR) }\end{array}$ & \multicolumn{1}{c}{ Elements } & \multicolumn{1}{c}{$\begin{array}{c}\text { Mass } \\
(\mathbf{k g})\end{array}$} \\
\hline 1 & $\mathrm{Kr}, \mathrm{Xe}$ & 1.0112 \\
2 & $\mathrm{Na}, \mathrm{Rb}, \mathrm{Cs}$ & 0.40142 \\
3 & $\mathrm{Sr}, \mathrm{Ba}$ & 0.680 \\
4 & $\mathrm{Br}, \mathrm{I}$ & 0.09667 \\
5 & $\mathrm{Se}, \mathrm{Te}$ & 0.11537 \\
6 & $\mathrm{Ru}, \mathrm{Rh}$ & 0.38511 \\
7 & $\mathrm{Mn}, \mathrm{Nb}, \mathrm{Mo}, \mathrm{Tc}$ & 0.65289 \\
8 & $\mathrm{Zr}, \mathrm{Ce}, \mathrm{Np}$ & 1.4386 \\
9 & $\mathrm{Al}, \mathrm{Y}, \mathrm{La}, \mathrm{Pr}, \mathrm{Nd}$, & 87.042 \\
10 & $\mathrm{Ua}$ & 10.68 \\
11 & $\mathrm{As}, \mathrm{Sb}$ & 0.004156 \\
12 & $\mathrm{Ge}, \mathrm{In}, \mathrm{Sn}$ & 0.0068828 \\
\hline
\end{tabular}

$a_{16.61} \mathrm{~kg}$ of $93 \%$ enriched $\mathrm{U}$ is present in the core at the beginning-of-cycle. 
Table 2.2. Activity levels for important radionuclides at end-of-cycle for ANS core

\begin{tabular}{|c|c|c|c|c|c|}
\hline Nuclide & $\begin{array}{c}\text { Activity } \\
(\mathbf{B g})\end{array}$ & $\begin{array}{c}\text { Activity } \\
\text { (Ci) }\end{array}$ & Nuclide & $\begin{array}{c}\text { Activity } \\
\text { (Bq) }\end{array}$ & $\begin{array}{c}\text { Activity } \\
\text { (Ci) }\end{array}$ \\
\hline$m n-56$ & $1.56 \times 10^{16}$ & $4.23 \times 10^{5}$ & $\mathrm{i}-131$ & $2.22 \times 10^{17}$ & $5.99 \times 10^{6}$ \\
\hline co-58 & $0.00 \times 10^{0}$ & $0.00 \times 10^{0}$ & te-132 & $4.46 \times 10^{i 7}$ & $1.20 \times 10^{7}$ \\
\hline $\operatorname{co-} 60$ & $0.00 \times 10^{0}$ & $0.00 \times 10^{0}$ & $\mathrm{i}-132$ & $4.58 \times 10^{17}$ & $1.23 \times 10^{7}$ \\
\hline br- 83 & $4.78 \times 10^{16}$ & $1.29 \times 10^{6}$ & te-133 & $7.44 \times 10^{16}$ & $2.01 \times 10^{6}$ \\
\hline$k r-83 m$ & $5.44 \times 10^{16}$ & $1.46 \times 10^{6}$ & te- $133 \mathrm{~m}$ & $1.83 \times 10^{17}$ & $4.95 \times 10^{6}$ \\
\hline br-84 & $4.82 \times 10^{16}$ & $1.30 \times 10^{6}$ & $\mathrm{i}-133$ & $7.12 \times 10^{17}$ & $1.92 \times 10^{7}$ \\
\hline$k r-85$ & $7.34 \times 10^{13}$ & $1.98 \times 10^{3}$ & xe-133 & $5.22 \times 10^{17}$ & $1.41 \times 10^{7}$ \\
\hline$k r-85 m$ & $1.19 \times 10^{17}$ & $3.22 \times 10^{6}$ & $x e-133 m$ & $2.15 \times 10^{16}$ & $5.80 \times 10^{5}$ \\
\hline $\mathbf{k r}-87$ & $1.84 \times 10^{17}$ & $4.97 \times 10^{6}$ & te-134 & $3.56 \times 10^{17}$ & $9.62 \times 10^{6}$ \\
\hline$k r-88$ & $3.18 \times 10^{17}$ & $8.60 \times 106$ & cs- 134 & $2.88 \times 10^{14}$ & $7.78 \times 10^{3}$ \\
\hline $\mathrm{rb}-86$ & $1.31 \times 10^{14}$ & $3.54 \times 10^{3}$ & $\mathrm{i}-134$ & $6.67 \times 10^{17}$ & $1.80 \times 10^{7}$ \\
\hline $\mathrm{rb}-88$ & $3.47 \times 10^{17}$ & $9.37 \times 10^{6}$ & $\mathrm{i}-135$ & $6.15 \times 10^{17}$ & $1.66 \times 10^{7}$ \\
\hline rb-89 & $9.91 \times 10^{16}$ & $2.68 \times 10^{6}$ & xe-135 & $5.29 \times 10^{16}$ & $1.42 \times 10^{6}$ \\
\hline sr-89 & $9.28 \times 10^{16}$ & $2.51 \times 10^{6}$ & $x e-135 m$ & $1.00 \times 10^{17}$ & $2.72 \times 10^{6}$ \\
\hline sr-90 & $5.79 \times 10^{14}$ & $1.56 \times 10^{4}$ & cs-136 & $8.62 \times 10^{14}$ & $2.33 \times 10^{4}$ \\
\hline sr-91 & $5.86 \times 10^{17}$ & $1.58 \times 10^{7}$ & cs- 137 & $6.04 \times 10^{14}$ & $1.63 \times 10^{4}$ \\
\hline$y-90$ & $5.32 \times 10^{14}$ & $1.43 \times 10^{4}$ & xe-138 & $9.10 \times 10^{16}$ & $2.46 \times 10^{6}$ \\
\hline$y-91$ & $9.71 \times 10^{16}$ & $2.63 \times 10^{6}$ & cs- 138 & $4.36 \times 10^{17}$ & $1.17 \times 10^{7}$ \\
\hline$y-91 m$ & $3.53 \times 10^{17}$ & $9.55 \times 10^{6}$ & cs-139 & $3.65 \times 10^{16}$ & $9.86 \times 10^{5}$ \\
\hline sr-92 & $5.18 \times 10^{17}$ & $1.40 \times 10^{7}$ & ba-139 & $5.35 \times 10^{17}$ & $1.44 \times 10^{7}$ \\
\hline$y-92$ & $6.11 \times 10^{17}$ & $1.65 \times 10^{7}$ & ba- 140 & $3.65 \times 10^{17}$ & $9.86 \times 10^{6}$ \\
\hline sr-93 & $1.63 \times 10^{16}$ & $4.41 \times 10^{5}$ & la- 140 & $3.31 \times 10^{17}$ & $8.94 \times 10^{6}$ \\
\hline$y-93$ & $6.56 \times 10^{17}$ & $1.77 \times 10^{7}$ & ba-141 & $1.36 \times 10^{17}$ & $3.68 \times 10^{6}$ \\
\hline$y-94$ & $1.60 \times 10^{17}$ & $4.32 \times 10^{6}$ & la-141 & $5.82 \times 10^{17}$ & $1.57 \times 10^{7}$ \\
\hline$y-95$ & $4.85 \times 10^{16}$ & $1.31 \times 10^{6}$ & ce- 141 & $1.64 \times 10^{17}$ & $4.42 \times 10^{6}$ \\
\hline zr-95 & $1.00 \times 10^{17}$ & $2.71 \times 10^{6}$ & ba-142 & $4.46 \times 10^{16}$ & $1.20 \times 10^{6}$ \\
\hline nb-95 & $1.29 \times 10^{16}$ & $3.50 \times 10^{5}$ & la-142 & $5.00 \times 10^{17}$ & $1.35 \times 10^{7}$ \\
\hline zrr-97 & $6.12 \times 10^{17}$ & $1.65 \times 10^{7}$ & la-143 & $8.47 \times 10^{16}$ & $2.29 \times 10^{6}$ \\
\hline nb-97 & $6.28 \times 10^{17}$ & $1.70 \times 10^{7}$ & ce- 143 & $6.31 \times 10^{17}$ & $1.71 \times 10^{7}$ \\
\hline $\mathrm{nb}-97 \mathrm{~m}$ & $5.80 \times 10^{17}$ & $1.56 \times 10^{7}$ & pr-143 & $2.74 \times 10^{17}$ & $7.41 \times 10^{6}$ \\
\hline mo-99 & $6.35 \times 10^{17}$ & $1.71 \times 10^{7}$ & ce- 144 & $2.03 \times 10^{16}$ & $5.48 \times 10^{5}$ \\
\hline
\end{tabular}


Table 2.2. (continued)

\begin{tabular}{|c|c|c|c|c|c|}
\hline Nuclide & $\begin{array}{c}\text { Activity } \\
\text { (Bq) }\end{array}$ & $\begin{array}{c}\text { Activity } \\
\text { (Ci) }\end{array}$ & Nuclide & $\begin{array}{c}\text { Activity } \\
\text { (Bg) }\end{array}$ & $\begin{array}{c}\text { Activity } \\
\text { (Ci) }\end{array}$ \\
\hline tc- $-99 \mathrm{~m}$ & $5.60 \times 10^{17}$ & $1.51 \times 10^{7}$ & pr-144 & $4.04 \times 10^{16}$ & $1.09 \times 10^{6}$ \\
\hline mo-101 & $8.00 \times 10^{16}$ & $2.16 \times 10^{6}$ & pr- 145 & $3.83 \times 10^{17}$ & $1.03 \times 10^{7}$ \\
\hline tc-101 & $2.27 \times 10^{17}$ & $6.13 \times 10^{6}$ & ce- 146 & $4.37 \times 10^{16}$ & $1.18 \times 10^{6}$ \\
\hline mo-102 & $3.70 \times 10^{16}$ & $9.99 \times 10^{5}$ & pr-146 & $1.74 \times 10^{17}$ & $4.71 \times 10^{6}$ \\
\hline tc- 102 & $3.73 \times 10^{16}$ & $1.00 \times 10^{6}$ & pr-147 & $2.59 \times 10^{16}$ & $7.01 \times 10^{5}$ \\
\hline$r u-103$ & $7.57 \times 10^{16}$ & $2.04 \times 10^{6}$ & nd-147 & $1.26 \times 10^{17}$ & $3.41 \times 10^{6}$ \\
\hline $\mathrm{rh}-103 \mathrm{~m}$ & $6.83 \times 10^{16}$ & $1.84 \times 10^{6}$ & nd-149 & $9.12 \times 10^{16}$ & $2.46 \times 10^{6}$ \\
\hline tc- 104 & $4.79 \times 10^{16}$ & $1.29 \times 10^{6}$ & $\mathrm{pm}-149$ & $1.13 \times 10^{17}$ & $3.07 \times 10^{6}$ \\
\hline ru-105 & $1.06 \times 10^{17}$ & $2.87 \times 10^{6}$ & pm-150 & $6.42 \times 10^{16}$ & $1.73 \times 10^{6}$ \\
\hline rh-105 & $1.84 \times 10^{16}$ & $4.97 \times 10^{5}$ & $\mathrm{pm}-151$ & $3.65 \times 10^{16}$ & $9.87 \times 10^{5}$ \\
\hline rh-105m & $2.98 \times 10^{16}$ & $8.06 \times 10^{5}$ & $\mathrm{sm}-153$ & $6.11 \times 10^{16}$ & $1.65 \times 10^{6}$ \\
\hline ru-106 & $1.28 \times 10^{15}$ & $3.46 \times 10^{4}$ & $u-237$ & $1.51 \times 10^{17}$ & $4.09 \times 10^{6}$ \\
\hline rh-106m & $2.27 \times 10^{16}$ & $6.14 \times 10^{5}$ & pu-238 & $7.69 \times 10^{11}$ & $2.08 \times 10^{1}$ \\
\hline sb-127 & $1.63 \times 10^{16}$ & $4.42 \times 10^{5}$ & np-238 & $1.24 \times 10^{16}$ & $3.35 \times 10^{5}$ \\
\hline te- 127 & $1.42 \times 10^{16}$ & $3.84 \times 10^{5}$ & $u-239$ & $2.35 \times 10^{17}$ & $6.35 \times 10^{6}$ \\
\hline te- $127 \mathrm{~m}$ & $1.35 \times 10^{14}$ & $3.65 \times 10^{3}$ & np-239 & $2.04 \times 10^{17}$ & $5.52 \times 10^{6}$ \\
\hline sn-128 & $2.42 \times 10^{16}$ & $6.53 \times 10^{5}$ & pu-239 & $5.66 \times 10^{10}$ & $1.53 \times 10^{0}$ \\
\hline $\mathrm{sb} 128 \mathrm{~m}$ & $2.88 \times 10^{16}$ & $7.79 \times 10^{5}$ & $n p-240$ & $1.24 \times 10^{16}$ & $3.35 \times 10^{5}$ \\
\hline sb129 & $6.57 \times 10^{16}$ & $1.77 \times 10^{6}$ & $n p-240 m$ & $3.07 \times 10^{15}$ & $8.30 \times 10^{4}$ \\
\hline te 129 & $6.47 \times 10^{16}$ & $1.75 \times 10^{6}$ & $\mathrm{pu}-240$ & $9.25 \times 10^{10}$ & $2.50 \times 10^{0}$ \\
\hline te $129 \mathrm{~m}$ & $2.82 \times 10^{15}$ & $7.62 \times 10^{4}$ & $u-240$ & $3.11 \times 10^{13}$ & $8.41 \times 10^{2}$ \\
\hline sb131 & $8.10 \times 10^{16}$ & $2.19 \times 10^{6}$ & $a m-241$ & $1.88 \times 10^{8}$ & $5.08 \times 10^{-3}$ \\
\hline te 131 & $1.83 \times 10^{17}$ & $4.93 \times 10^{6}$ & pu-241 & $1.71 \times 10^{13}$ & $4.62 \times 10^{2}$ \\
\hline \multirow[t]{3}{*}{ te $131 \mathrm{~m}$} & $3.93 \times 10^{16}$ & $1.06 \times 10^{6}$ & $\mathrm{~cm}-242$ & $4.54 \times 10^{10}$ & $1.23 \times 10^{0}$ \\
\hline & & & pu-243 & $1.12 \times 10^{15}$ & $3.03 \times 10^{4}$ \\
\hline & & & $\mathrm{cm}-244$ & $4.09 \times 10^{10}$ & $1.11 \times 10^{0}$ \\
\hline
\end{tabular}


Table 2.3. MELCOR estimates for fractional fission product mass released into the environment for various accident scenarios

\begin{tabular}{lccccc}
\hline & $\begin{array}{c}\text { Transient } \\
\text { time } \\
\text { Scenario }\end{array}$ & \multicolumn{4}{c}{ Fractional mass release } \\
\cline { 4 - 6 } & Xe, Kr & Cs, Na, Rb & I, Br & Te, Se \\
\hline SC1-A & 72 & $2.83 \times 10^{-1}$ & $1.59 \times 10^{-2}$ & $2.61 \times 10^{-1}$ & $1.59 \times 10^{-2}$ \\
SC1-B & 72 & $1.05 \times 10^{-3}$ & $2.35 \times 10^{-7}$ & $6.21 \times 10^{-6}$ & $2.35 \times 10^{-7}$ \\
SC1-C & 72 & $1.42 \times 10^{-1}$ & $1.45 \times 10^{-3}$ & $2.23 \times 10^{-2}$ & $1.45 \times 10^{-3}$ \\
CFR-100 & 72 & $1.07 \times 10^{-3}$ & $2.71 \times 10^{-9}$ & $1.69 \times 10^{-6}$ & $2.72 \times 10^{-9}$ \\
SC2-A & 20 & $1.05 \times 10^{-1}$ & $1.01 \times 10^{-1}$ & $9.95 \times 10^{-2}$ & $1.01 \times 10^{-1}$ \\
SC2-B & 20 & $8.63 \times 10^{-5}$ & $5.58 \times 10^{-7}$ & $3.91 \times 10^{-7}$ & $4.56 \times 10^{-6}$ \\
SC2-C & 20 & $2.56 \times 10^{-2}$ & $1.62 \times 10^{-2}$ & $1.36 \times 10^{-2}$ & $1.62 \times 10^{-2}$ \\
SC2-AF & 72 & $2.40 \times 10^{-1}$ & $1.61 \times 10^{-1}$ & $2.36 \times 10^{-1}$ & $1.61 \times 10^{-1}$ \\
SC2-BF & 72 & $1.03 \times 10^{-3}$ & $1.12 \times 10^{-6}$ & $4.94 \times 10^{-6}$ & $1.13 \times 10^{-6}$ \\
SC2-CF & 72 & $1.09 \times 10^{-1}$ & $3.16 \times 10^{-2}$ & $3.77 \times 10^{-2}$ & $3.16 \times 10^{-2}$ \\
\hline
\end{tabular}

$a_{T e}$, Se class for the CFR100 Scenario includes all other non-volatiles. 


\begin{tabular}{|c|c|c|c|c|c|c|}
\hline \multirow[b]{2}{*}{ Case } & \multirow{2}{*}{$\begin{array}{c}\text { Time } \\
\text { (h) }\end{array}$} & \multirow[b]{2}{*}{$\mathbf{X e}, \mathbf{K r}$} & \multicolumn{3}{|c|}{ Fractional Mass Release } & \multirow{2}{*}{$\begin{array}{c}\text { Energy rate } \\
\text { (W) }\end{array}$} \\
\hline & & & $\mathrm{Cs}, \mathrm{Na}, \mathrm{Rb}$ & $\mathrm{I}, \mathrm{Br}$ & Te, Se & \\
\hline \multirow[t]{3}{*}{ SC1-A } & $0-4$ & $4.367 \times 10^{-2}$ & $1.340 \times 10^{-6}$ & $1.967 \times 10^{-2}$ & $1.340 \times 10^{-6}$ & $1.823 \times 10^{4}$ \\
\hline & $4-12$ & $1.560 \times 10^{-1}$ & $5.212 \times 10^{-3}$ & $1.561 \times 10^{-1}$ & $5.212 \times 10^{-3}$ & $6.555 \times 10^{4}$ \\
\hline & $12-72$ & $8.290 \times 10^{-2}$ & $1.066 \times 10^{-2}$ & $8.540 \times 10^{-2}$ & $1.066 \times 10^{-2}$ & $4.658 \times 10^{3}$ \\
\hline \multirow{2}{*}{ SC1-B } & $0-10$ & $1.467 \times 10^{-5}$ & $1.652 \times 10^{-9}$ & $4.867 \times 10^{-8}$ & $1.652 \times 10^{-9}$ & $1.181 \times 10^{0}$ \\
\hline & $10-72$ & $1.032 \times 10^{-3}$ & $2.334 \times 10^{-7}$ & $6.164 \times 10^{-6}$ & $2.334 \times 10^{-7}$ & $2.526 \times 10^{0}$ \\
\hline \multirow[t]{3}{*}{ SC1-C } & $0-4$ & $3.538 \times 10^{-3}$ & $1.550 \times 10^{-8}$ & $1.140 \times 10^{-3}$ & $1.550 \times 10^{-8}$ & $1.196 \times 10^{3}$ \\
\hline & $4-12$ & $6.312 \times 10^{-2}$ & $6.948 \times 10^{-4}$ & $1.510 \times 10^{-2}$ & $6.948 \times 10^{-4}$ & $9.043 \times 10^{3}$ \\
\hline & $12-72$ & $7.584 \times 10^{-2}$ & $7.482 \times 10^{-4}$ & $6.080 \times 10^{-3}$ & $7.582 \times 10^{-4}$ & $5.171 \times 10^{2}$ \\
\hline \multirow[t]{2}{*}{ CFR100 } & $0-10$ & $1.380 \times 10^{-5}$ & $1.169 \times 10^{-9}$ & $1.461 \times 10^{-8}$ & $1.173 \times 10^{-9}$ & $1.099 \times 10^{0}$ \\
\hline & $10-72$ & $1.053 \times 10^{-3}$ & $1.536 \times 10^{-9}$ & $1.677 \times 10^{-6}$ & $1.542 \times 10^{-9}$ & $1.921 \times 10^{1}$ \\
\hline \multirow{4}{*}{ SC2-A } & $0-0.48$ & $8.242 \times 10^{-2}$ & $8.039 \times 10^{-2}$ & $7.768 \times 10^{-2}$ & $8.041 \times 10^{-2}$ & $1.753 \times 10^{5}$ \\
\hline & $0.48-1.31$ & $1.316 \times 10^{-2}$ & $1.236 \times 10^{-2}$ & $1.252 \times 10^{-2}$ & $1.235 \times 10^{-2}$ & $1.840 \times 10^{4}$ \\
\hline & $1.31-2.75$ & $5.320 \times 10^{-3}$ & $4.770 \times 10^{-3}$ & $5.340 \times 10^{-3}$ & $4.750 \times 10^{-3}$ & $5.131 \times 10^{3}$ \\
\hline & $2.75-20$ & $3.900 \times 10^{-3}$ & $3.080 \times 10^{-3}$ & $3.940 \times 10^{-3}$ & $3.090 \times 10^{-3}$ & $8.438 \times 10^{2}$ \\
\hline \multirow[t]{4}{*}{ SC2-B } & $0-0.48$ & $3.140 \times 10^{-8}$ & $1.500 \times 10^{-10}$ & $1.433 \times 10^{-10}$ & $1.500 \times 10^{-10}$ & $1.032 \times 10^{2}$ \\
\hline & $0.48-1.31$ & $3.842 \times 10^{-7}$ & $6.790 \times 10^{-8}$ & $6.768 \times 10^{-8}$ & $6.795 \times 10^{-8}$ & $1.538 \times 10^{1}$ \\
\hline & $1.31-2.75$ & $1.654 \times 10^{-6}$ & $1.344 \times 10^{-7}$ & $1.366 \times 10^{-7}$ & $1.342 \times 10^{-7}$ & $2.317 \times 10^{1}$ \\
\hline & $2.75-20$ & $8.419 \times 10^{-5}$ & $3.553 \times 10^{-7}$ & $1.861 \times 10^{-7}$ & $4.355 \times 10^{-6}$ & $3.661 \times 10^{0}$ \\
\hline \multirow[t]{4}{*}{ SC2-C } & $0-0.48$ & $1.201 \times 10^{-2}$ & $1.146 \times 10^{-2}$ & $1.060 \times 10^{-2}$ & $1.147 \times 10^{-2}$ & $2.466 \times 10^{4}$ \\
\hline & $0.48-1.31$ & $3.940 \times 10^{-3}$ & $3.270 \times 10^{-3}$ & $2.150 \times 10^{-3}$ & $3.270 \times 10^{-3}$ & $4.064 \times 10^{3}$ \\
\hline & $1.31-2.75$ & $2.150 \times 10^{-3}$ & $1.270 \times 10^{-3}$ & $8.100 \times 10^{-4}$ & $1.260 \times 10^{-3}$ & $1.090 \times 10^{3}$ \\
\hline & $2.75-20$ & $7.510 \times 10^{-3}$ & $1.700 \times 10^{-4}$ & $2.000 \times 10^{-5}$ & $1.800 \times 10^{-4}$ & $1.909 \times 10^{2}$ \\
\hline \multirow{4}{*}{ SC2-AF } & $0-1.48$ & $7.477 \times 10^{-2}$ & $7.068 \times 10^{-3}$ & $7.017 \times 10^{-2}$ & $7.076 \times 10^{-3}$ & $1.128 \times 10^{5}$ \\
\hline & $1.48-5.75$ & $1.015 \times 10^{-2}$ & $8.320 \times 10^{-3}$ & $1.020 \times 10^{-2}$ & $8.330 \times 10^{-3}$ & $6.983 \times 10^{3}$ \\
\hline & $5.75-11.69$ & $6.898 \times 10^{-2}$ & $4.930 \times 10^{-2}$ & $6.933 \times 10^{-2}$ & $4.941 \times 10^{-2}$ & $3.078 \times 10^{4}$ \\
\hline & $11.69-72$ & $8.600 \times 10^{-2}$ & $3.230 \times 10^{-2}$ & $8.640 \times 10^{-2}$ & $3.240 \times 10^{-2}$ & $2.651 \times 10^{3}$ \\
\hline \multirow[t]{4}{*}{ SC2-BF } & $0-1.48$ & $3.560 \times 10^{-7}$ & $1.414 \times 10^{-8}$ & $1.426 \times 10^{-8}$ & $1.416 \times 10^{-8}$ & $9.343 \times 10^{2}$ \\
\hline & $1.48-5.75$ & $6.148 \times 10^{-6}$ & $3.614 \times 10^{-8}$ & $4.073 \times 10^{-8}$ & $3.620 \times 10^{-8}$ & $5.853 \times 10^{1}$ \\
\hline & $5.75-11.69$ & $2.634 \times 10^{-5}$ & $9.600 \times 10^{-8}$ & $5.633 \times 10^{-8}$ & $9.616 \times 10^{-8}$ & $1.074 \times 10^{0}$ \\
\hline & $11.69-72$ & $9.946 \times 10^{-4}$ & $9.786 \times 10^{-7}$ & $4.829 \times 10^{-6}$ & $9.802 \times 10^{-7}$ & $1.810 \times 10^{1}$ \\
\hline \multirow{4}{*}{ SC2-CF } & $0-1.48$ & $1.007 \times 10^{-2}$ & $8.968 \times 10^{-3}$ & $8.896 \times 10^{-3}$ & $8.978 \times 10^{-3}$ & $5.382 \times 10^{5}$ \\
\hline & $1.48-5.75$ & $3.410 \times 10^{-3}$ & $1.402 \times 10^{-3}$ & $1.001 \times 10^{-3}$ & $1.402 \times 10^{-3}$ & $9.978 \times 10^{2}$ \\
\hline & $5.75-11.69$ & $2.754 \times 10^{-2}$ & $1.502 \times 10^{-2}$ & $1.773 \times 10^{-3}$ & $1.504 \times 10^{-2}$ & $2.941 \times 10^{3}$ \\
\hline & $11.69-72$ & $6.768 \times 10^{-2}$ & $6.160 \times 10^{-3}$ & $2.599 \times 10^{-2}$ & $6.170 \times 10^{-3}$ & $7.755 \times 10^{2}$ \\
\hline
\end{tabular}

${ }^{a} \mathrm{Te}$, Se class for the CFR 100 Scenario includes all other non-volatiles. 


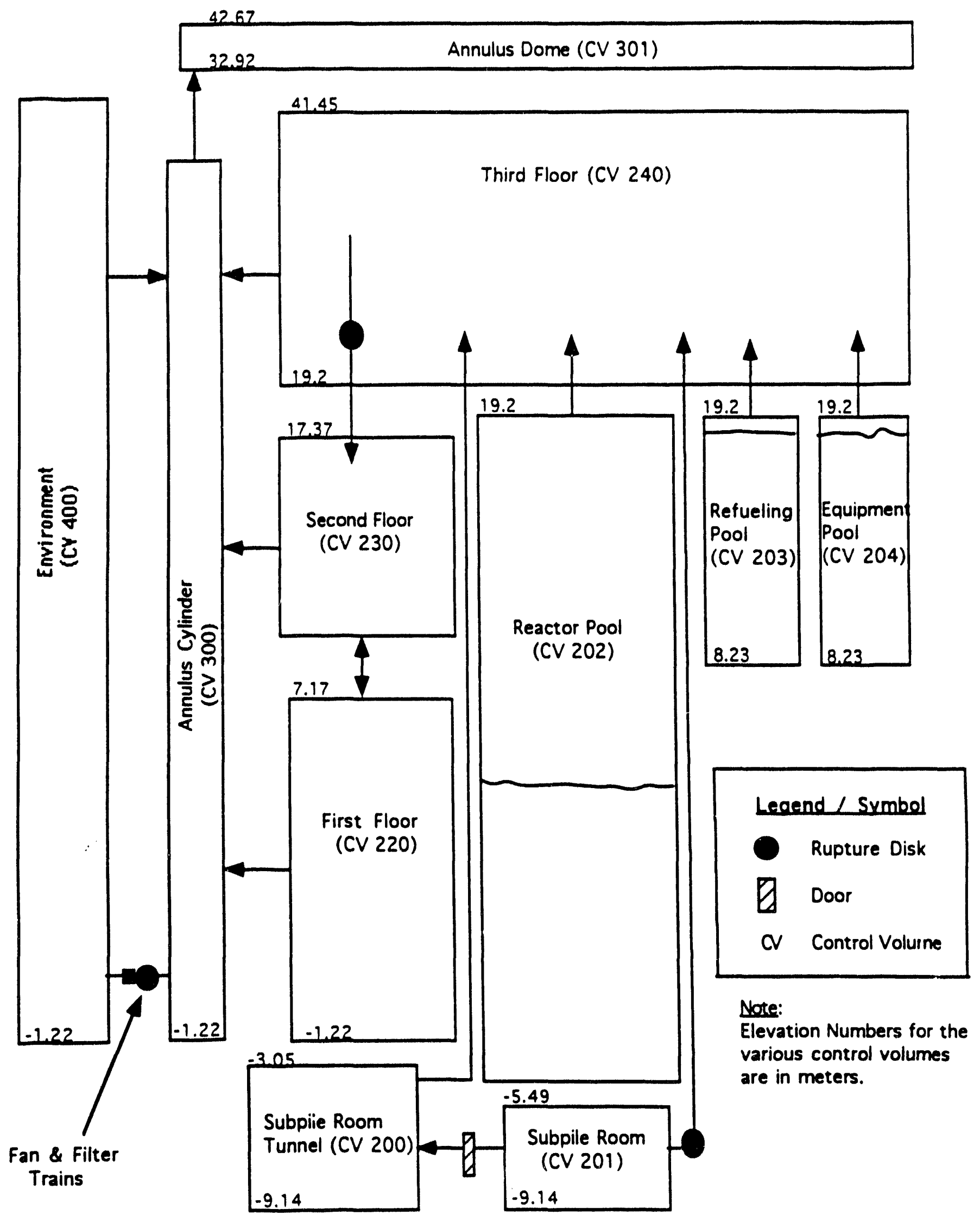

Figure 2.1 ANS Containment (MELCOR) Representation for ANS CSAR 


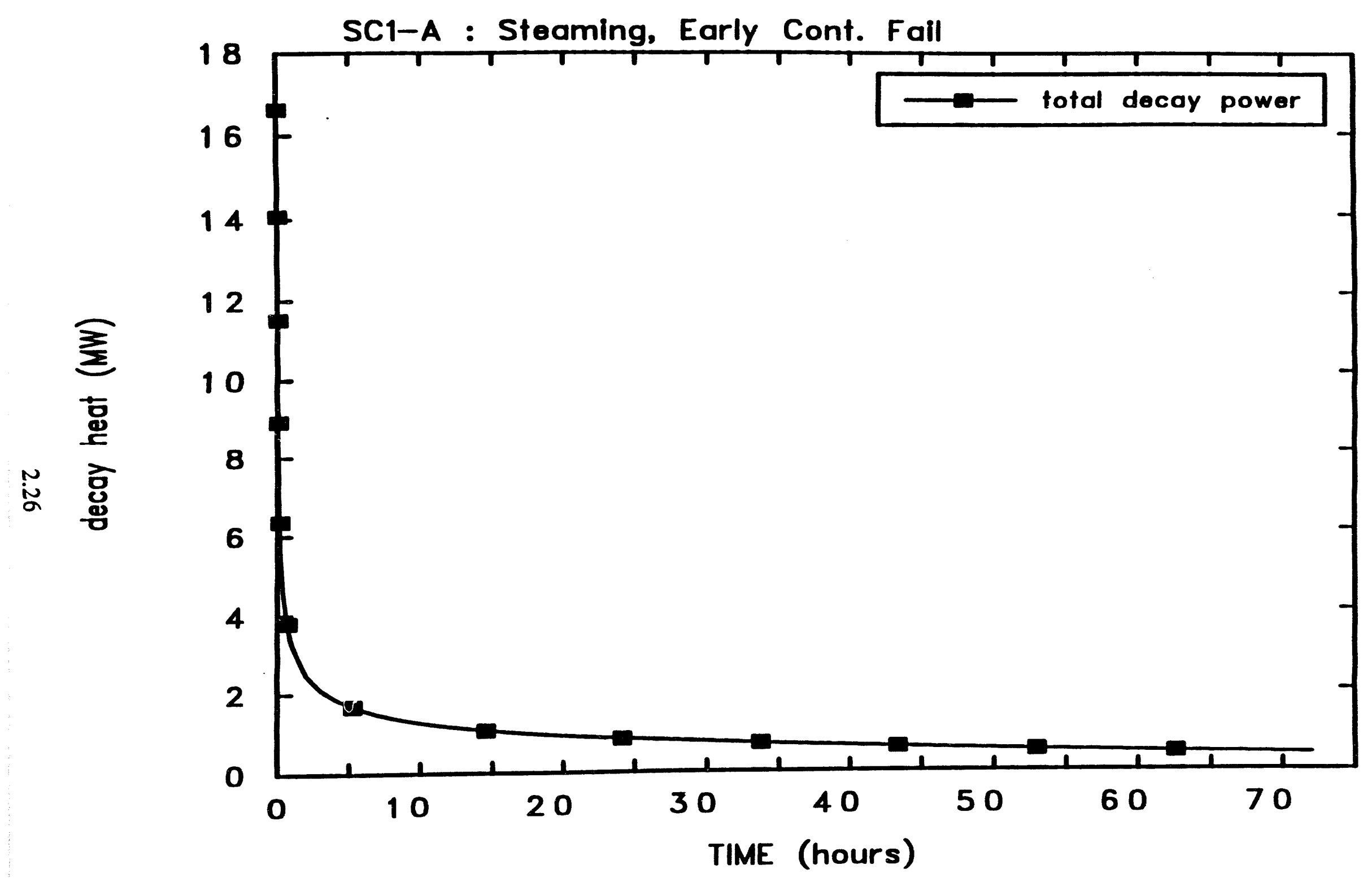

Figure 2.2 Variation of ANS Core Debris End-Of-Cycle Decay Power vs Time 


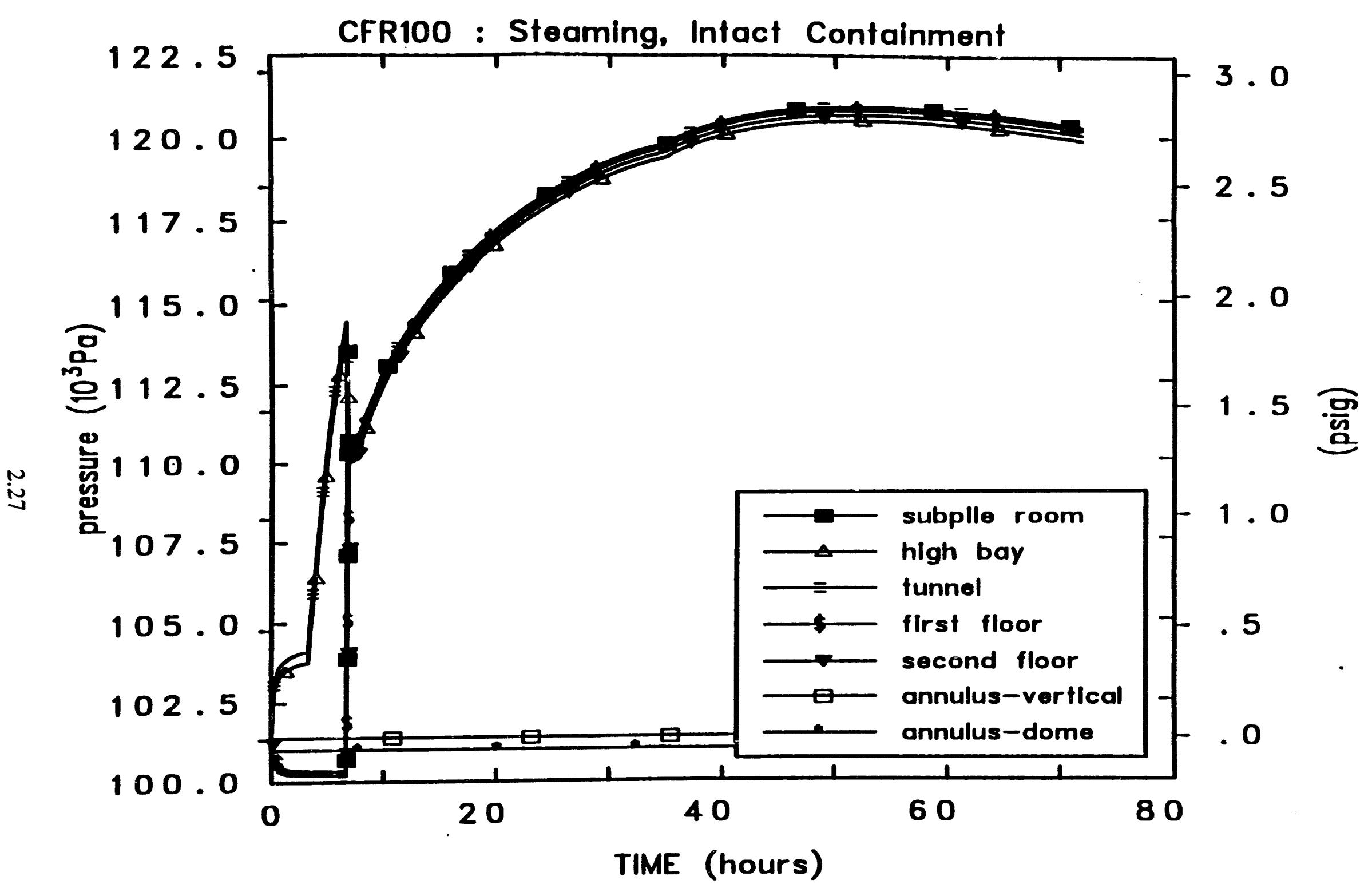

Figure 2.3 Variation of containment volume pressures vs time (Case - CFR 100) 


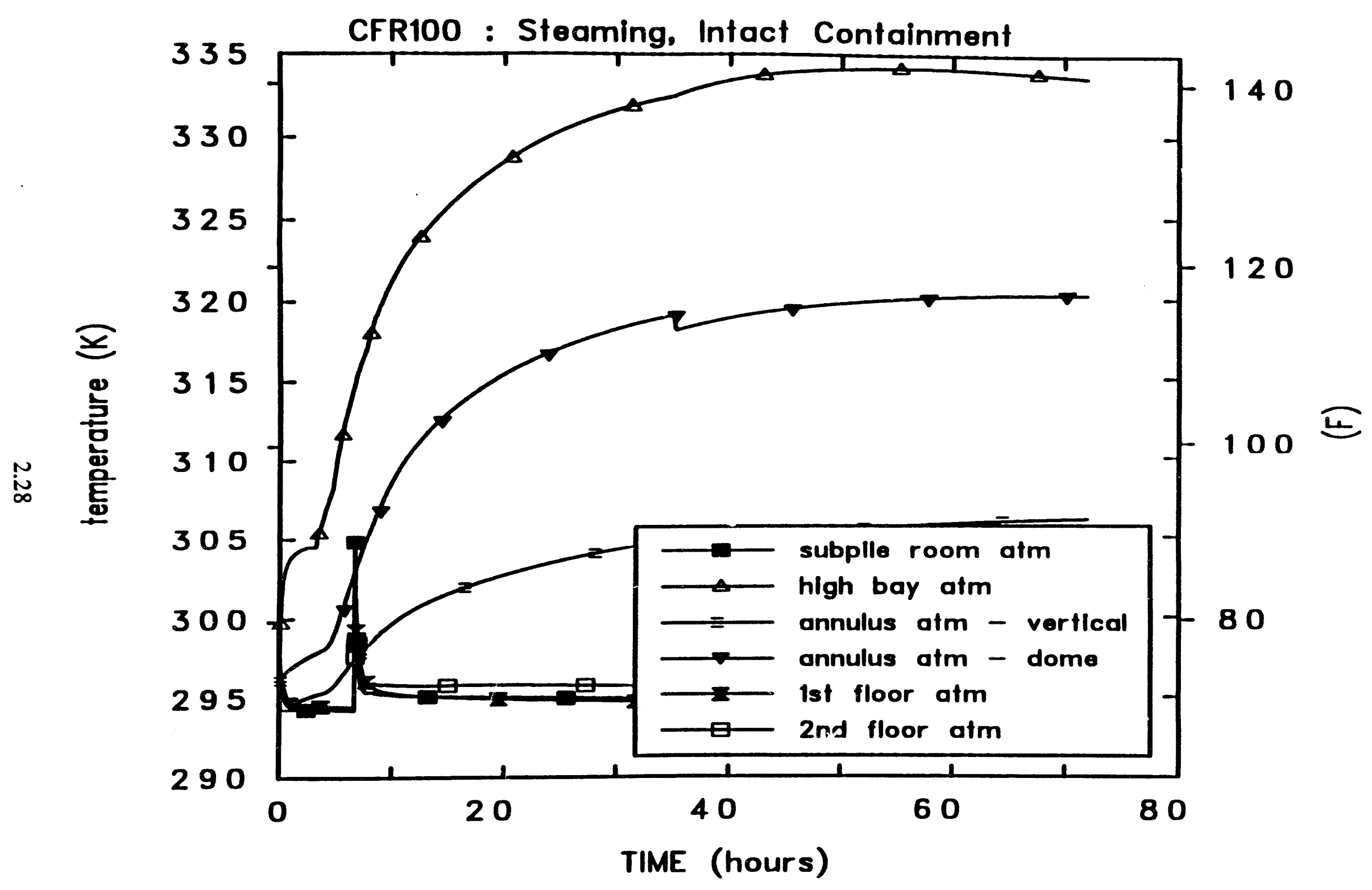

Figure 2.4 Variation of containment volume temperatures vs time (Case - CFR 100) 


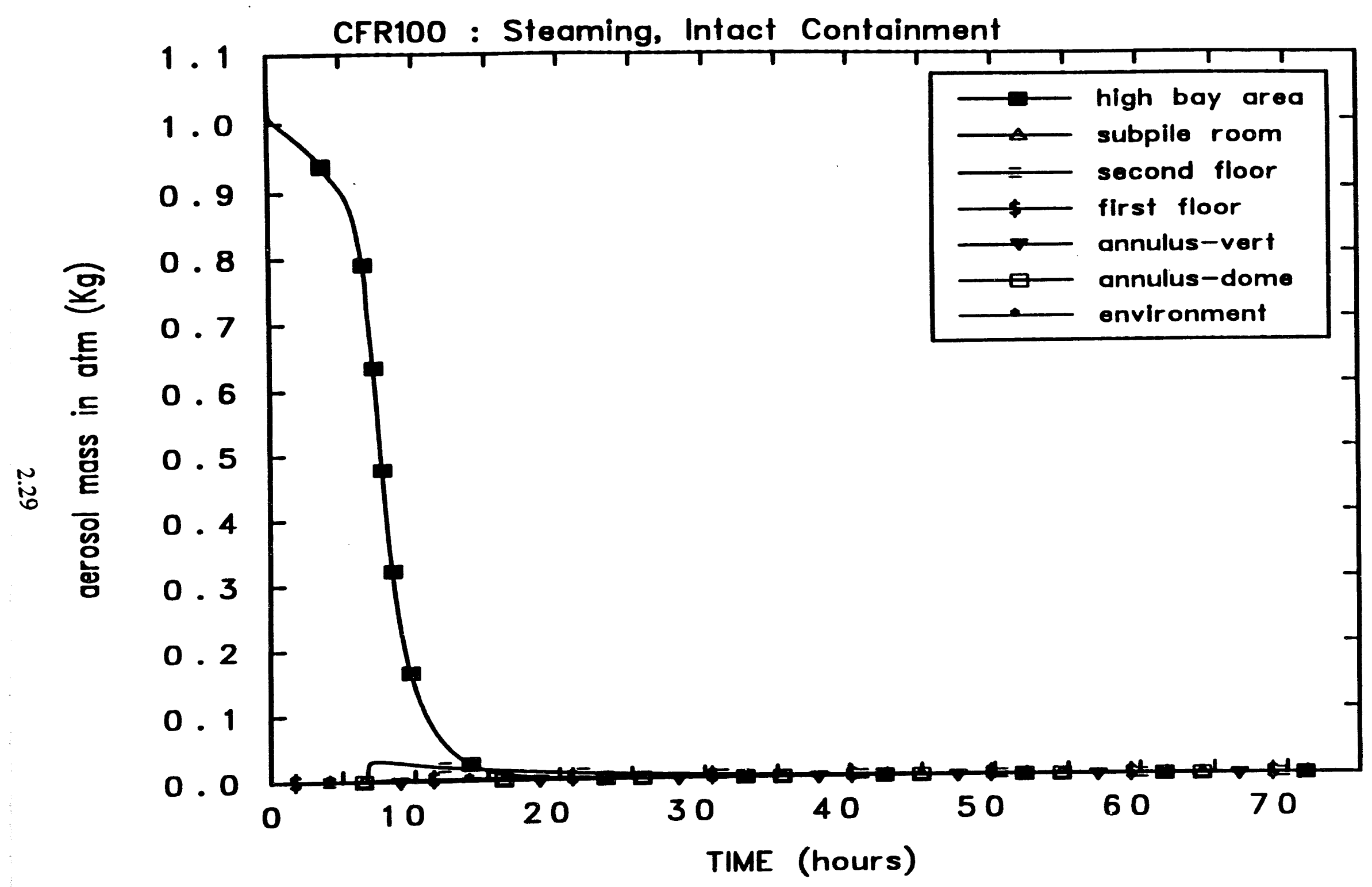

Figure 2.5 Variation of atmosphere aerosol masses vs time (Case - CFR100) 


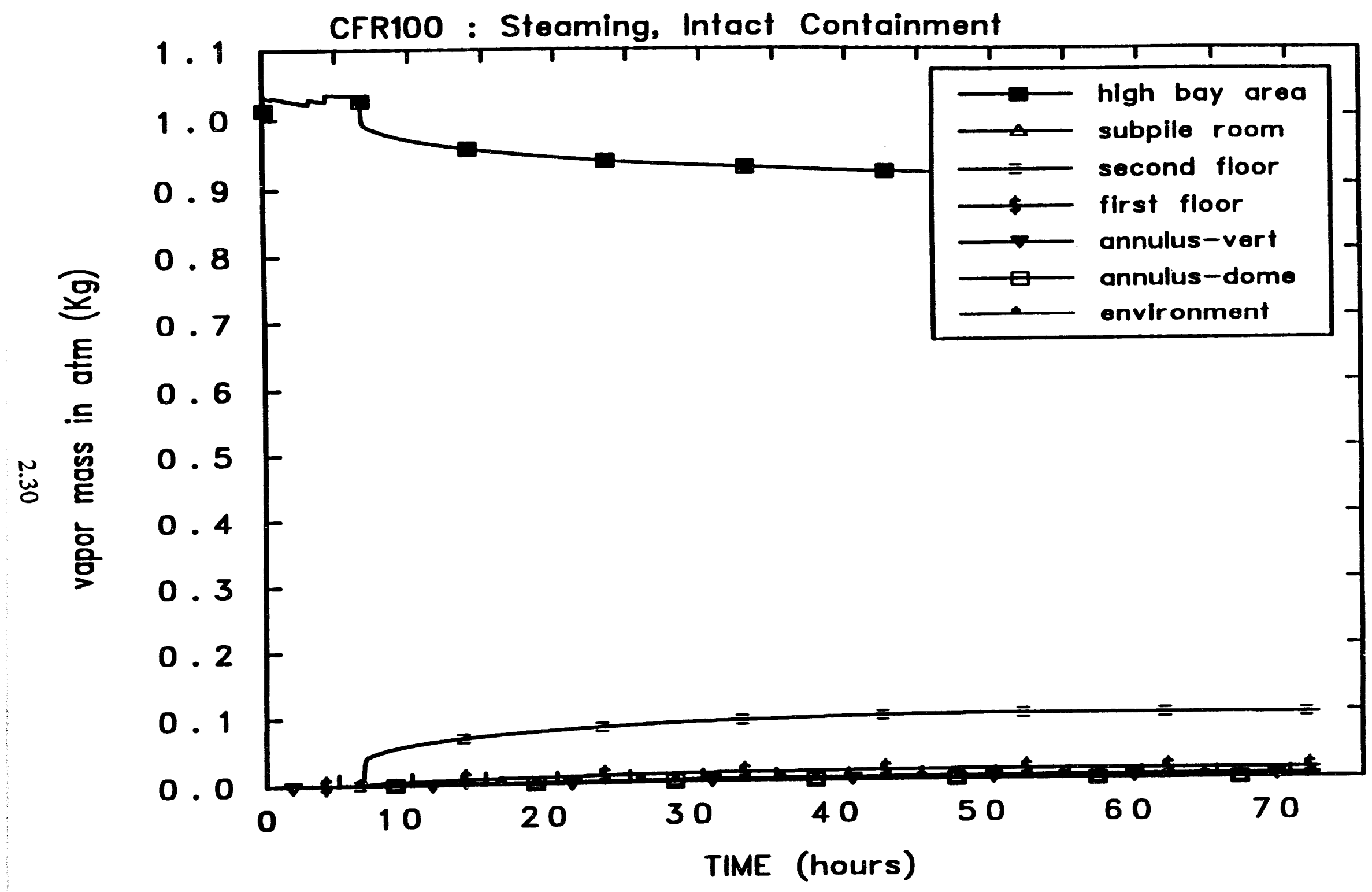

Figure 2.6 Variation of atmosphere radionuclide vapor masses vs time (Case - SC1 - C) 


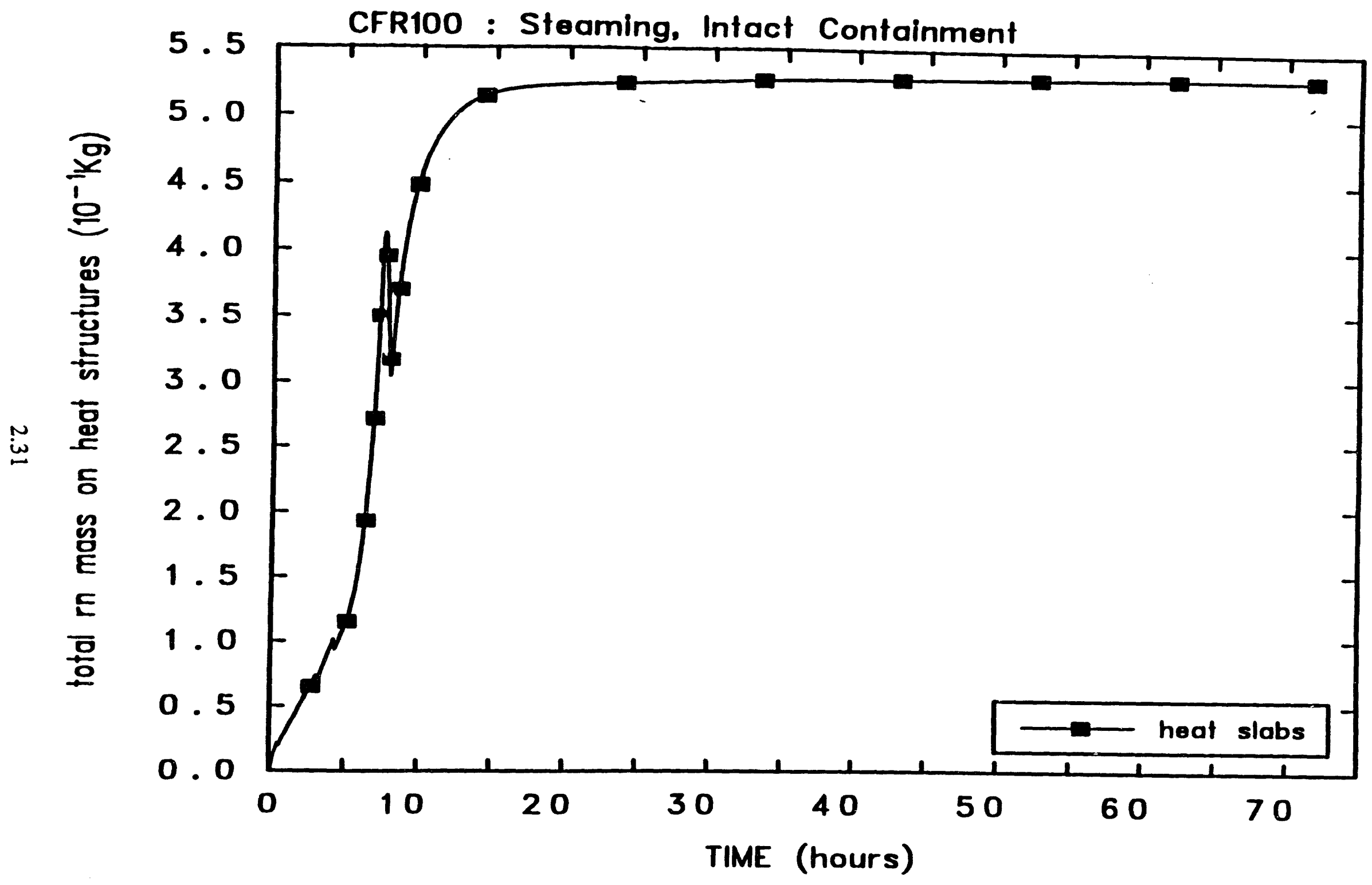

Figure 2.7 Variation of total radionuclide mass deposition on heat structures vs time (Case - CFR 100) 


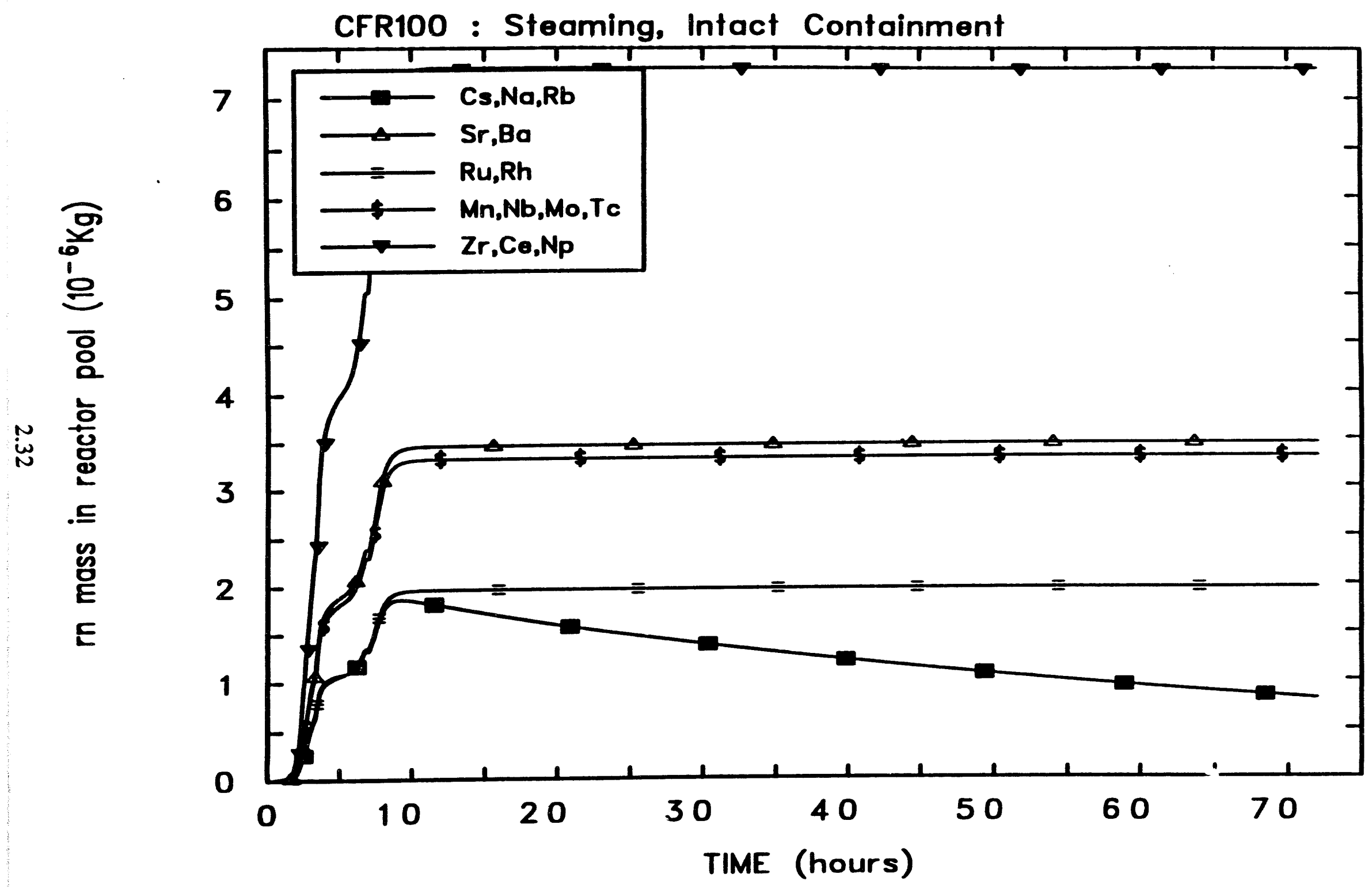

Figure 2.8 Variation of radionuclide masses in reactor pool vs time (Case - SC1 - B) 


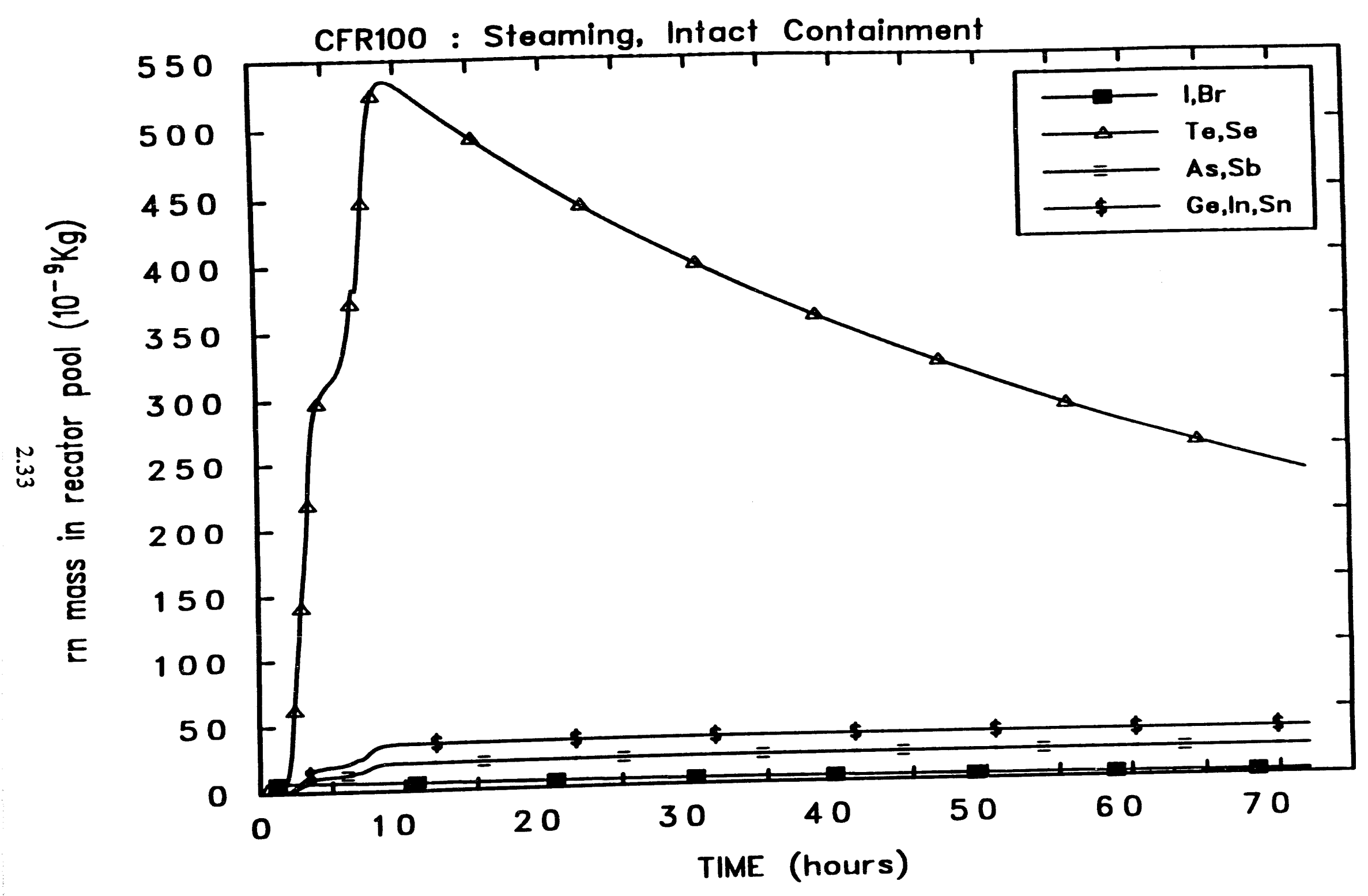

Figure $2.9 \quad$ Variation of radionuclide masses in reactor pool vs time (Case - SC1 - B) 


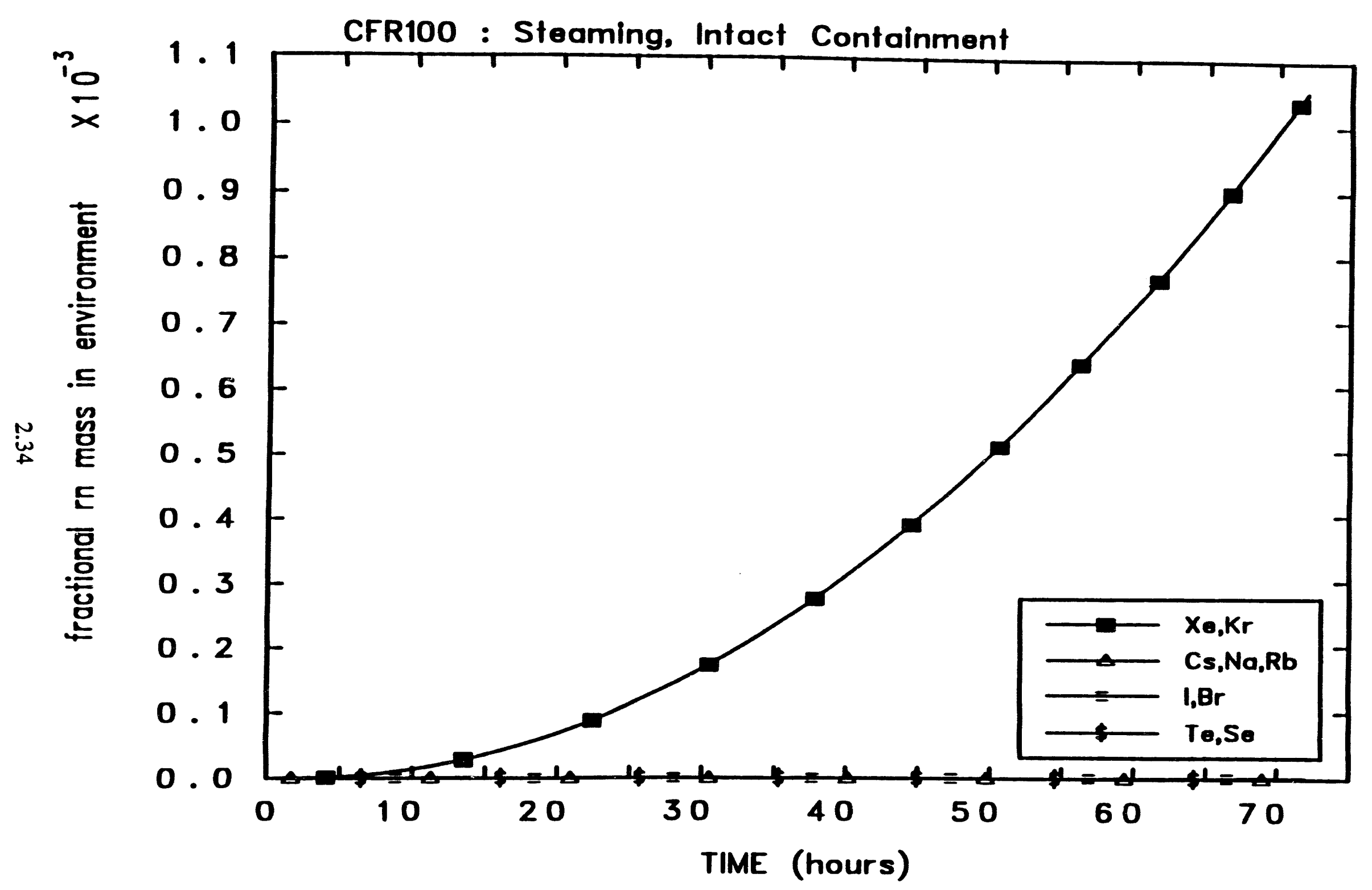

Figure 2.10 Variation of fractional radionuclide masses (volatile species) to the environment vs time (Case - CFR100) 


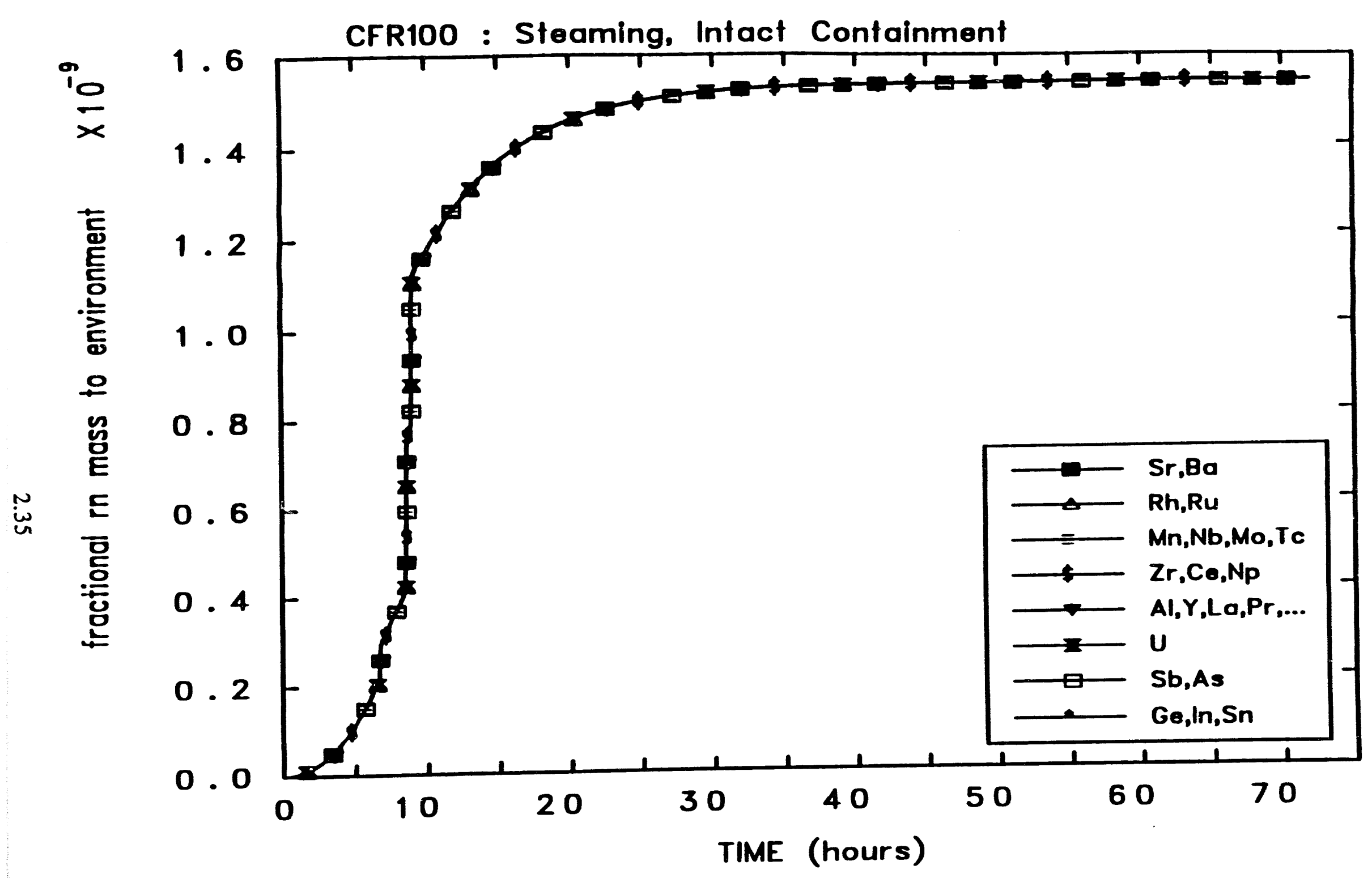

Figure 2.11 Variation of fractional radionuclide masses (non-volatile species) to the environment vs time (Case - CFR 10()) 


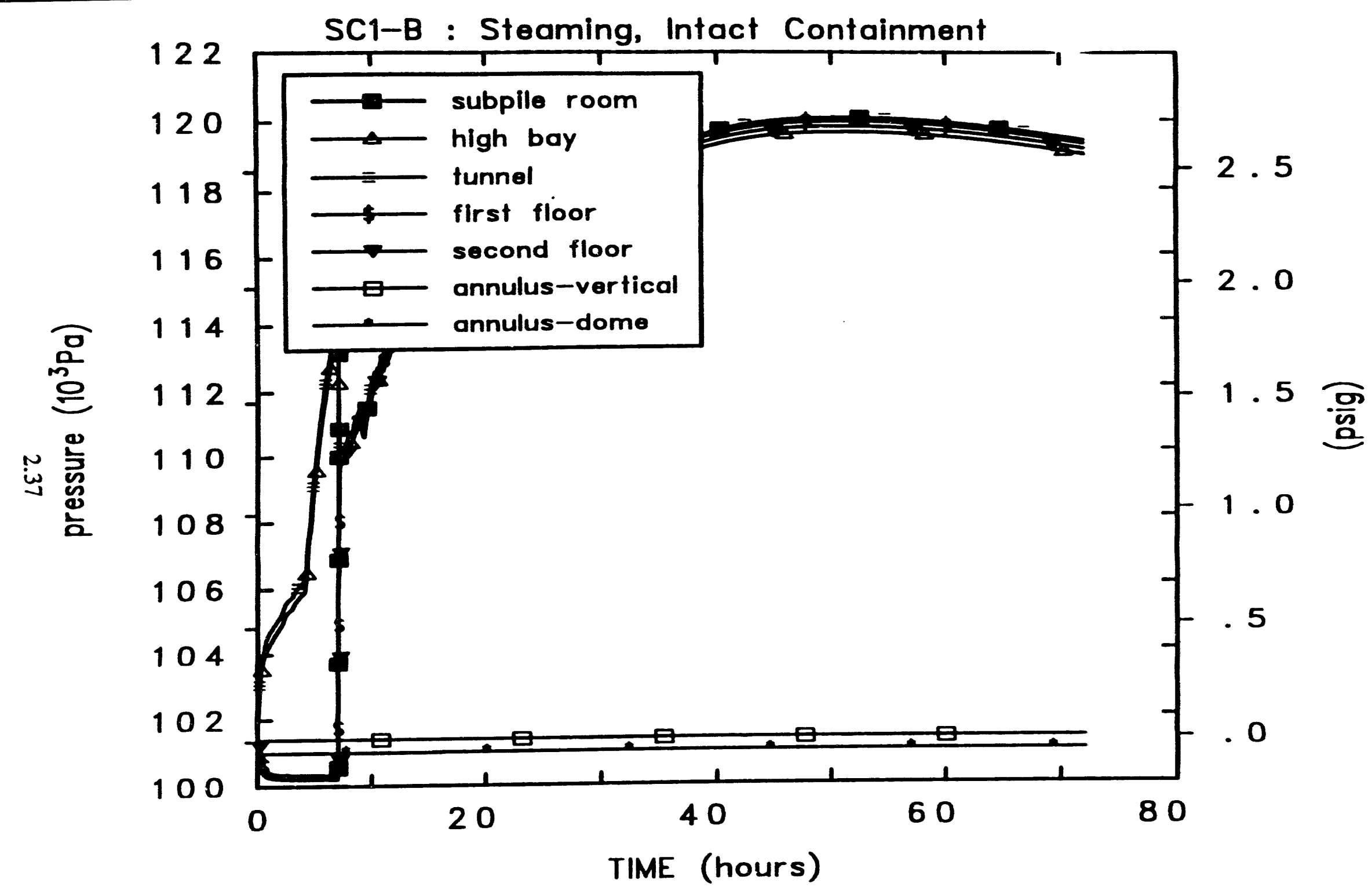

Figure 2.13 Variation of containment volume pressures vs time (Case - SCl-B) 


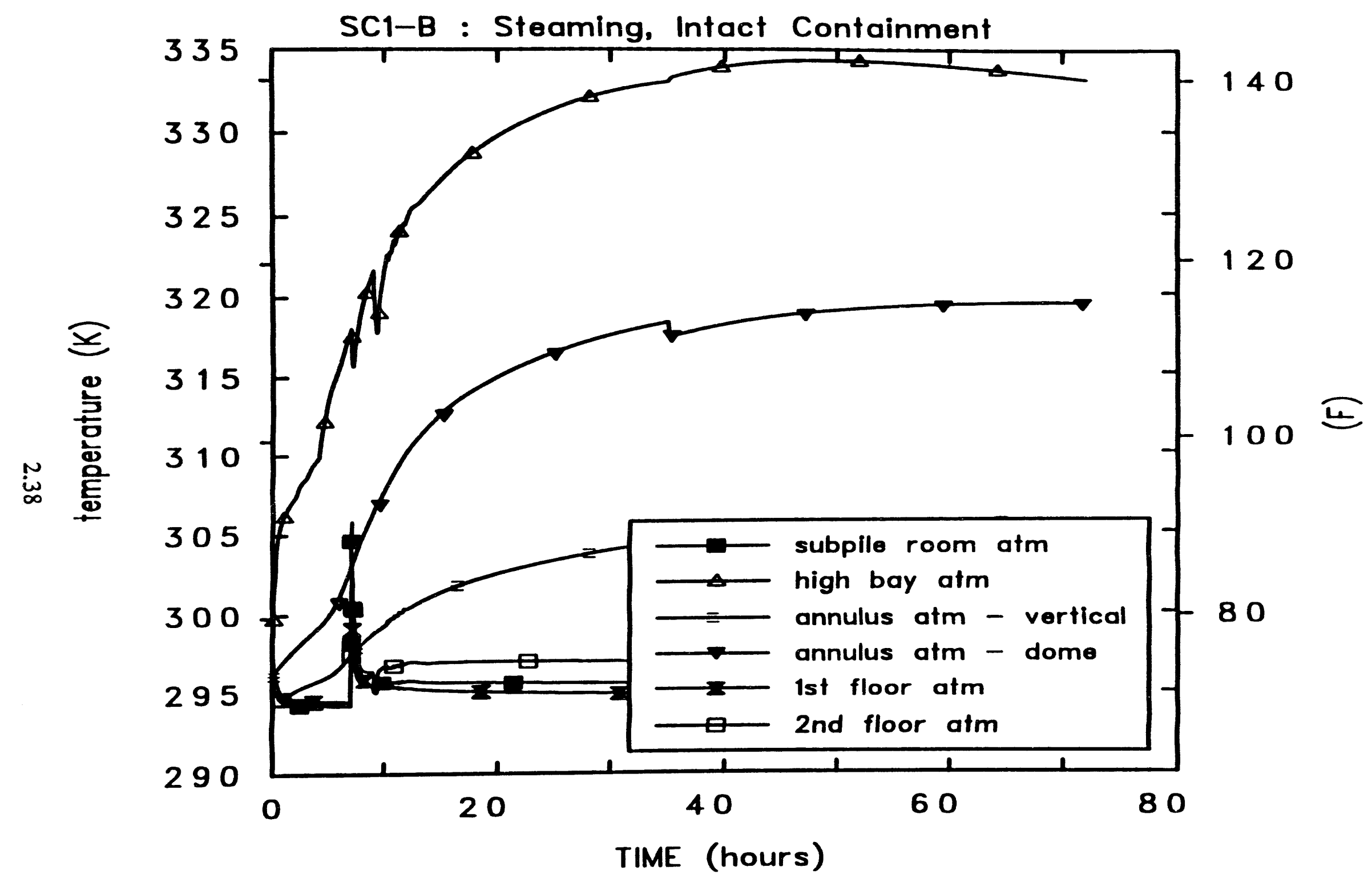

Figure 2.14 Variation of containment volume temperatures vs time (Case - SCI-B) 


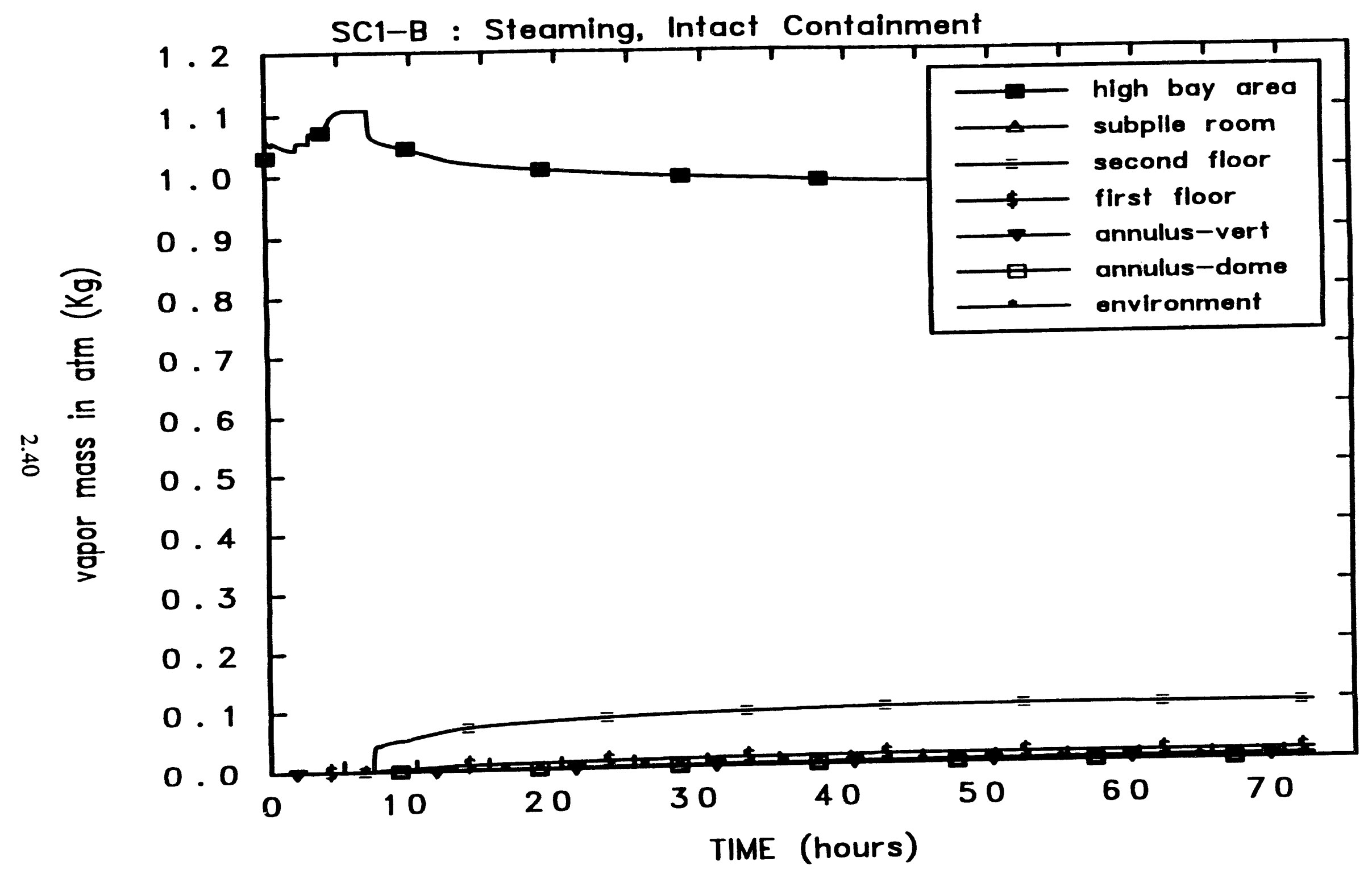

Figure 2.16 Variation of atmosphere radionuclide vapor masses vs time (Case - SC1 - B) 2.40 


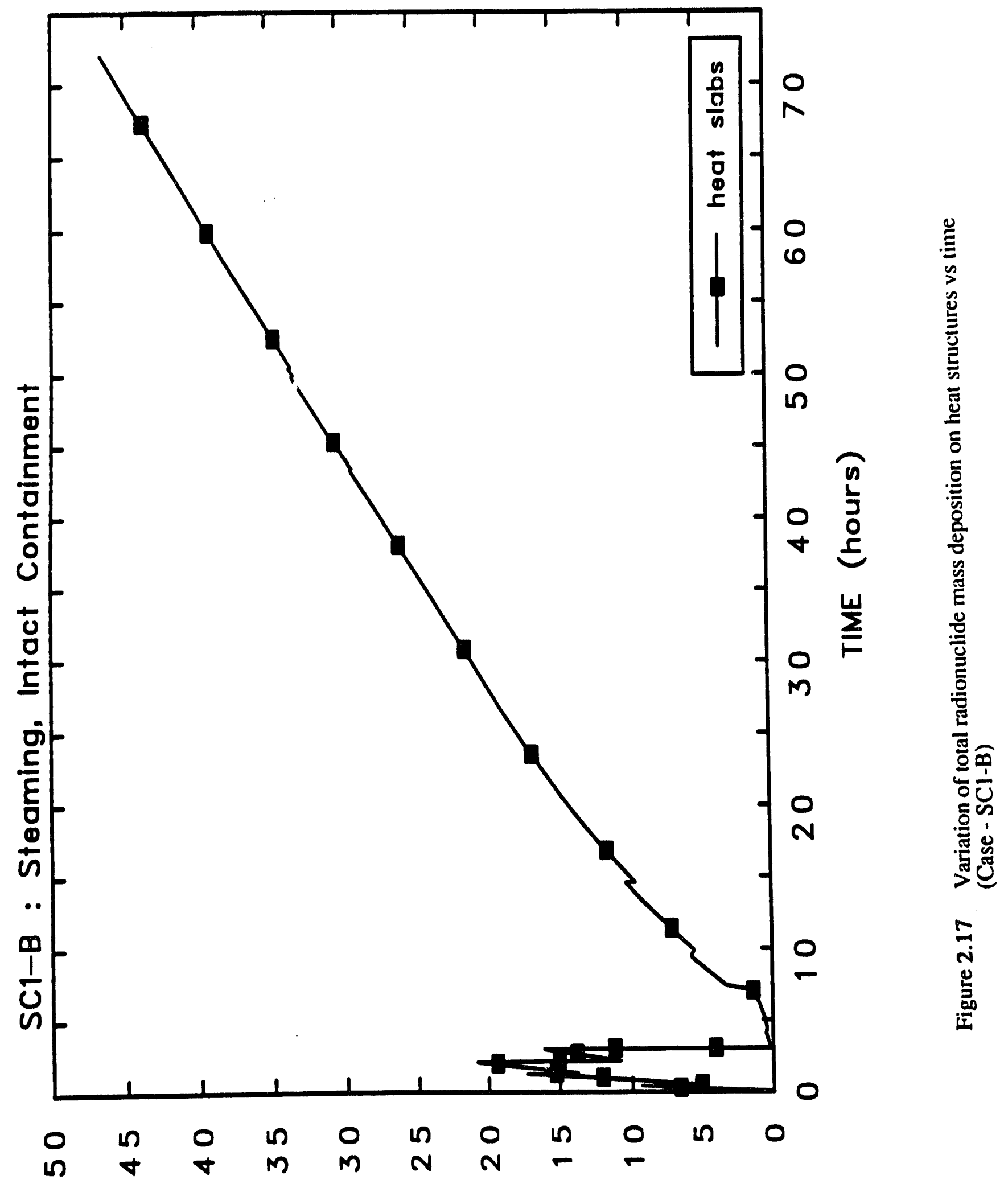

$\left(6 X_{\varepsilon}-01\right)$ sadnłondts tDay uo ssour ud plot 


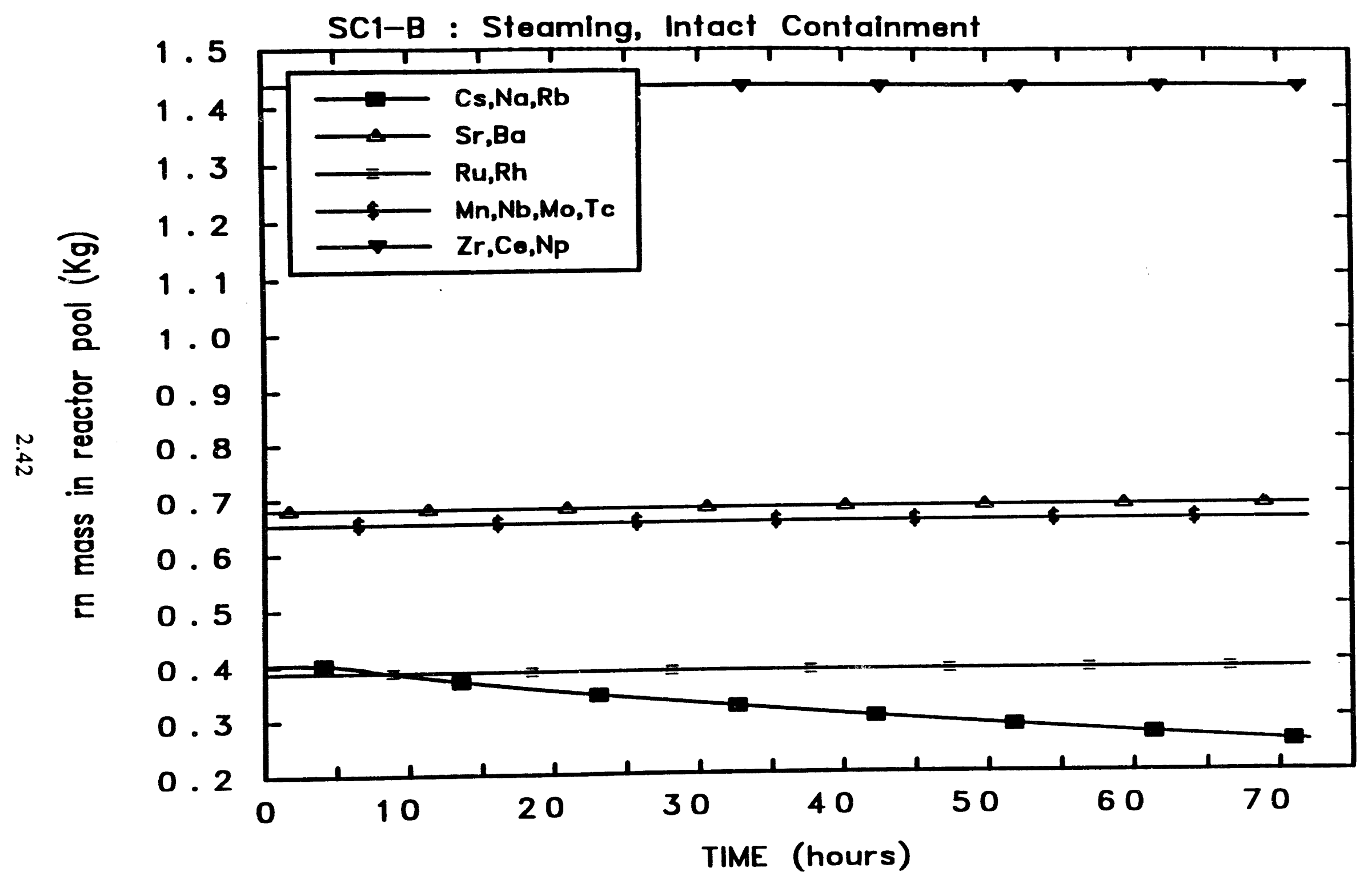

Figure 2.18 Variation of radionuclide masses in reactor pool vs time (Case - SC1-B) 


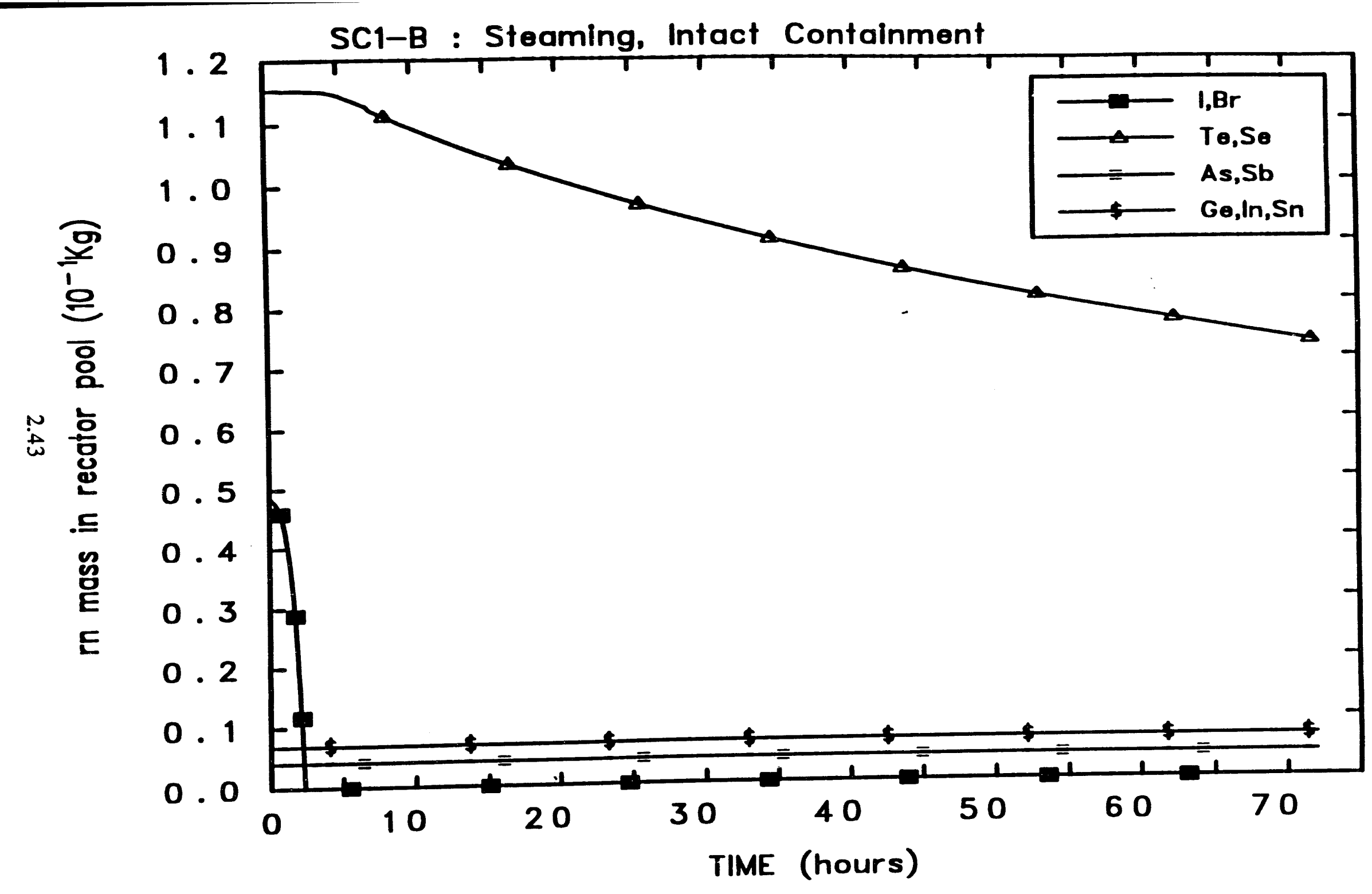

Figure 2.19 Variation of radionuclide masses in reactor pool vs time (Case - SC1-B) 


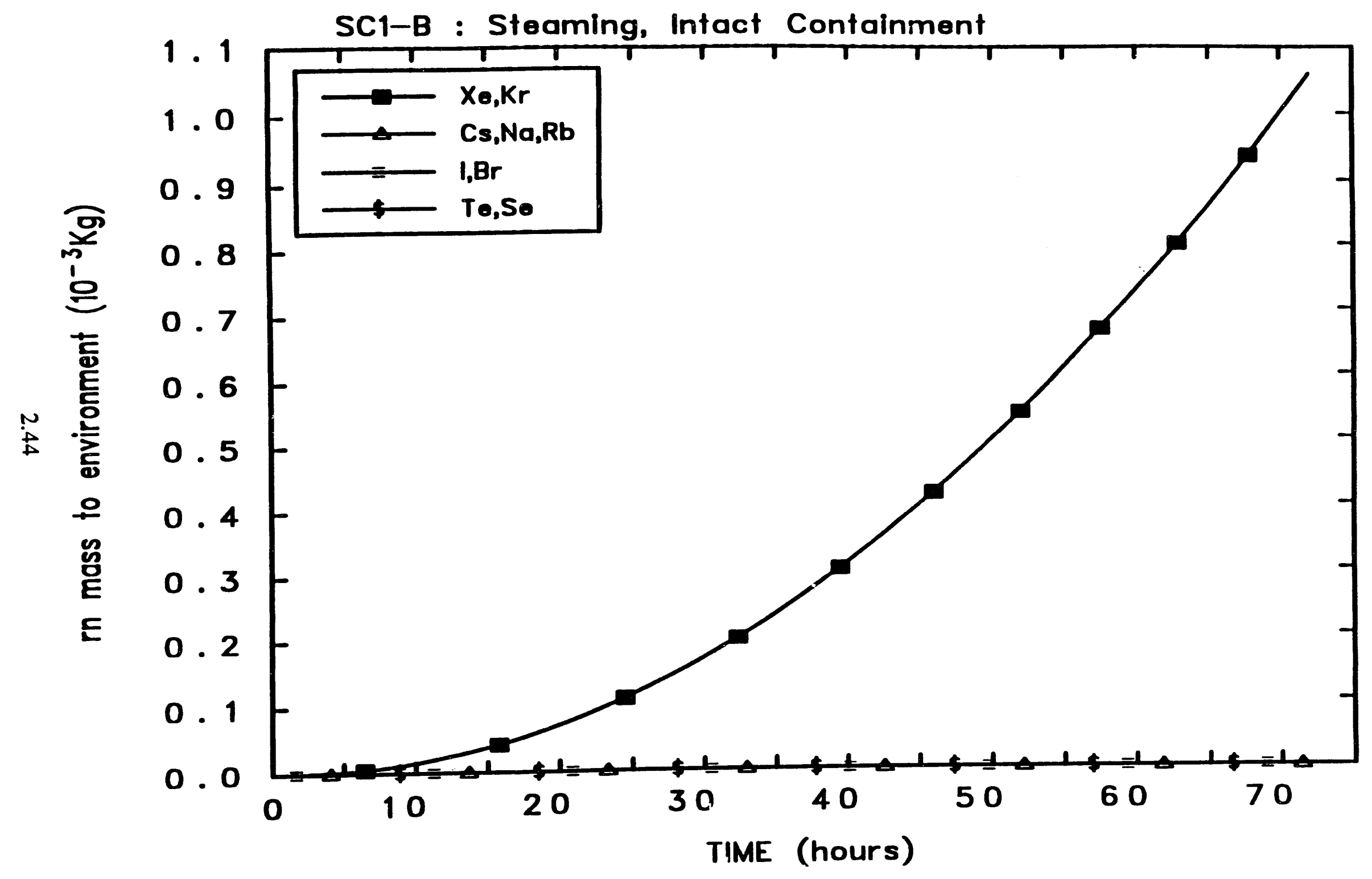

Figure 2.20 Variation of radionuclide masses (volatile species) to the environment vs time (Case - SC1-B) 


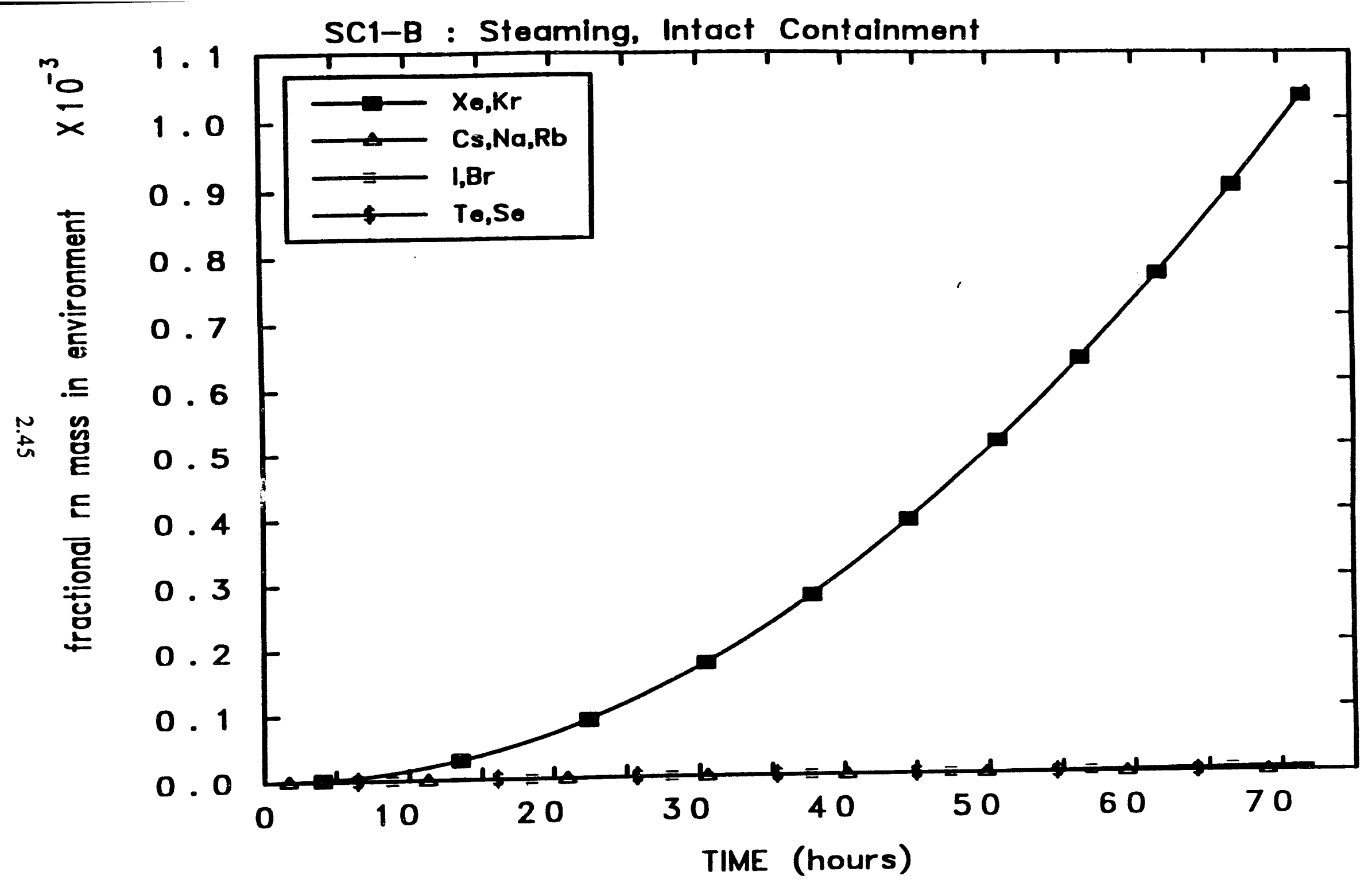

Figure 2.21 Variation of fractional radionuclide masses (volatile species) to the environment vs time (Case - SC1-B) 


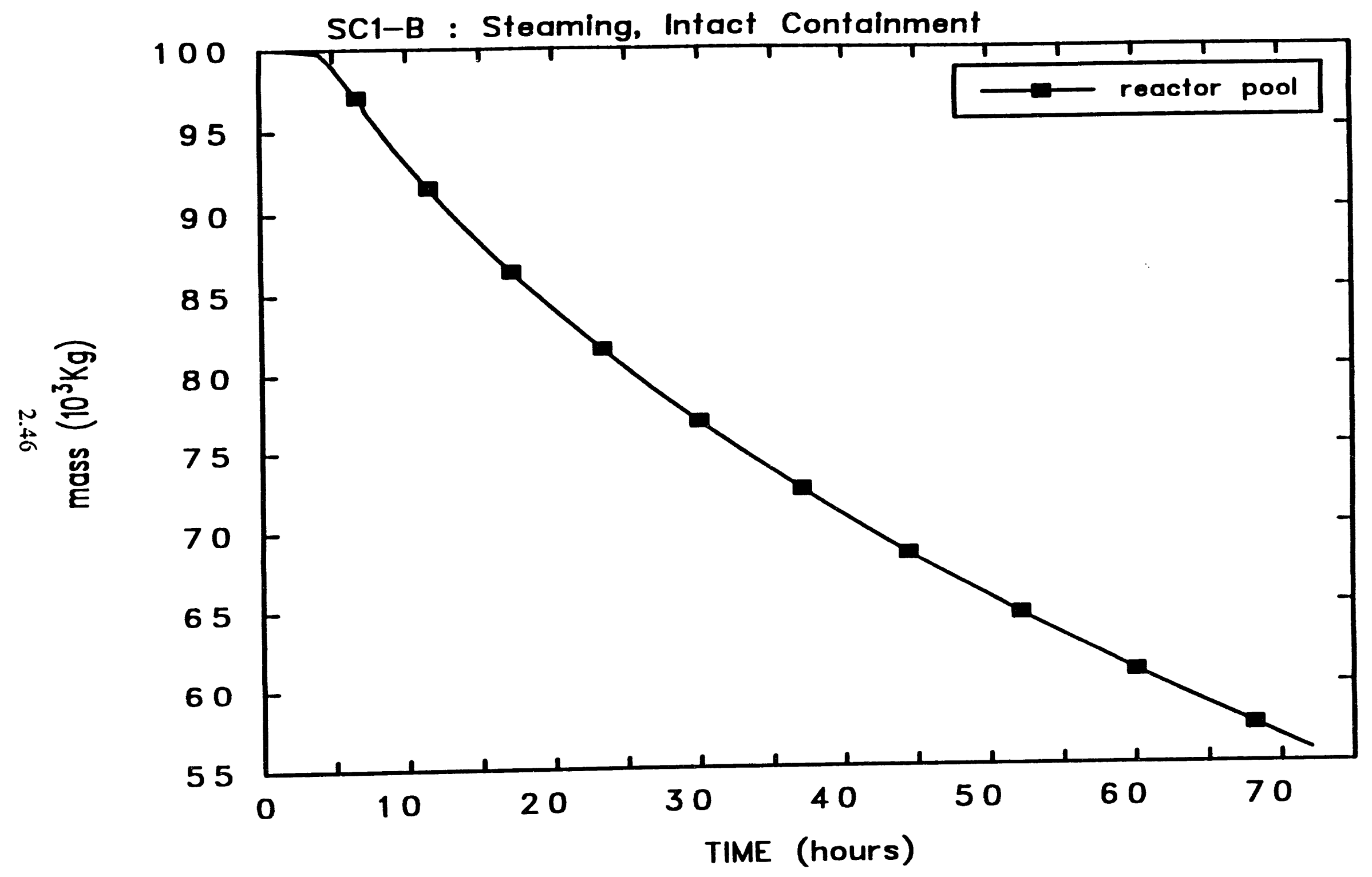

Figure 2.22 Variation of reactor pool water mass vs time (Case - SCl - B) 


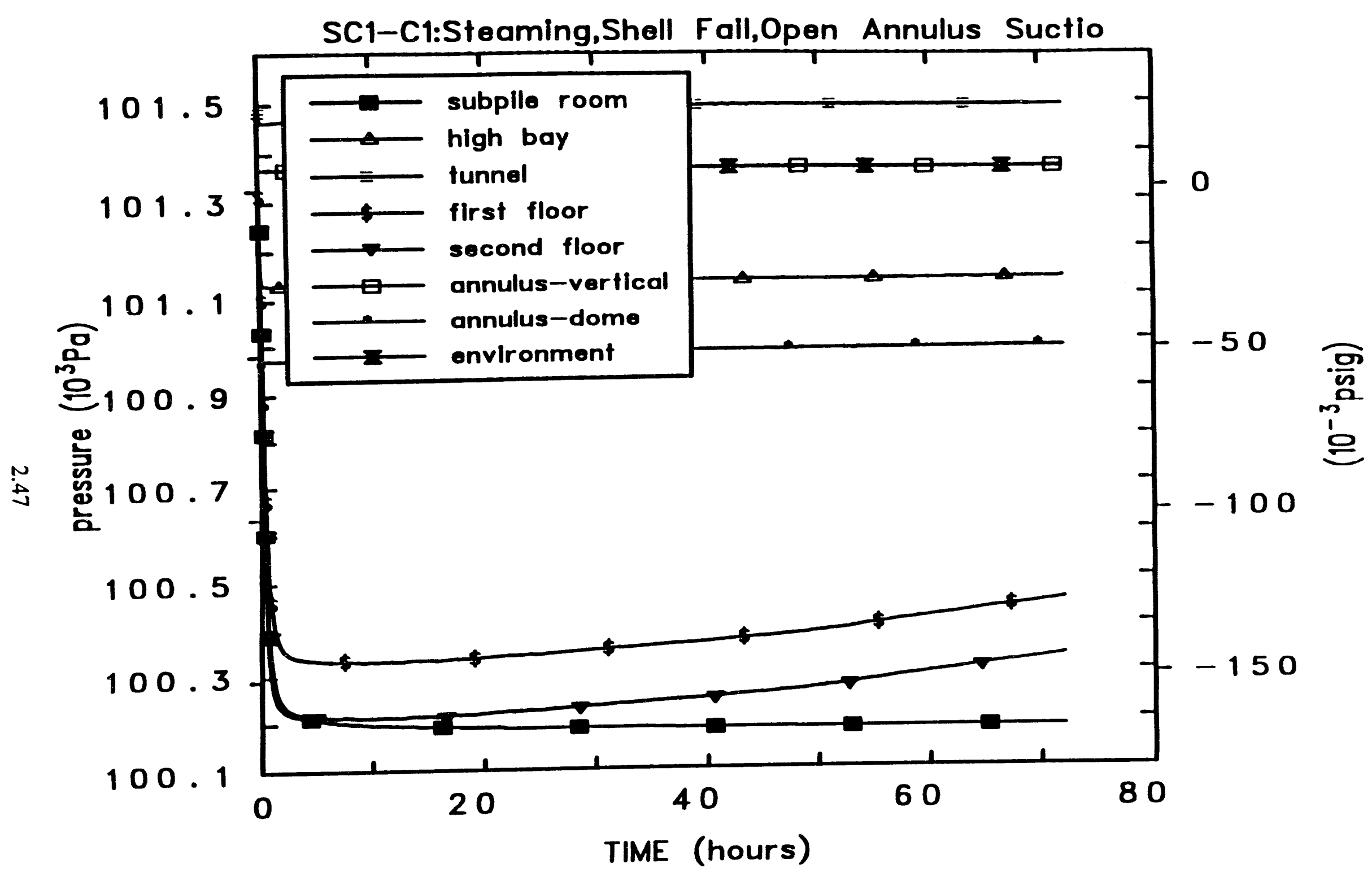

Figure 2.23 Variation of containment volume pressures vs time (Case - SC1-C) 


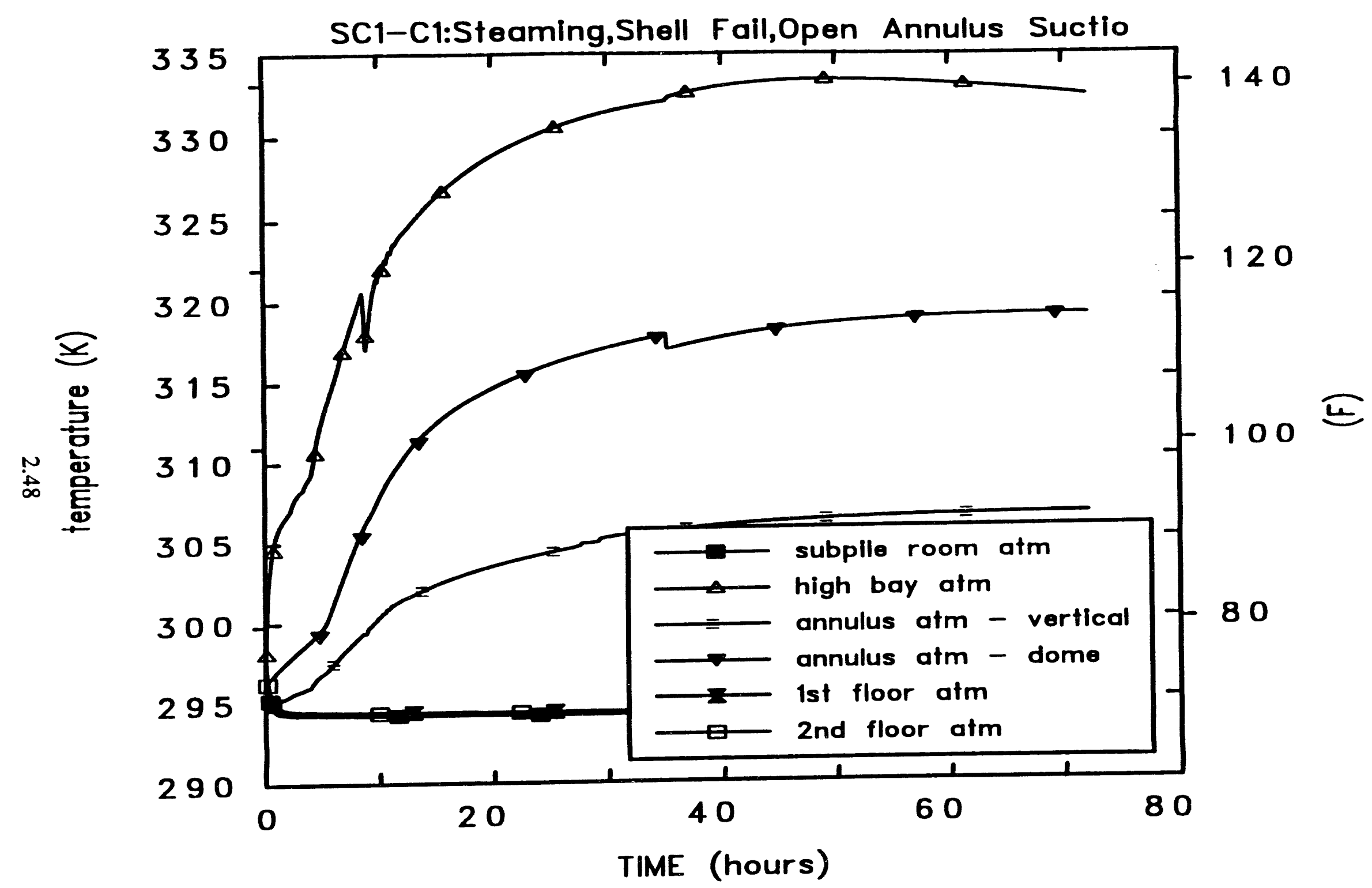

Figure 2.24 Variation of containment volume temperatures vs time (Case - SCl - C) 


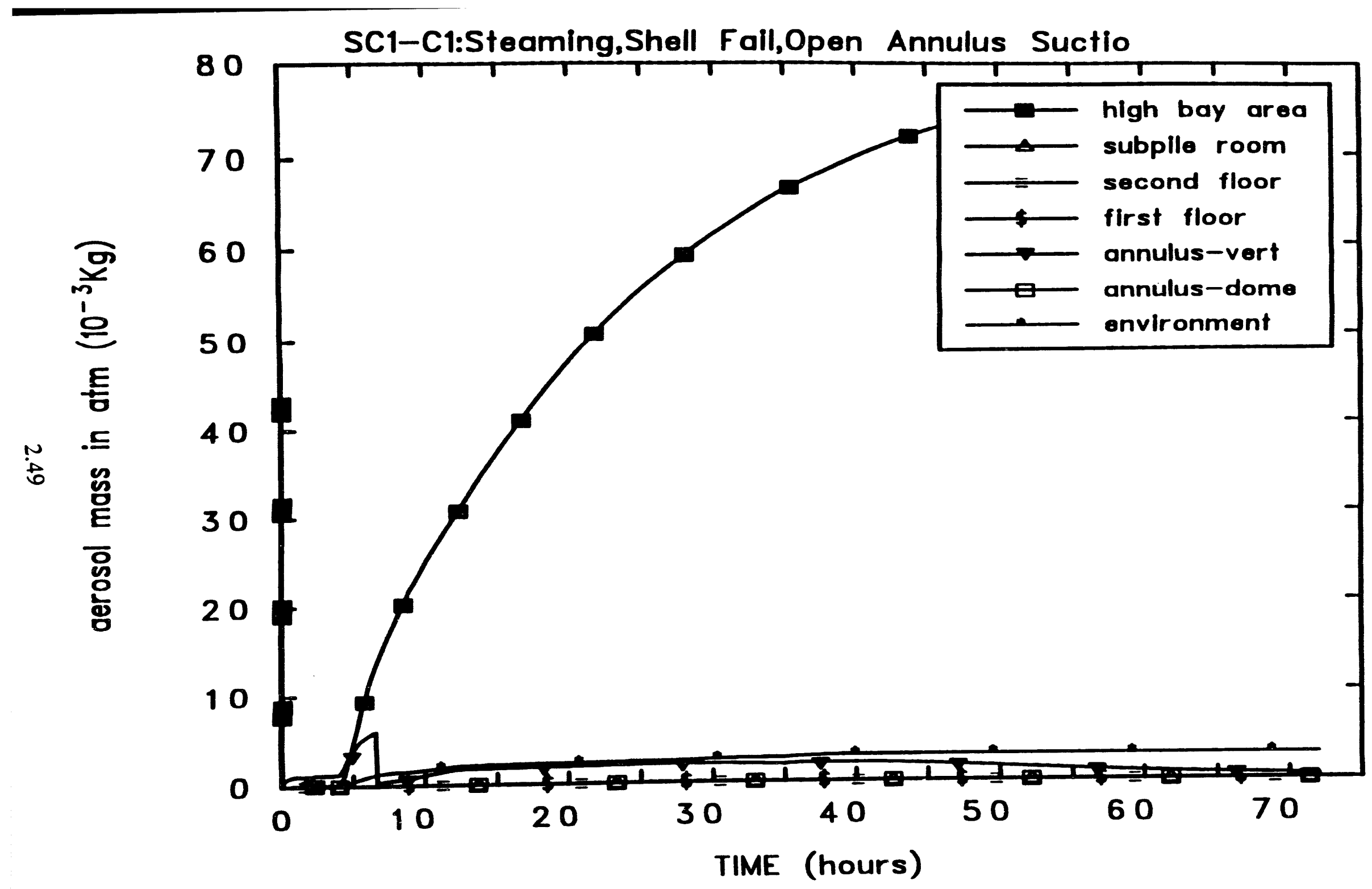

Figure 2.25 Variation of atmosphere aerosol masses vs time (Case - SC1-C) 


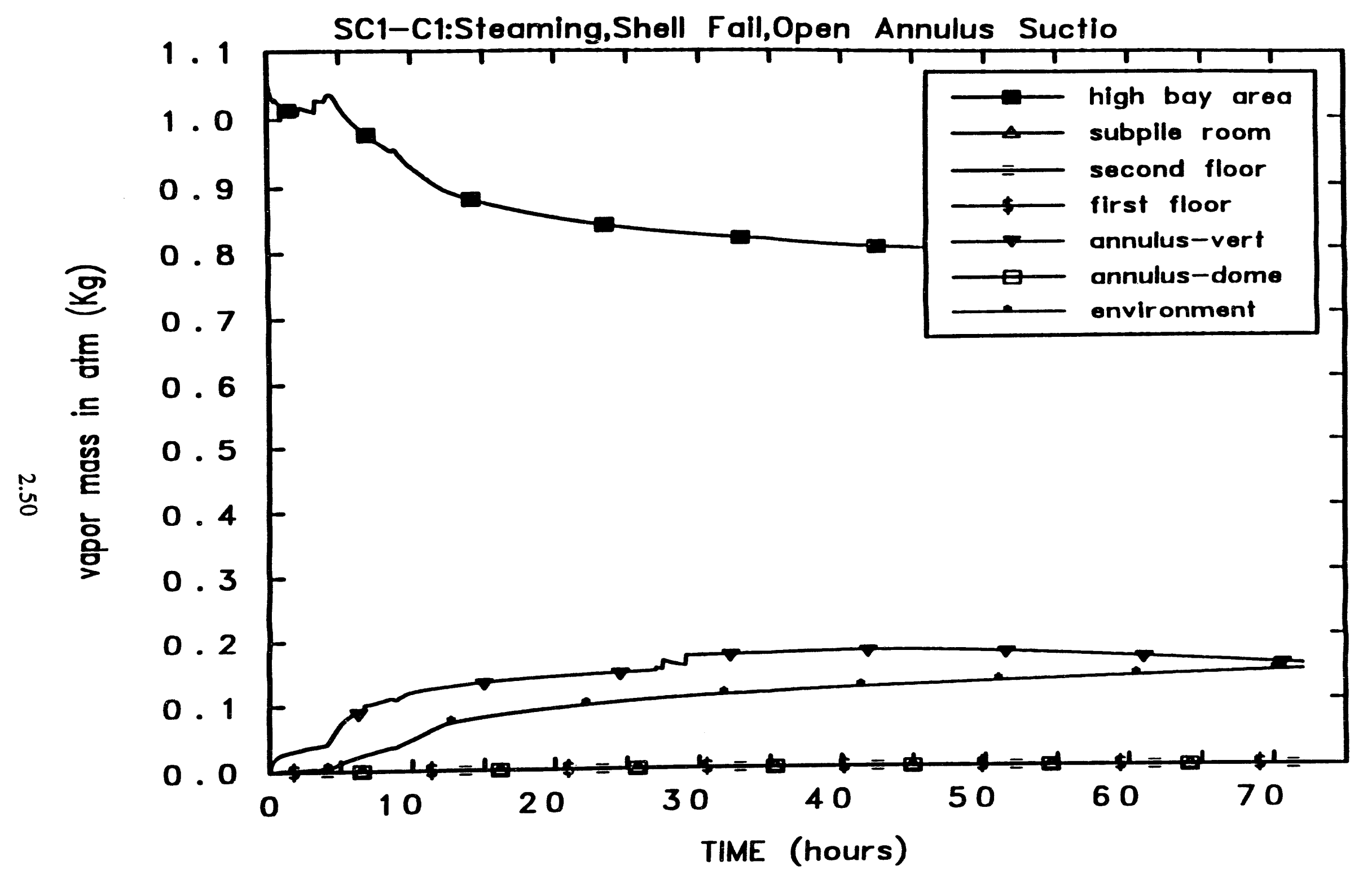

Figure 2.26 Variation of atmosphere radionuclide vapor masses vs time (Case - SCl-C) 


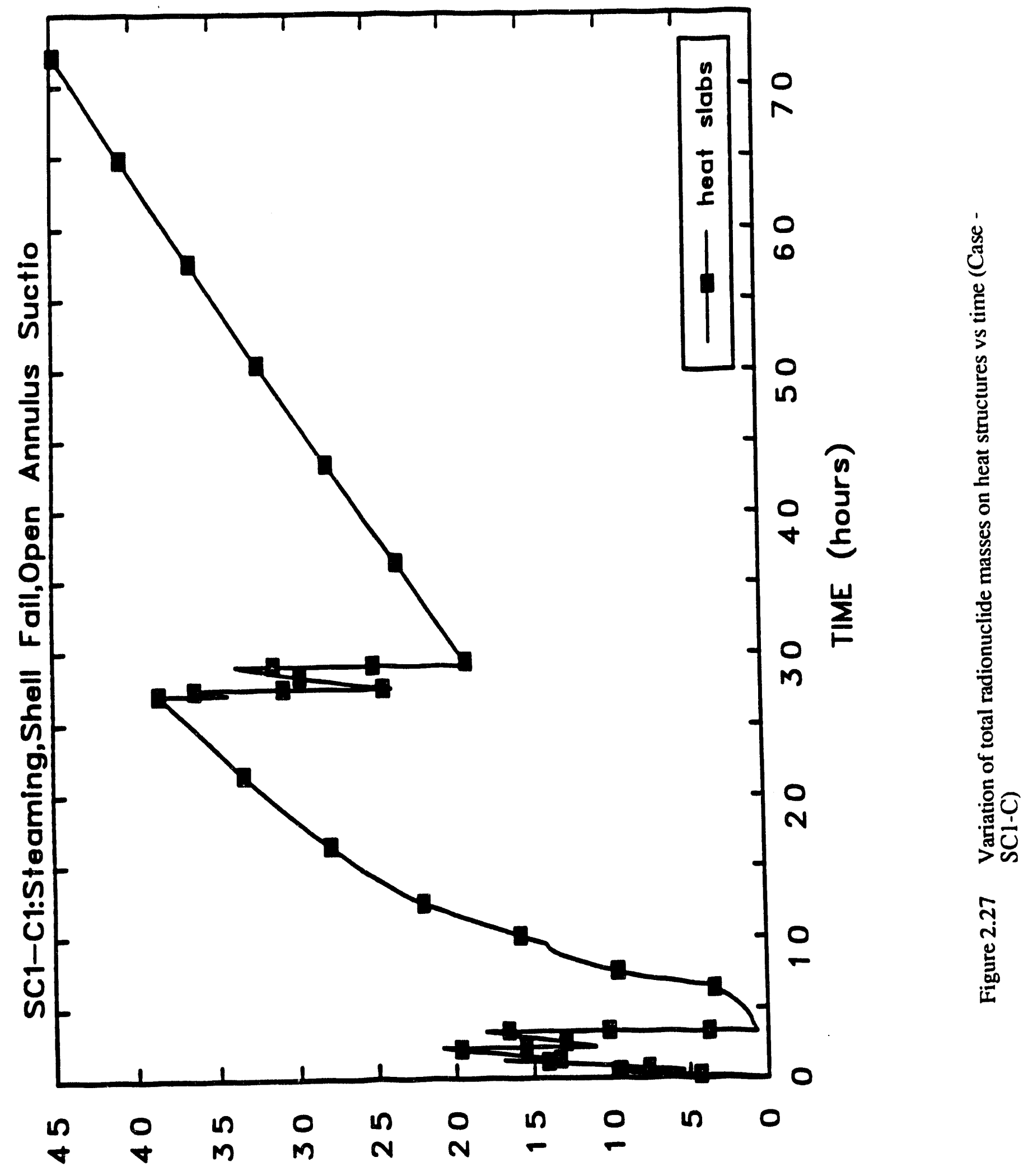

$\left(6 X_{\varepsilon}-01\right)$ sadniondfs tDay uo ssow ud plOt 


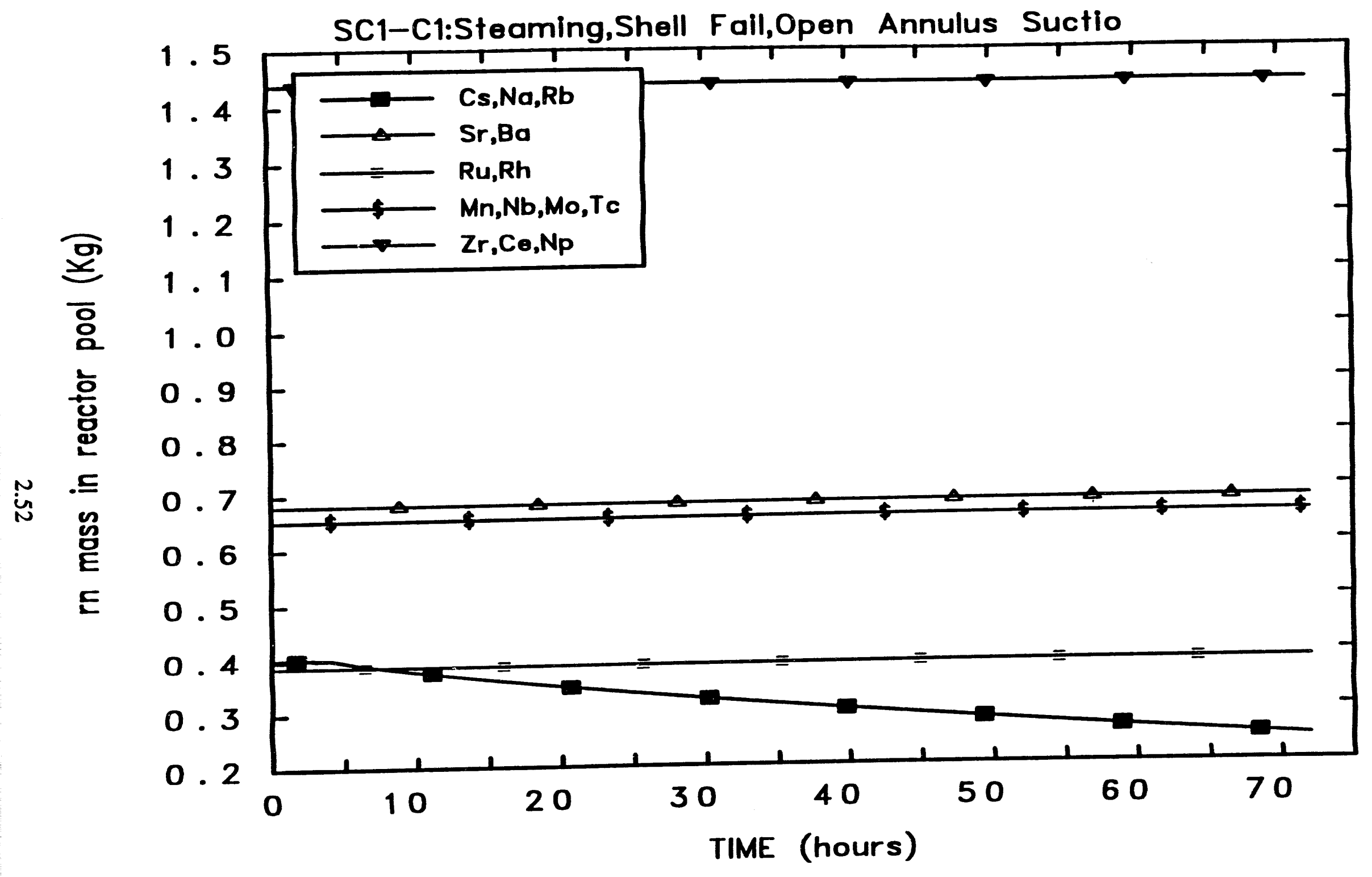

Figure 2.28 Variation of radionuclide masses in reactor pool vs time (Case - SC1 - C). 


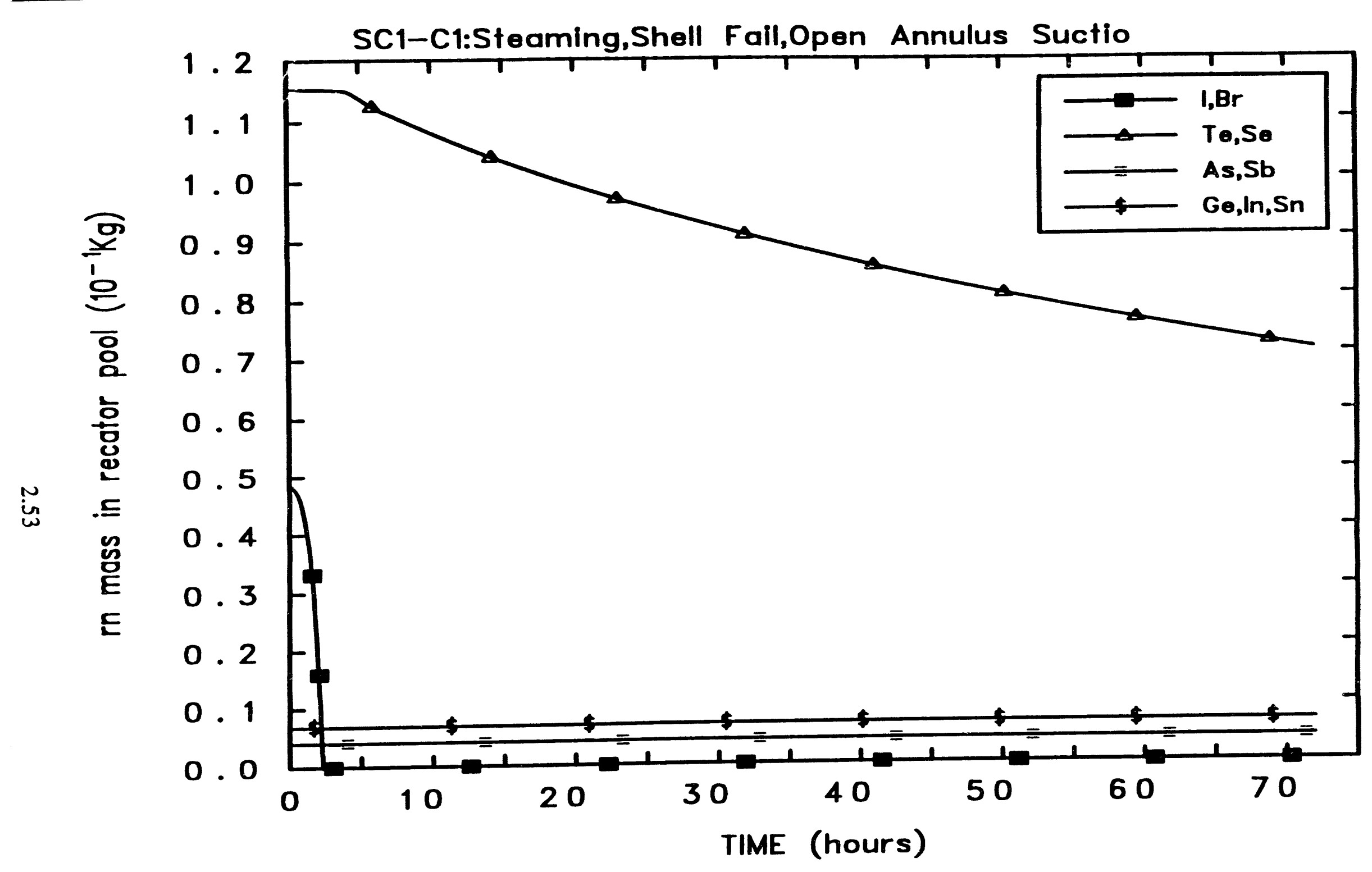

Figure 2.29 Variation of radionuclide masses in reactor pool vs time (Case - SC1 - C) 


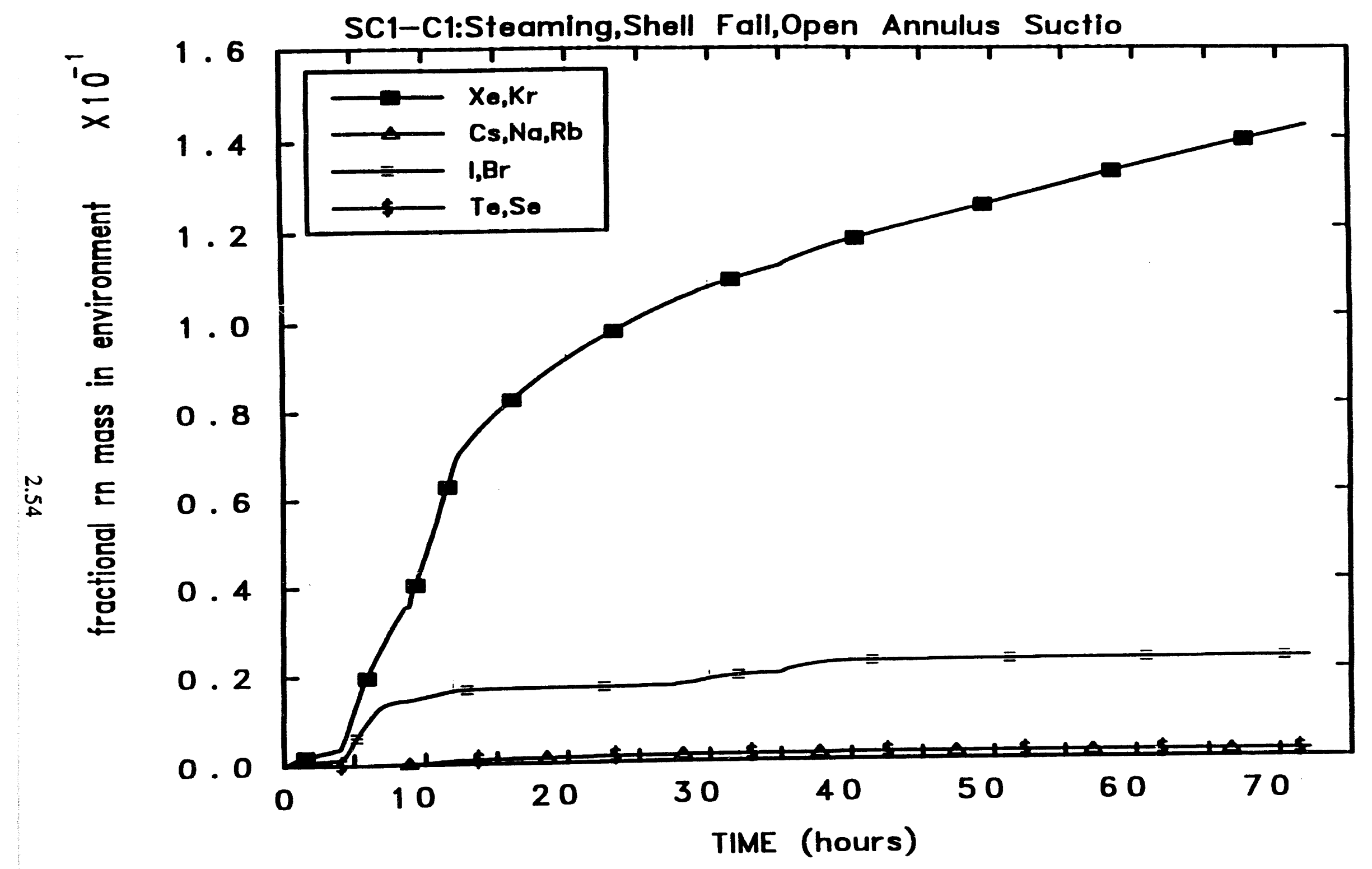

Figure 2.30 Variation of fractional radionuclide masses (volatile species) to the environment vs time (Case - SCl-C) 


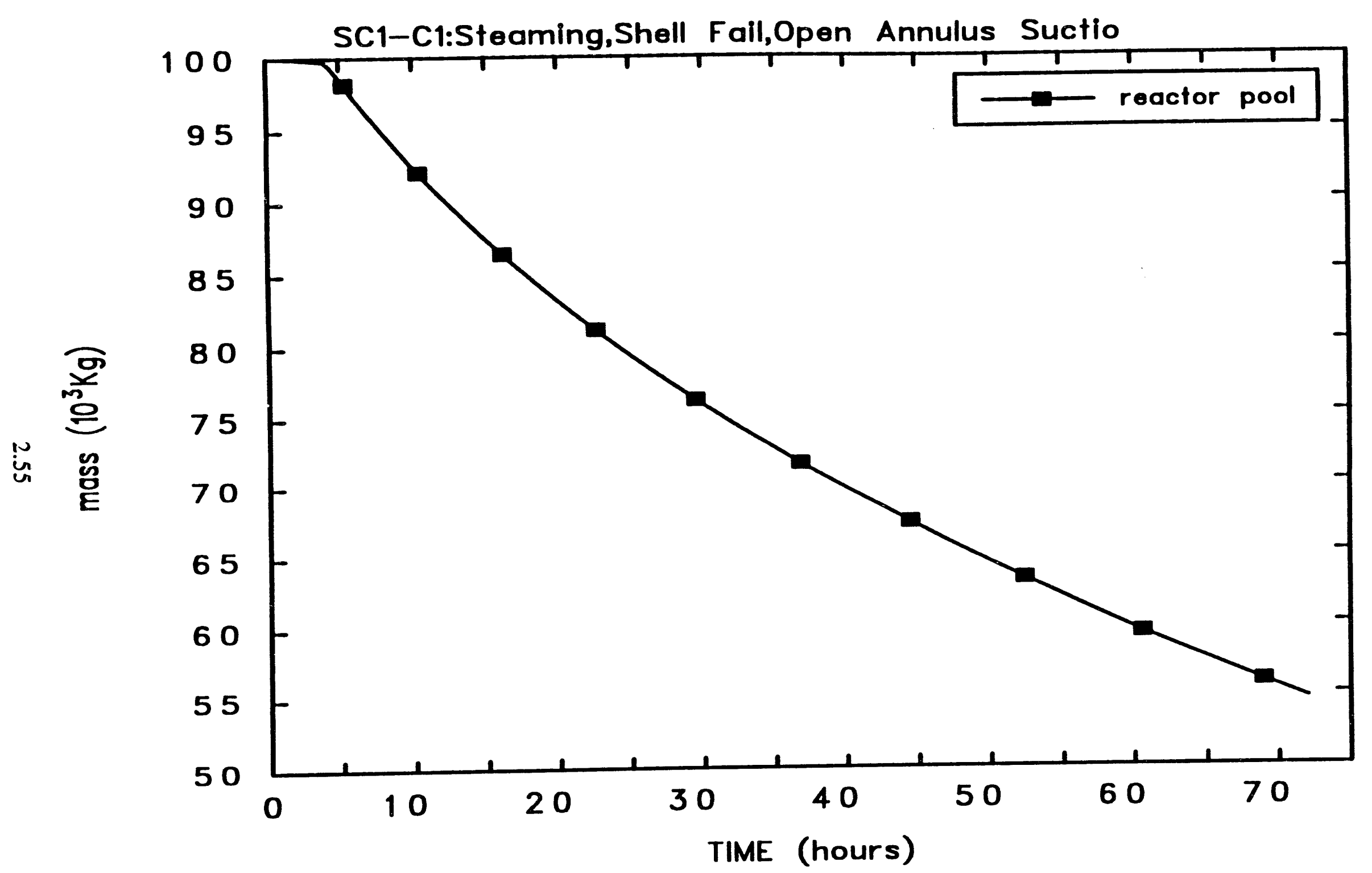

Figure 2.31 Variation of reactor pool water mass vs time (Case - SC1 - C) 


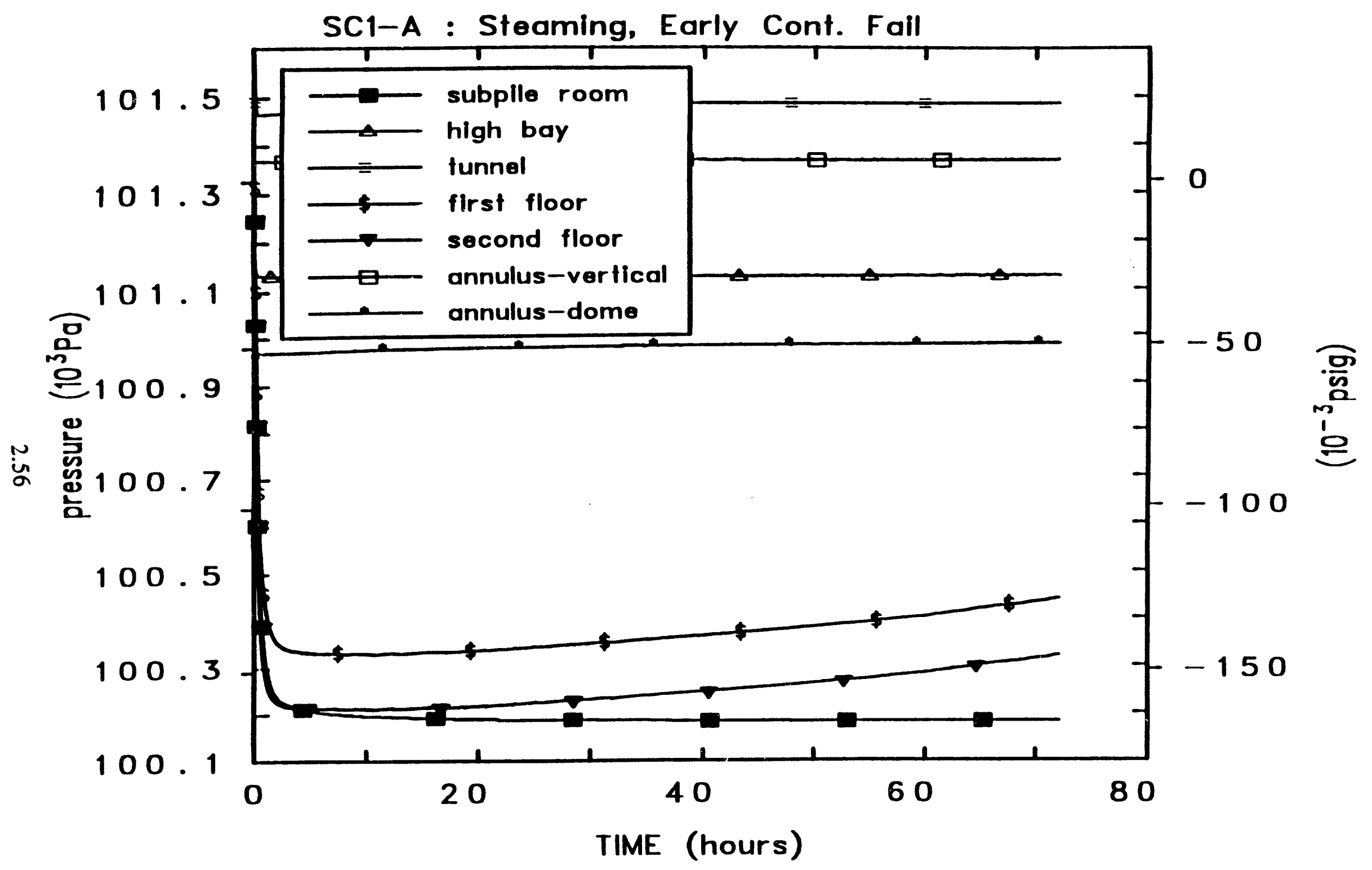

Figure 2.32 Variation of containment volume pressures vs time (Case - SC1-A) 


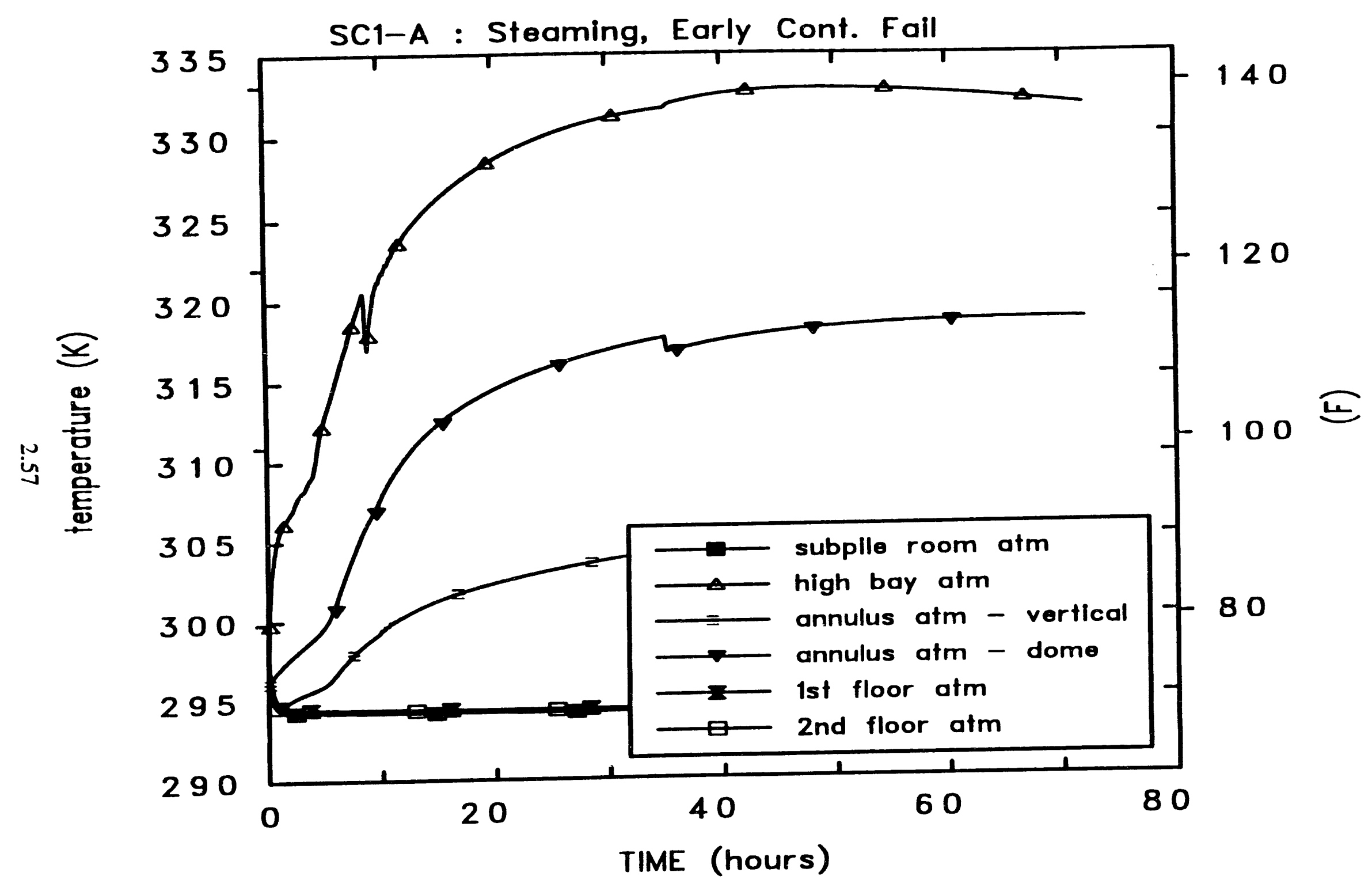

Figure 2.33 Variation of containment volume temperatures vs time (Case SC1 - A) 


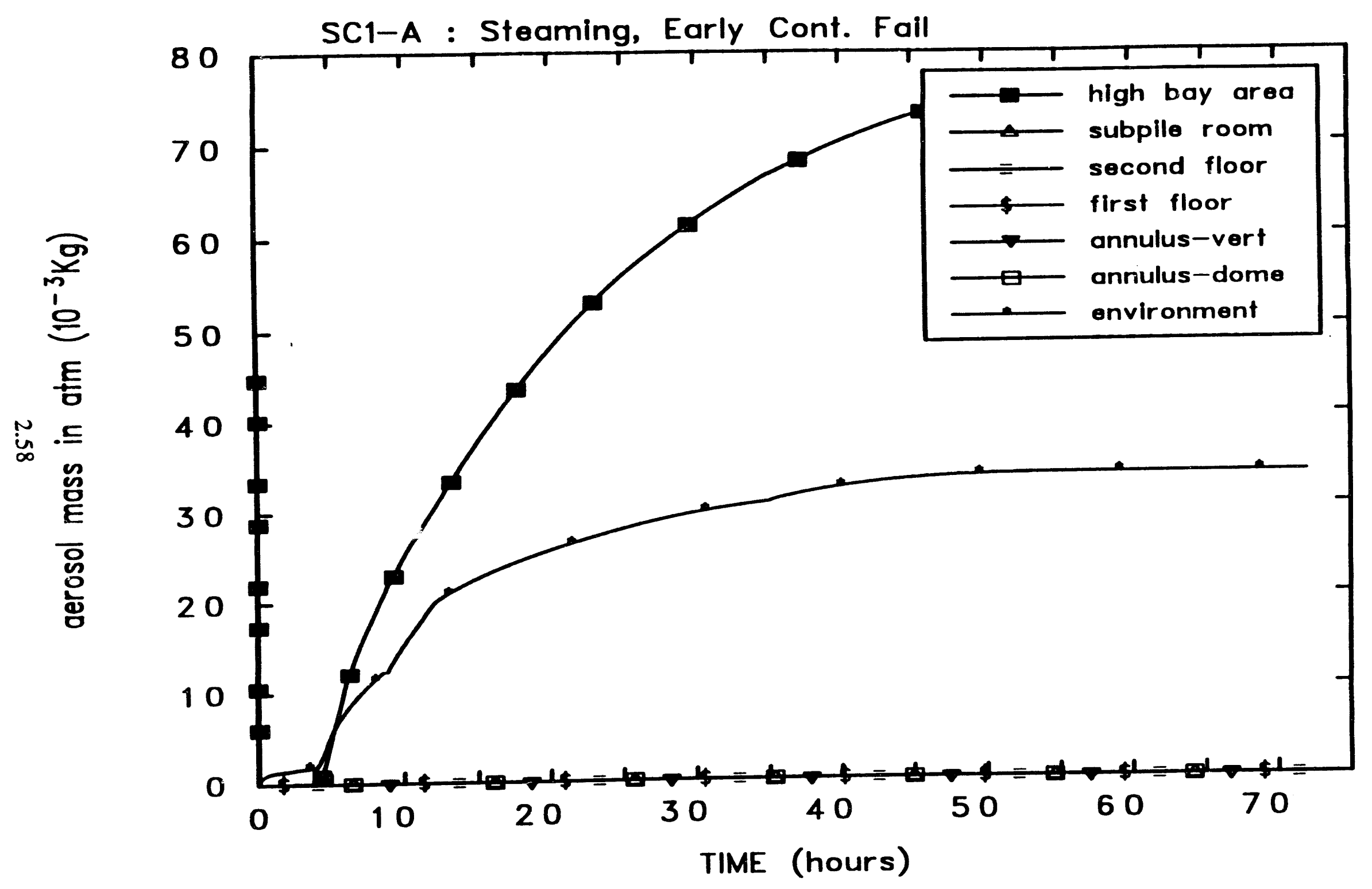

Figure 2.34 Variation of atmosphere aerosol masses vs time (Case - SC1-A) 


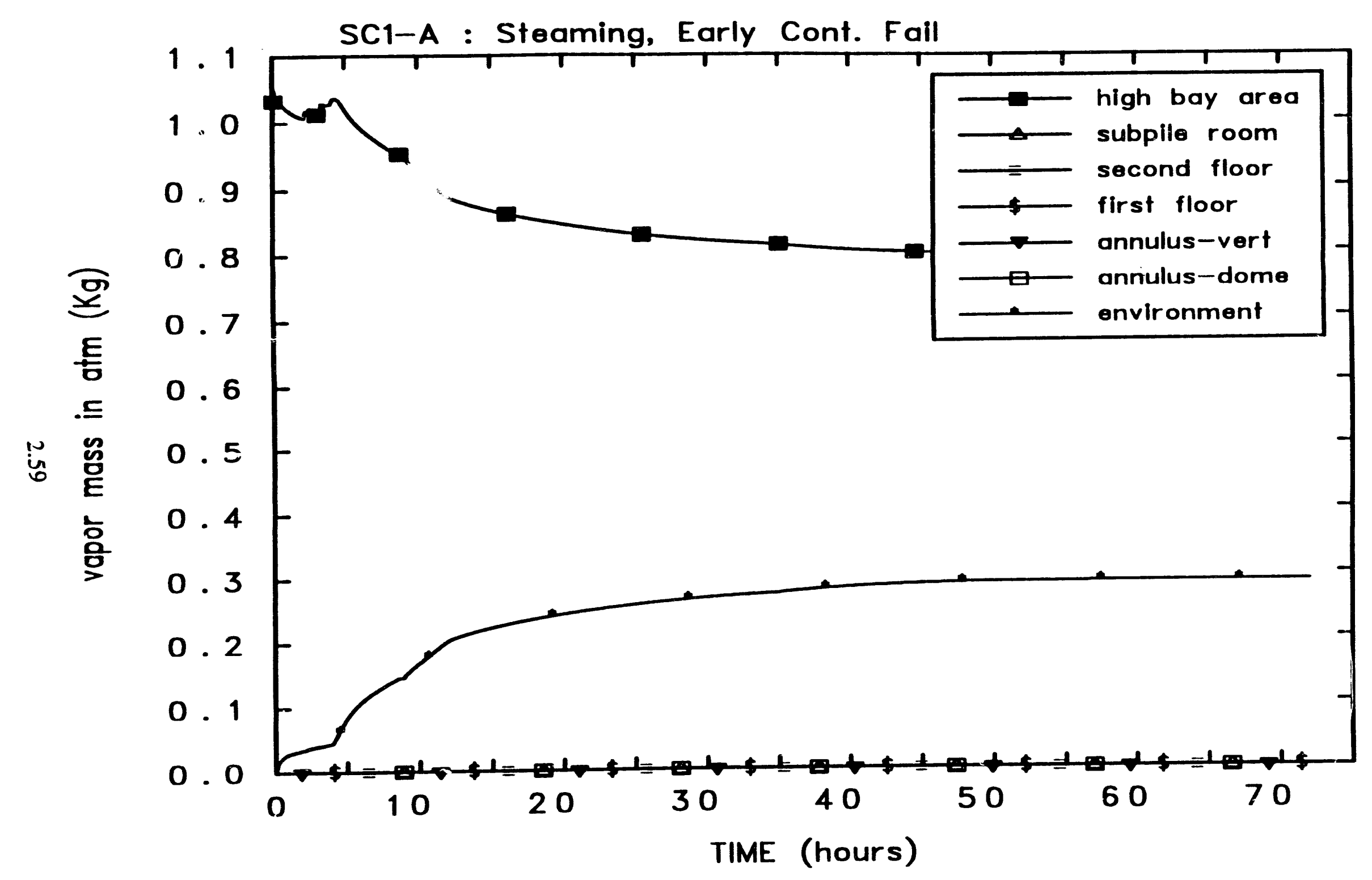

Figure 2.35 Variation of atmosphere radionuclide vapor masses vs time (Case - SC1-A) 


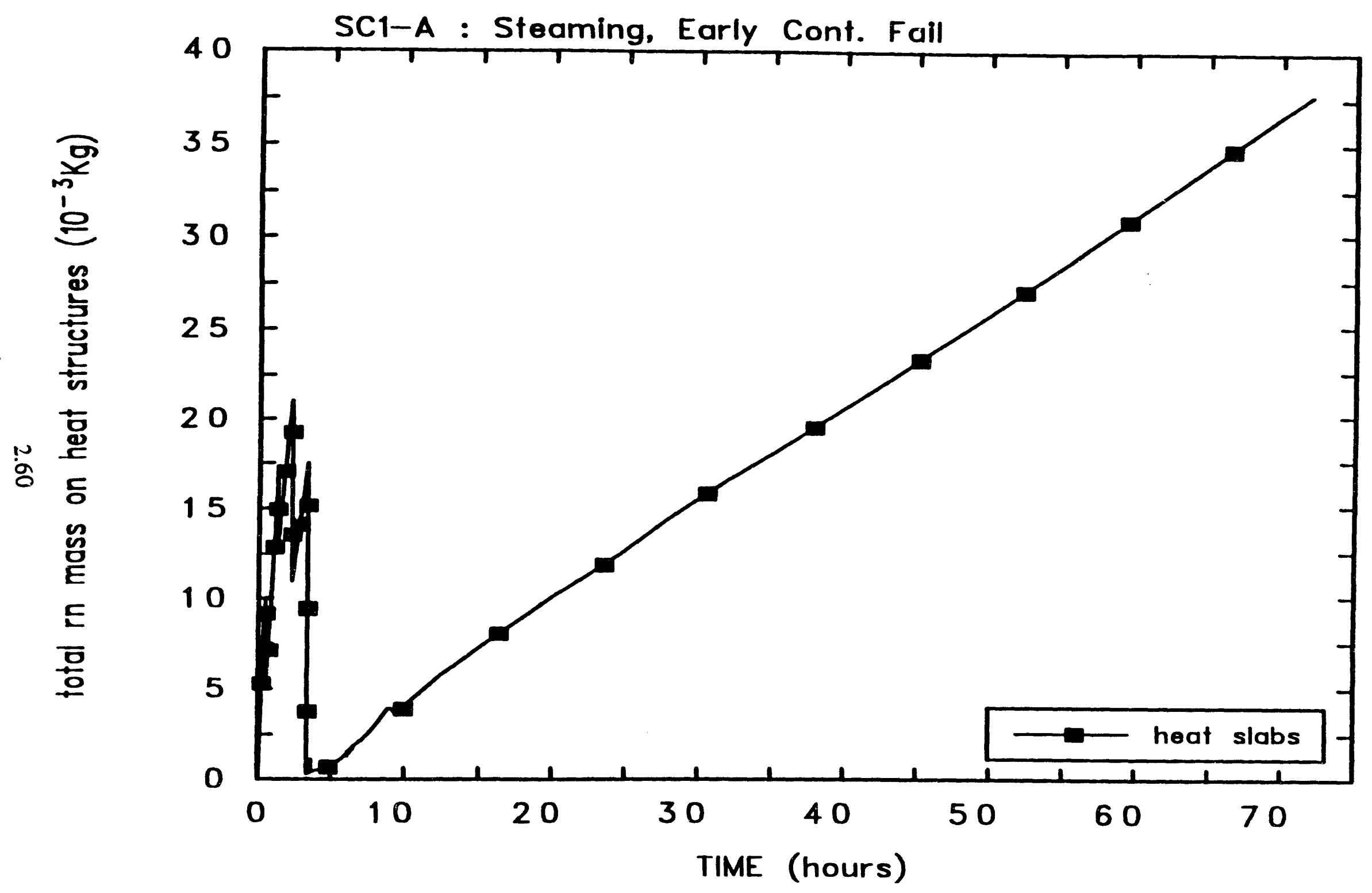

Figure 2.36 Variation of total radionuclide masses on heat structures vs time (Case SC1-A) 


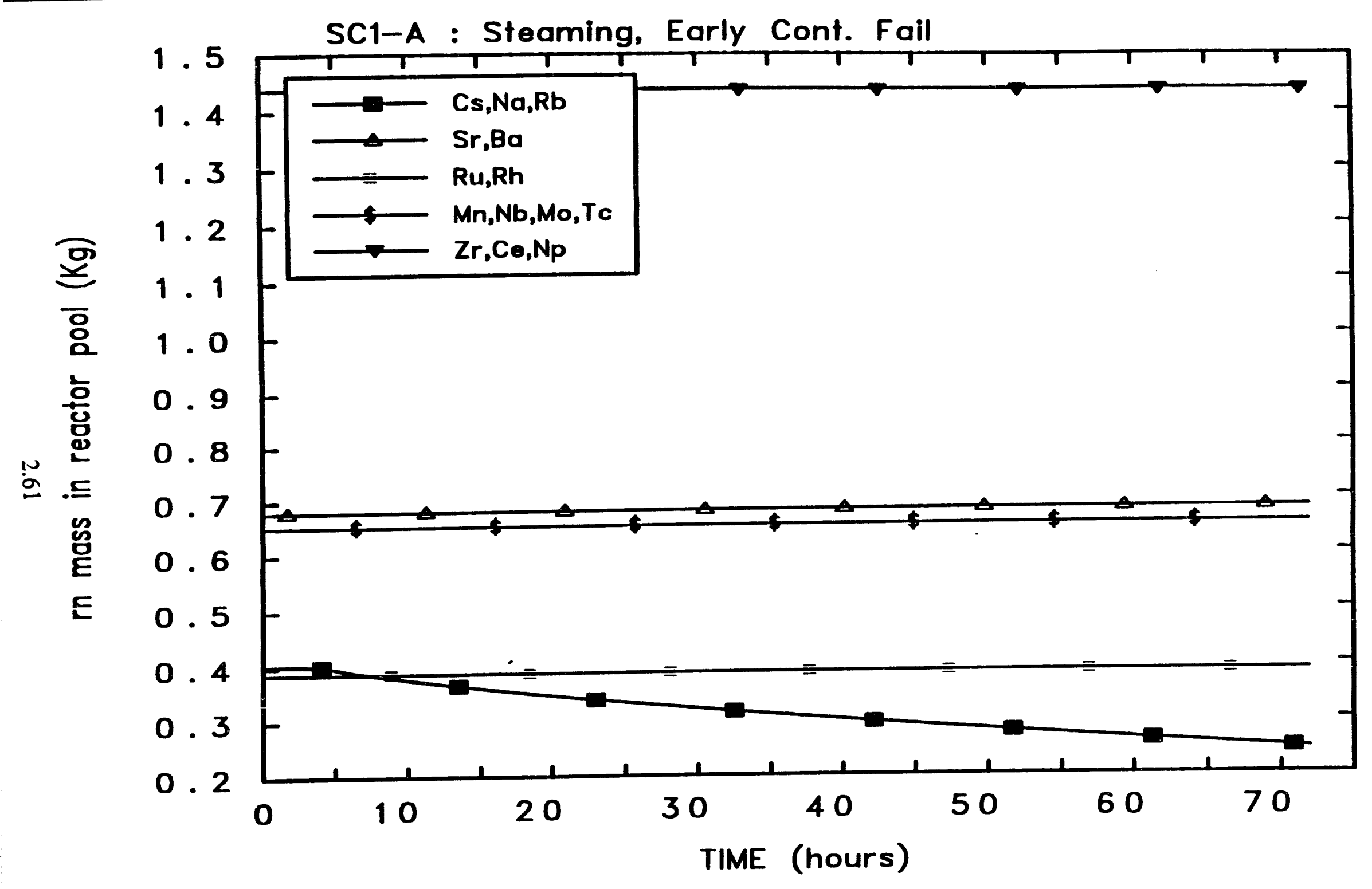

Figure 2.37 Variation of radionuclide masses in reactor pool vs time (Case - SC1 - A). 


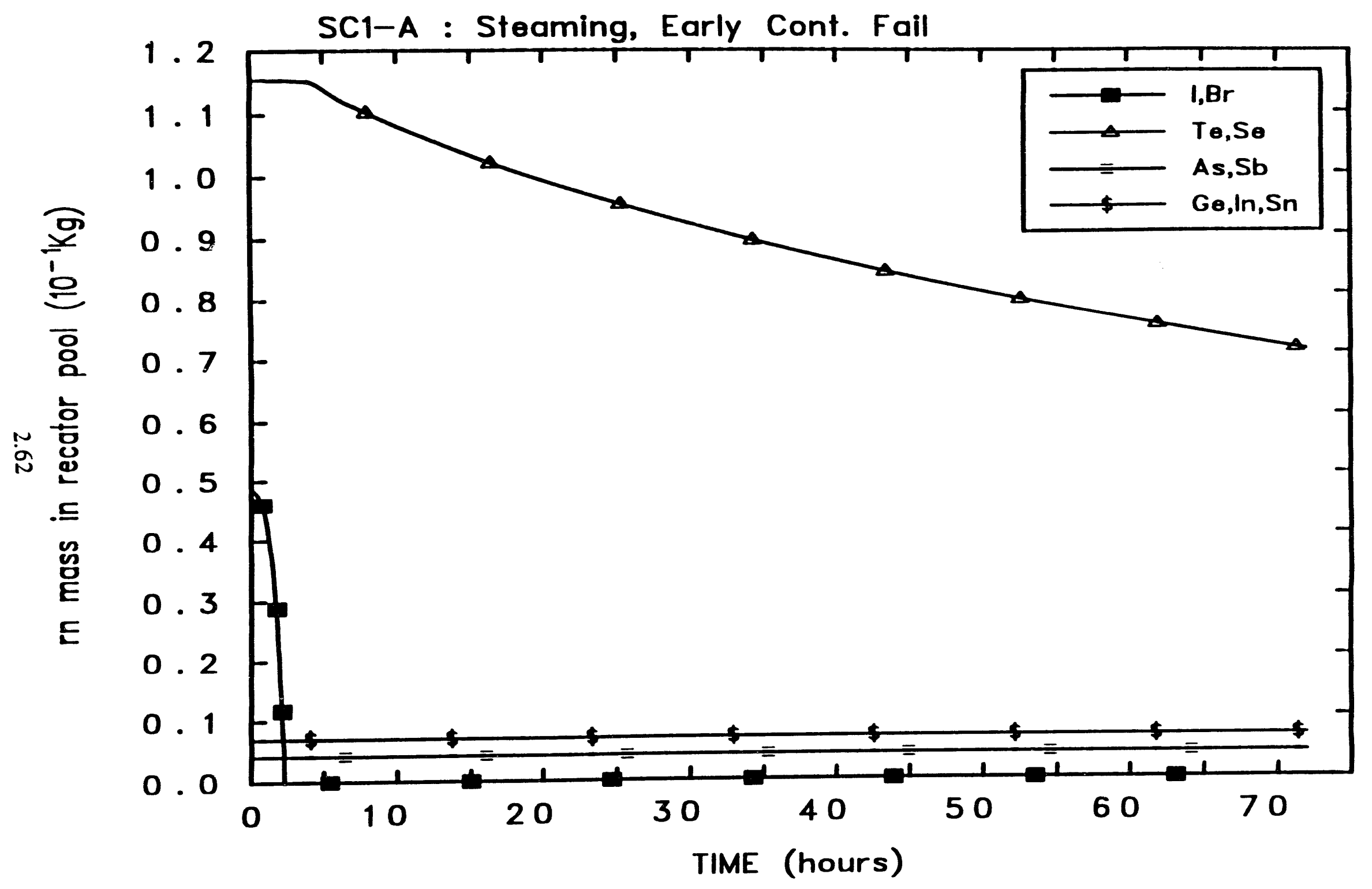

Figure 2.38 Variation of radionuclide masses in reactor pool vs time (Case - SCl - A) . 


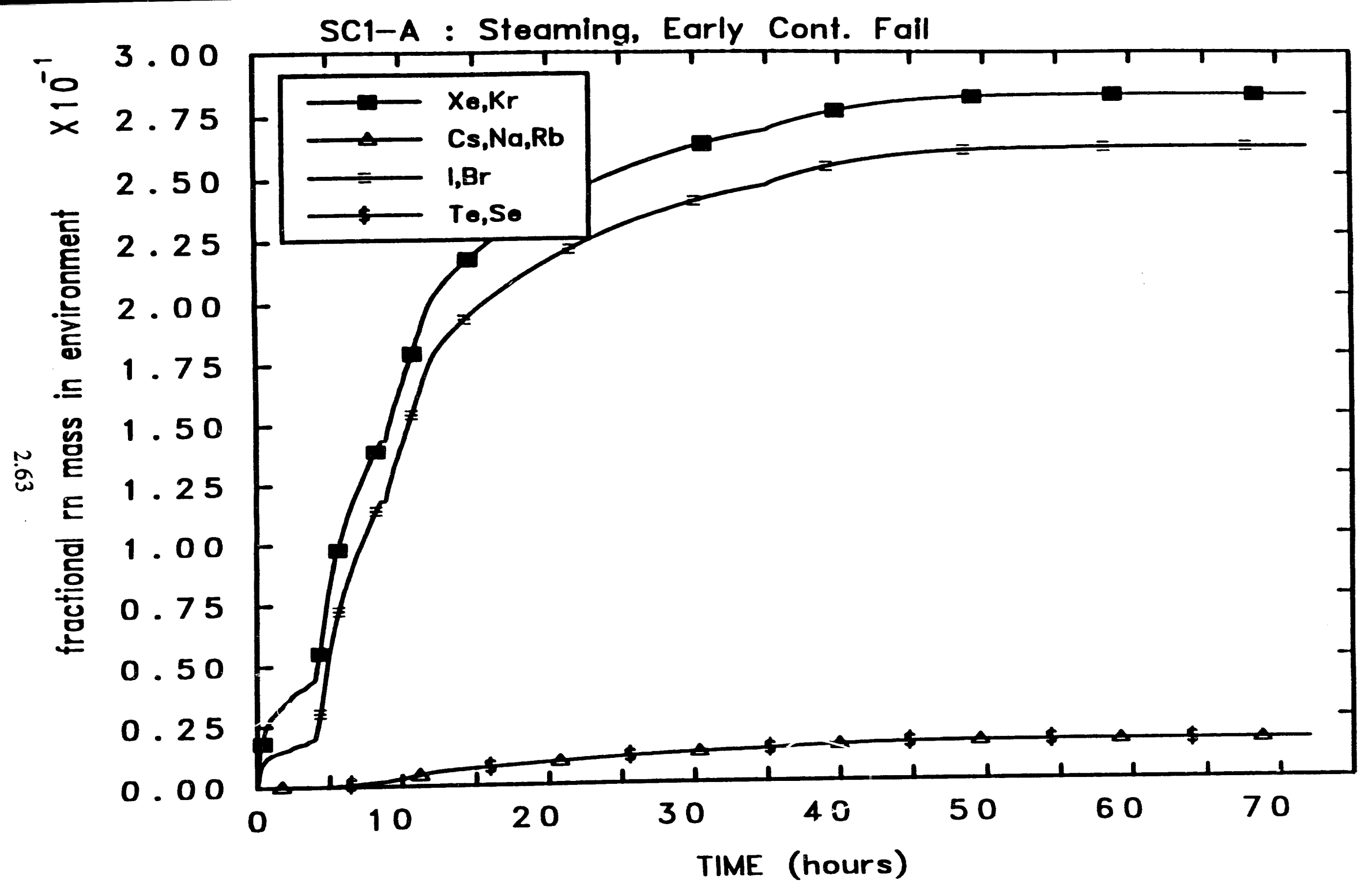

Figure 2.39 Variation of fractional radionuclide masses (volatile species) to the environment vs time (Case - SC1-A) 


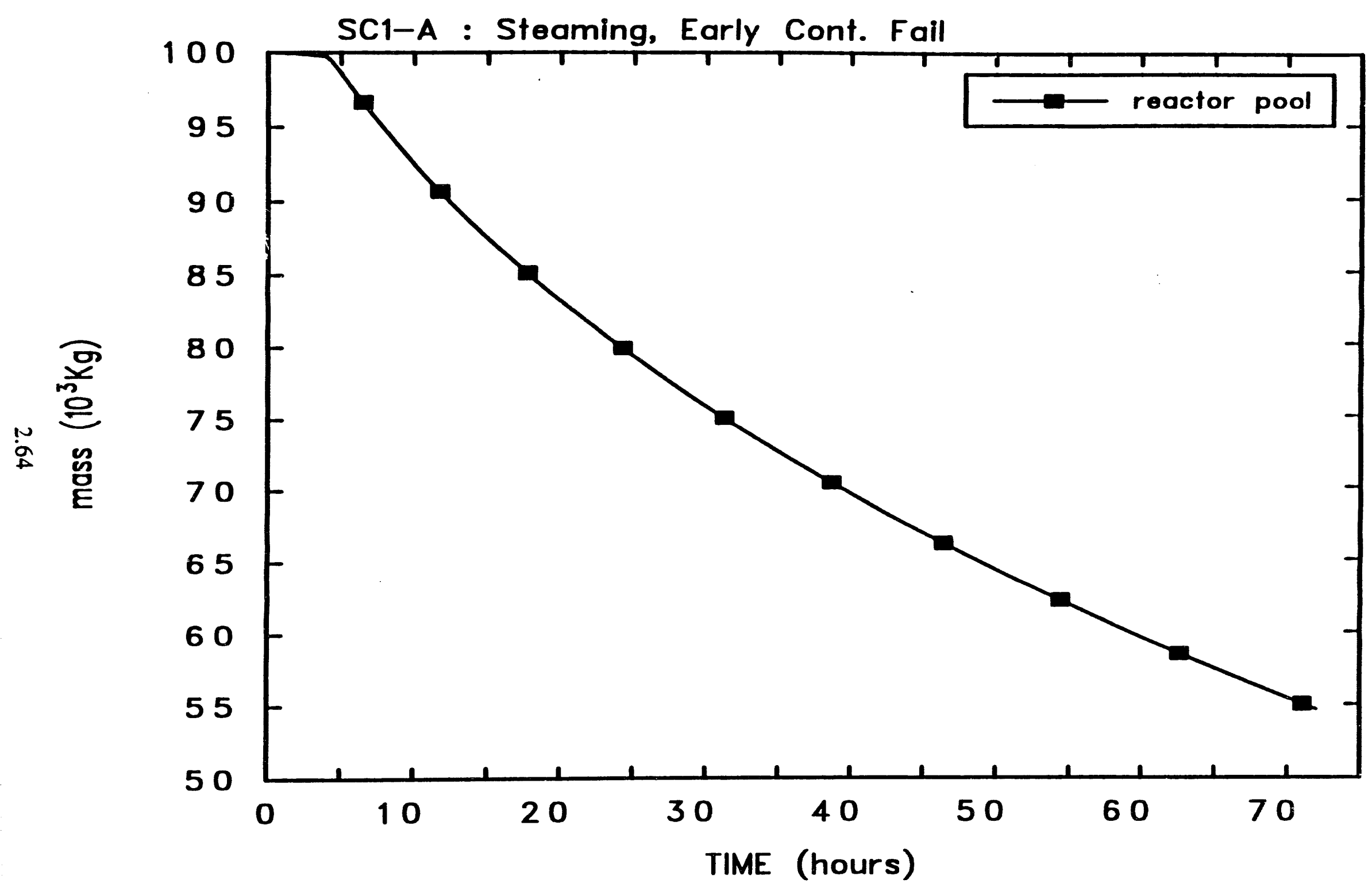

Figure $2.40 \quad$ Variation of reactor pool water mass vs time (Case SC1 - A) 


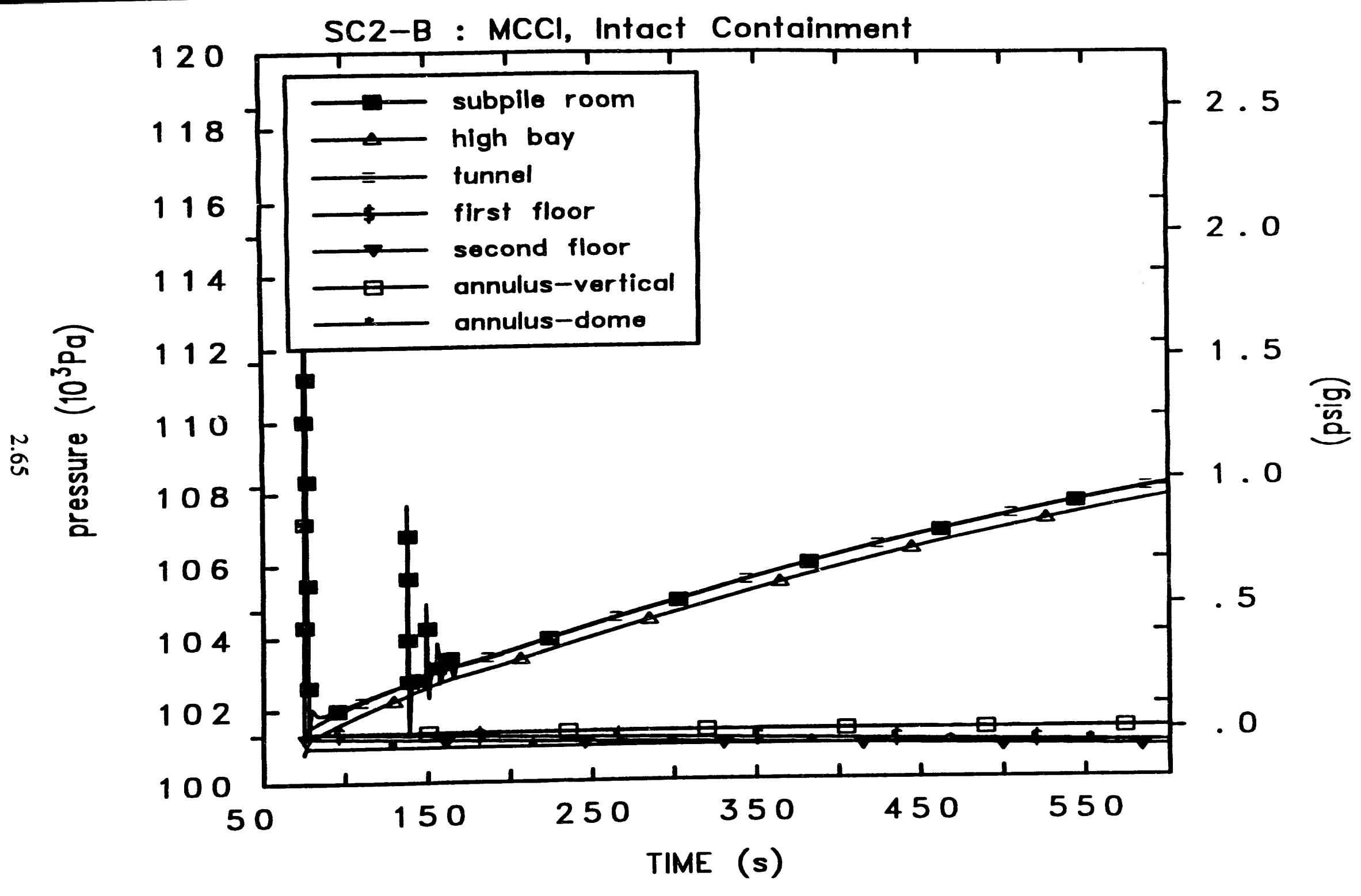

Figure 2.41a Variation of containment volume pressures vs time (Case - SC2-B) 


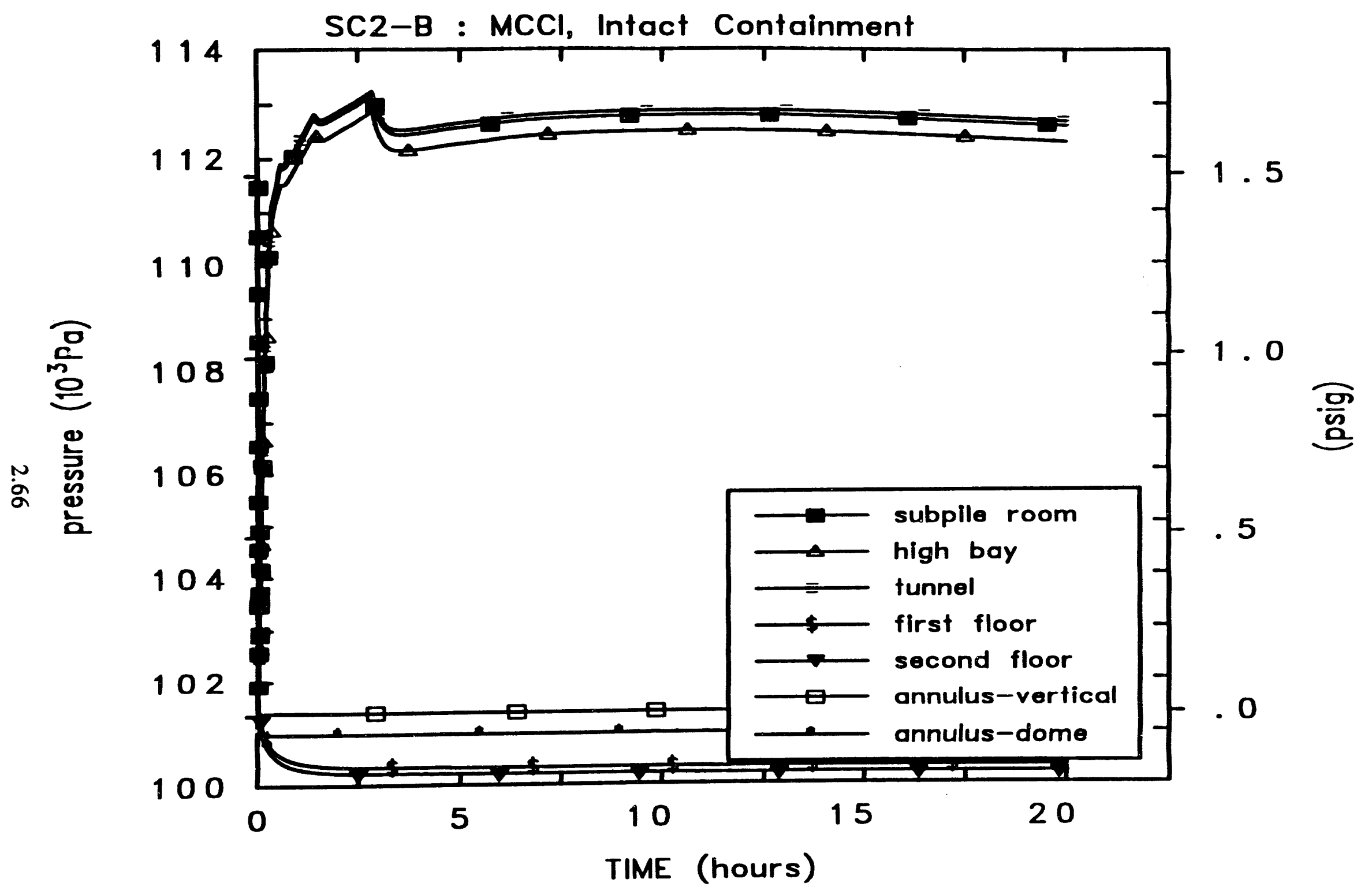

Figure 2.41b Variation of containment volume pressures vs time (Case - SC2-B) 


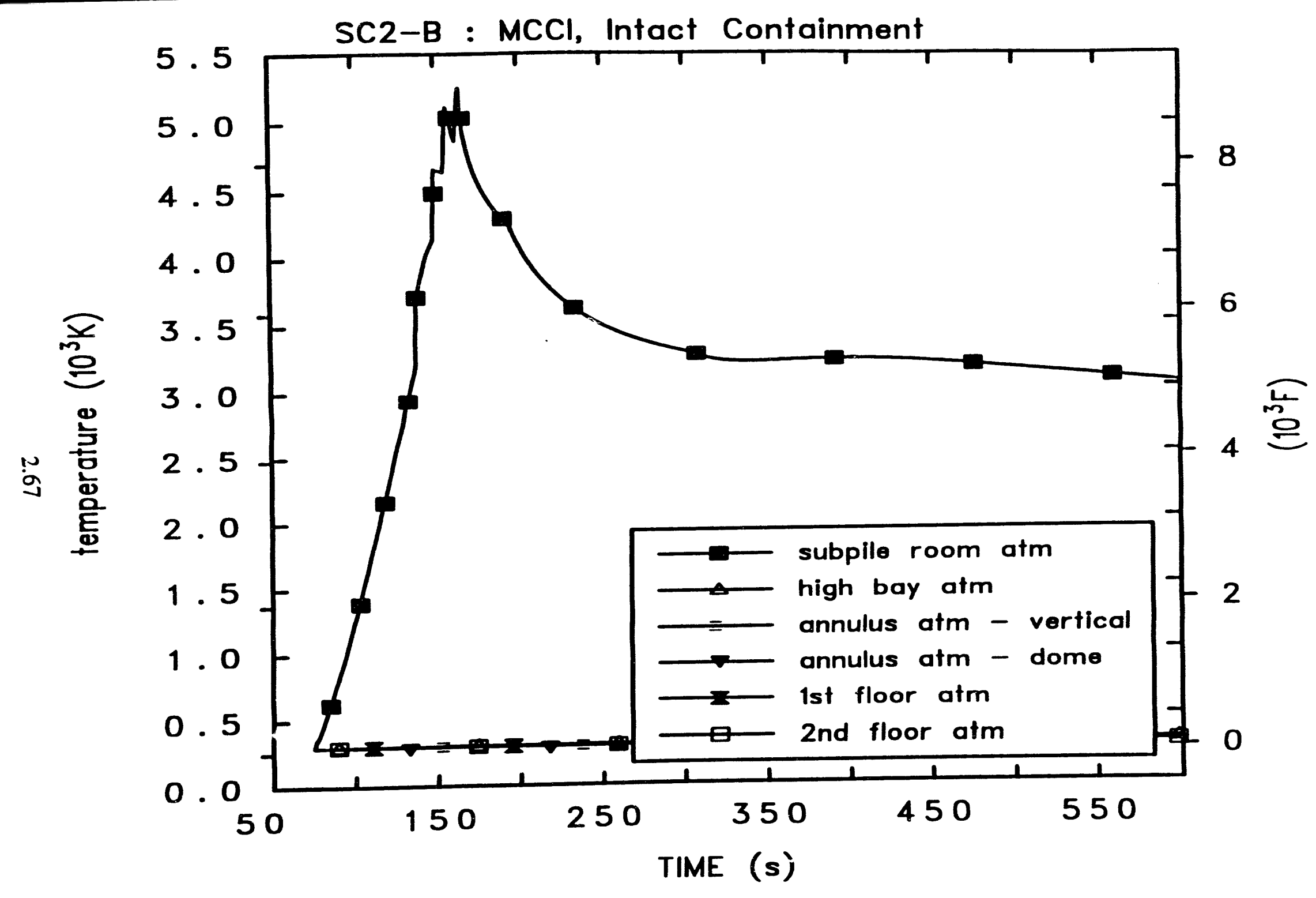

Figure 2.42a Variation of containment volume temperatures vs time (Case - SC2-B) 


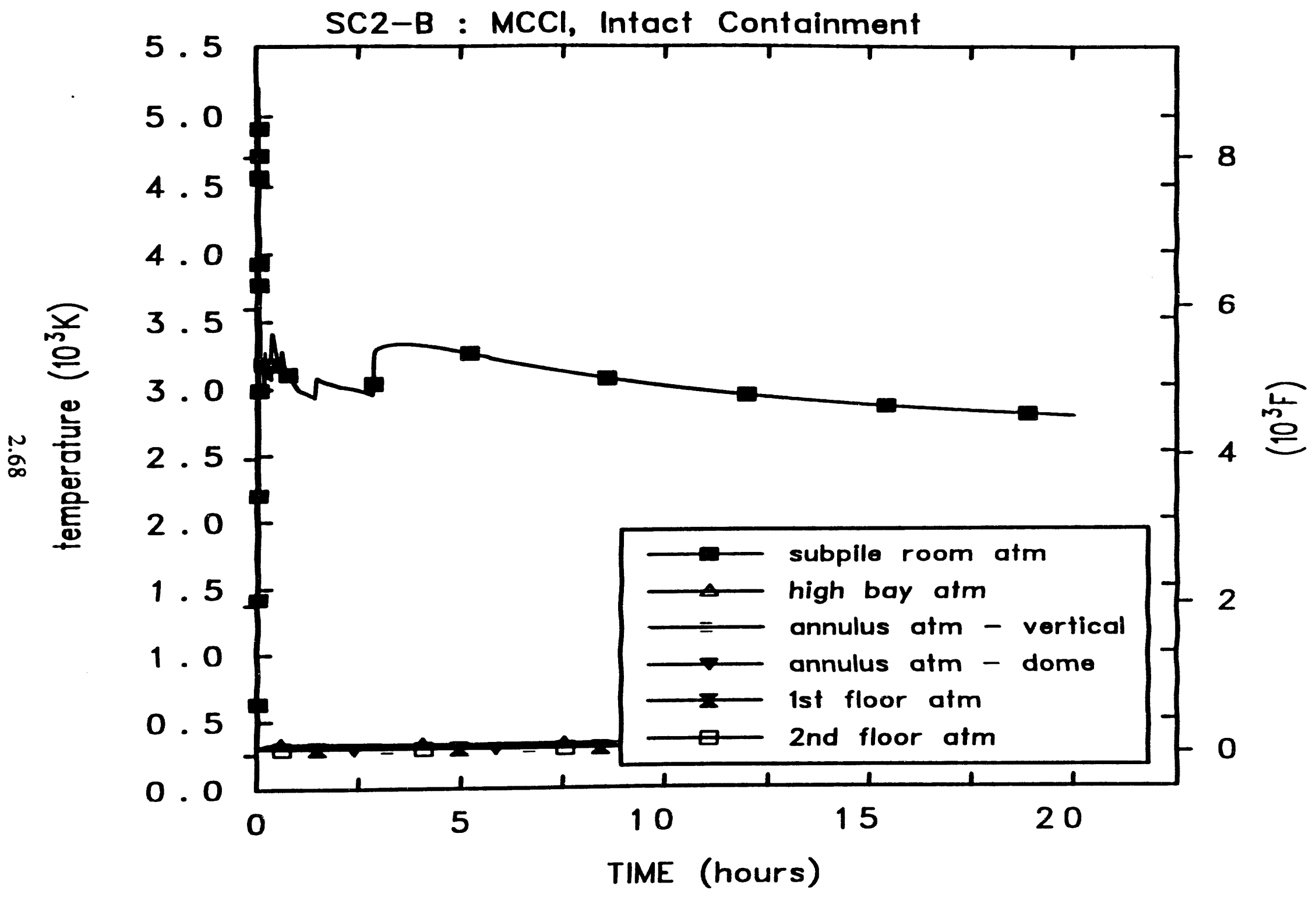

Figure 2.42b Variation of containment volume temperatures vs time (Case - SC2-B) 


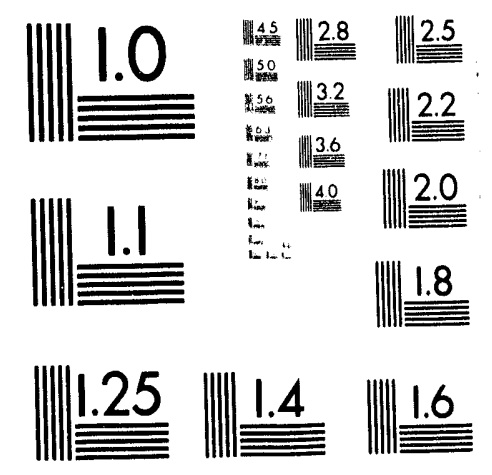



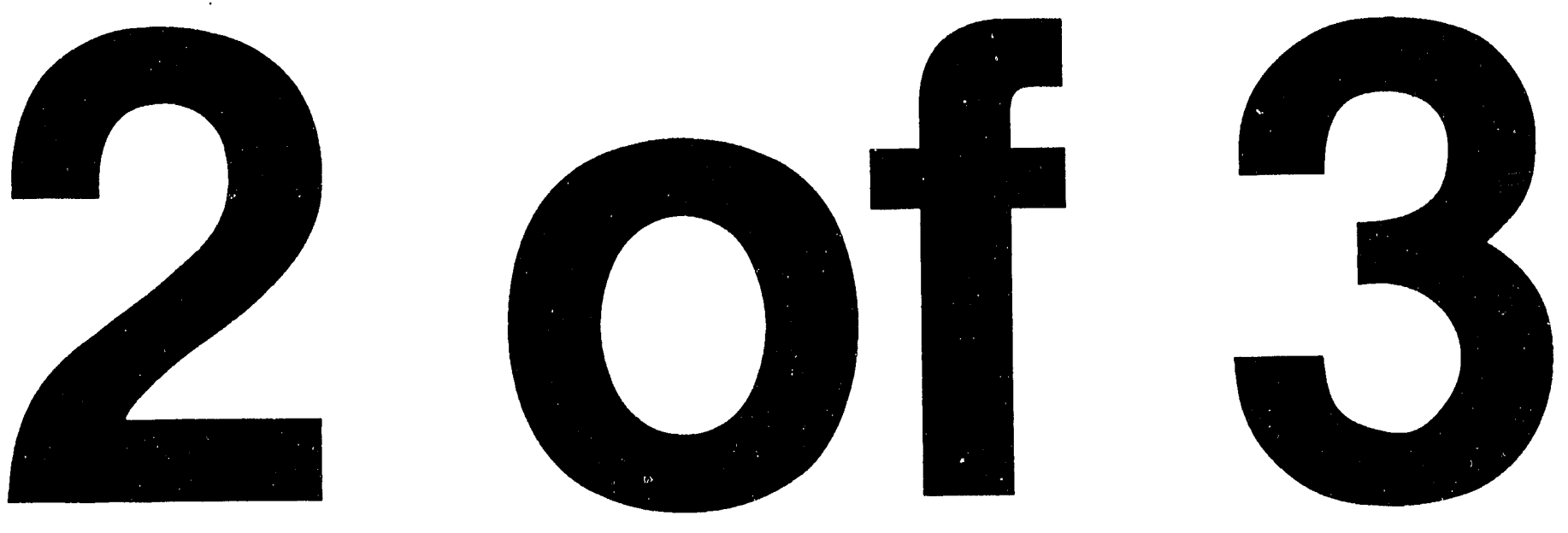


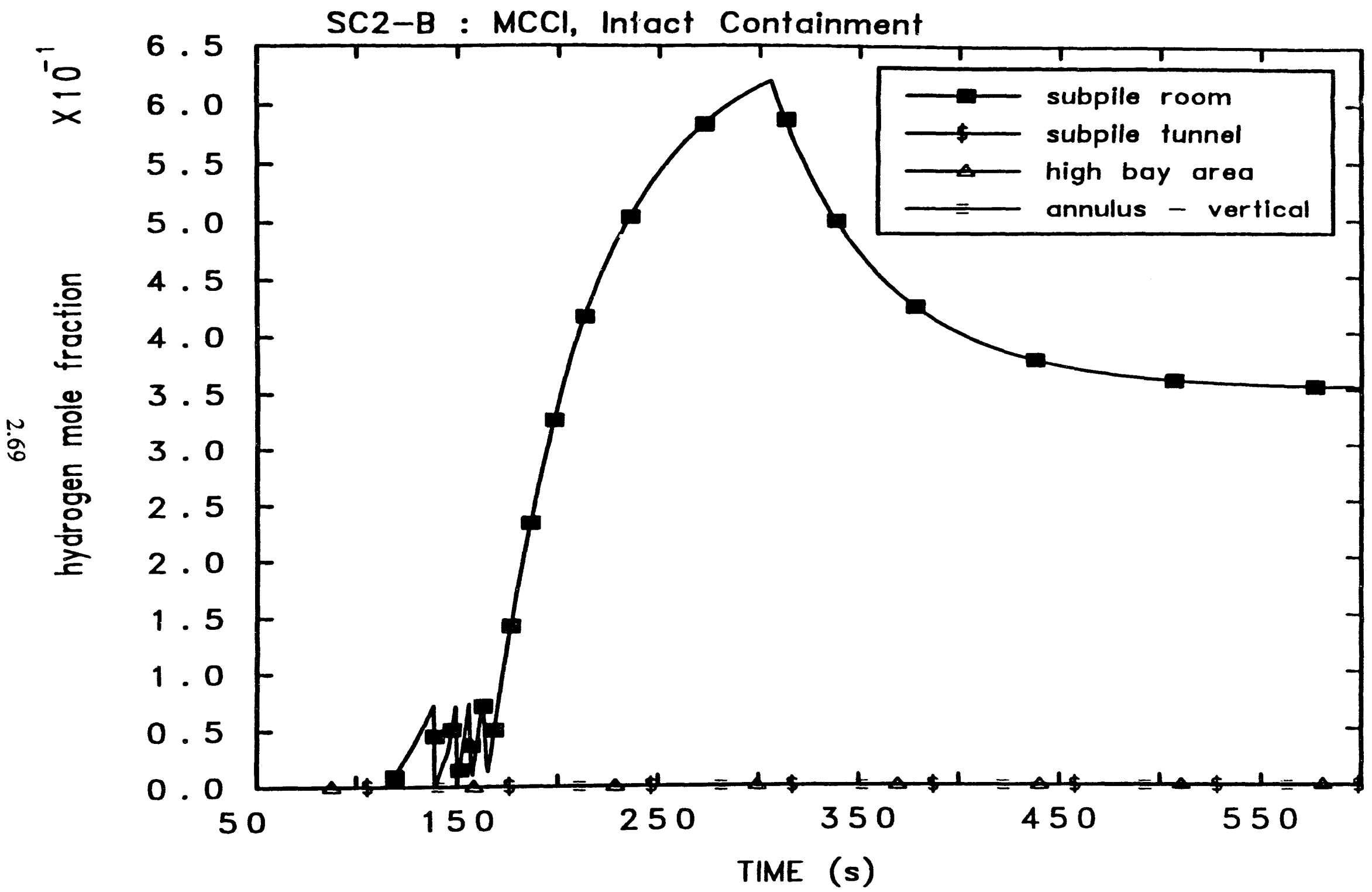

Figure 2.43a Variation of containment volume hydrogen mole fractions vs time (Case SC2-B) 


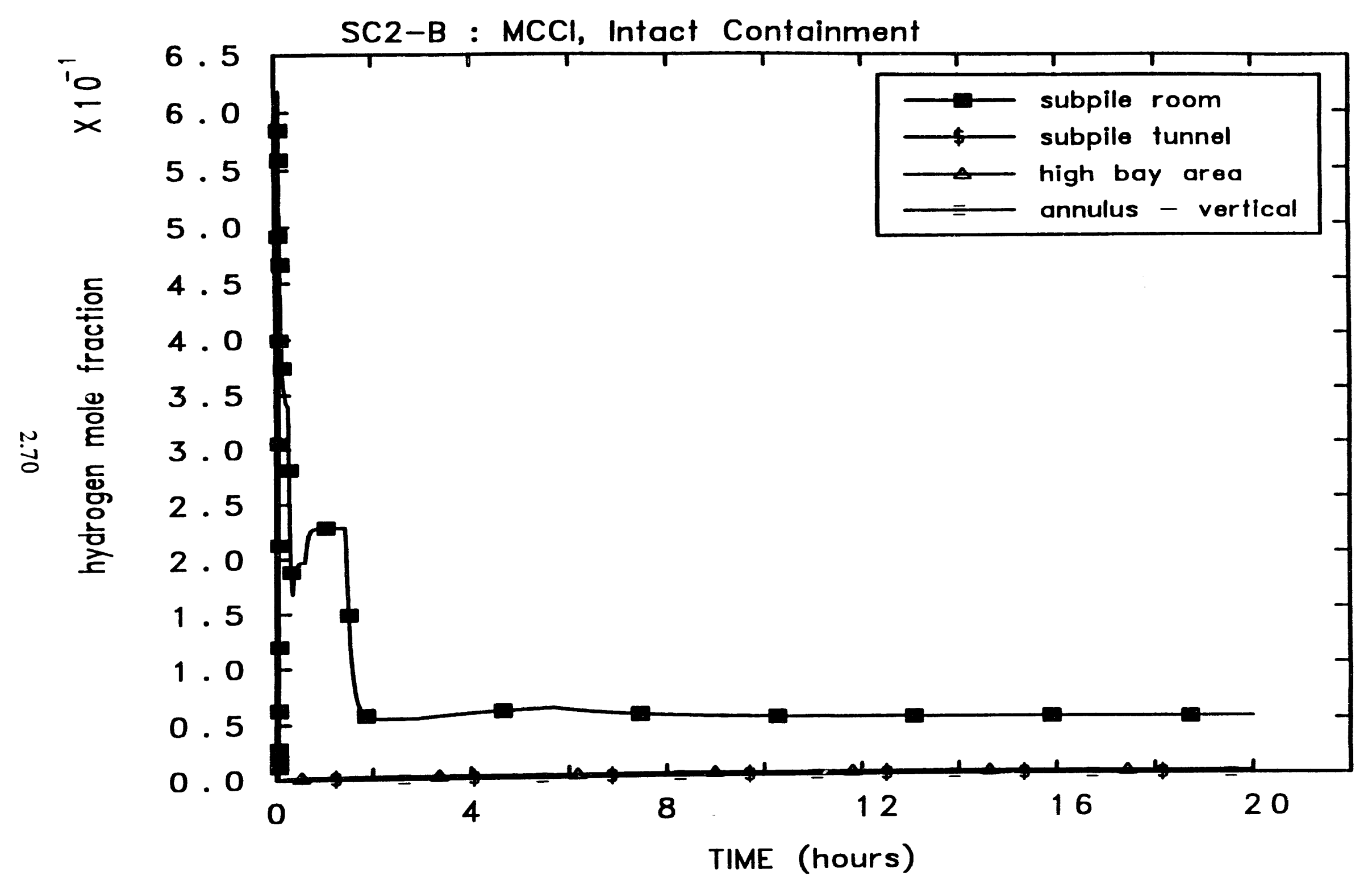

Figure 2.43b Variation of containment volume hydrogen mole fractions vs time (Case SC2-B) 


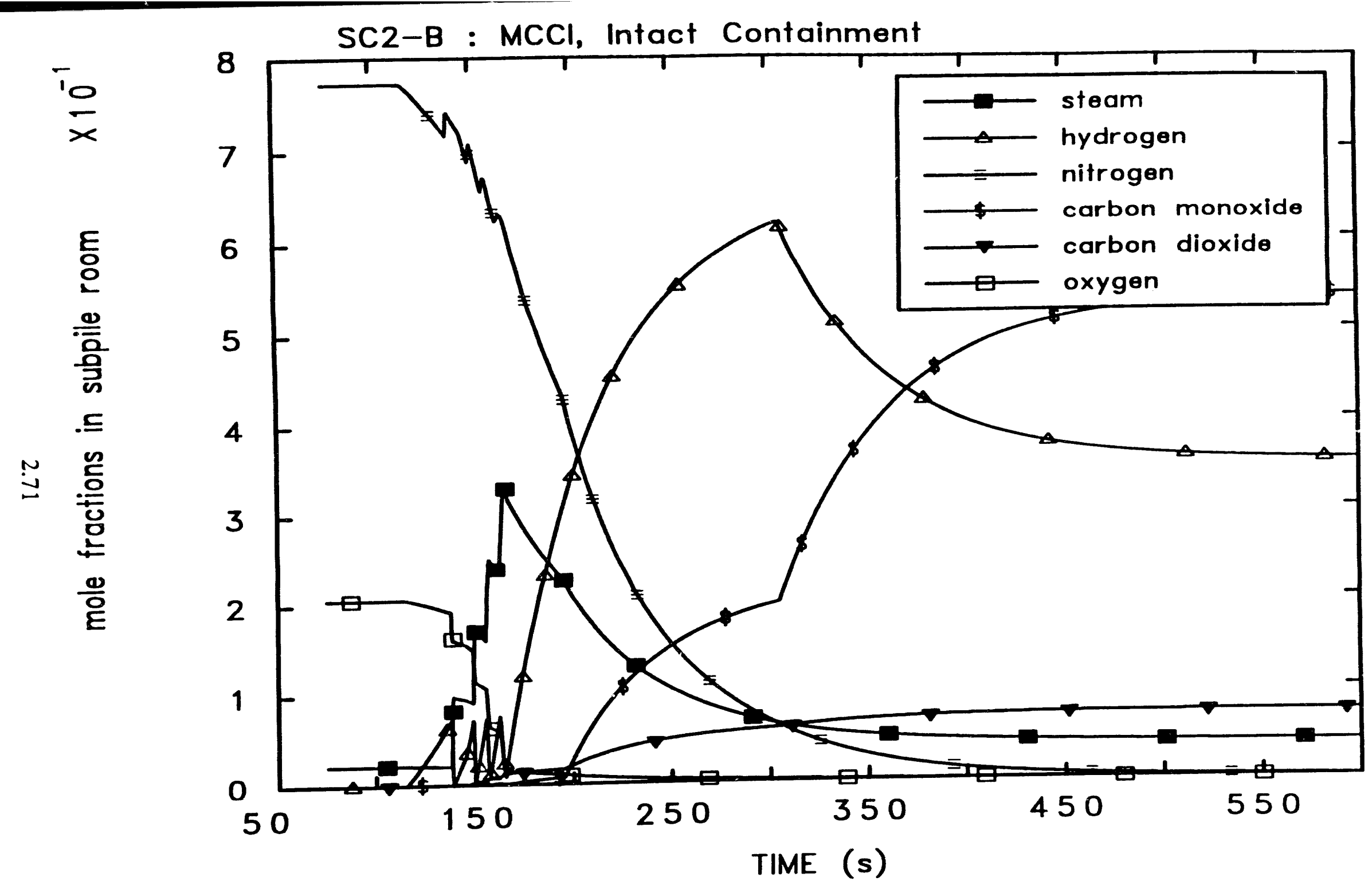

Figure 2.44 Variation of containment volume gas and steam mole fractions vs time (Case - SC2-B) 


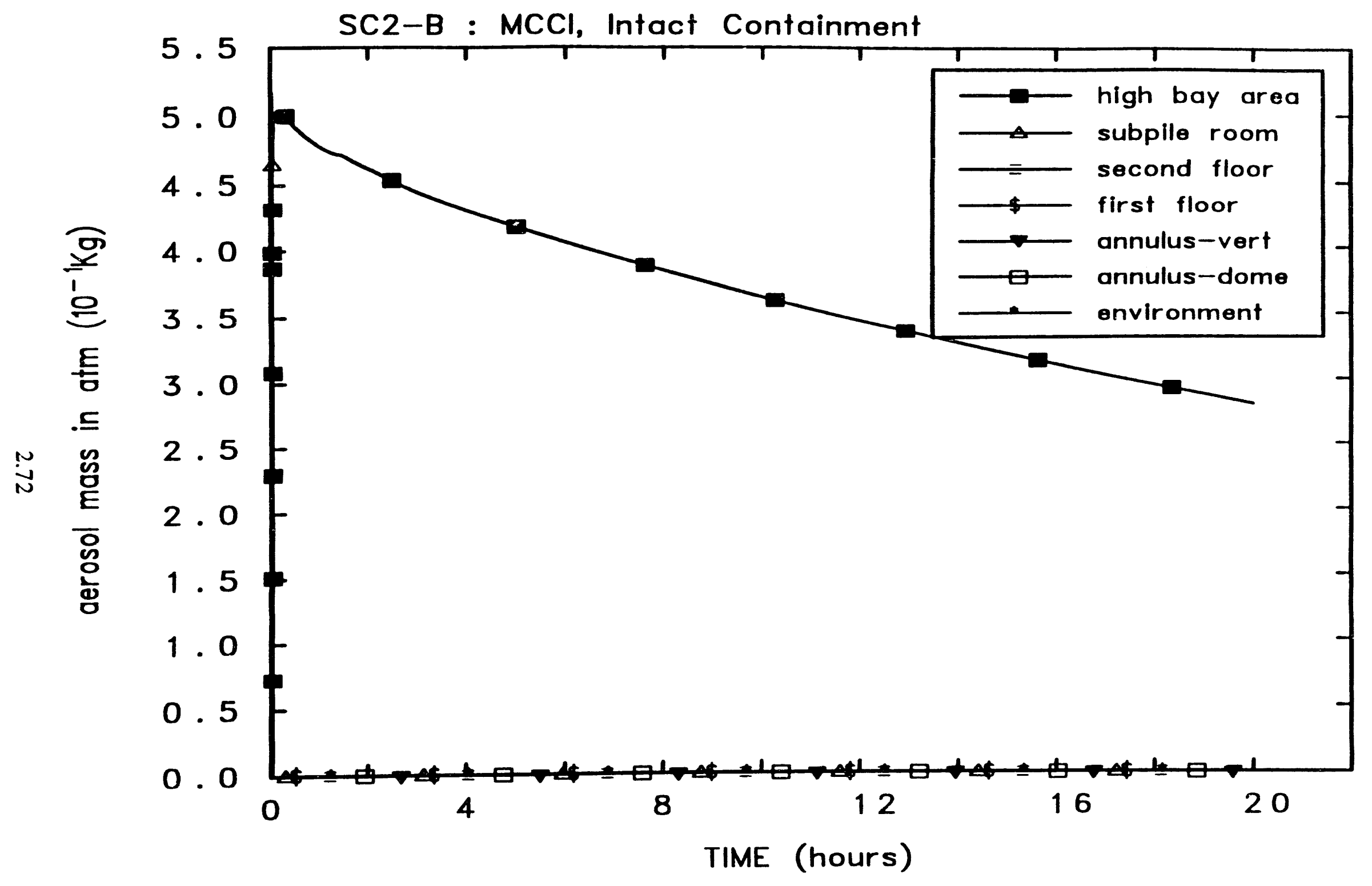

Figure 2.45 Variation of containment volume aerosol masses vs time (Case - SC2-B) 


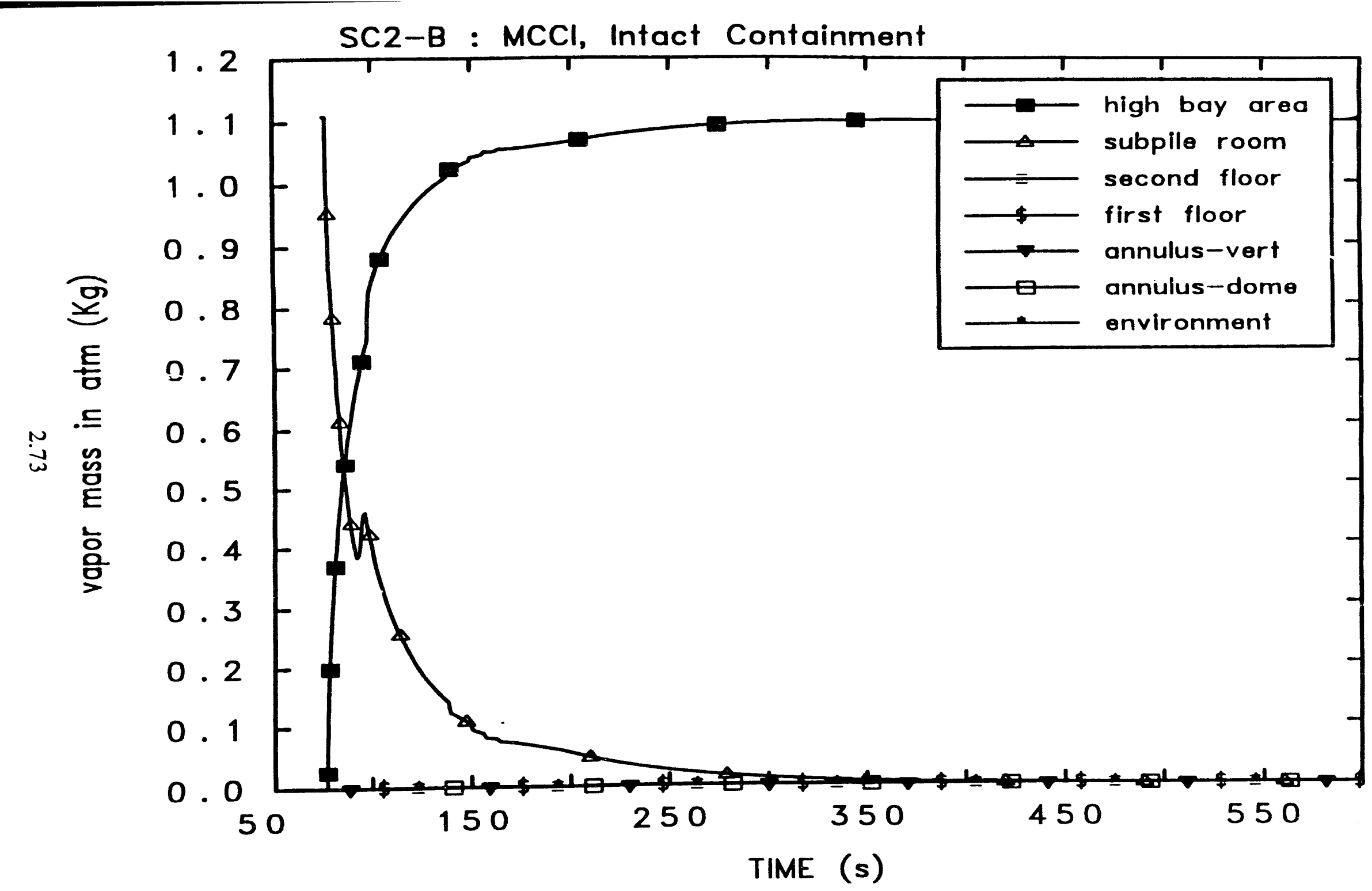

Figure 2.46 Variation of atmosphere radionuclide vapor masses vs time (Case - SC2-B) 


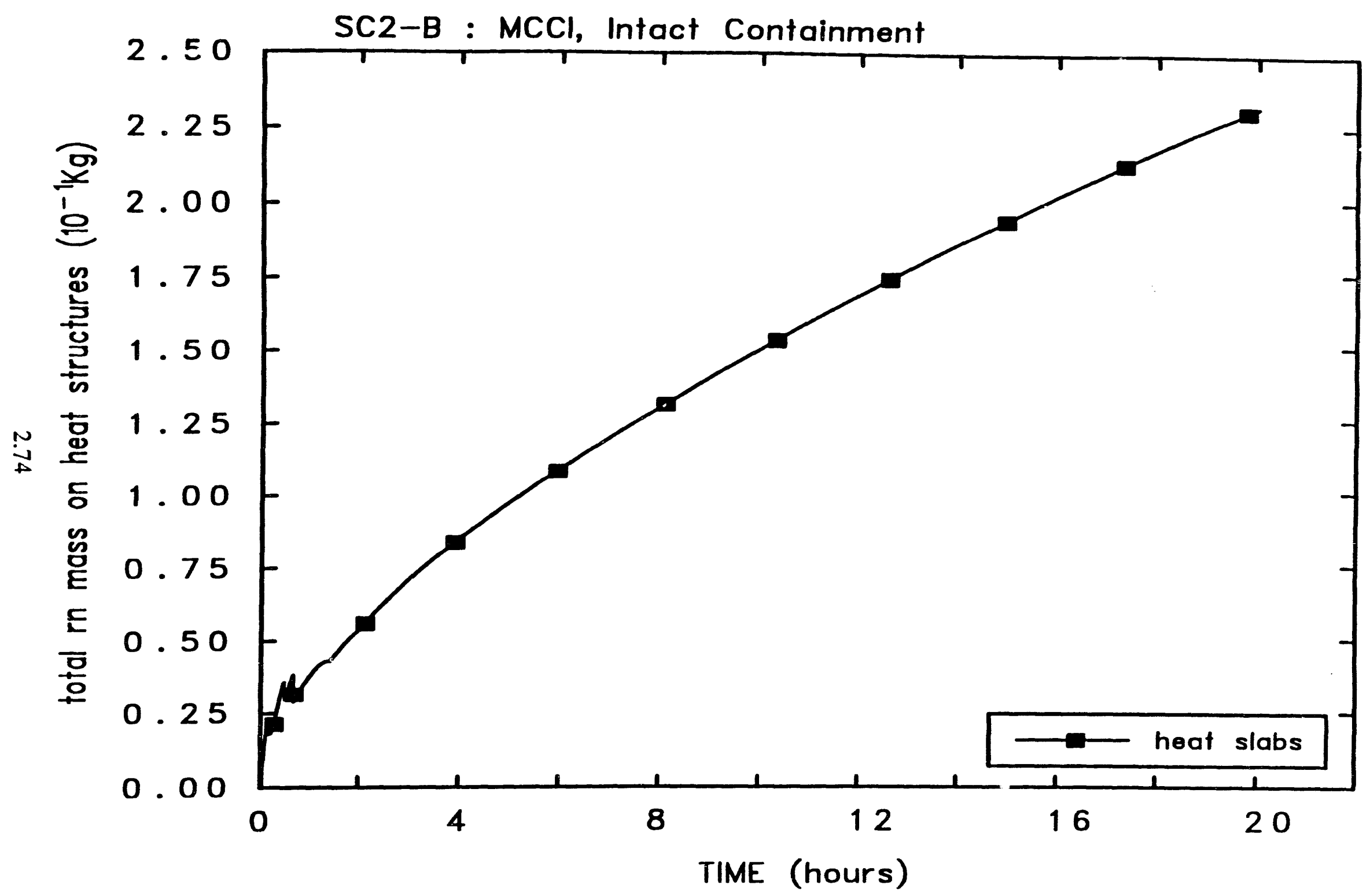

Figure 2.47 Variation of total deposited radionuclide masses on heat structures vs time (Case - SC2-B) 


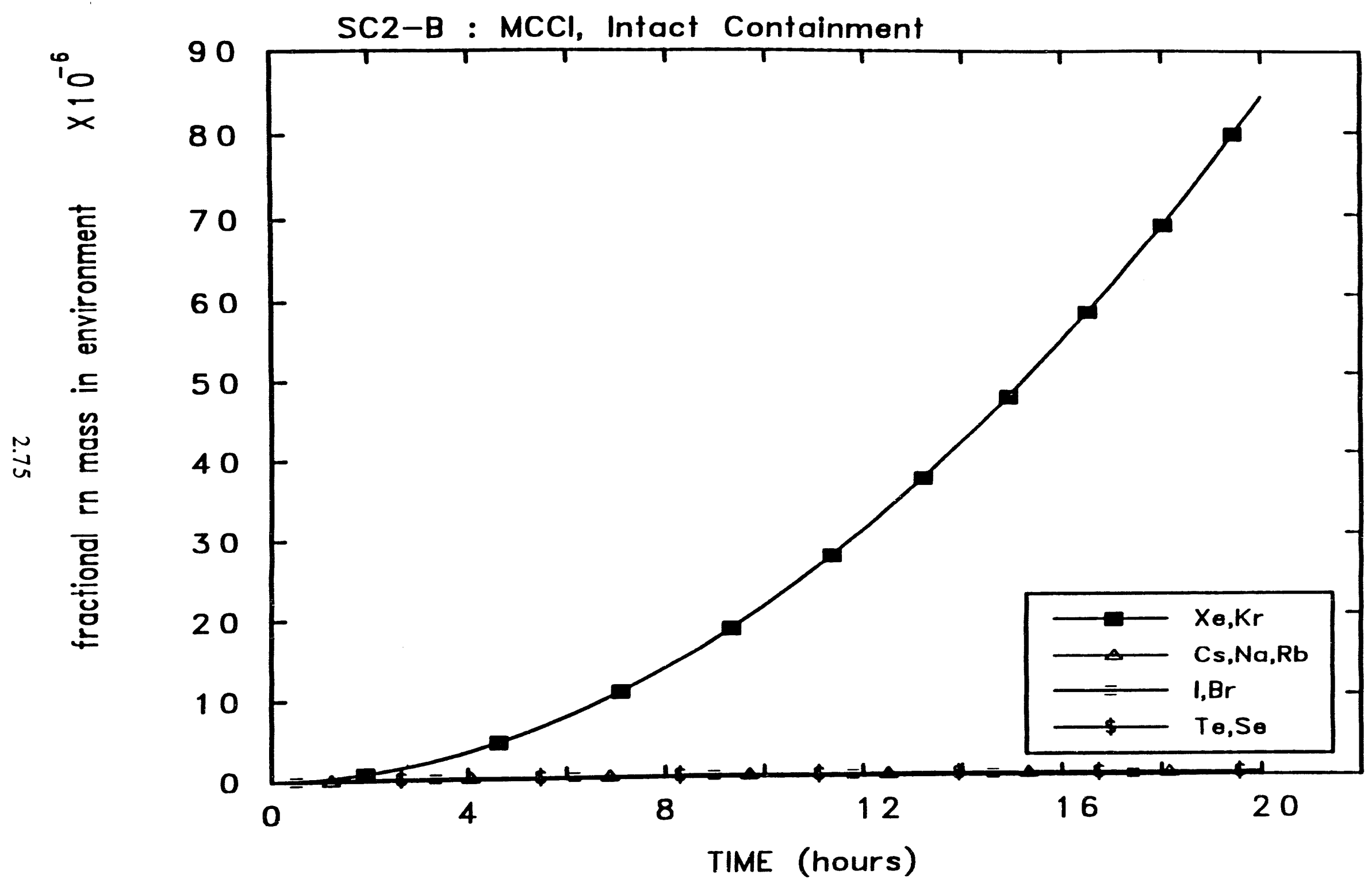

Figure 2.48 Variation of fractional radionuclide masses (volatile species) to the environment (Case - SC2-B) 


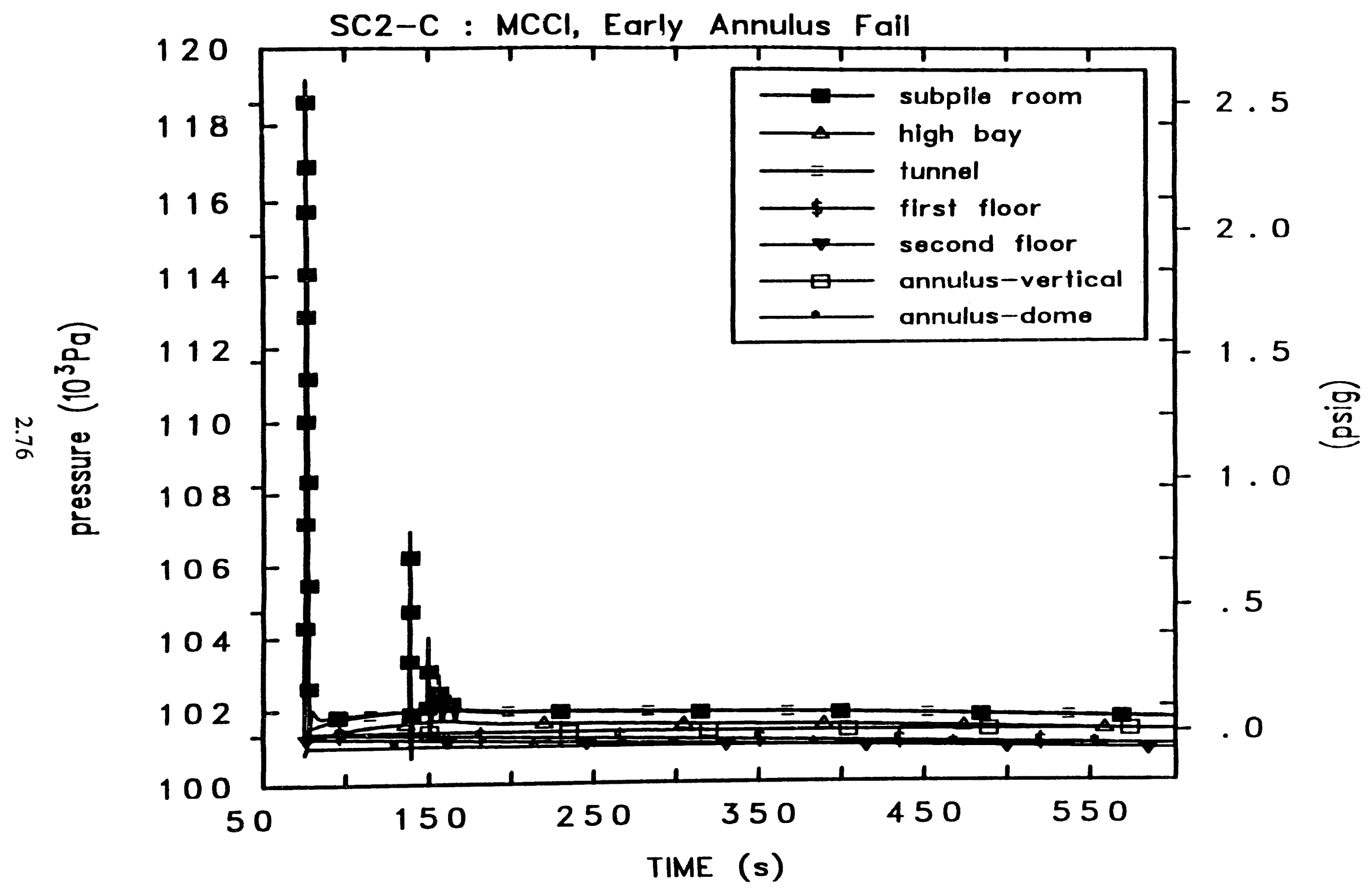

Figure 2.49a Variation of containment volume pressures vs time (Case - SC2-C) 


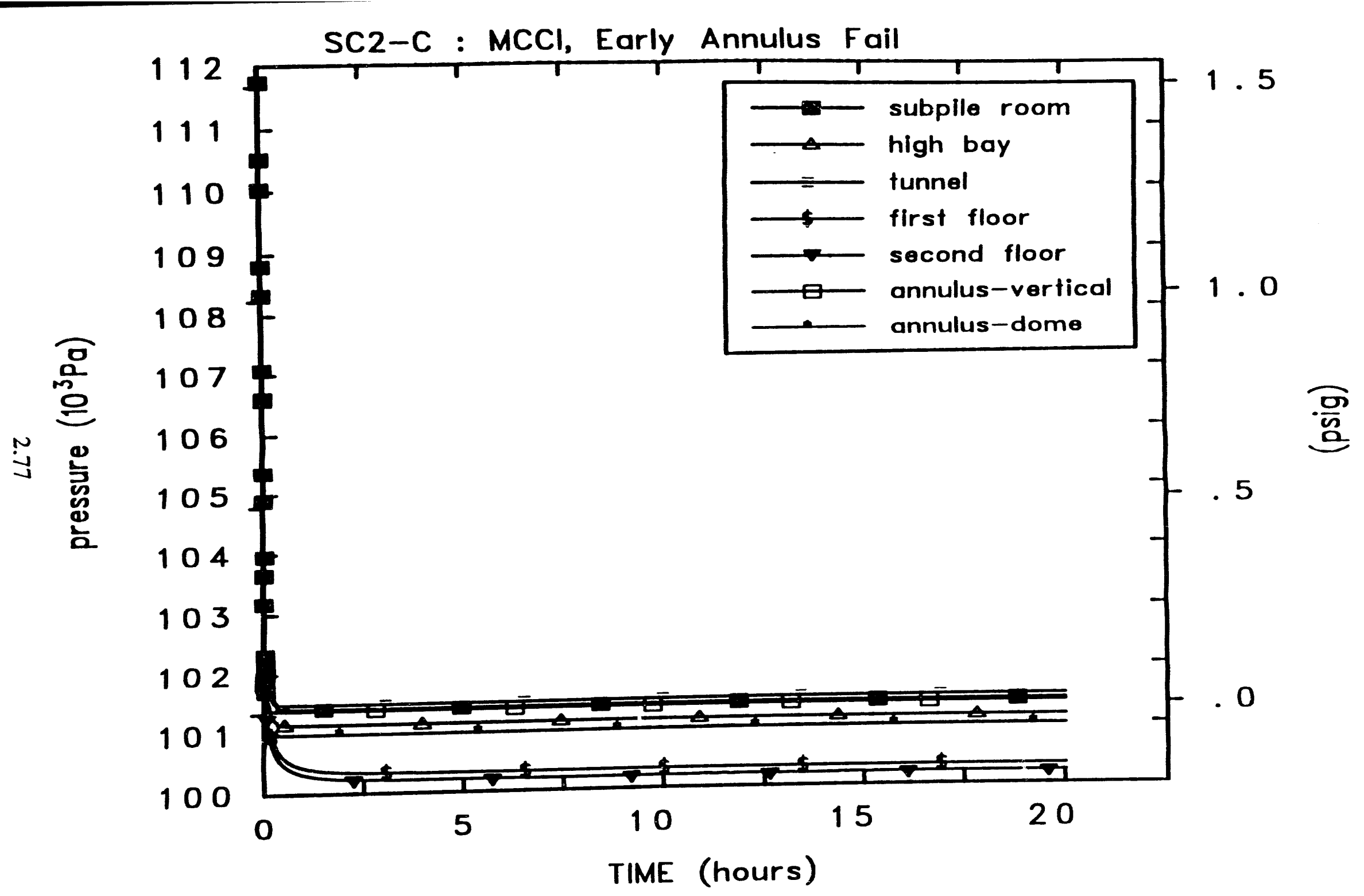

Figure 2.49b Variation of containment volume pressures vs time (Case - SC2-C) 


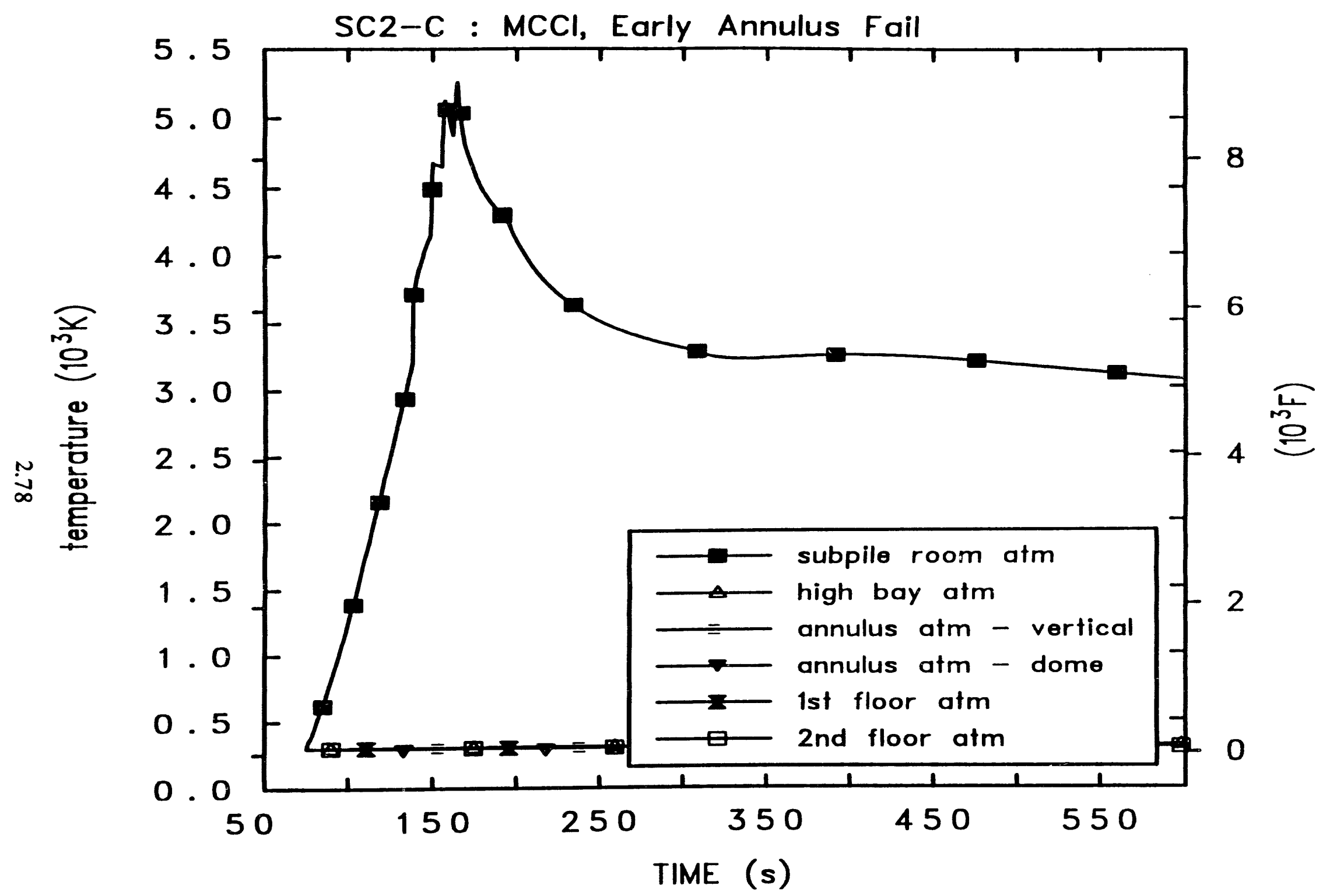

Figure 2.50a Variation of containment volume temperatures vs time (Case - SC2-C) 


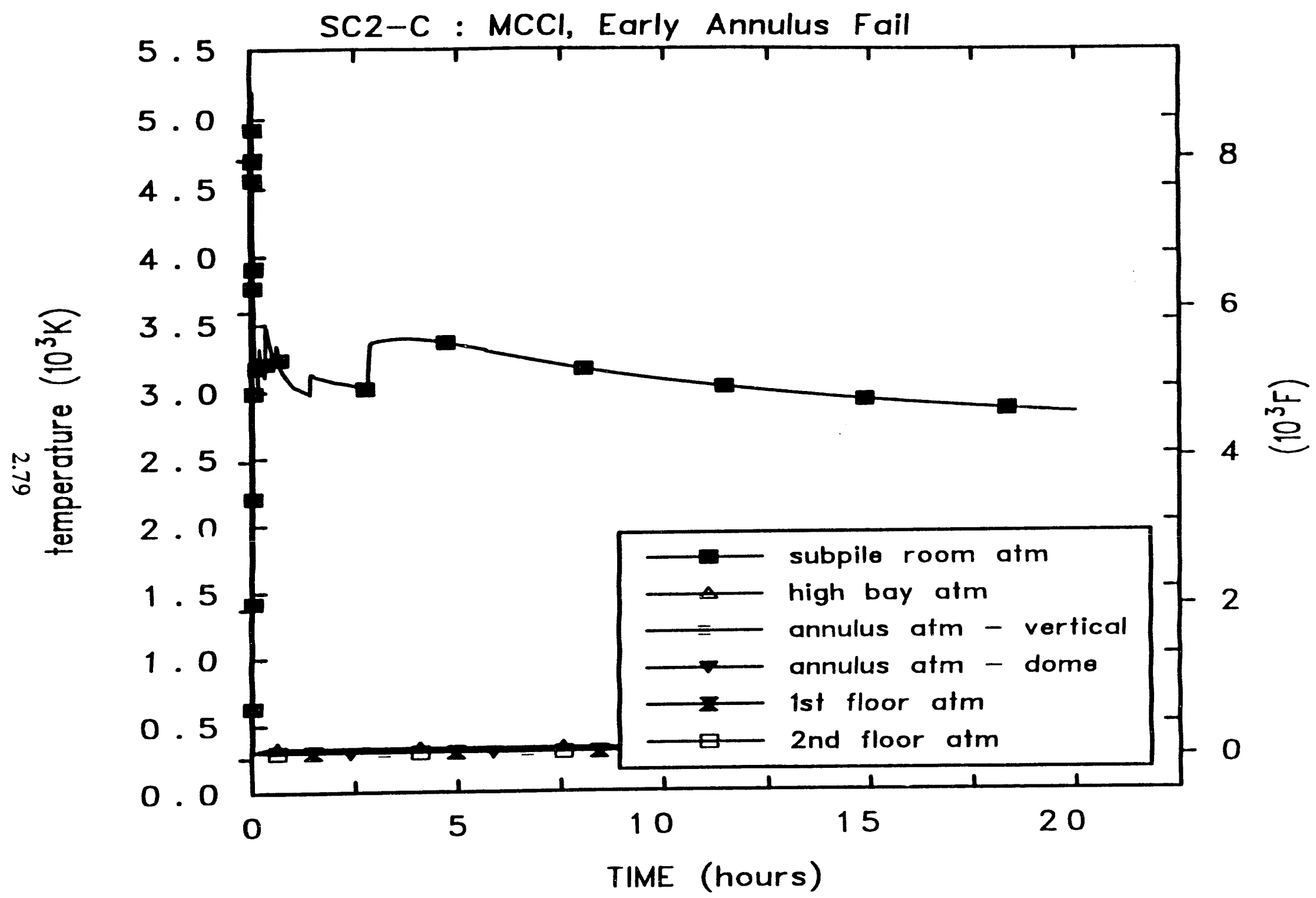

Figure 2.50b Variation of containment volume temperatures vs time (Case - SC2-C) 


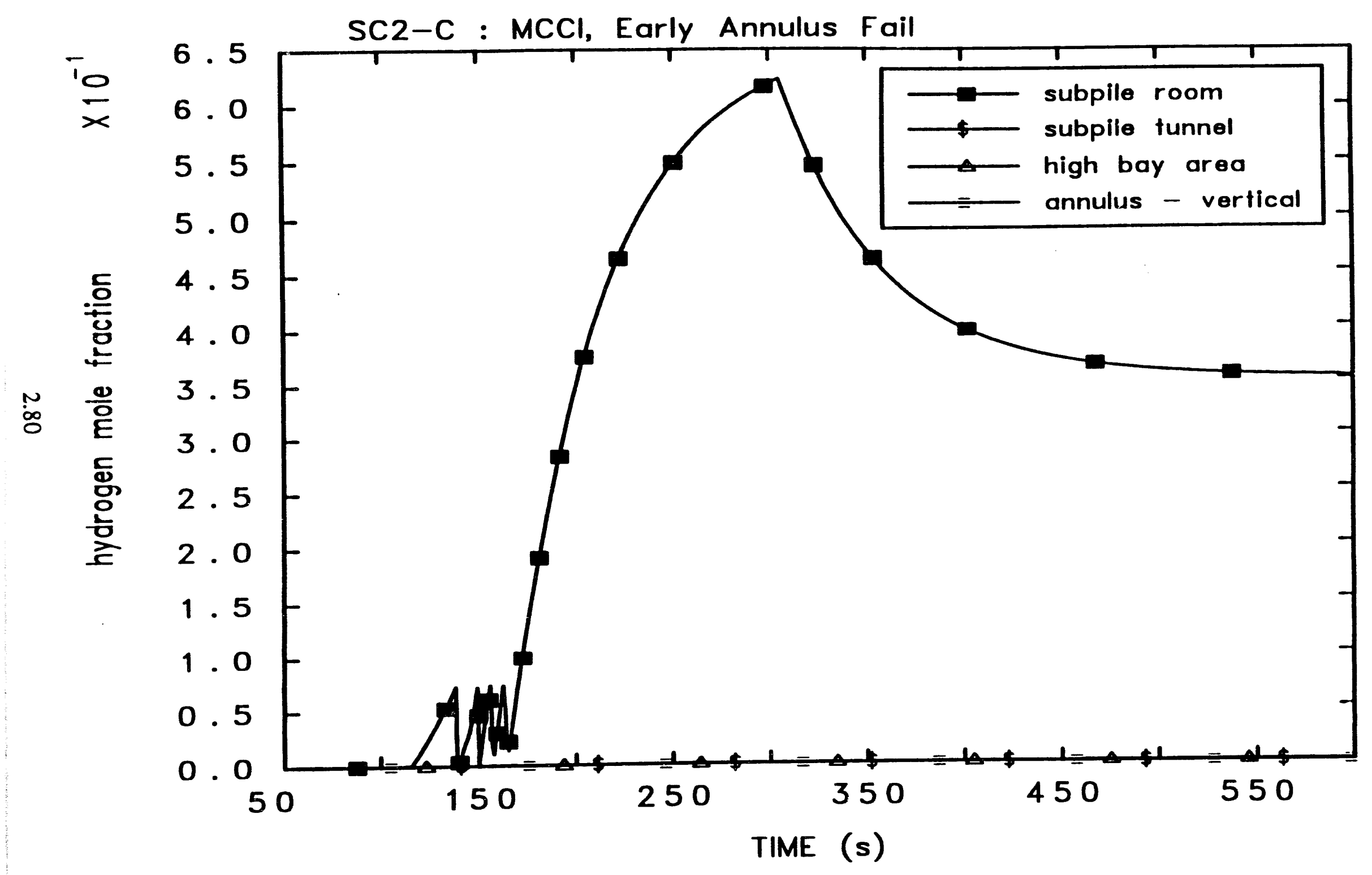

Figure 2.51a Variation of containment volume hydrogen mole fractions vs time (Case SC2-C) 


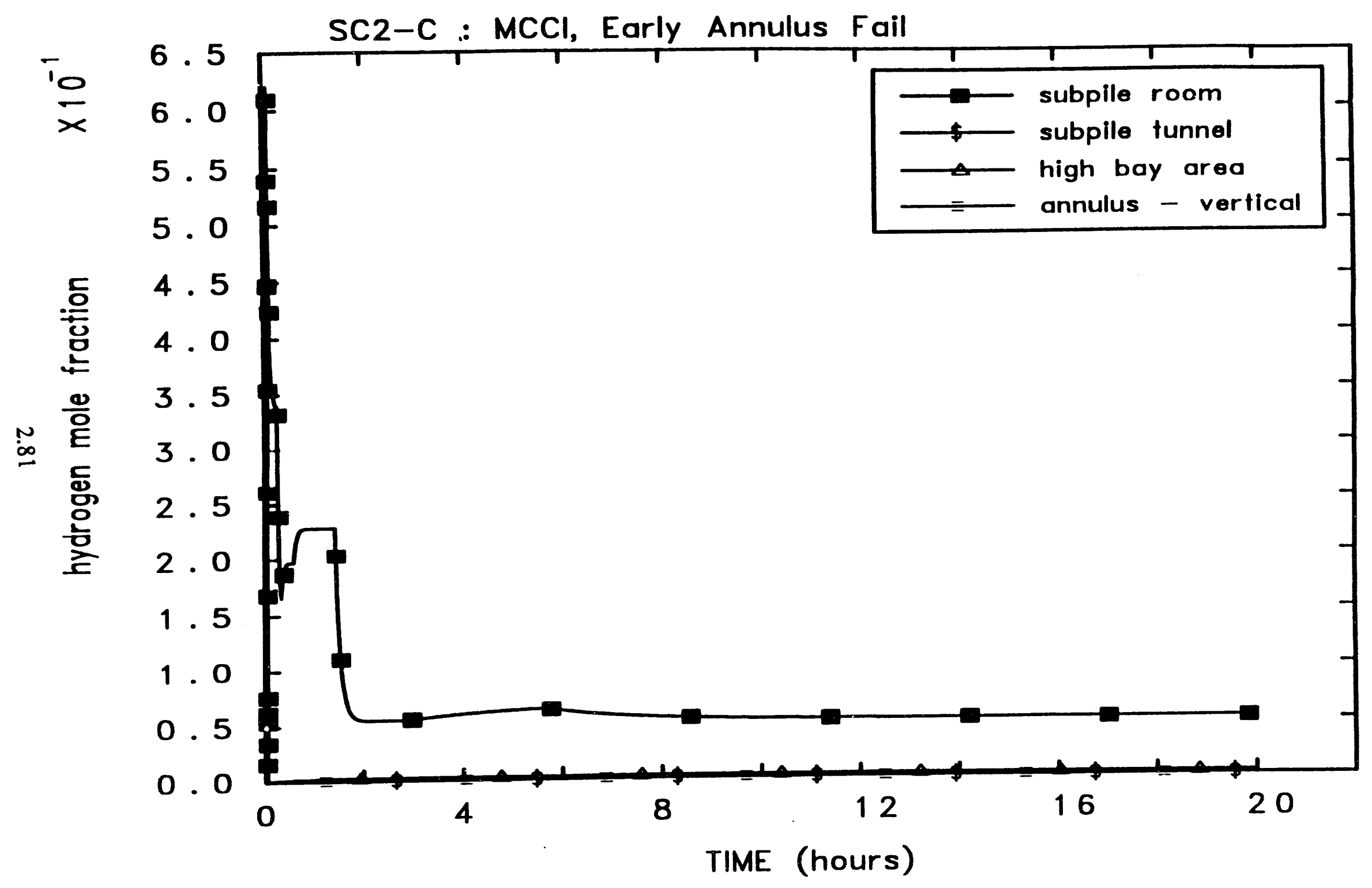

Figure 2.51b Variation of containment volume hydrogen mole fractions vs time (Case SC2-C) 


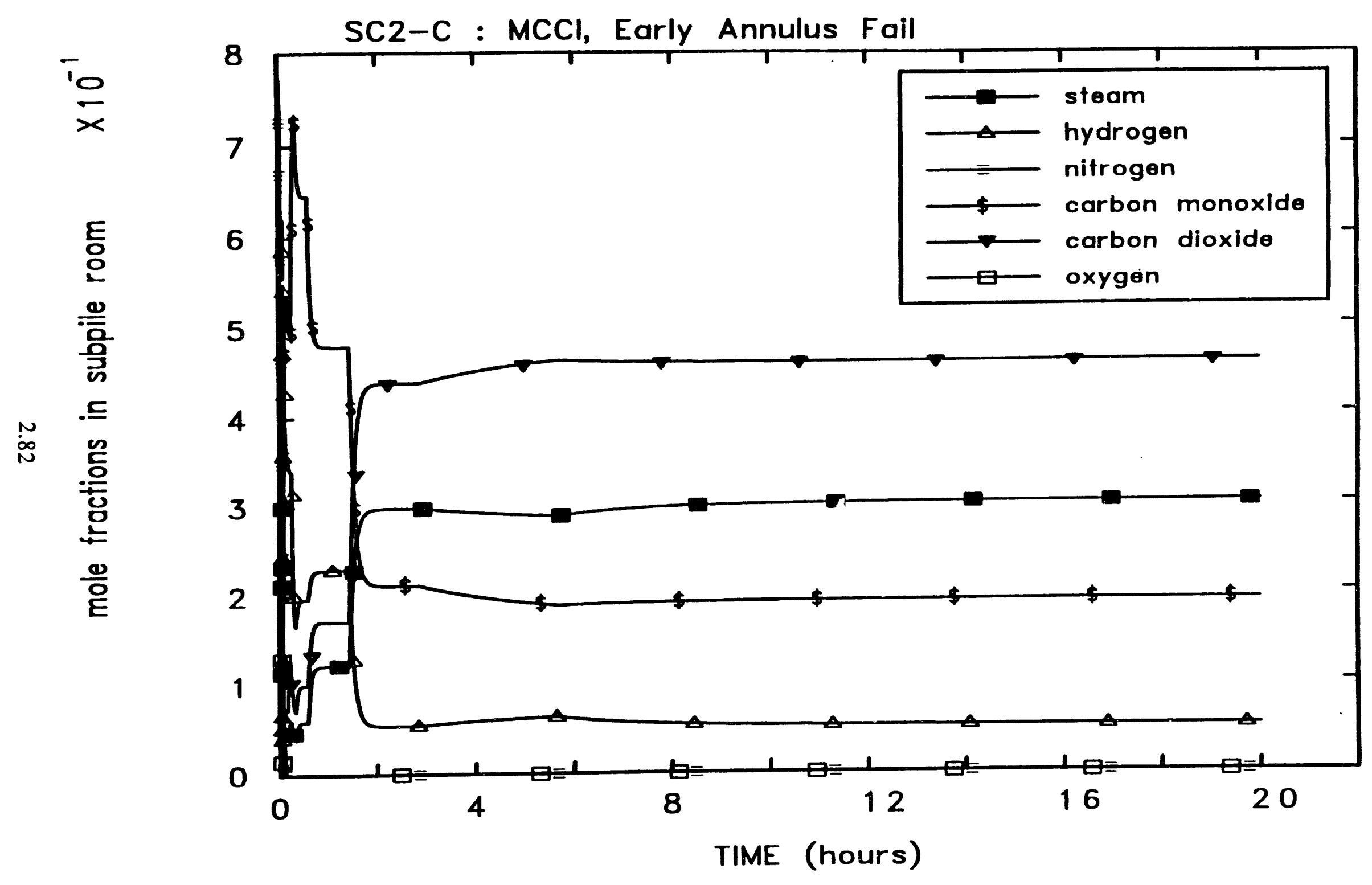

Figure 2.52 Variation of containment volume gas and steam mole fractions vs time (Case - SC2-C) 


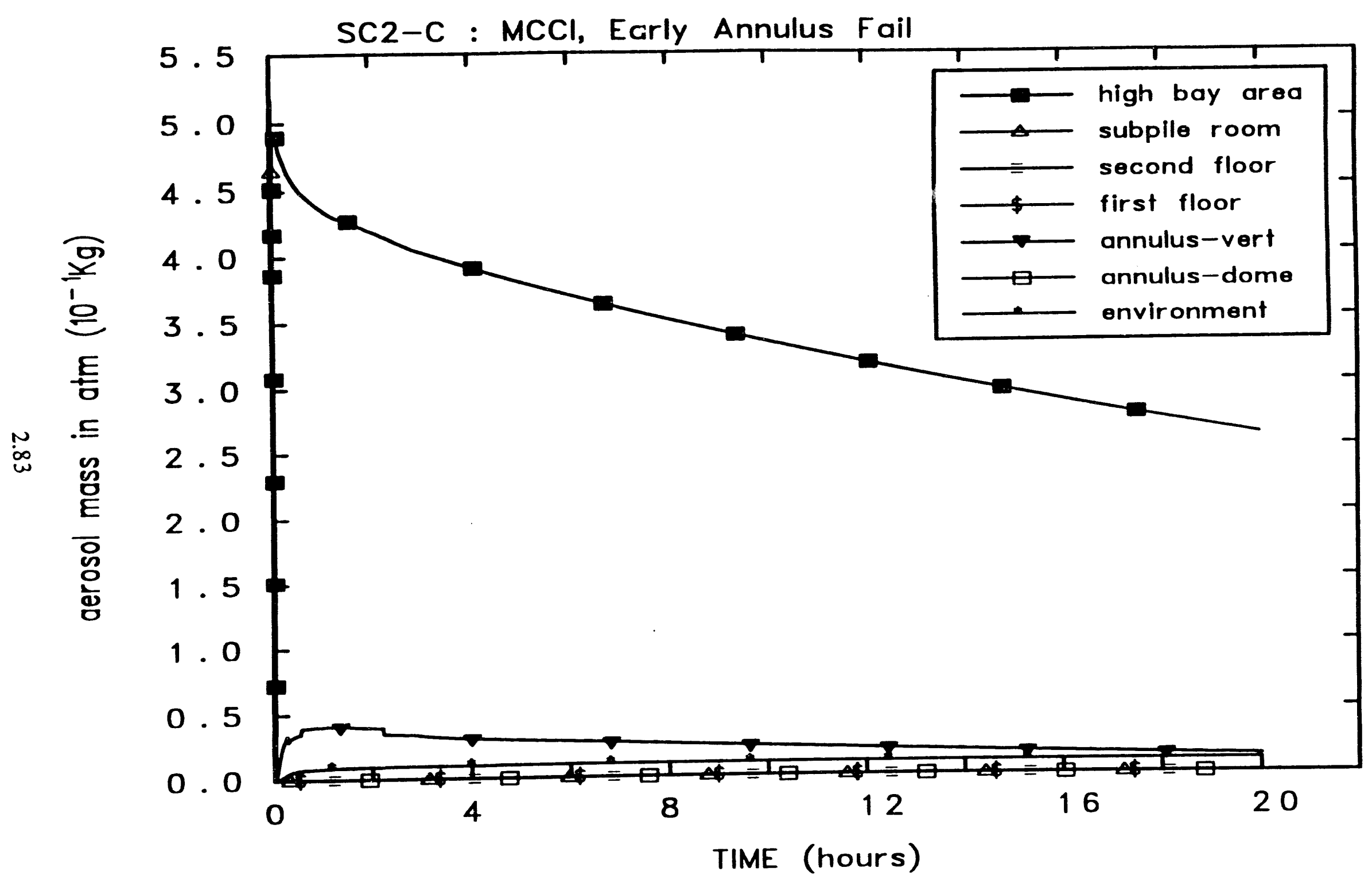

Figure 2.53 Variation of containment volume aerosol masses vs time (Case - SC2-C) 


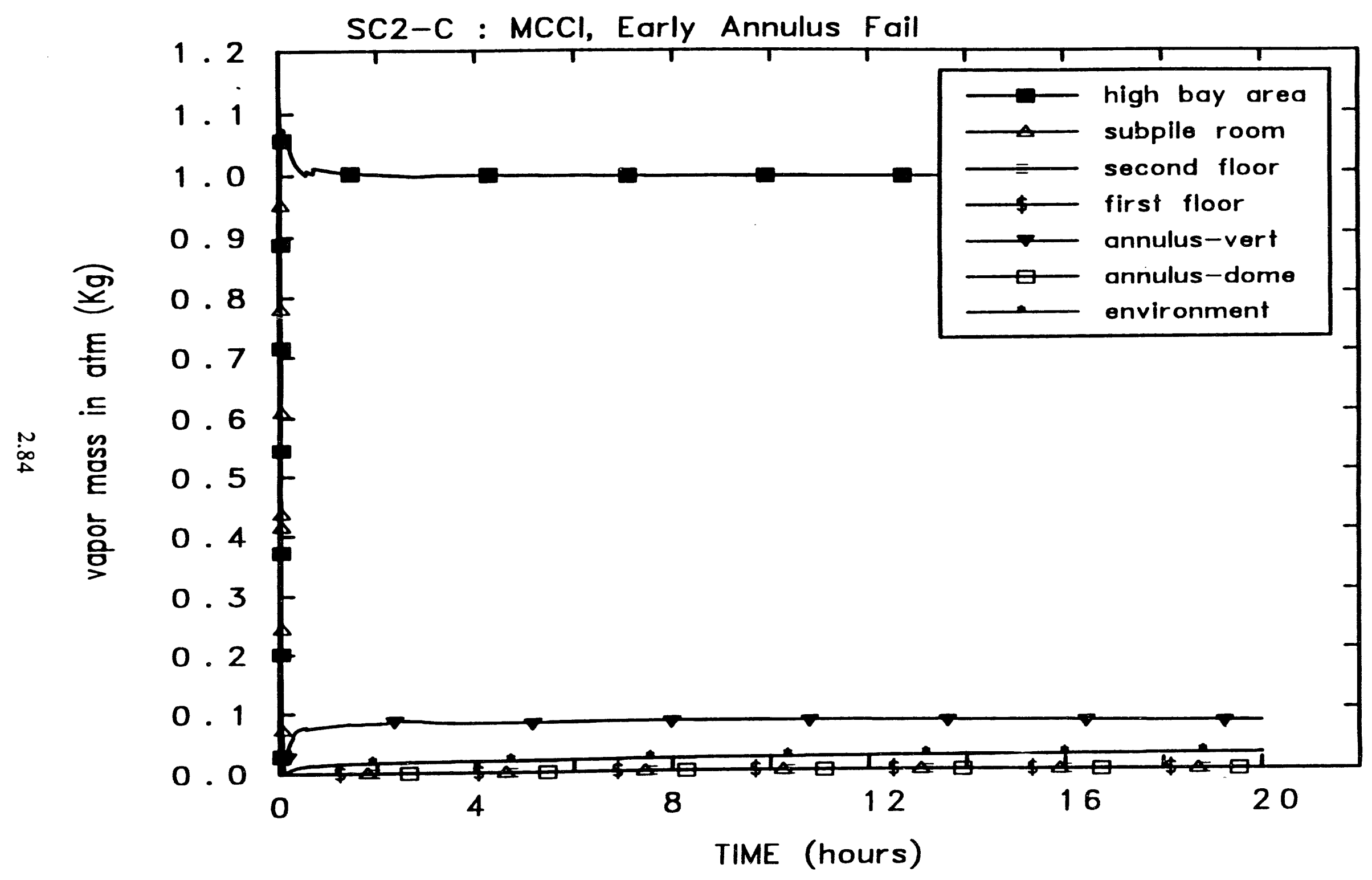

Figure 2.54 Variation of atmosphere radionuclide vapor masses vs time (Case - SC2-C) 


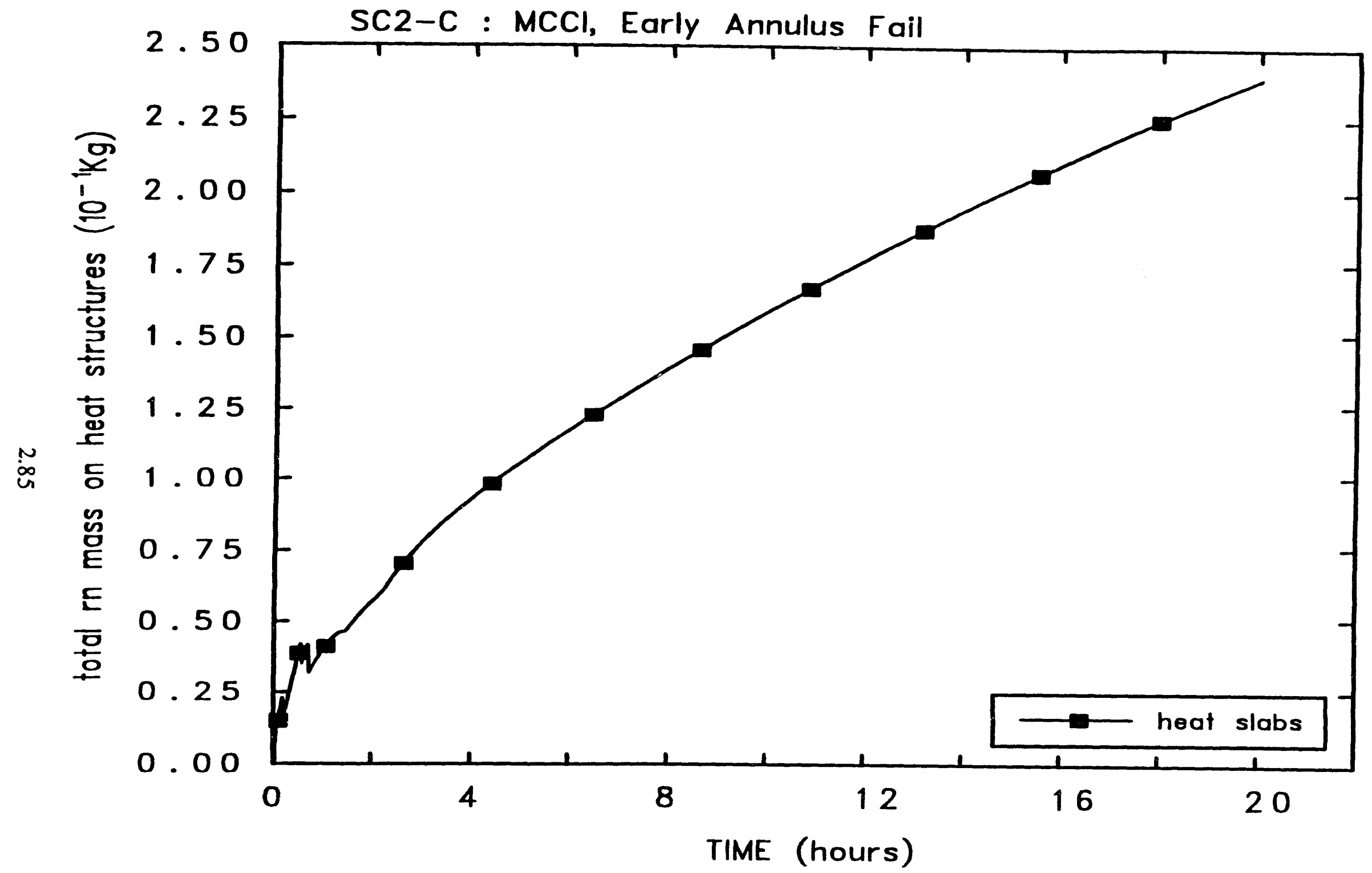

Figure 2.55 Variation of total deposited radionuclide masses on heat structures vs time (Case - SC2-C) 


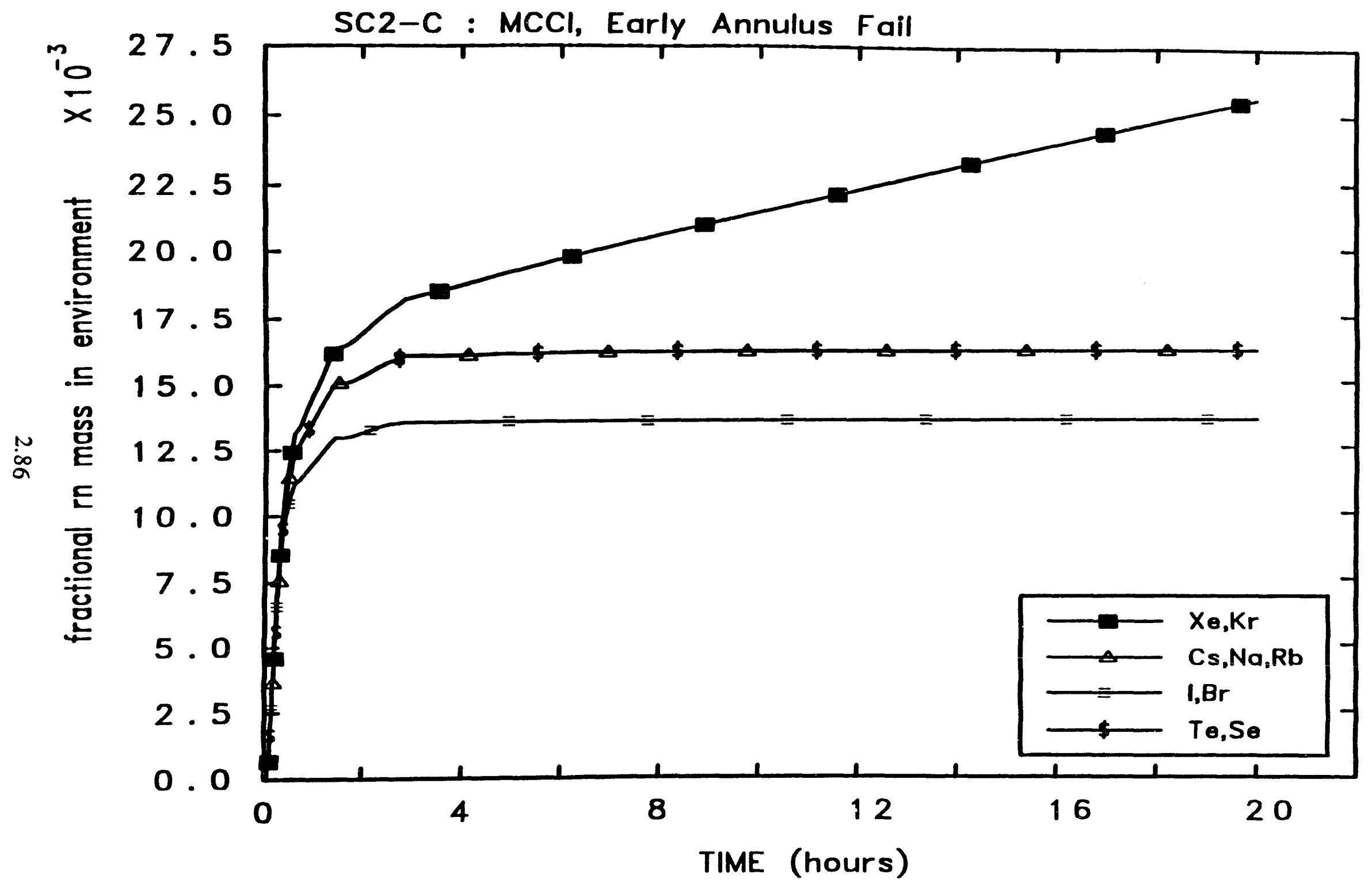

Figure 2.56 Variation of fractional radionuclide masses entering the environment vs time (Case - SC2-C) 


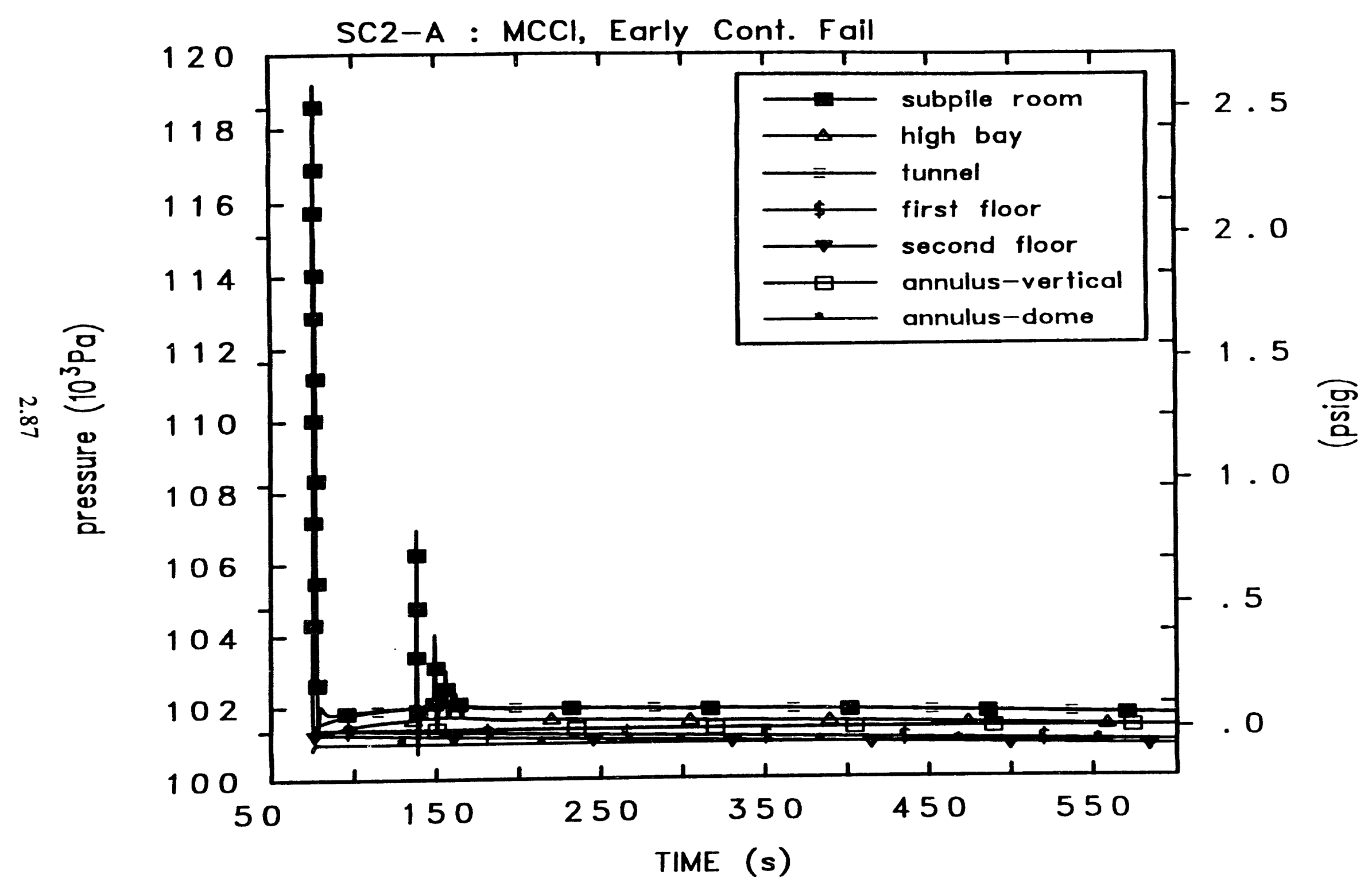

Figure $2.57 \mathrm{a}$ Variation of containment volume pressures vs time (Case - SC2-A) 


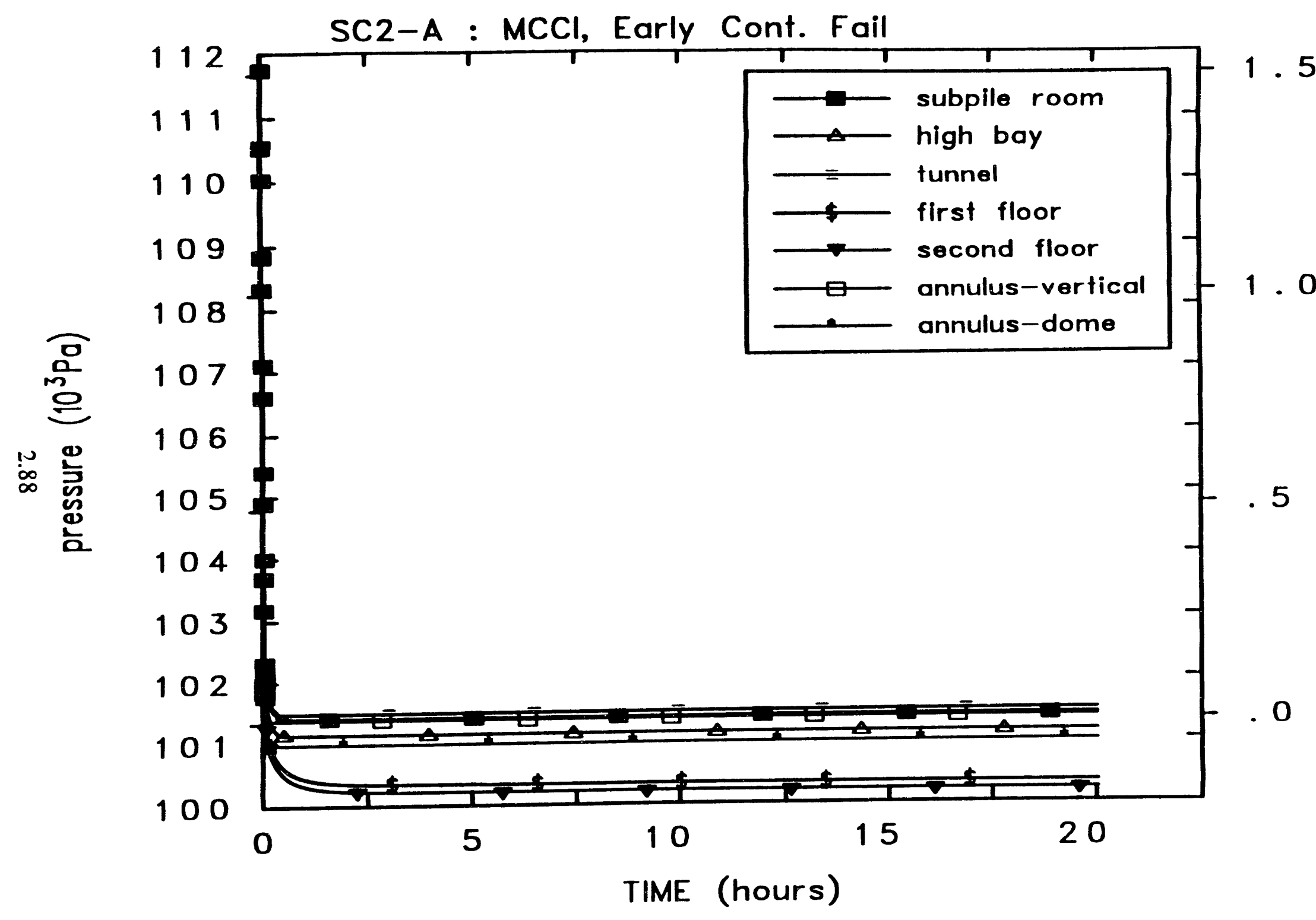

홈

Figure 2.57b Variation of containment volume pressures vs time (Case - SC2-A) 


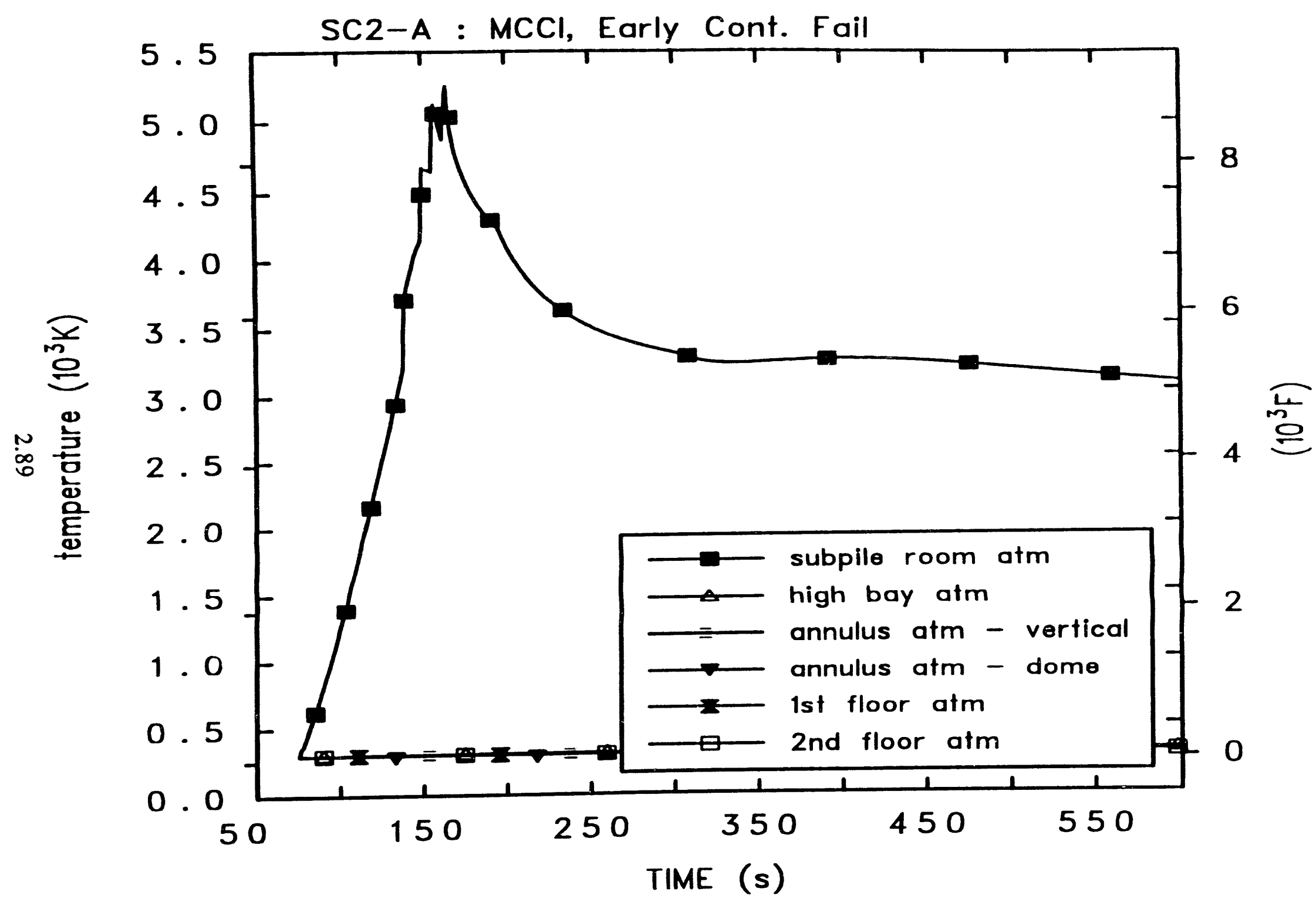

Figure 2.58a Variation of containment volume temperatures vs time (Case - SC2-A) 


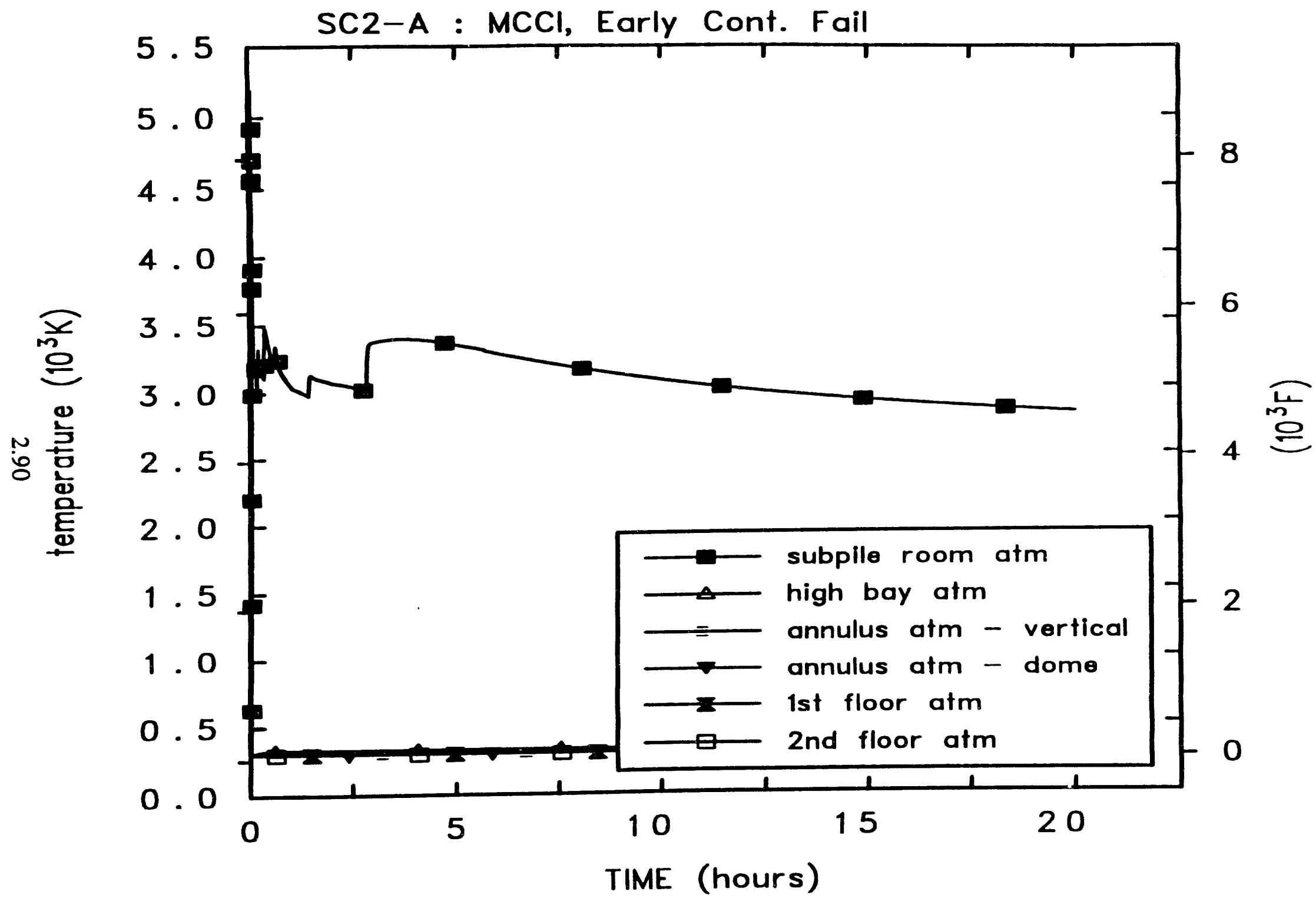

Figure 2.58b Variation of containment volume temperatures vs time (Case - SC2-A) 


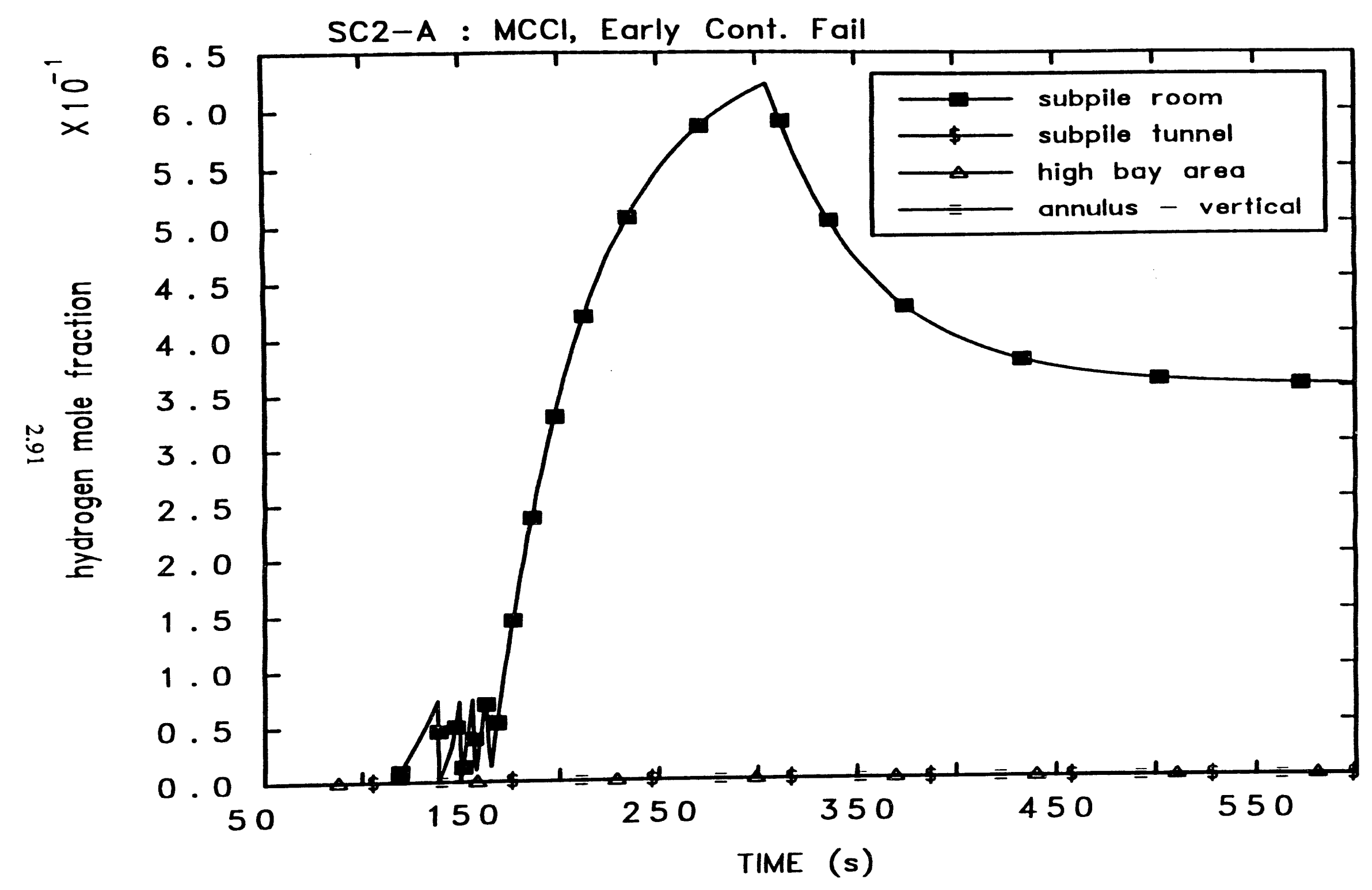

Figure 2.59a Variation of containment volume hydrogen mole fractions vs time (Case SC2-A) 


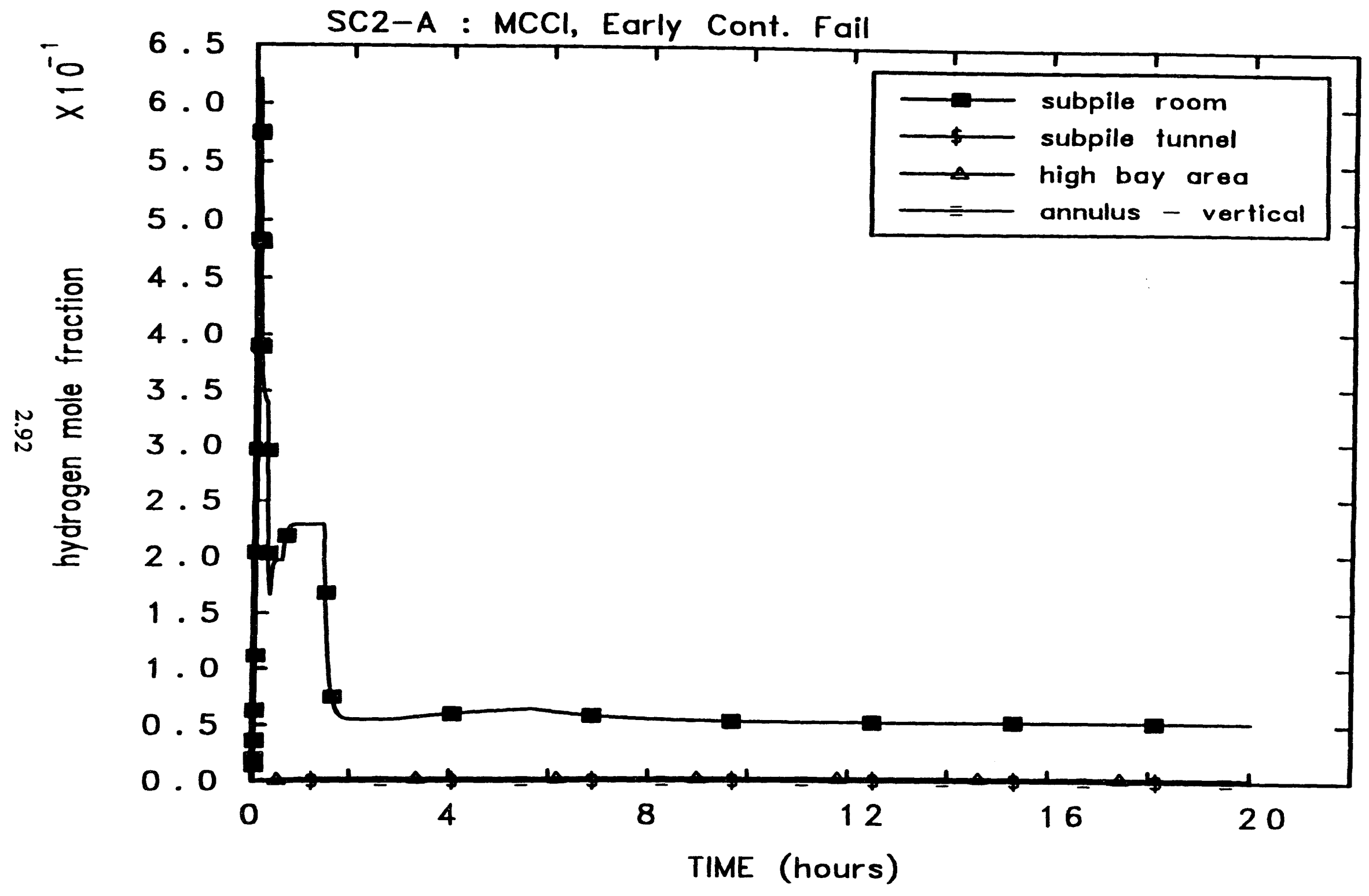

Figure $2.59 \mathrm{~b}$ Variation of containment volume hydrogen mole fractions vs time (Case SC2-A) 


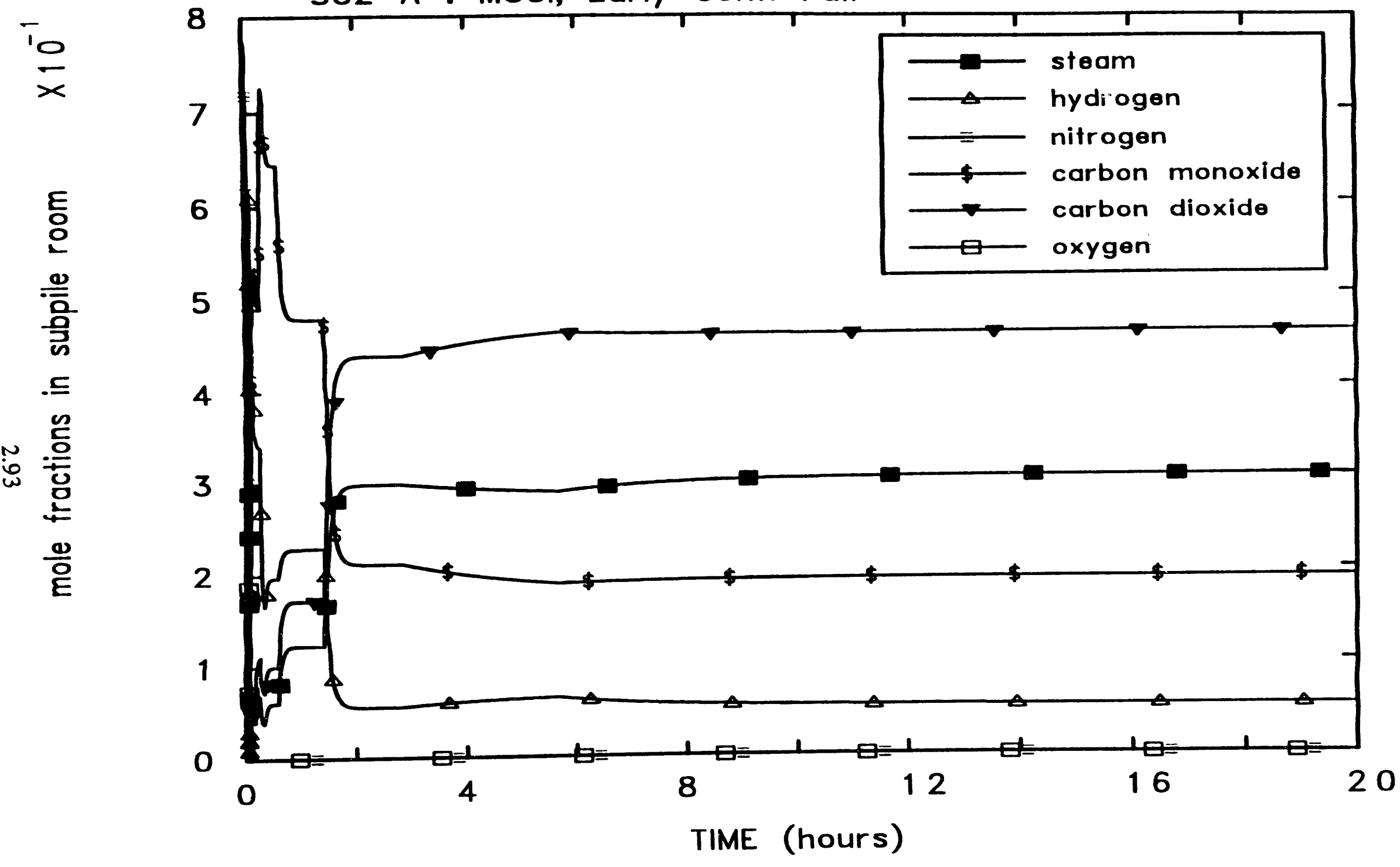

Figure 2.60 Variation of containment volume gas and steam mole fractions vs time (Case - SC2-A) 


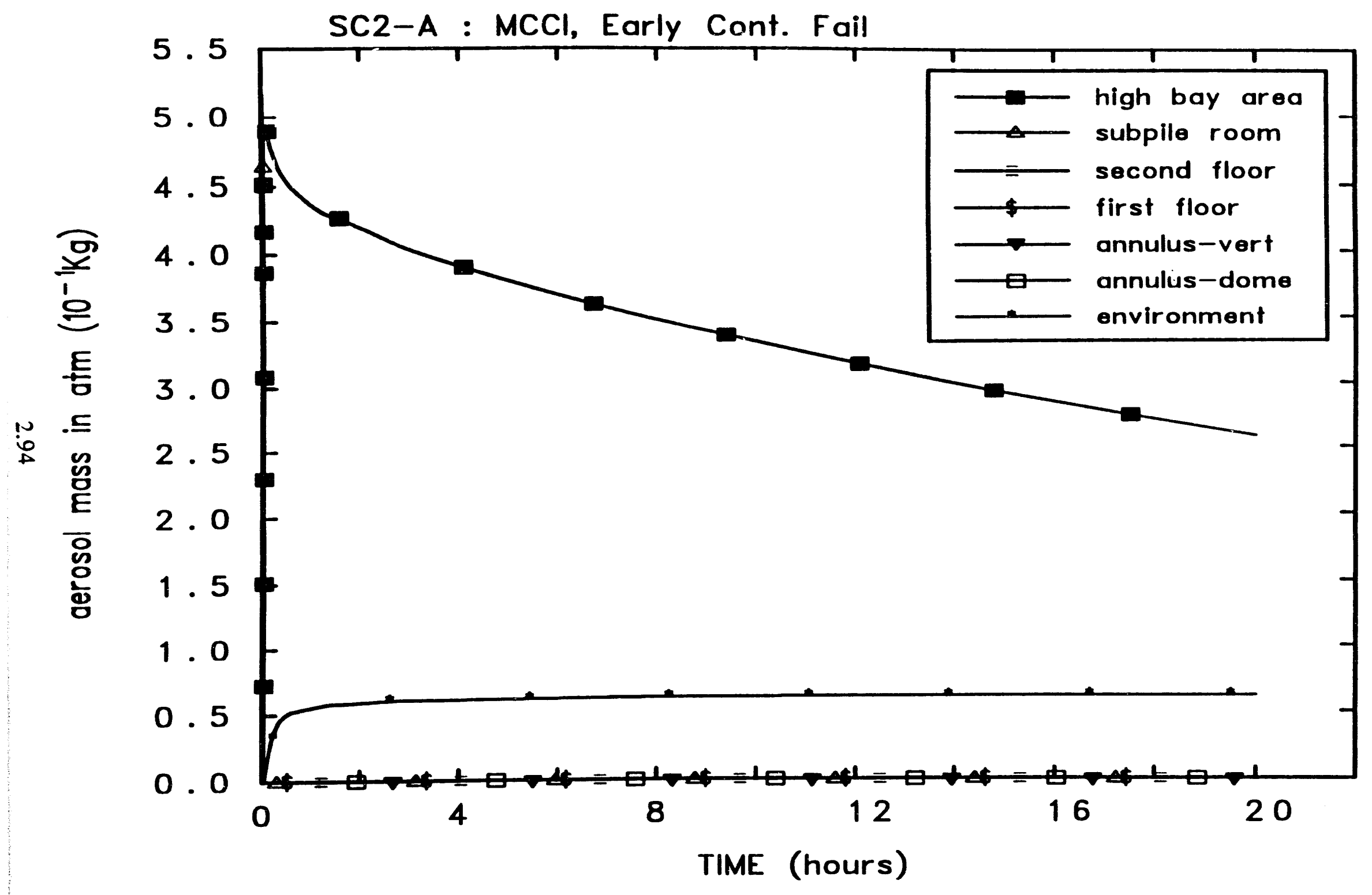

Figure 2.61 Variation of containment volume aerosol masses vs time (Case - SC2-A) 


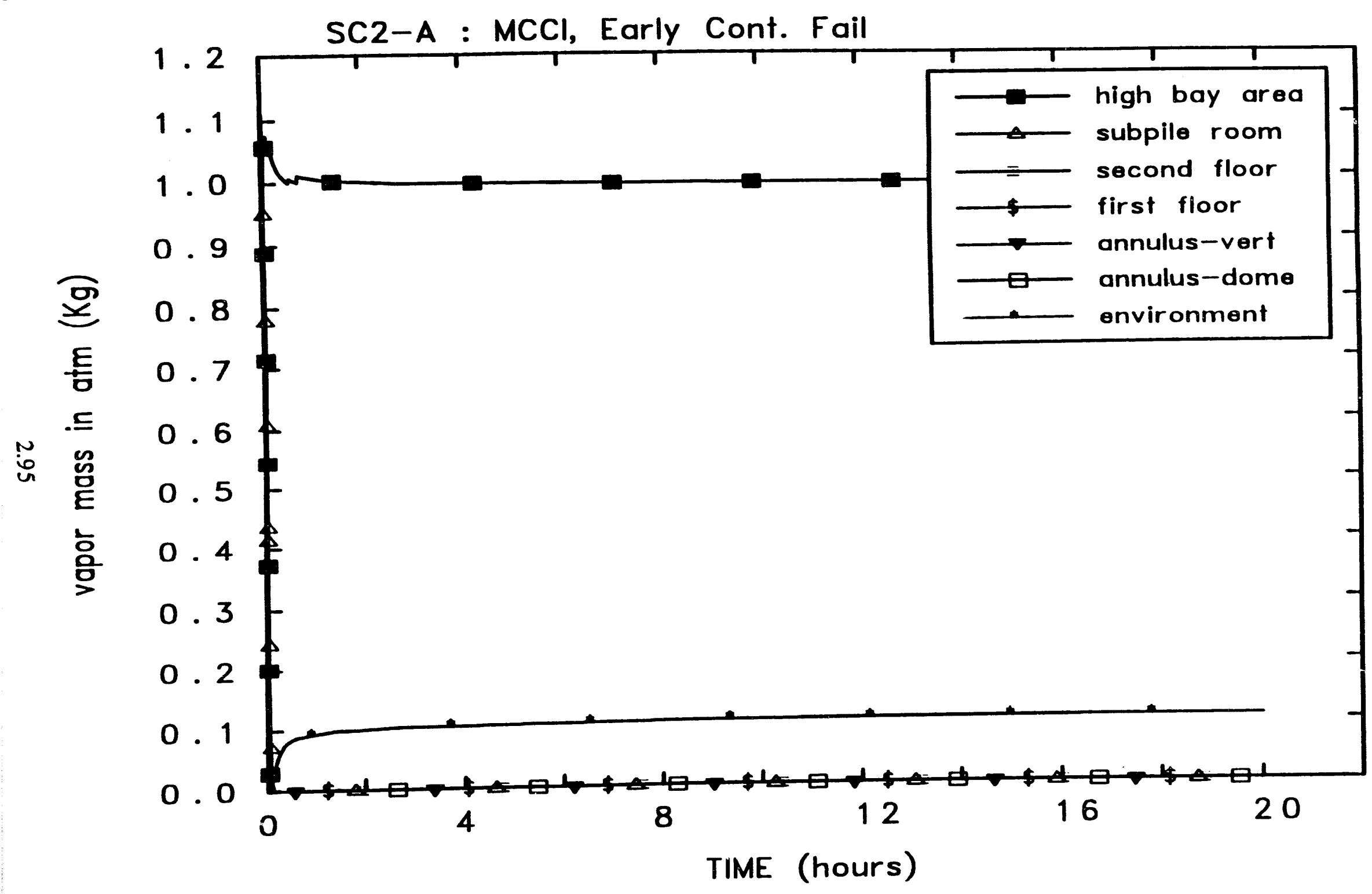

Figure 2.62 Variation of atmosphere radionuclide vapor masses vs time (Case - SC2-A) 


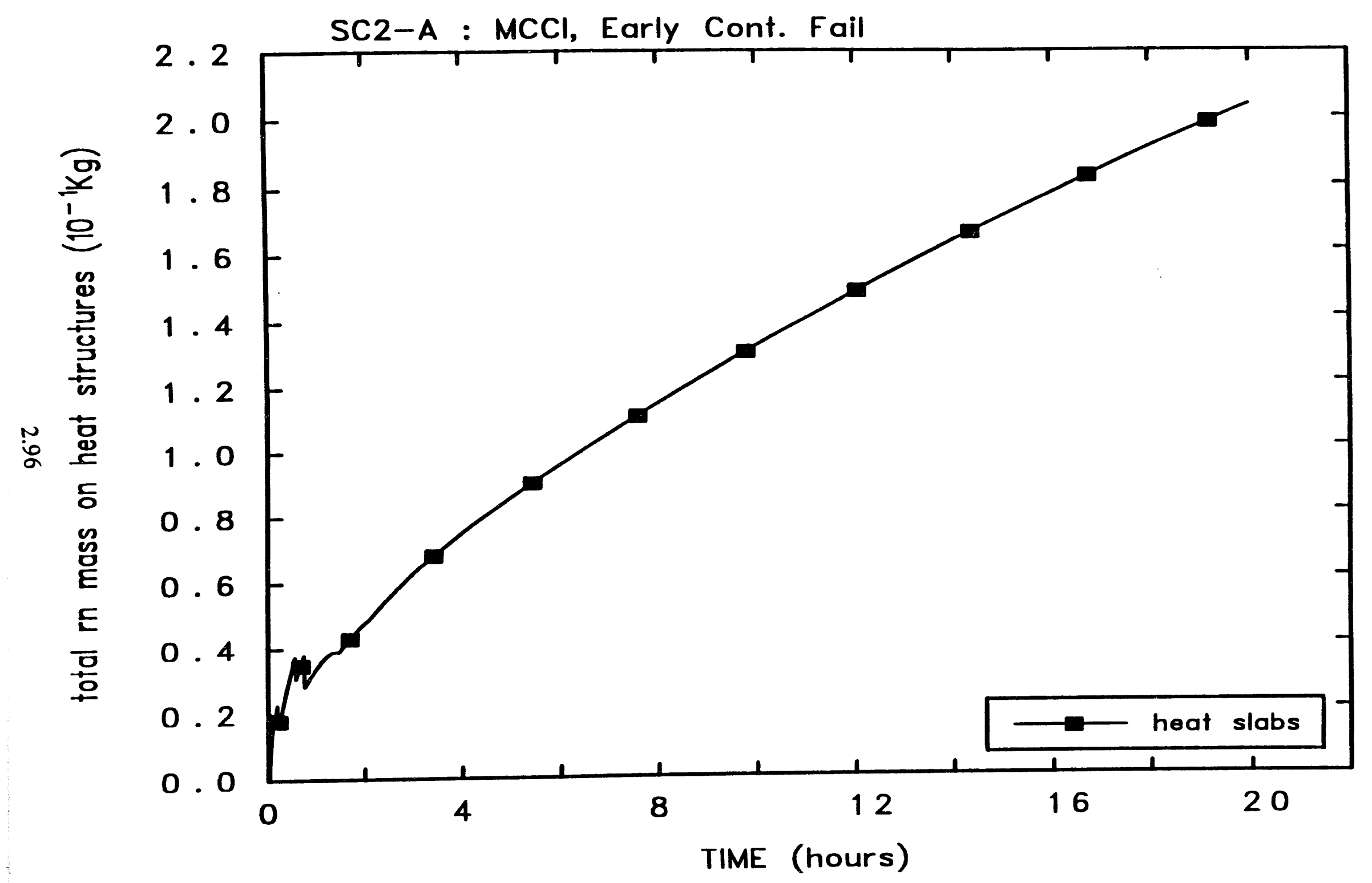

Figure 2.63 Variation of total deposited radionuclide masses on heat structures vs time (Case - SC2-A) 


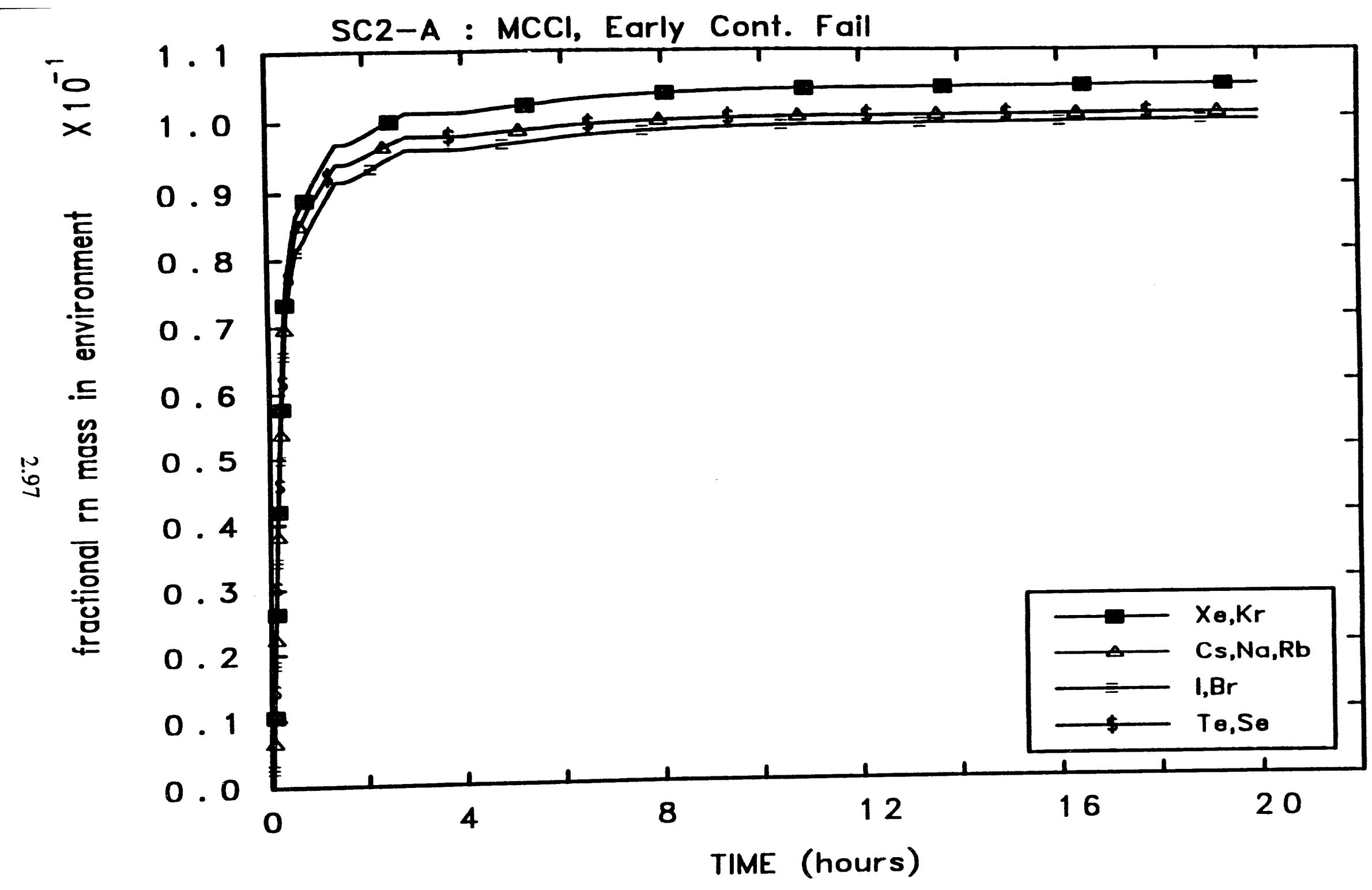

Figure 2.64 Variation of fractional radionuclide masses entering the environment vs time (Case - SC2-A) 


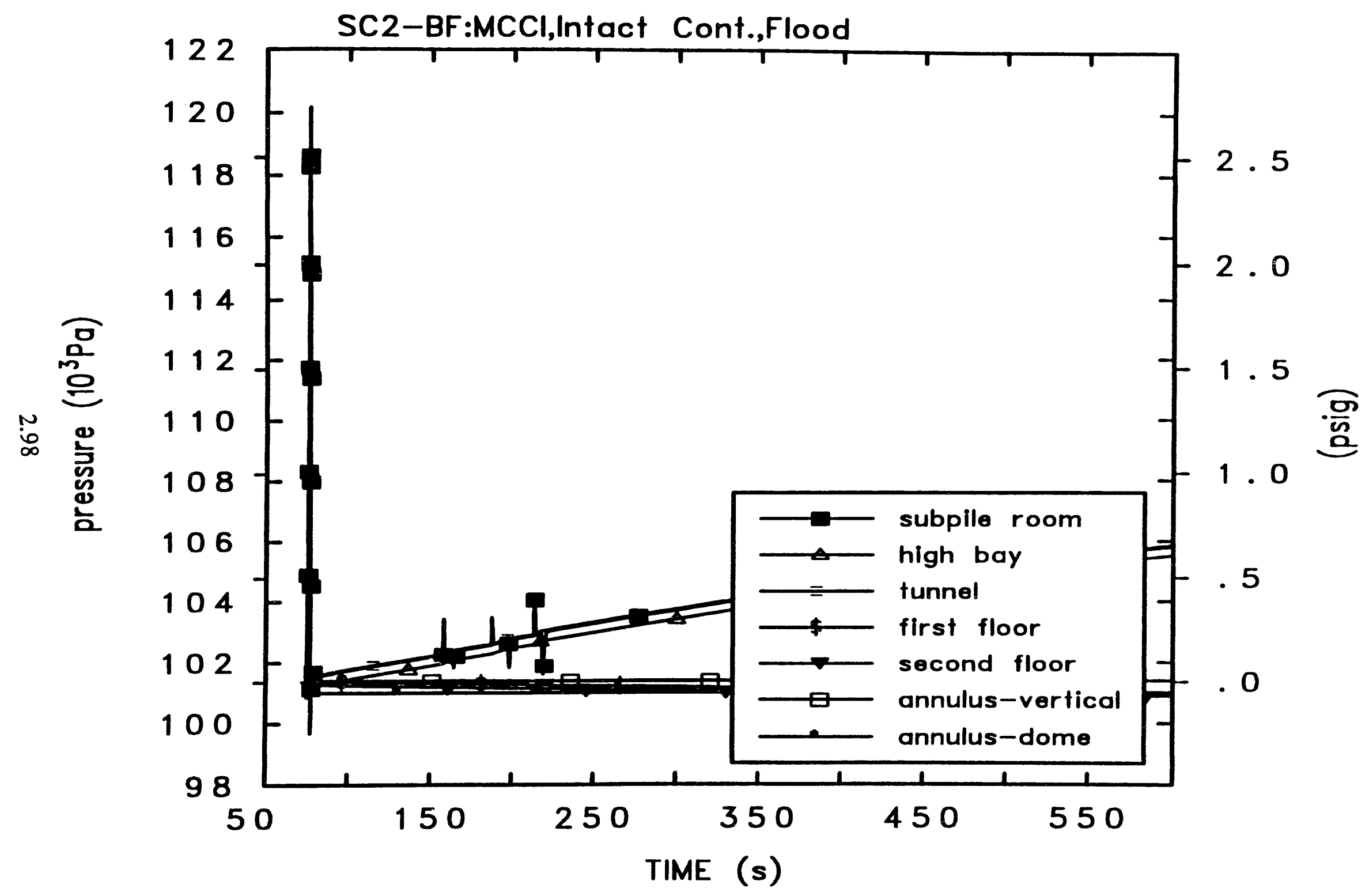

Figure 2.65a Variation of containment volume pressures vs time (Case - SC2-BF) 


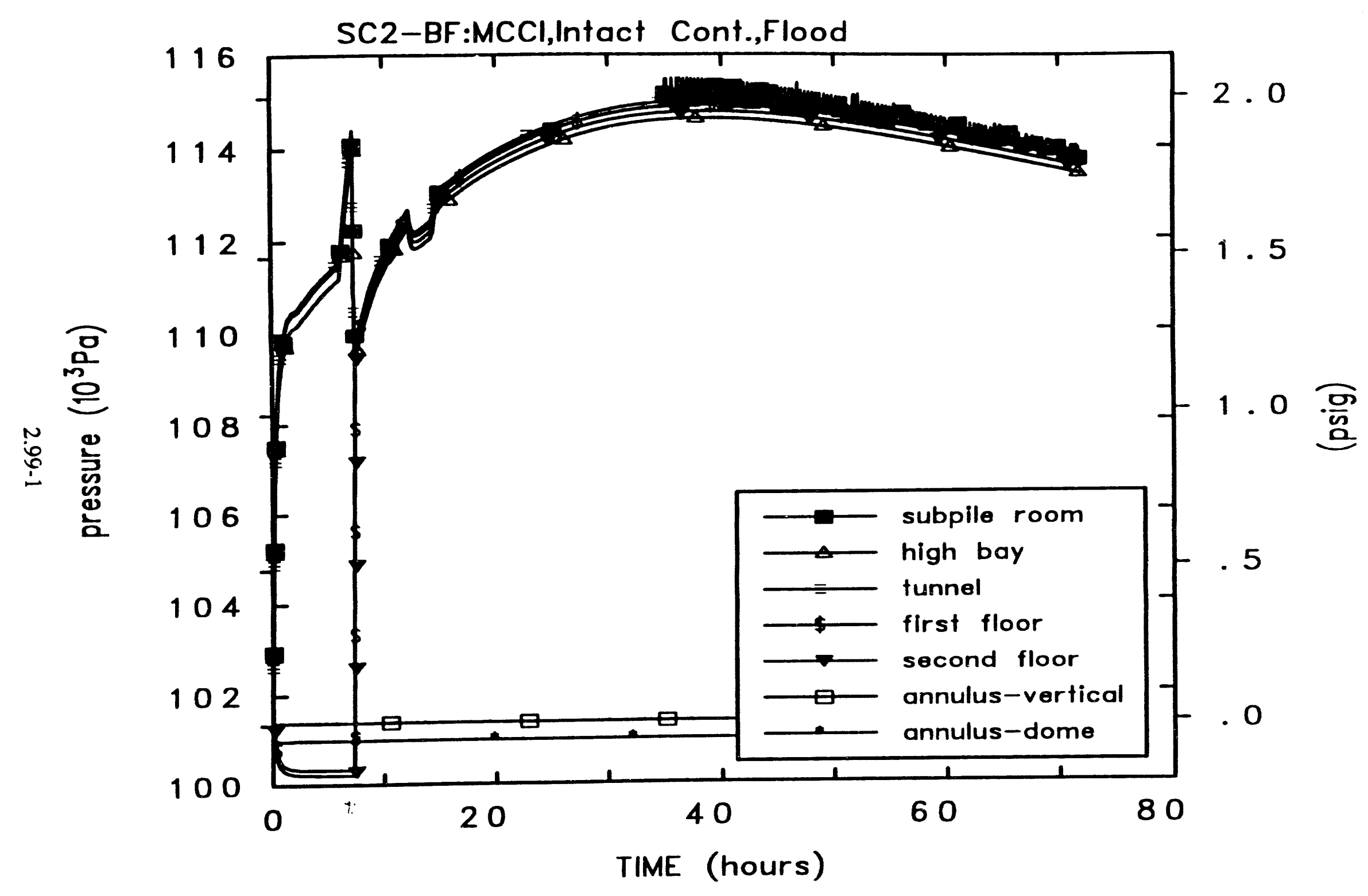

Figure 2.65b-1 Variation of containment volume pressures vs time (Case - SC2-BF) 


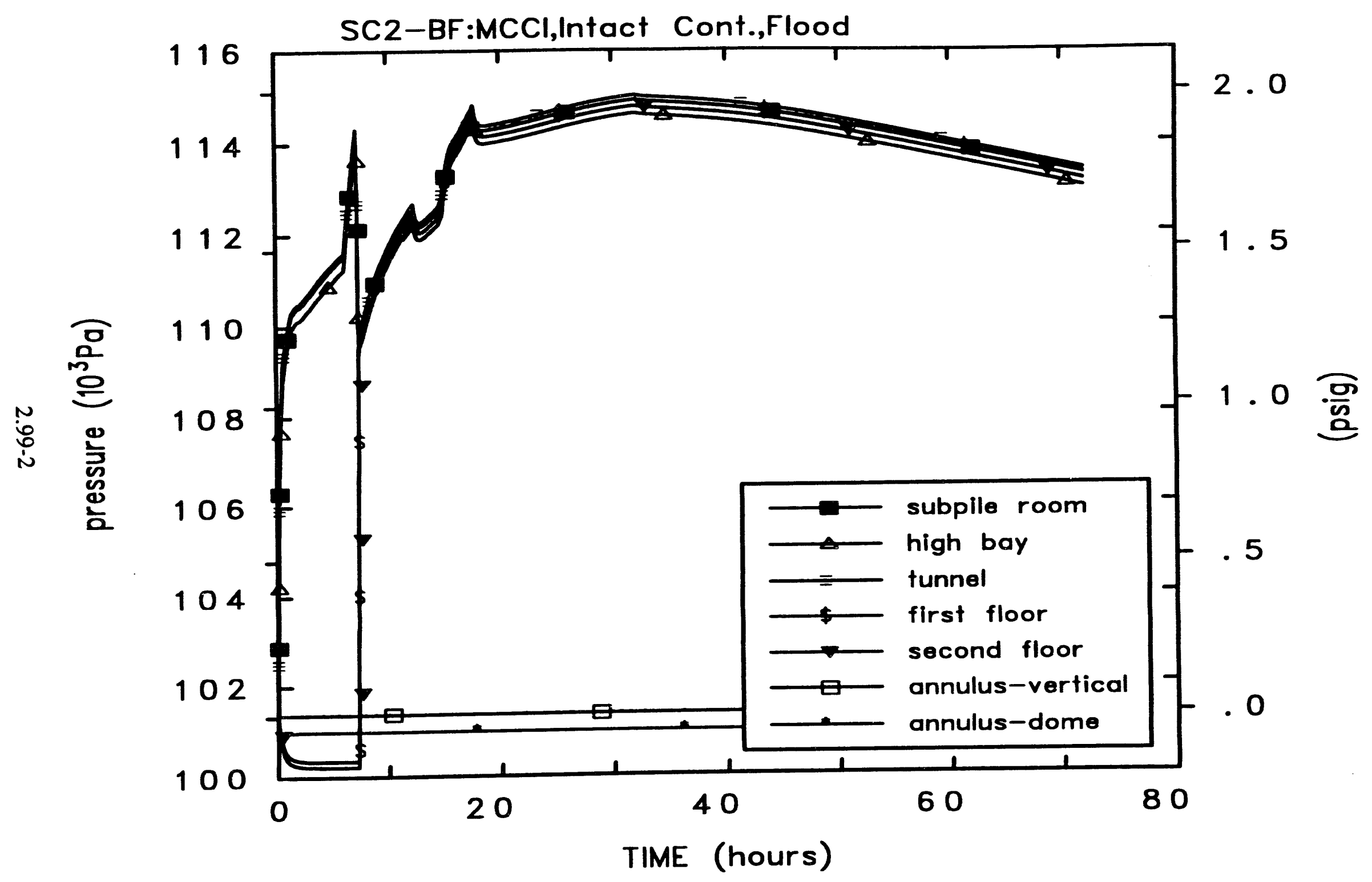

Figure $2.65 \mathrm{~b}-2$ Variation of containment volume pressures vs time (Case - SC2-BF) predicted by MELCOR Mod 1.8.2 


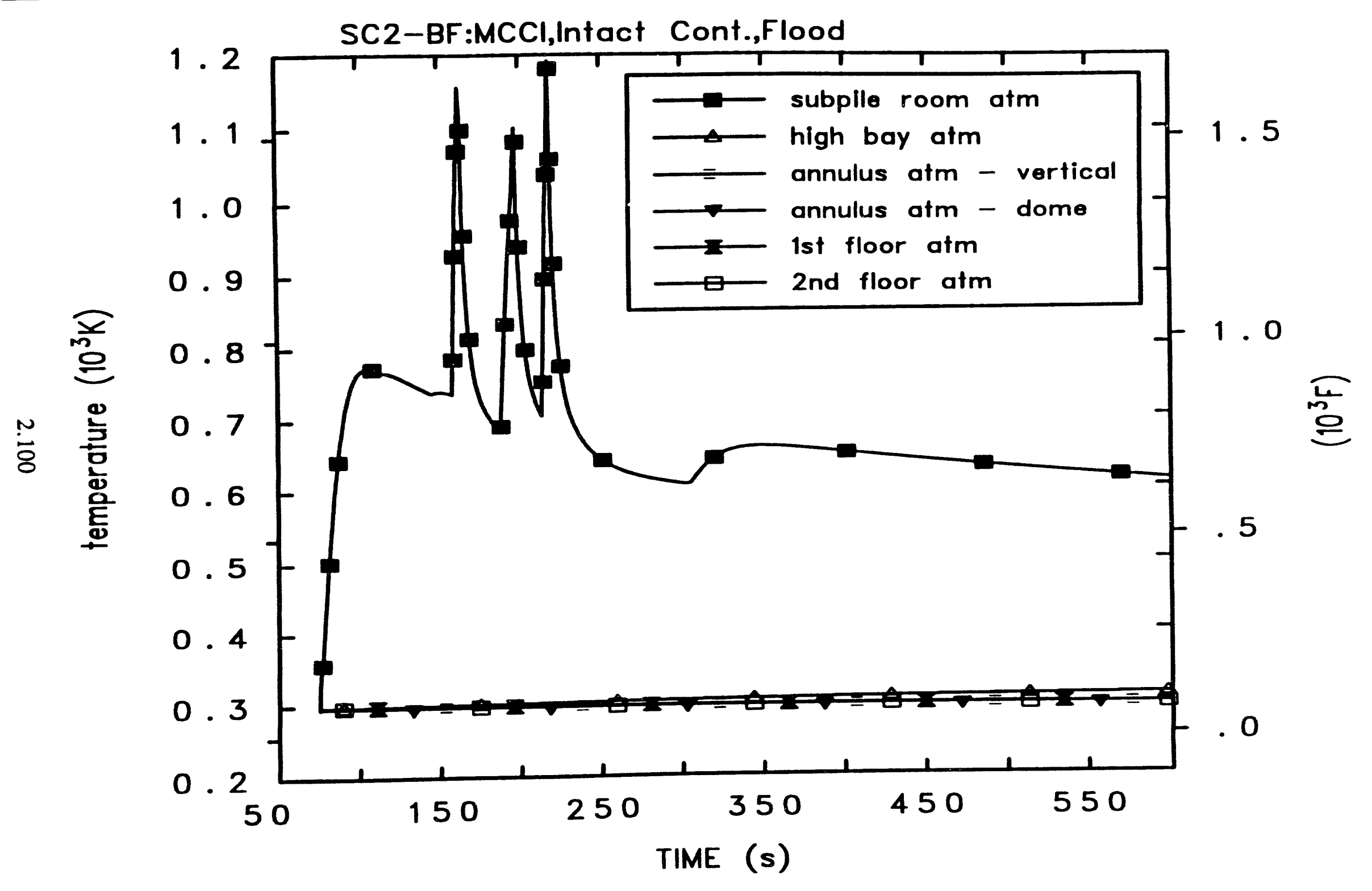

Figure 2.66a Variation of containment volume temperatures vs time (Case - SC2-BF) 


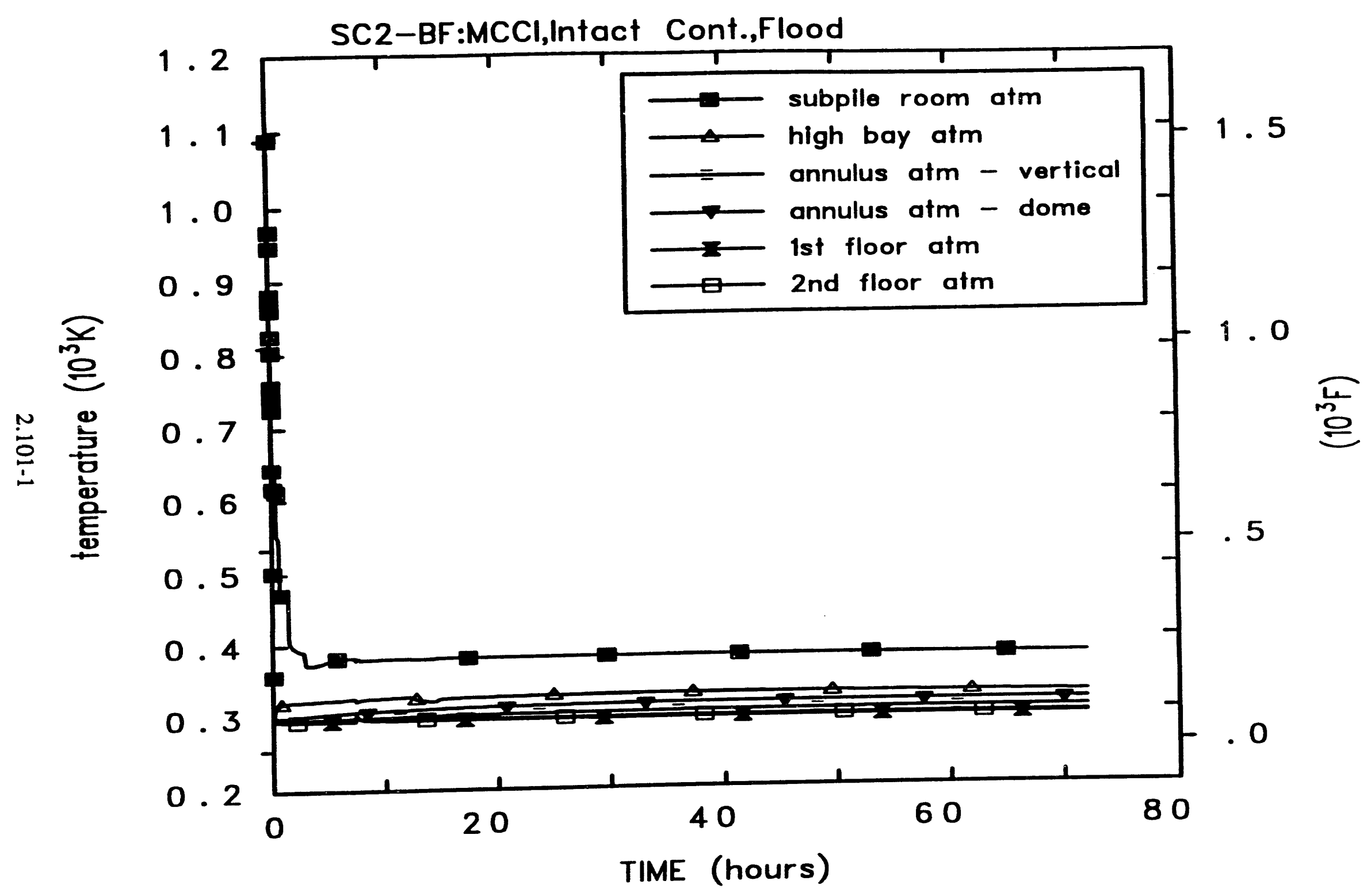

Figure $2.66 \mathrm{~b}-1$ Variation of containment volume temperatures vs time (Case - SC2-BF) 


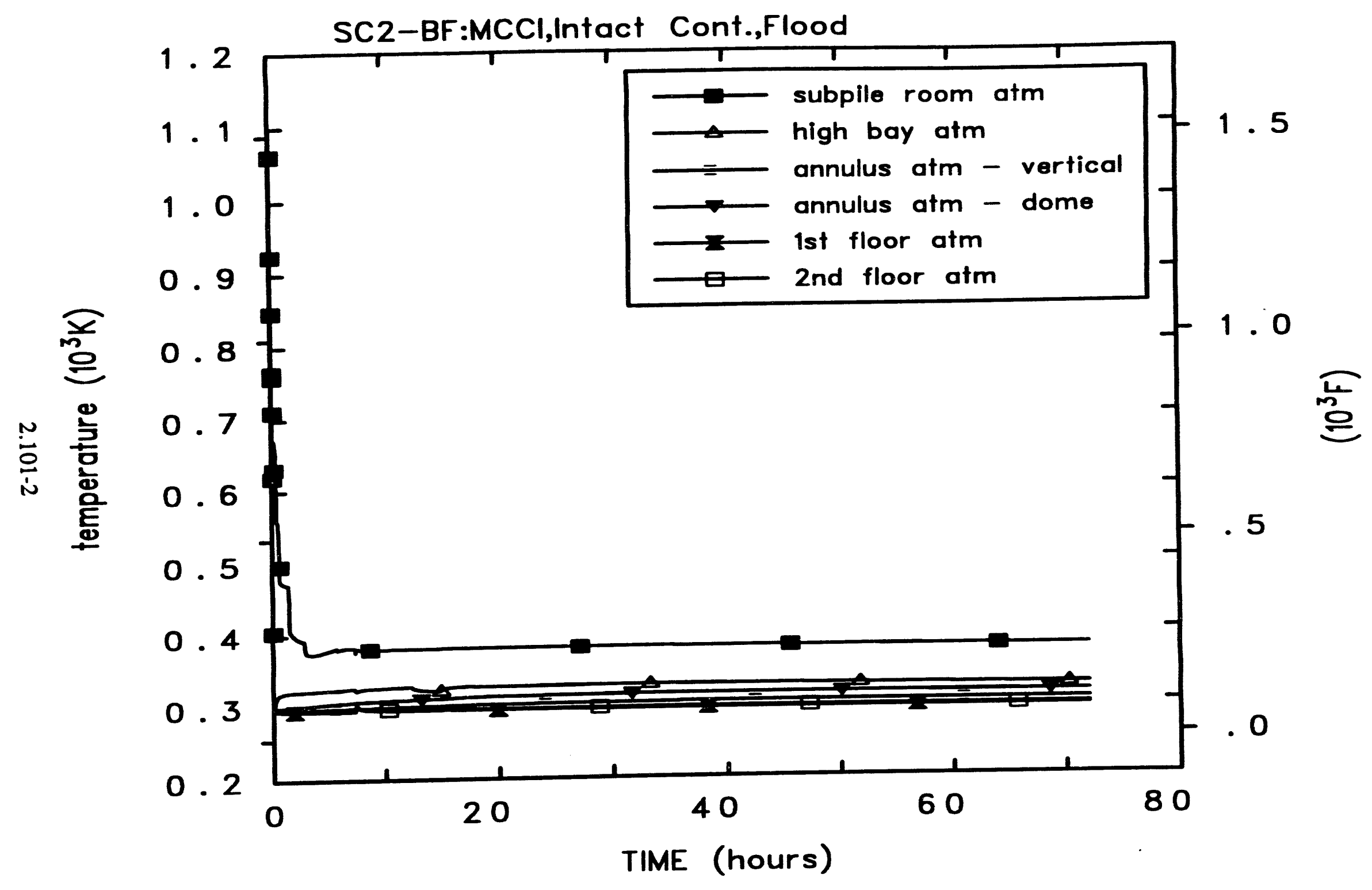

Figure $2.66 \mathrm{~b}-2$ Variation of containment volume temperatures vs time predicted by MELCOR Mod 1.8.2 


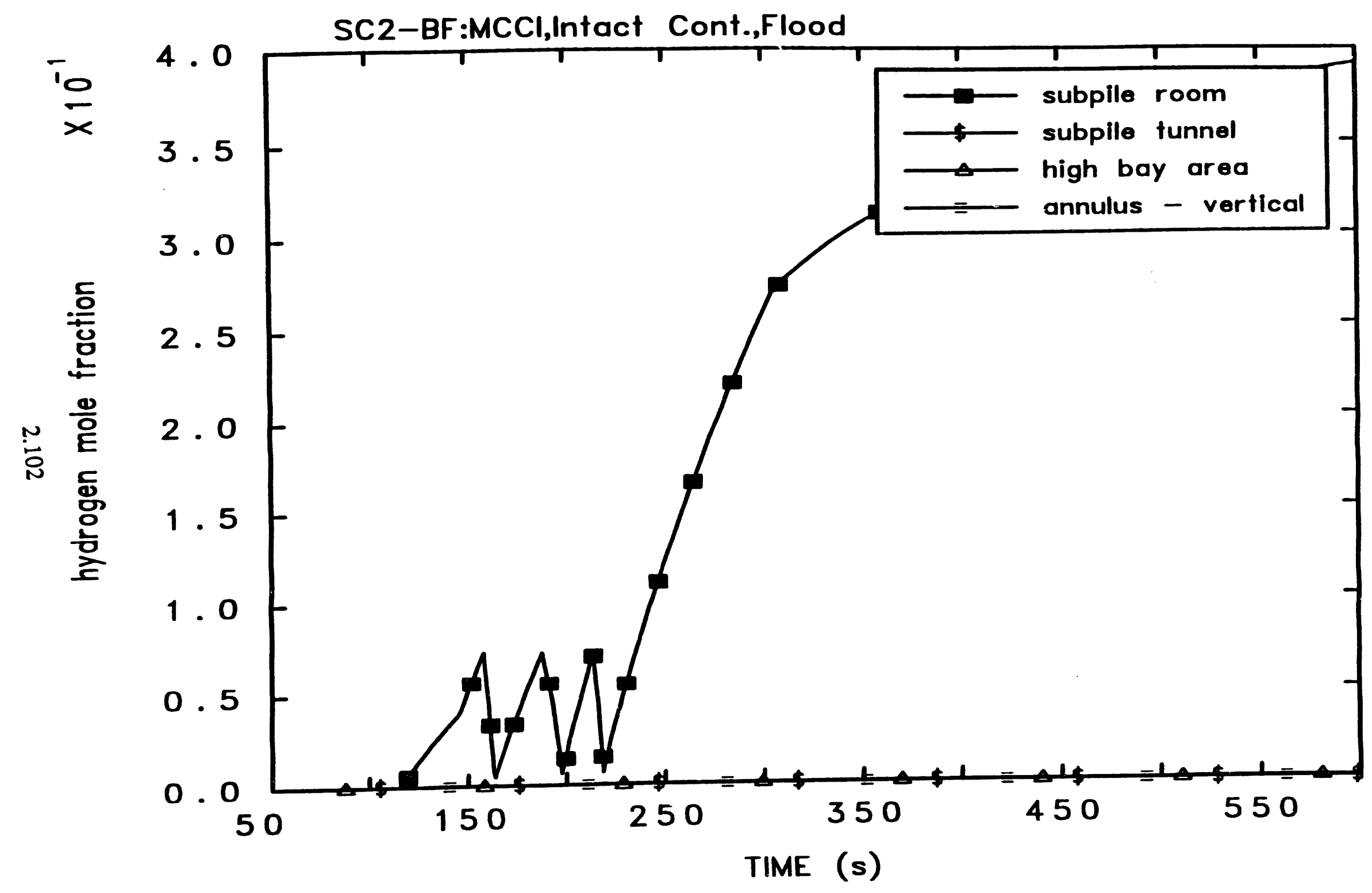

Figure 2.67a Variation of containment volume hydrogen mole fractions vs time (Case SC2-BF) 


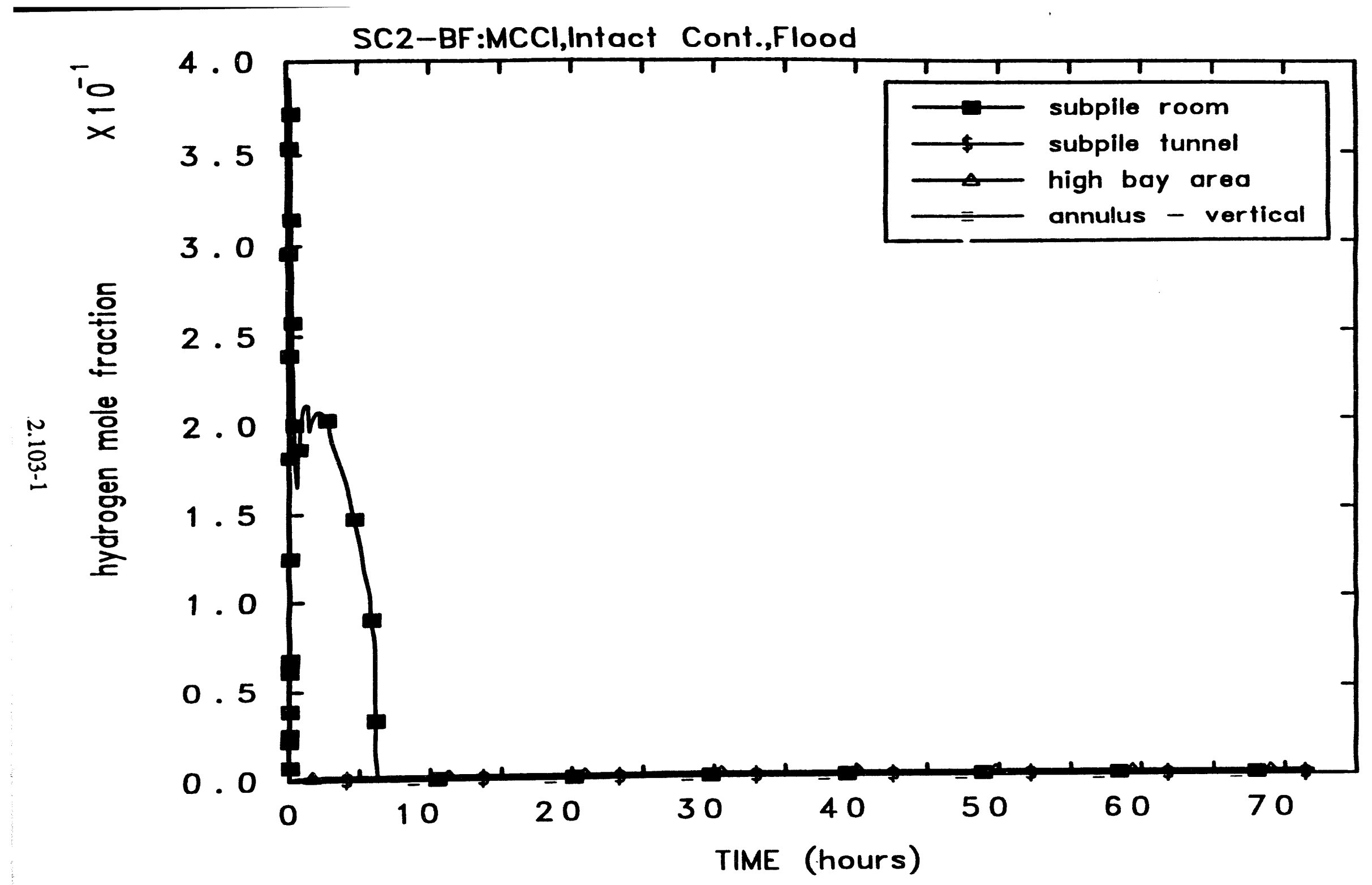

Figure 2.67b-1 Variation of containment volume hydrogen mole fractions vs time (Case - SC2-BF) 


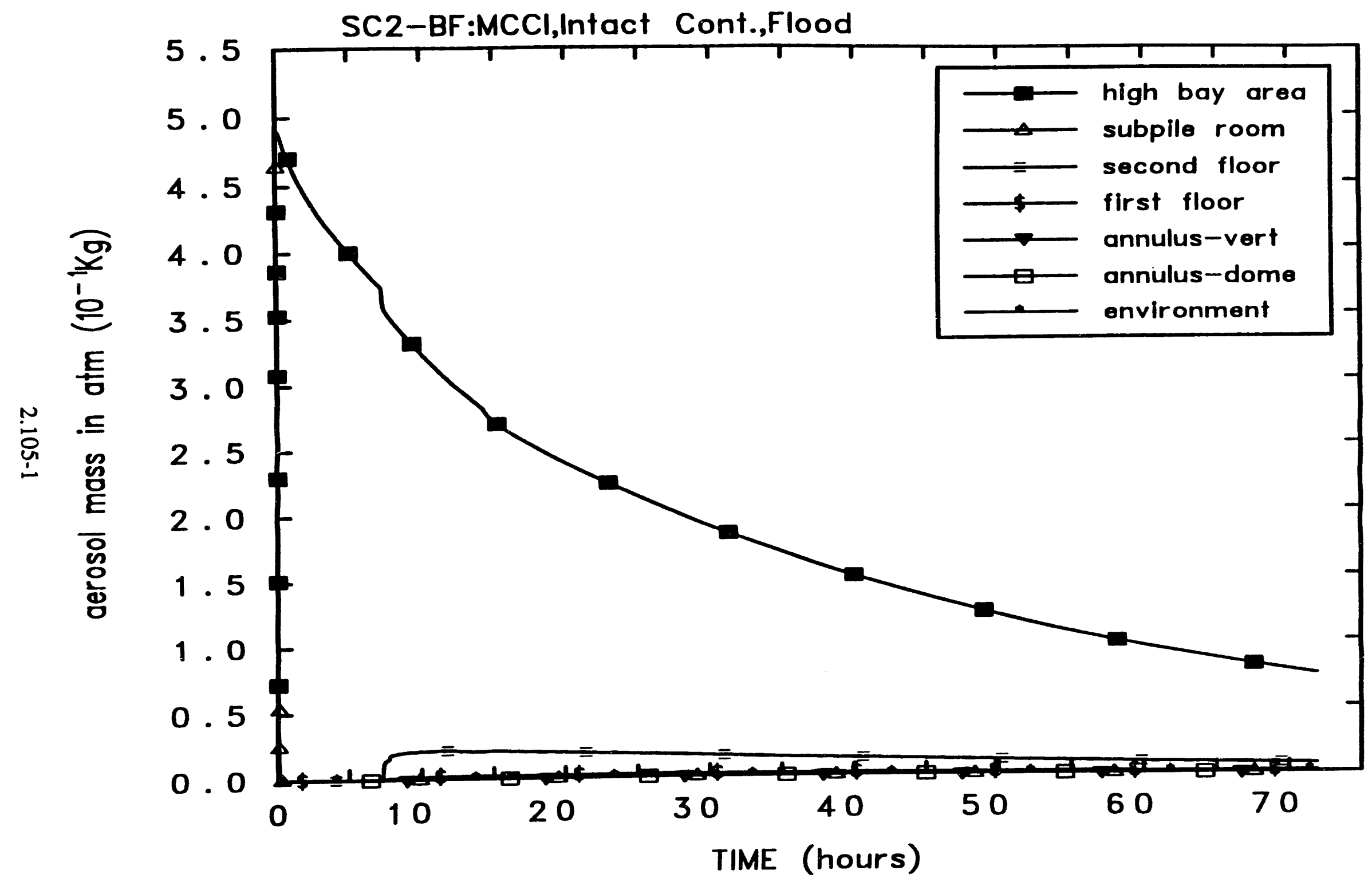

Figure 2.69-1 Variation of containment volume atmosphere aerosol mass vs time (Case - SC2-BF) 


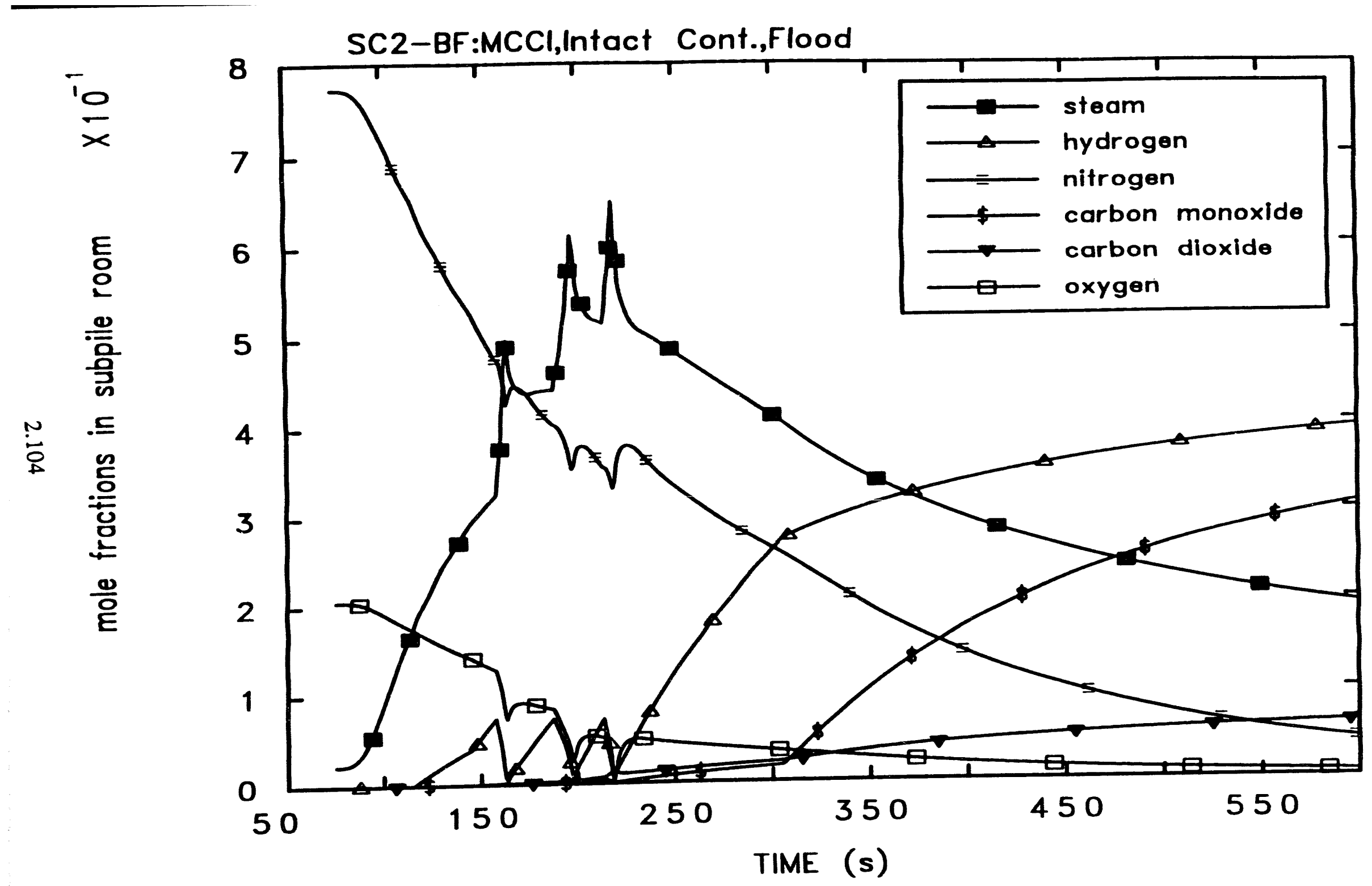

Figure 2.68 Variation of containment volume gas and steam mole fractions vs time ?Cast - SC2-BF) 


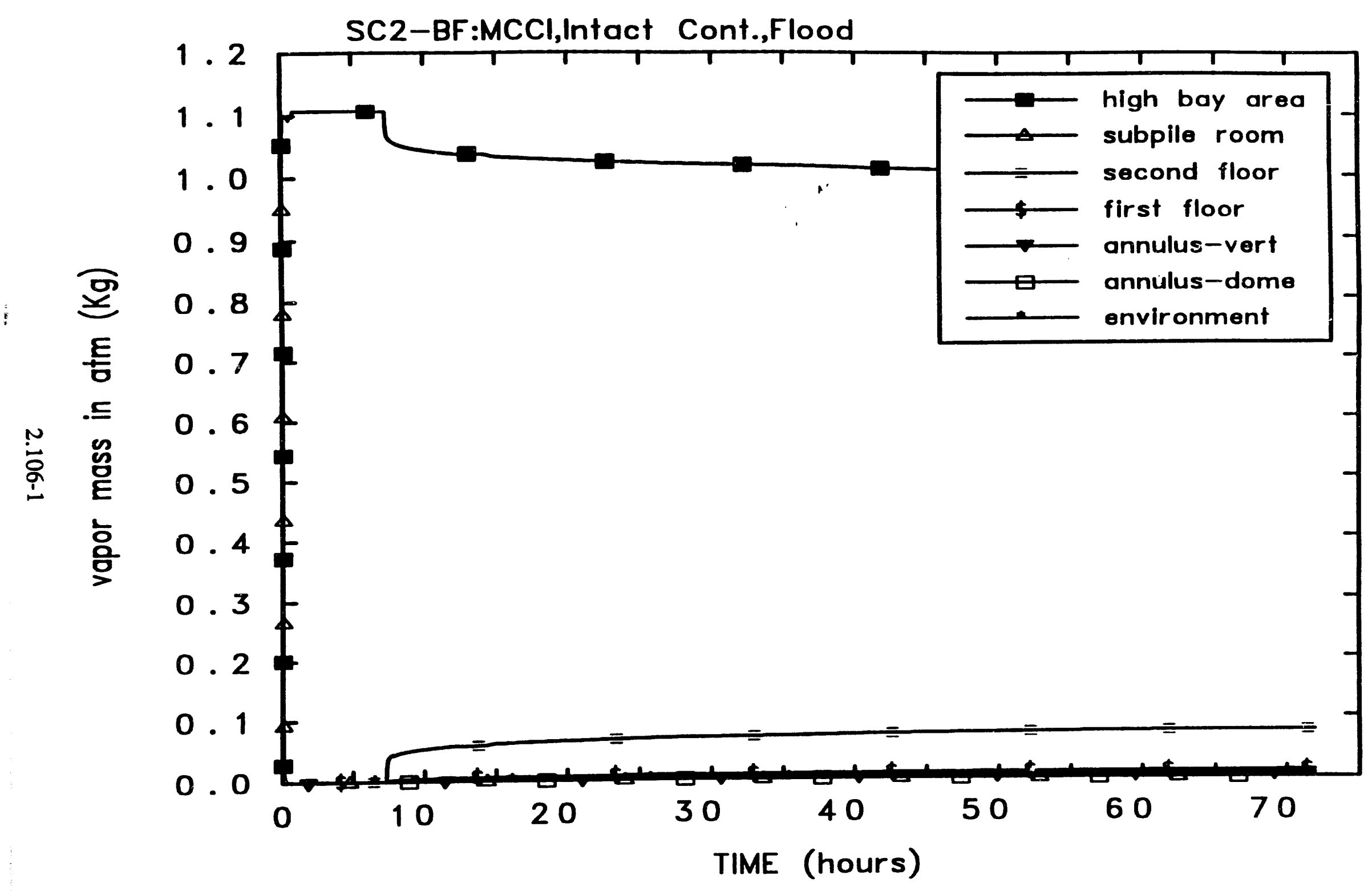

Figure 2.70-1 Variation of containment volume radionuclide vapor masses in atmosphere vs time (Case - SC2-BF) 


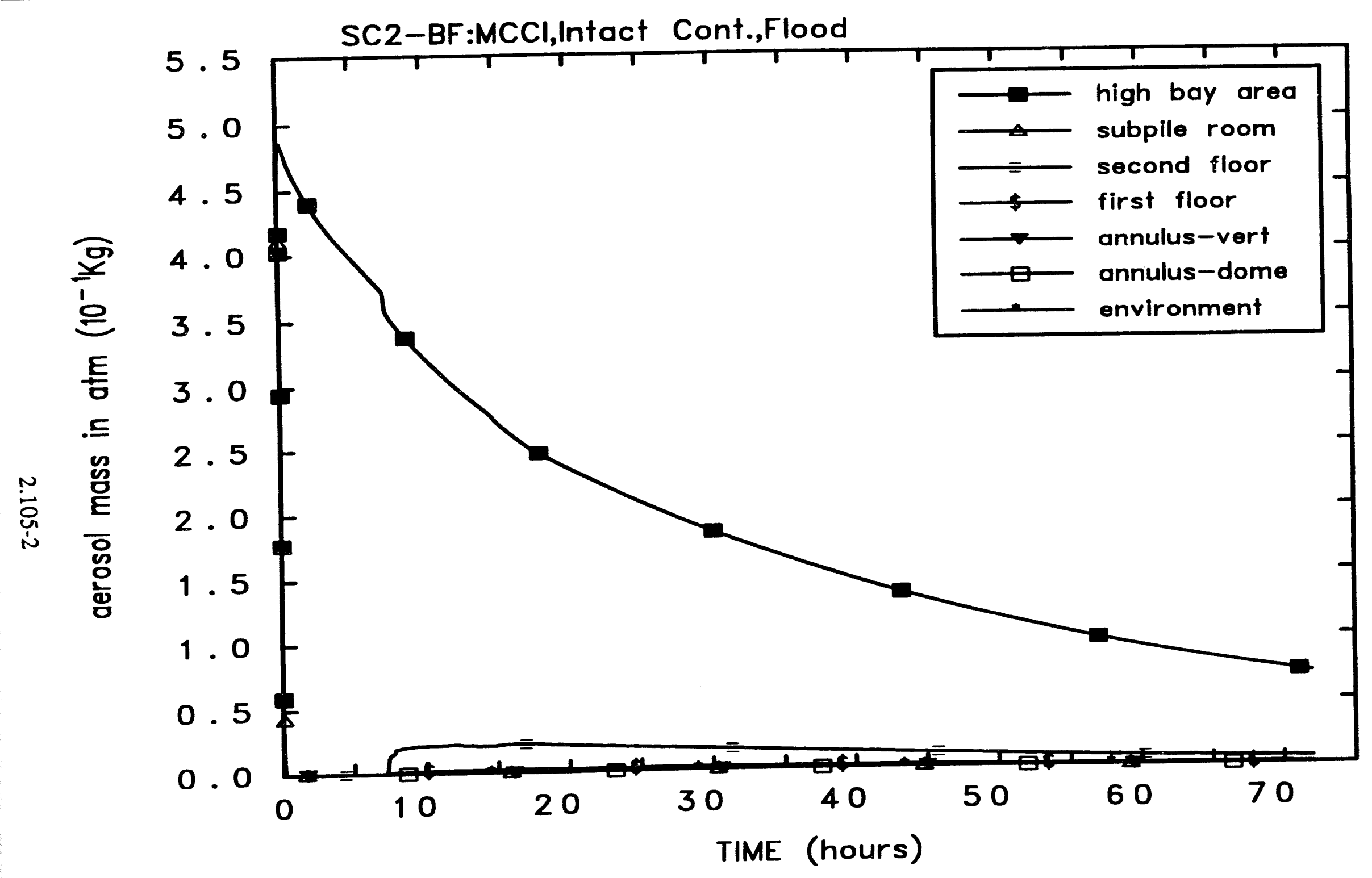

Figure 2.69-2 Variation of containment volume atmosphere aerosol mass vs time predicted by MELCOR Mod 1.8.2 


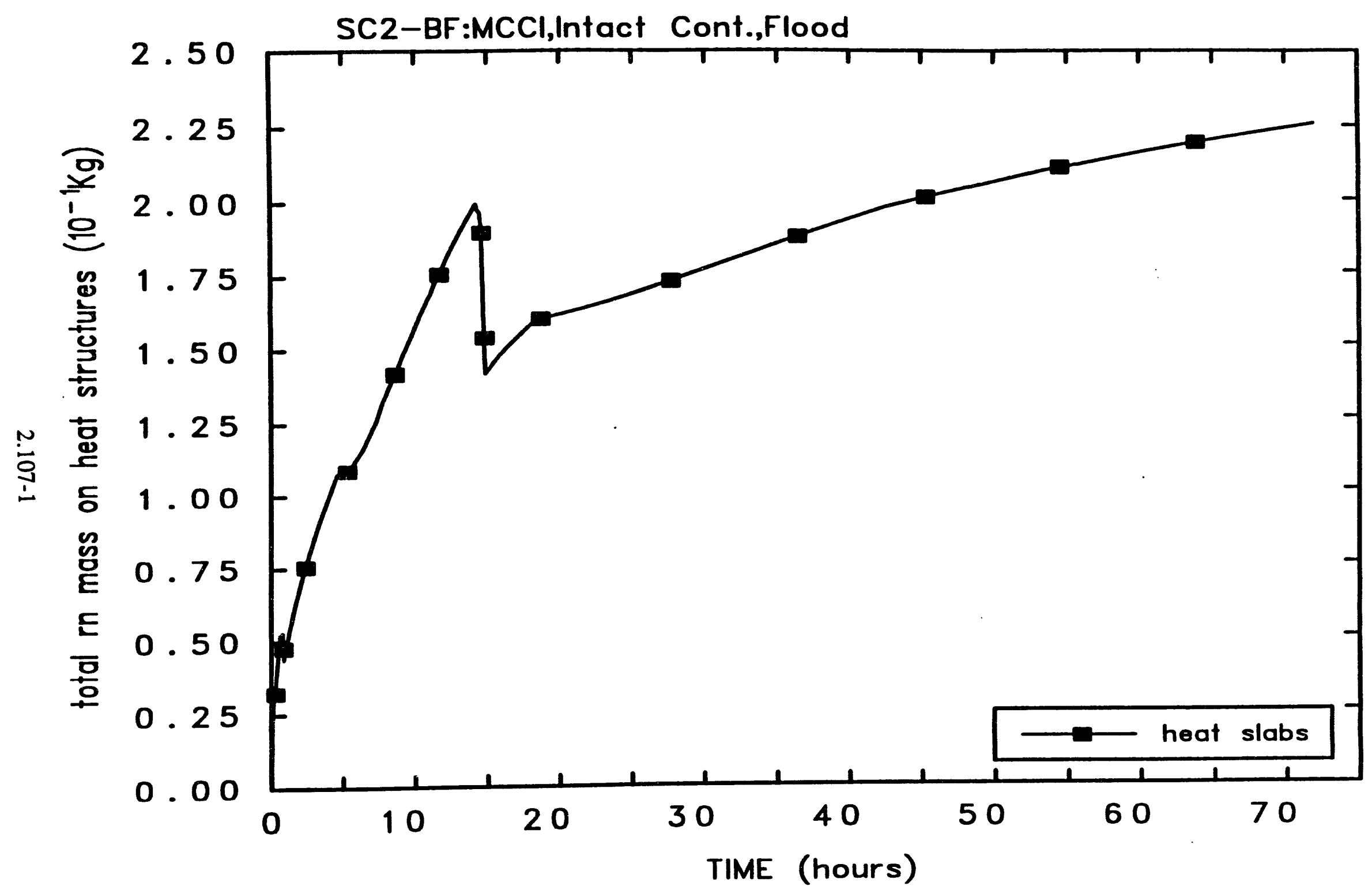

Figure 2.71-1 Variation of total radionuclide masses deposited on heat structures vs time (Case - SC2-BF) 


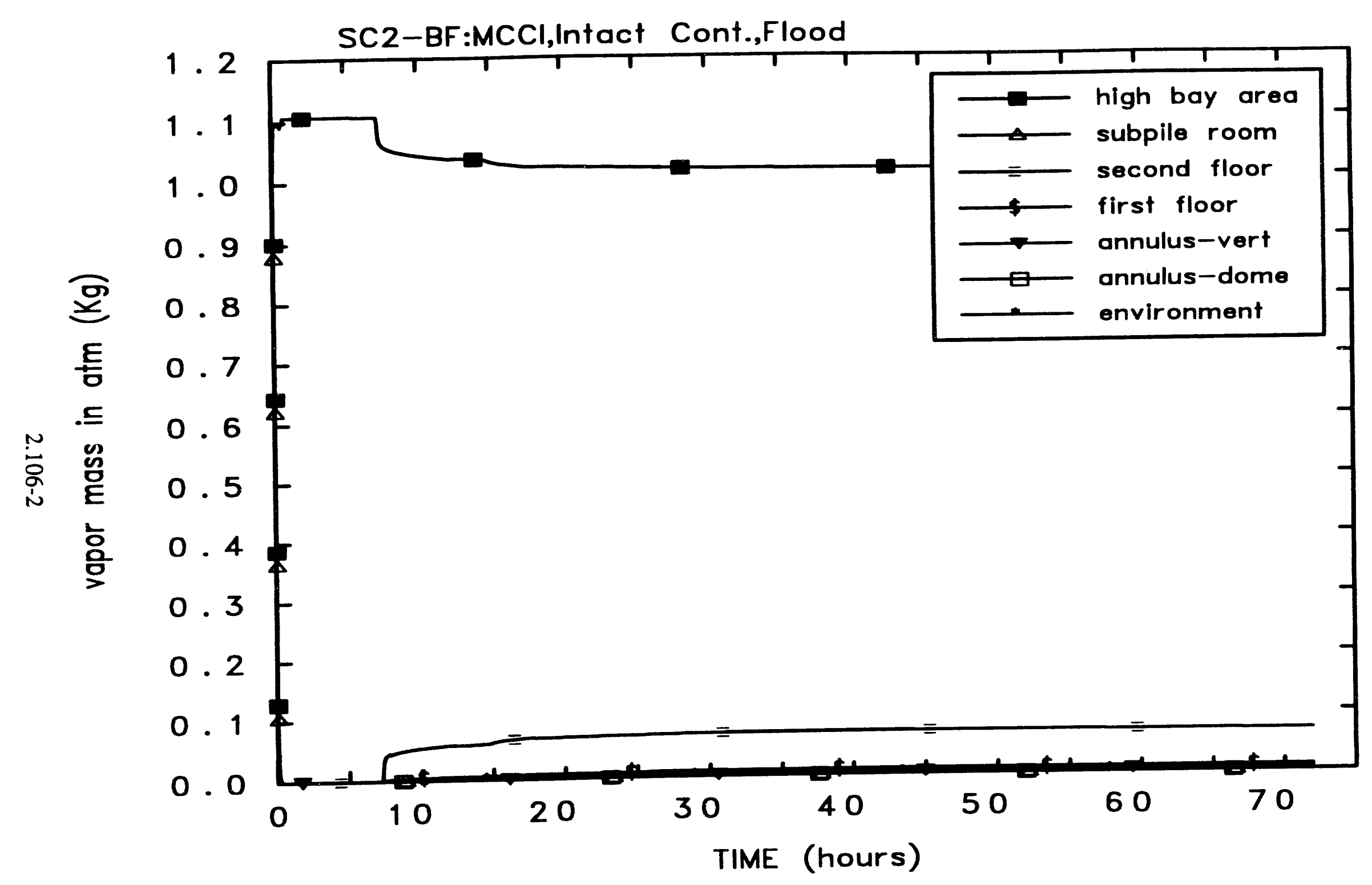

Figure 2.70-2 Variation of containment volume radionuclide vapor masses in atmosphere vs time predicted by MELCOR Mod 1.8.2 


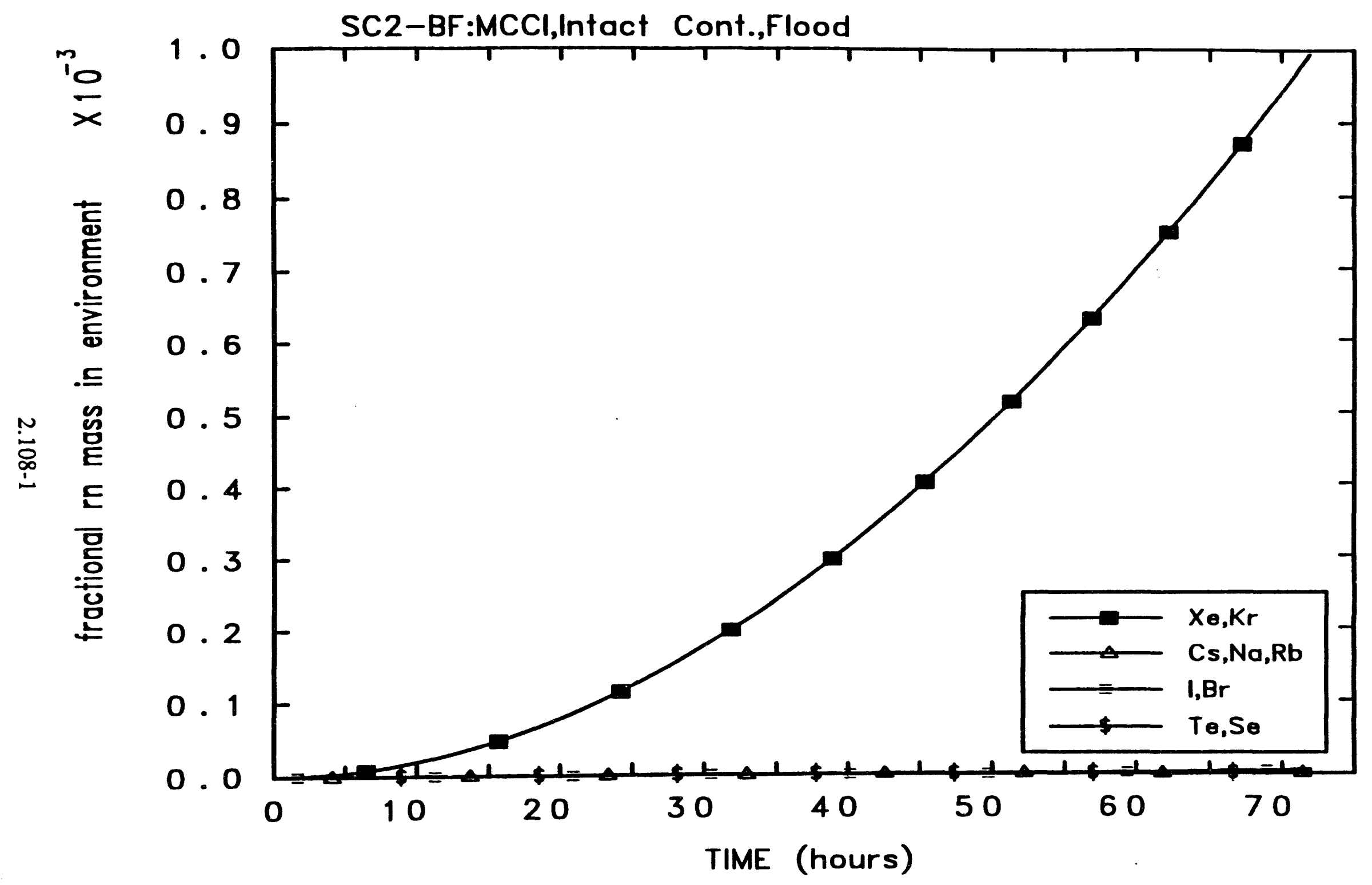

Figure 2.72-1 Variation of fractional radionuclide masses entering environment vs time (Case - SC2-BF) 


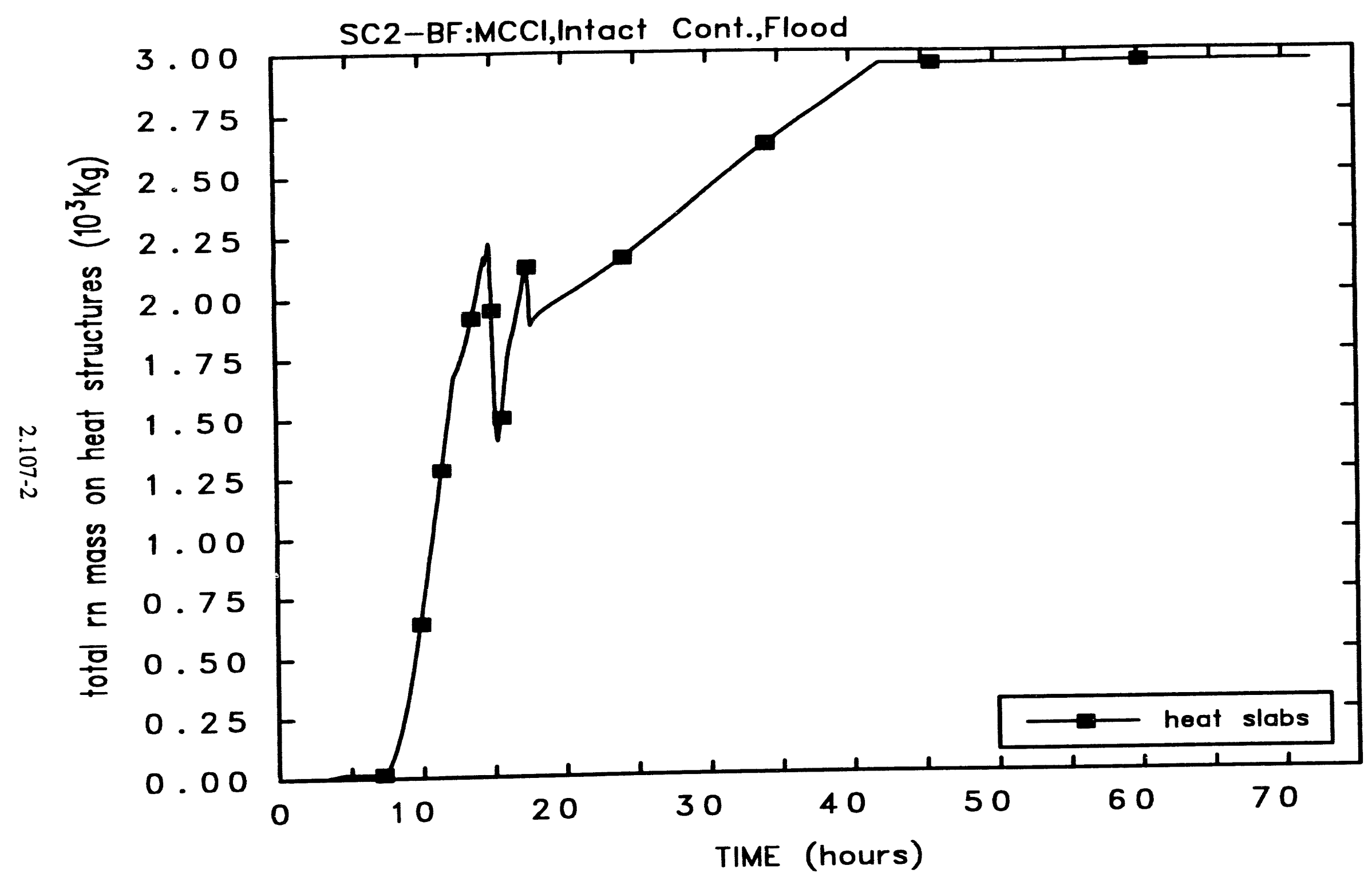

Figure 2.71-2 Variation of total radionuclide masses deposited on heat structures vs time predicted by MELCOR Mod 1.8.2 


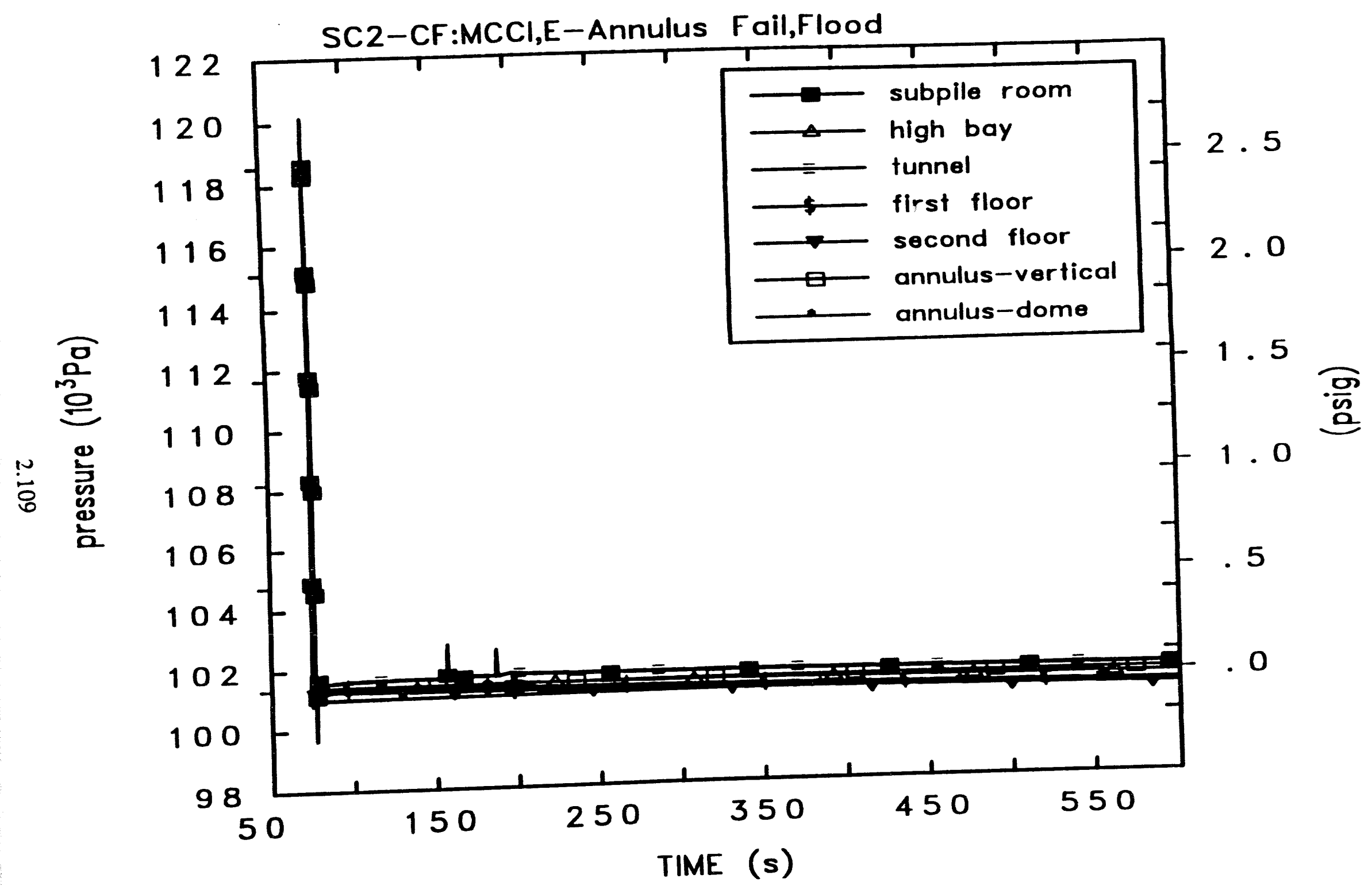

Figure 2.73a Variation of containment volume pressures vs time (Case - SC2-CF) 


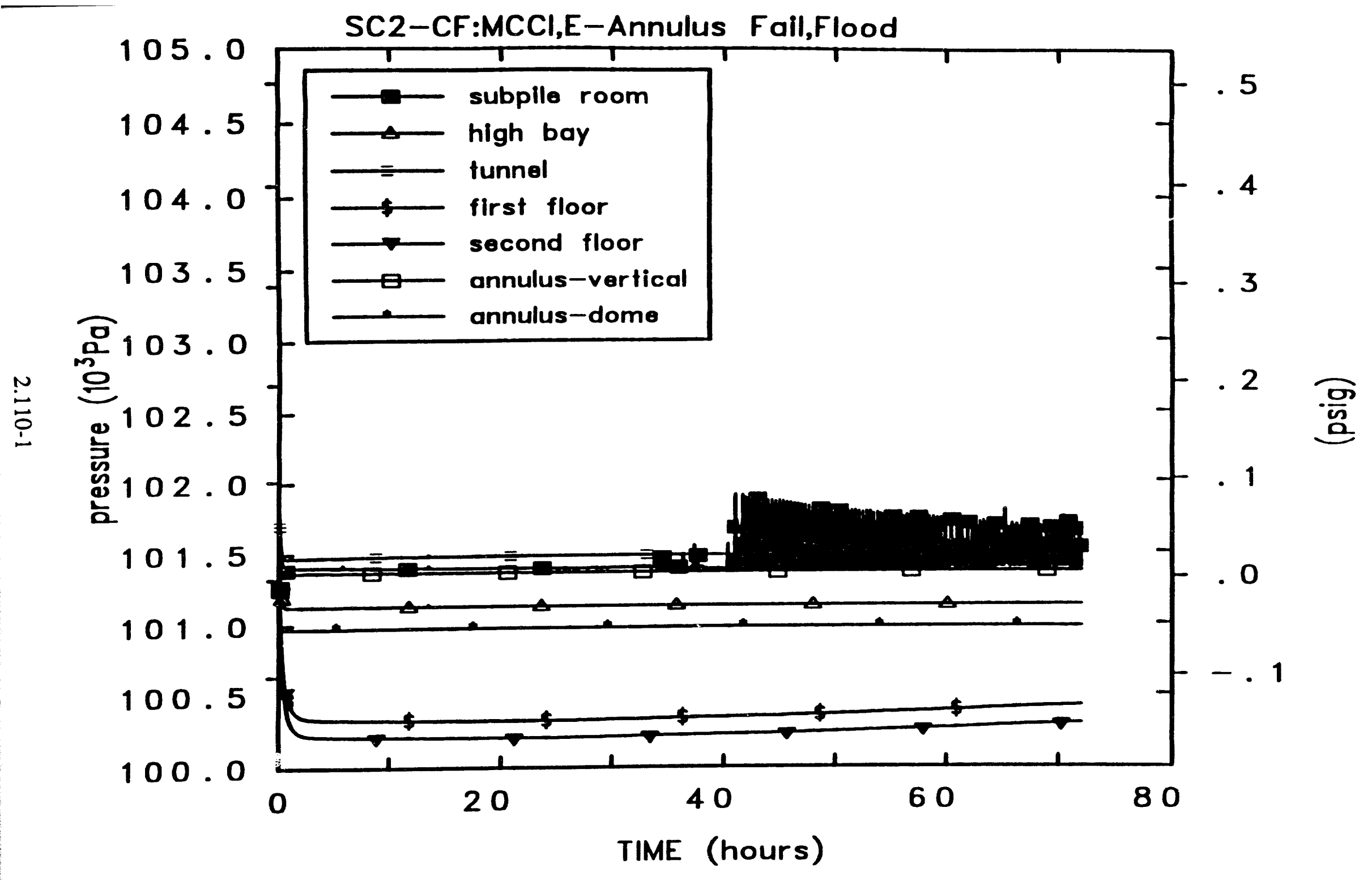

Figure $2.73 \mathrm{~b}-1$ Variation of containment volume pressures vs time (Case - SC2-CF) 


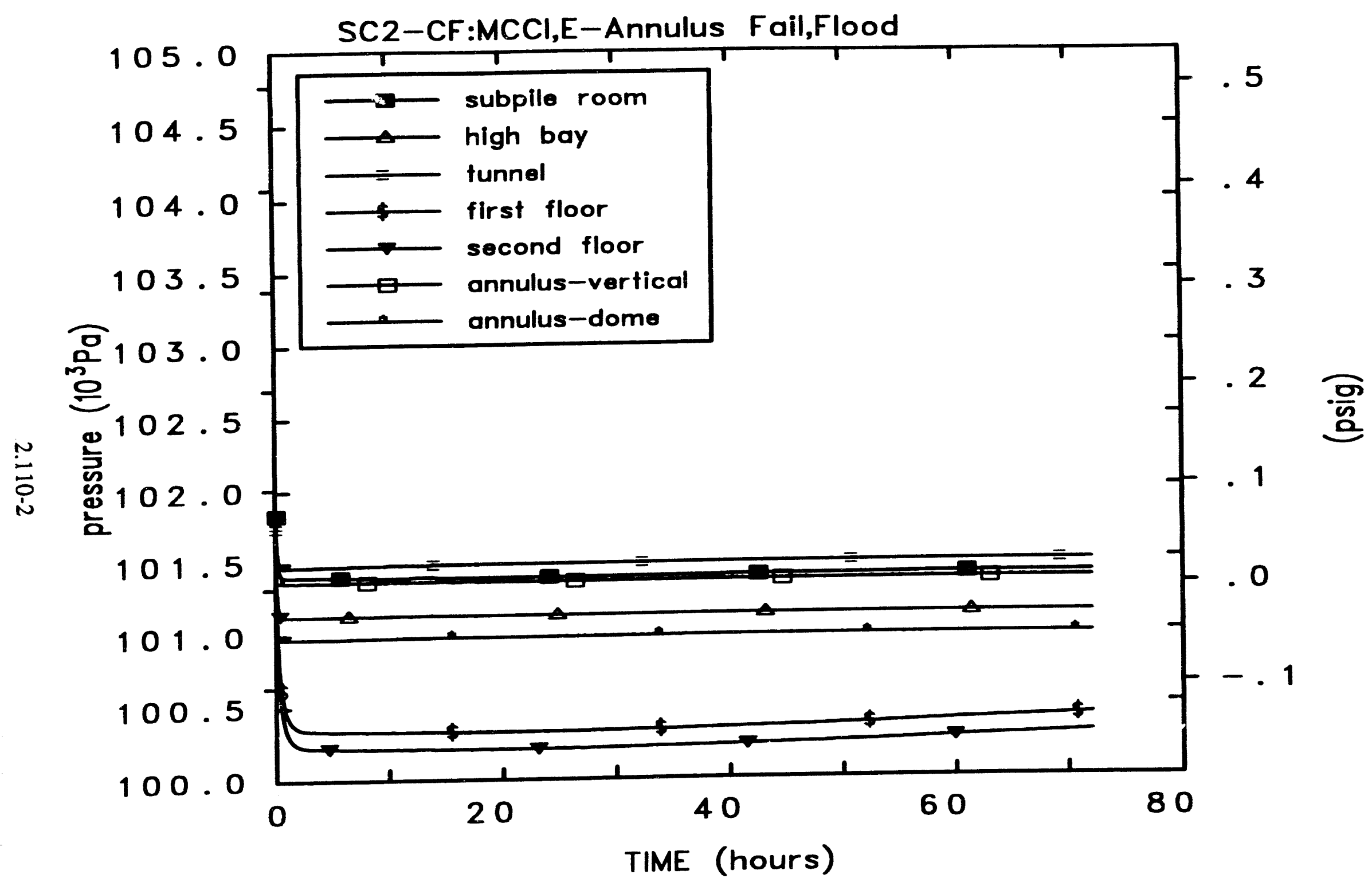

Figure $2.73 b-2$ Variation of containment volume pressures vs time predicted by MELCOR Mod 1.8.2 


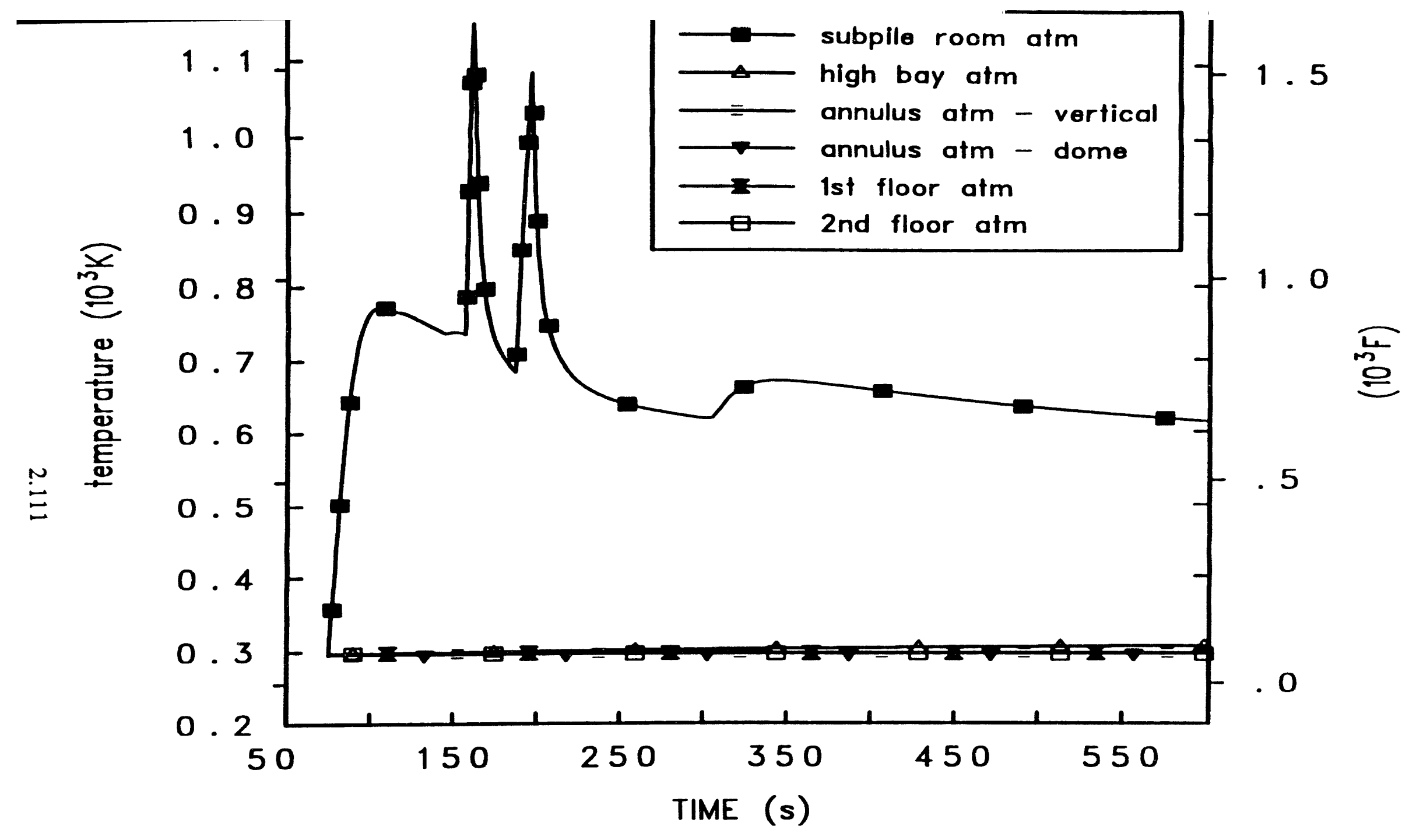

Figure 2.74a Variation of containment volume temperatures vs time (Case - SC2-CF) 


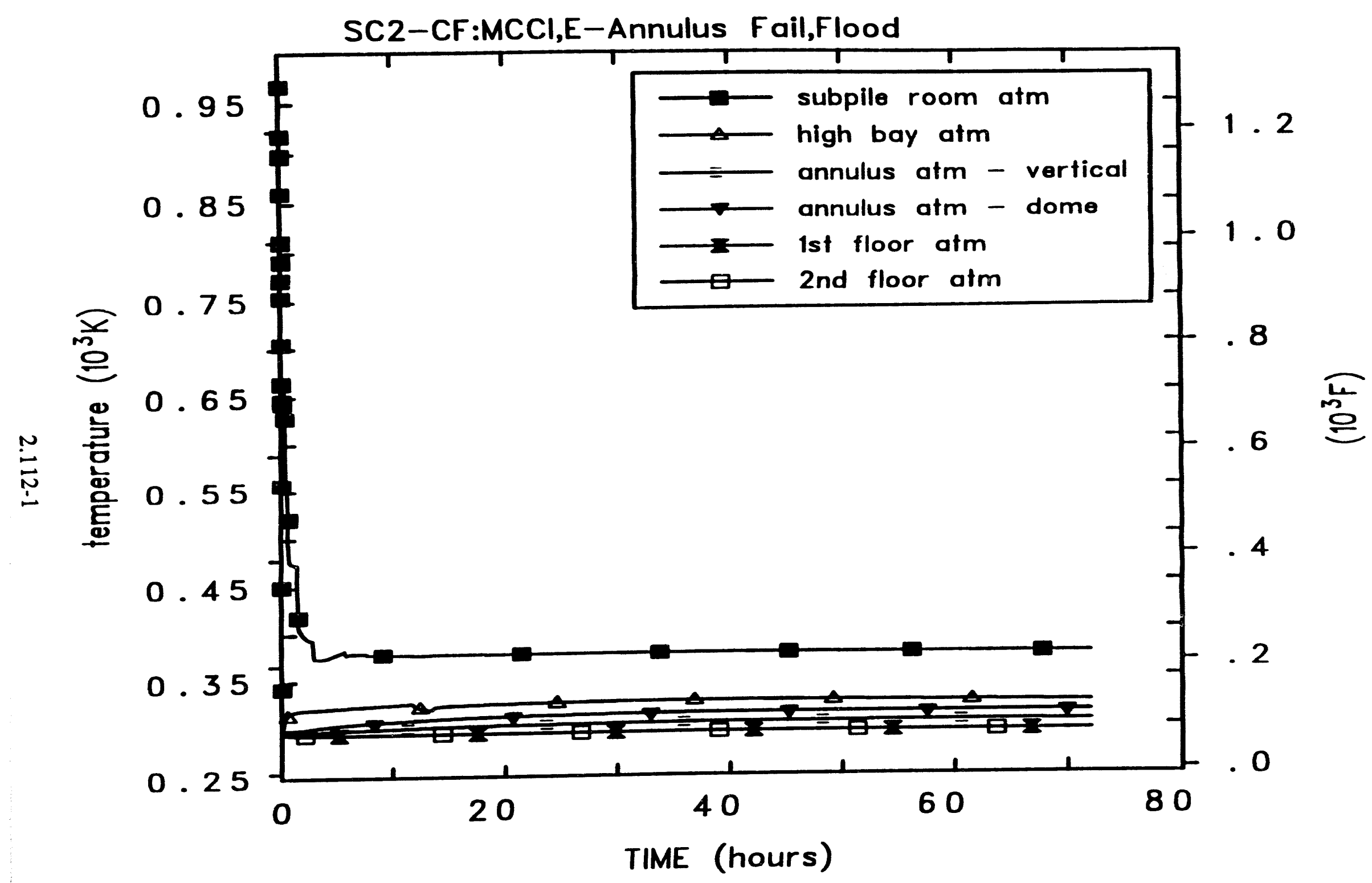

Figure 2.74b-1 Variation of containment volume temperatures vs time

(Case - SC2-CF) 


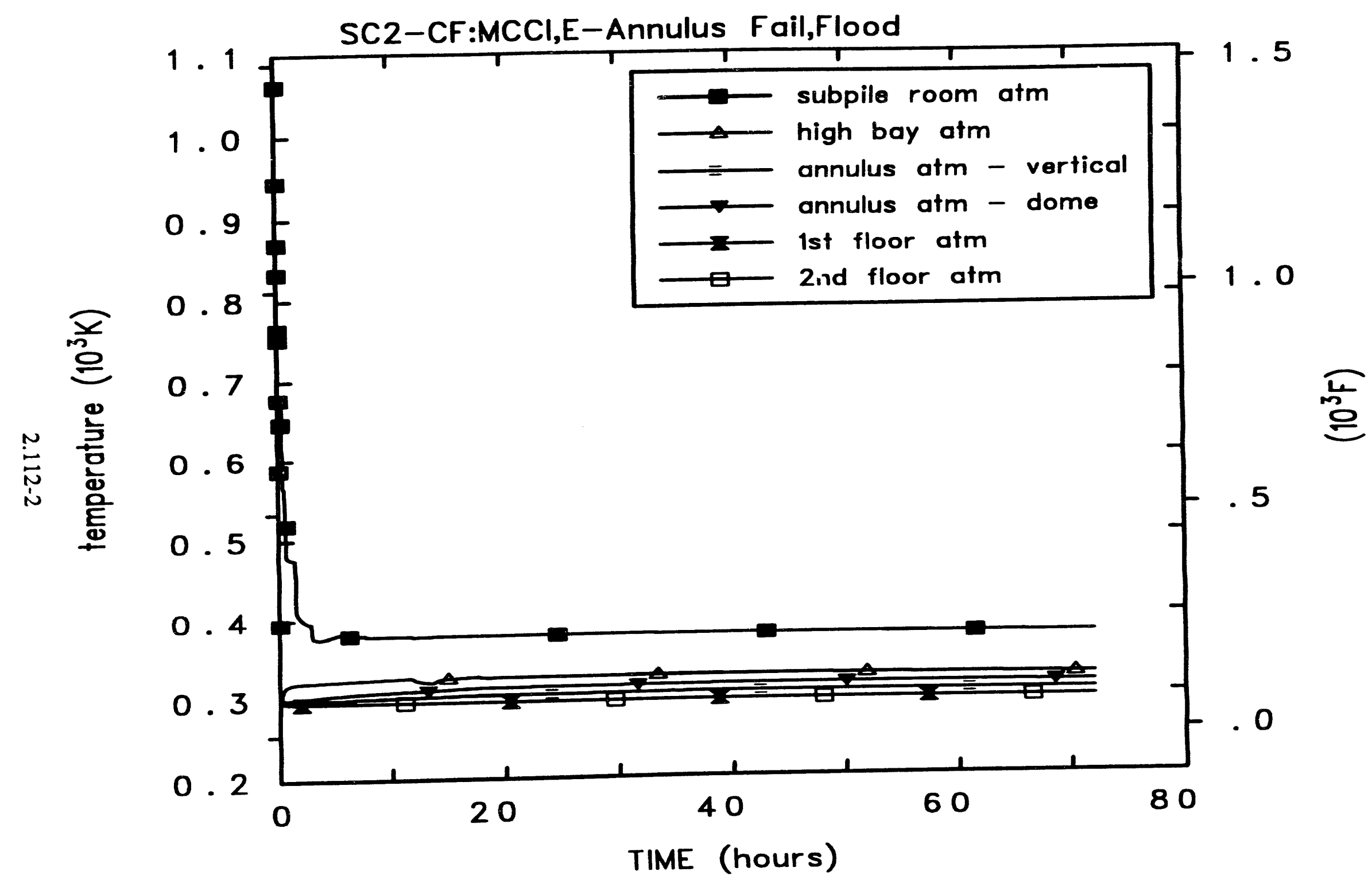

Figure $2.74 \mathrm{~b}-2$ Variation of containment volume temperatures vs time predicted by MELCOR Mod 1.8.2 


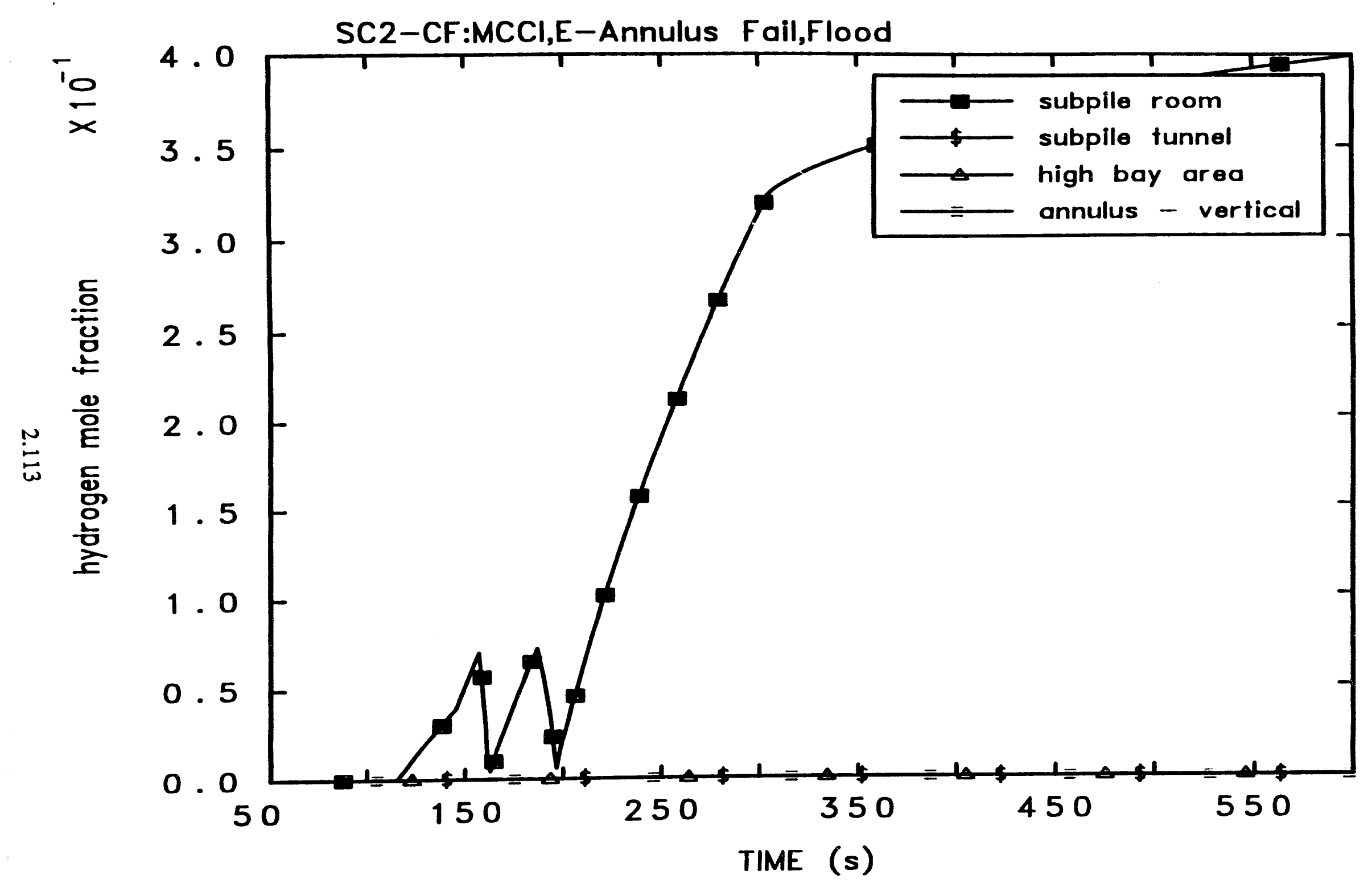

Figure $2.75 \mathrm{a}$ Variation of containment volume hydrogen mole fractions vs time (Case SC2-CF) 


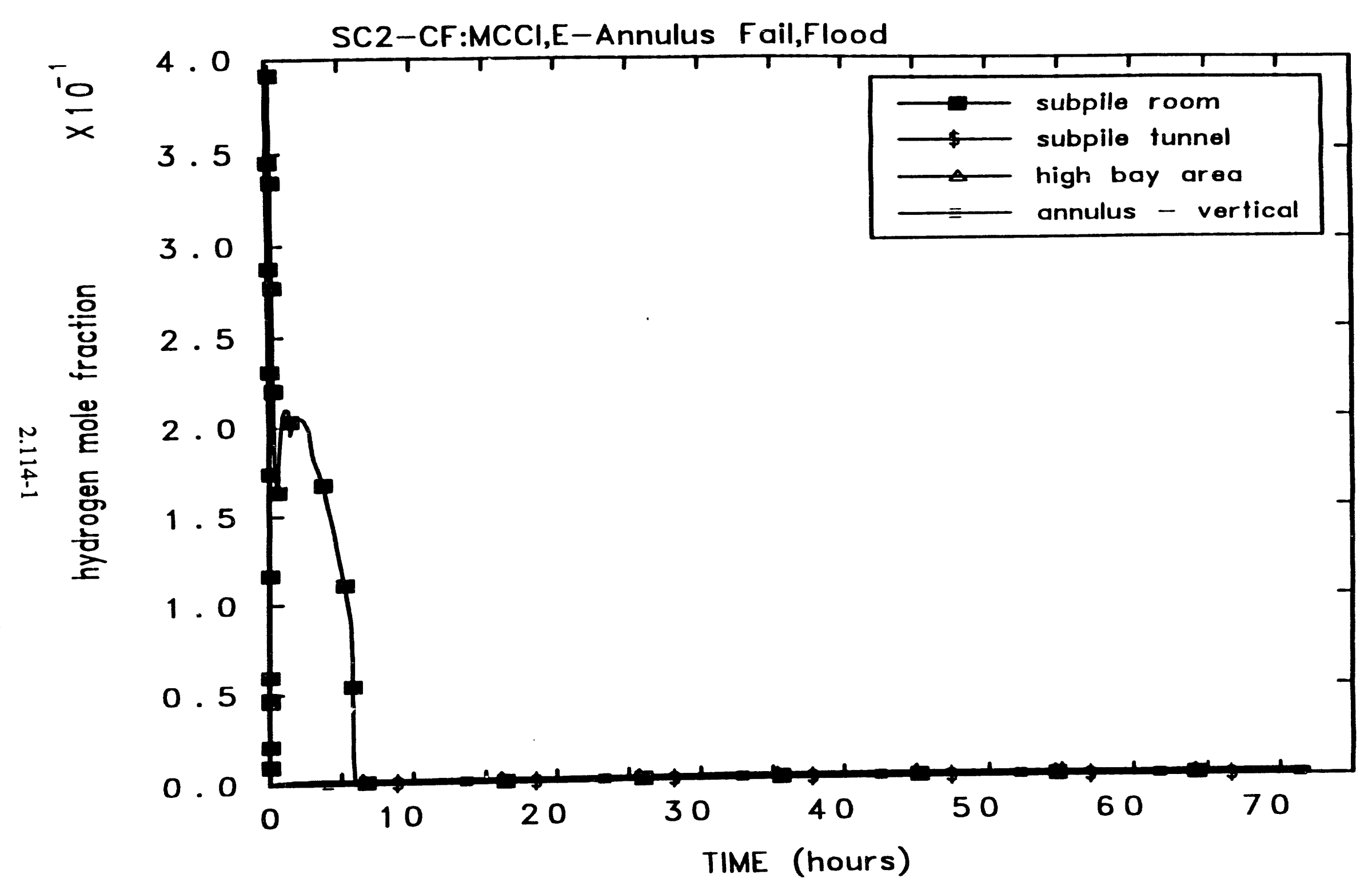

Figure $2.75 \mathrm{~b}-1$ Variation of containment volume hydrogen mole fractions vs time (Case - SC2-CF) 


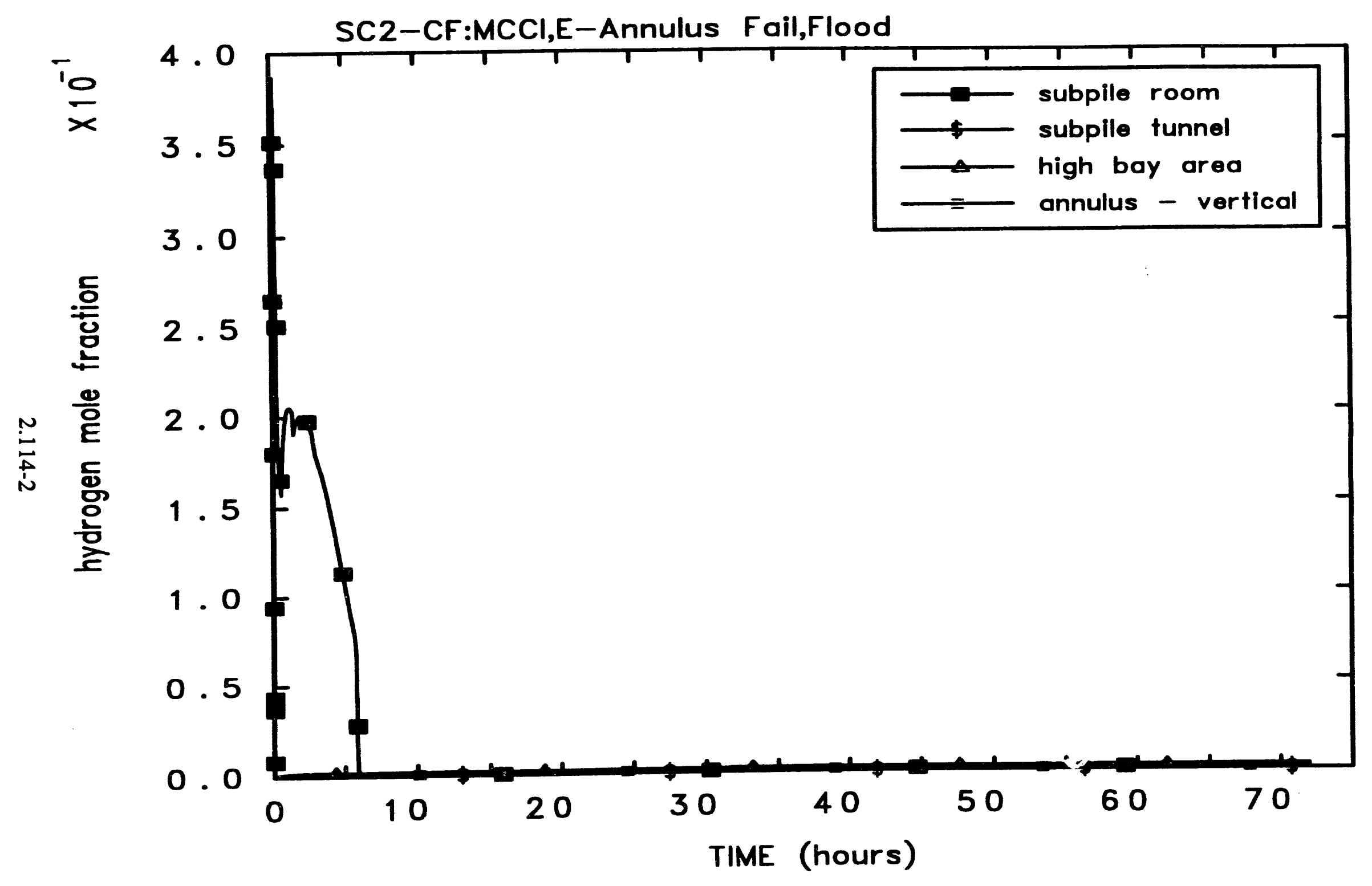

Figure $2.75 b-2$ Variation of containment volume hydrogen mole fractions vs time predicted by MELCOR Mod 1.8.2 


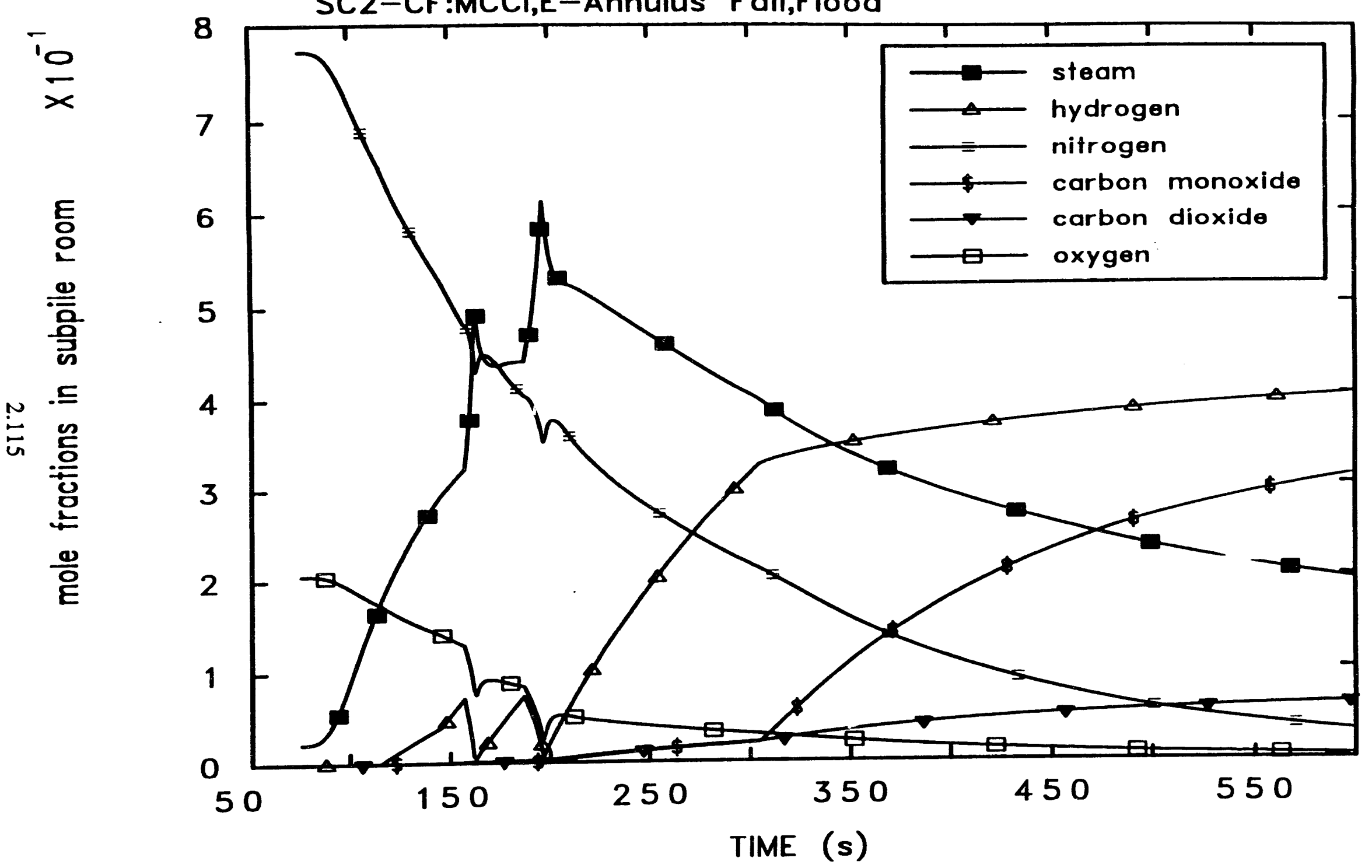

Figure 2.76 Variation of containment volume gas and steam mole fractions vs time (Case - SC2-CF) 


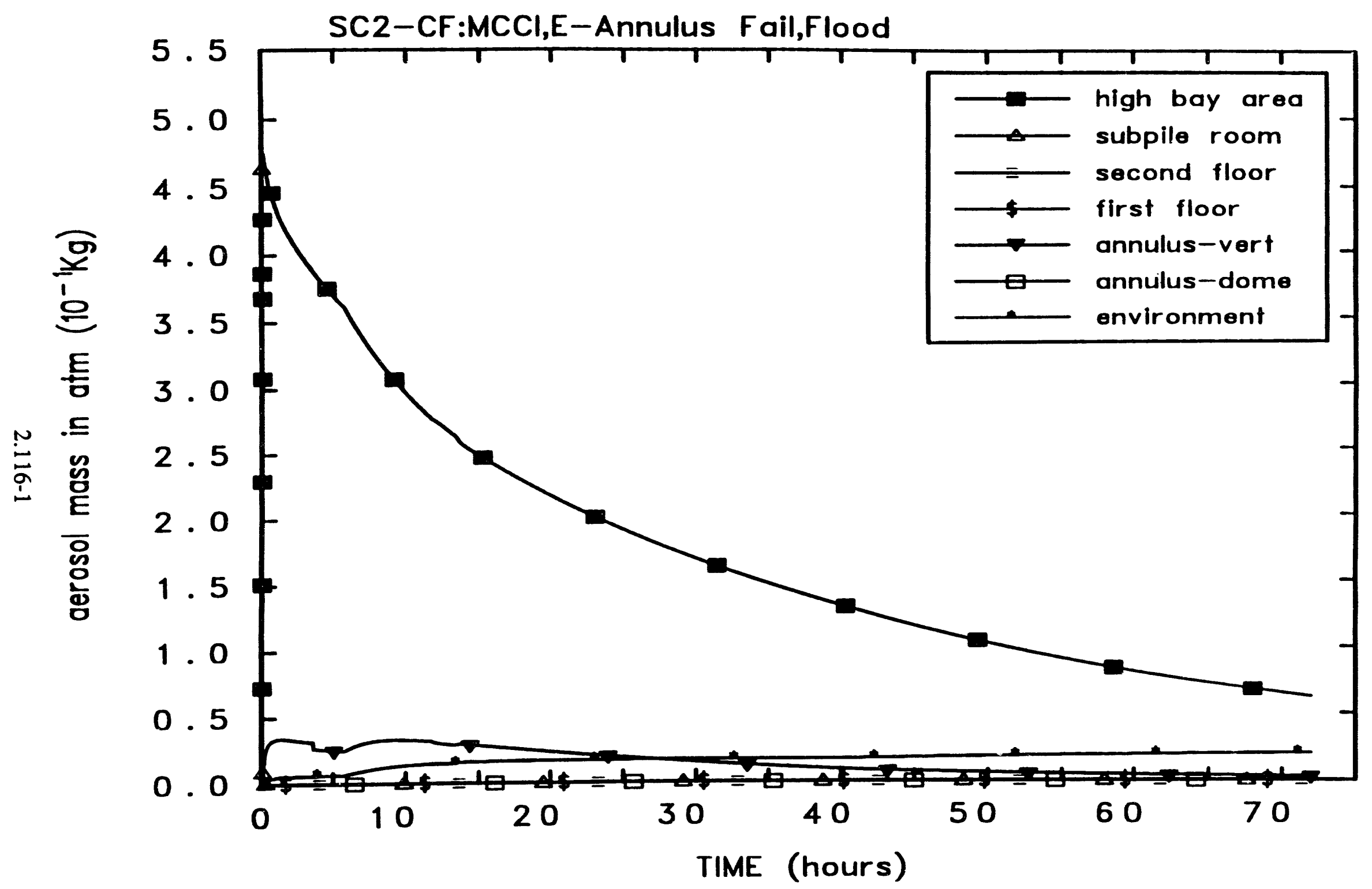

Figure 2.77-1 Variation of containment volume atmosphere aerosol mass vs time (Case - SC2-CF) 


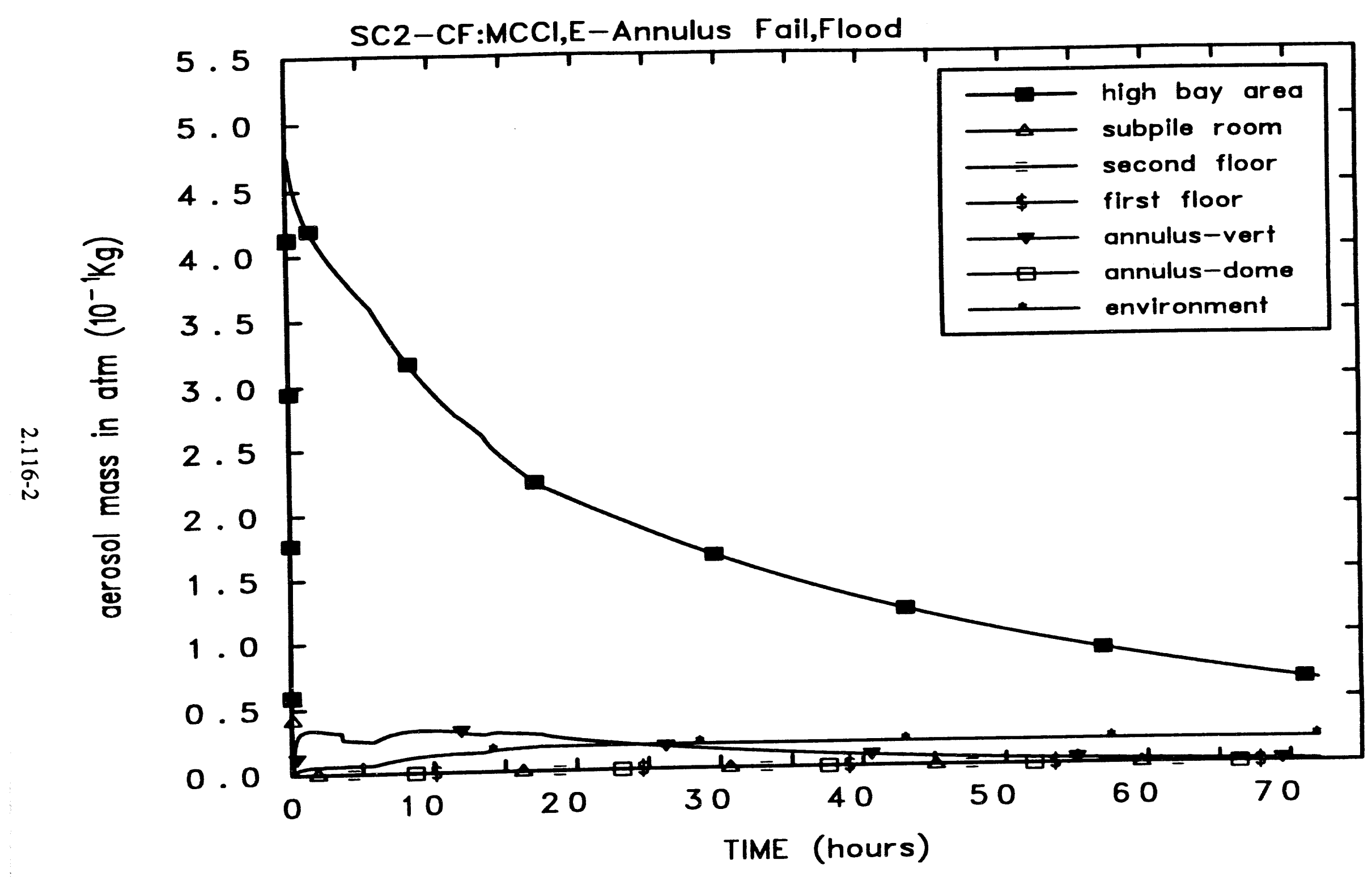

Figure 2.77-2 Variation of containment volume atmosphere aerosol mass vs time predicted by MELCOR Mod 1.8.2 


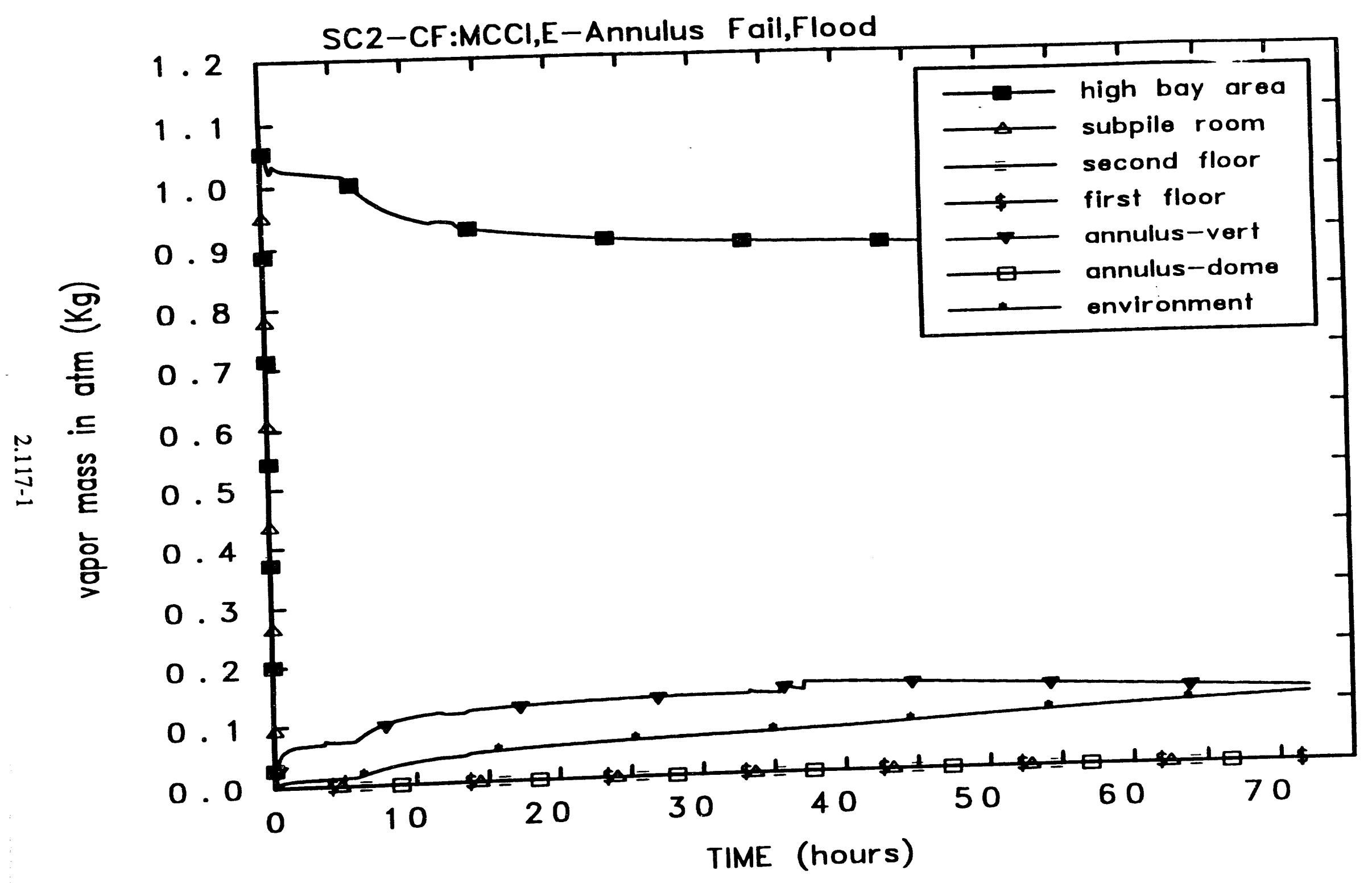

Figure 2.78-1 Variation of containment volume radionuclide vapor masses in atmosphere vs time (Case - SC2-CF) 


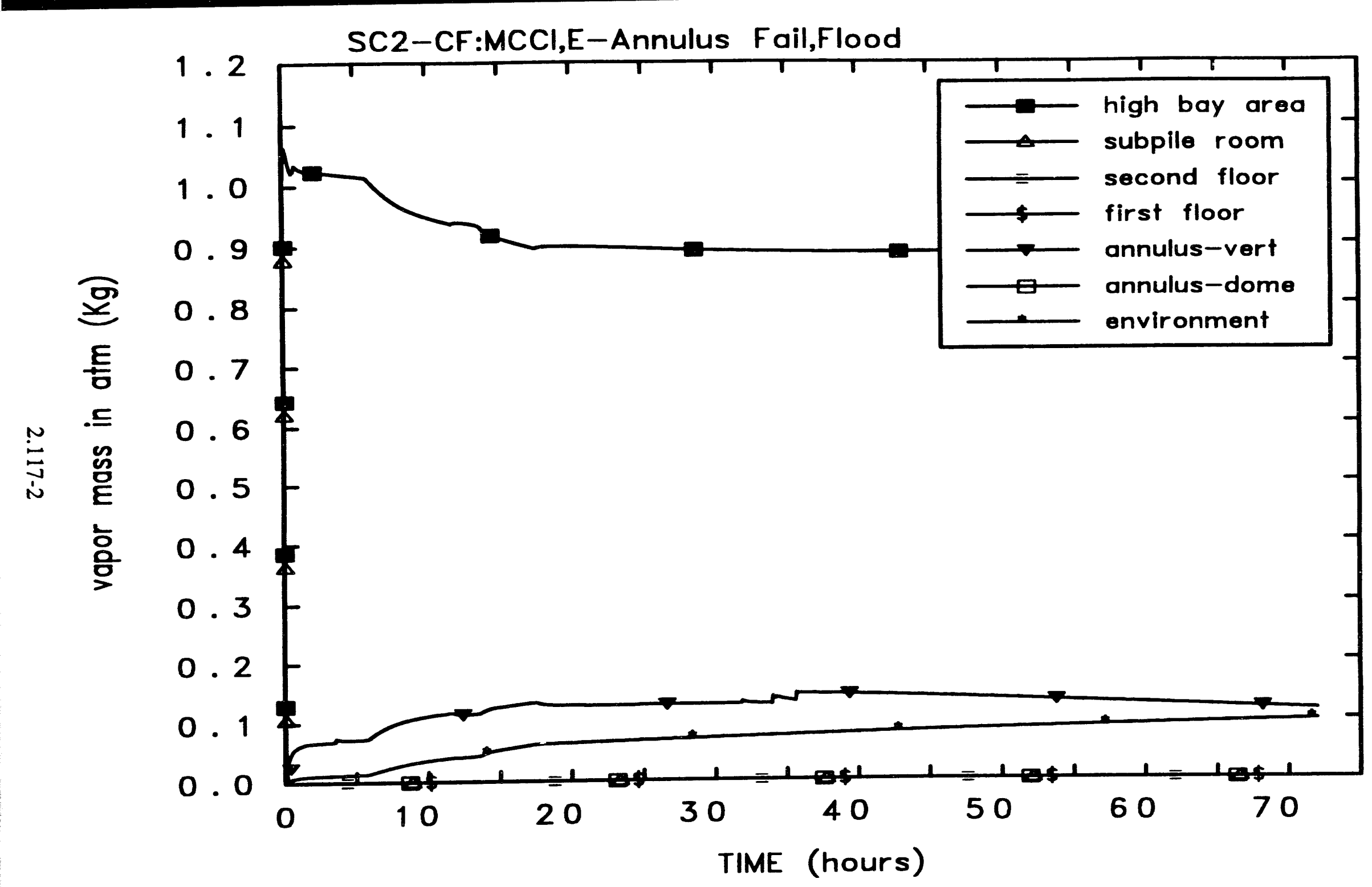

Figure 2.78-2 Variation of containment volume radionuclide vapor masses in atmosphere vs time predicted by MELCOR Mod 1.8.2 


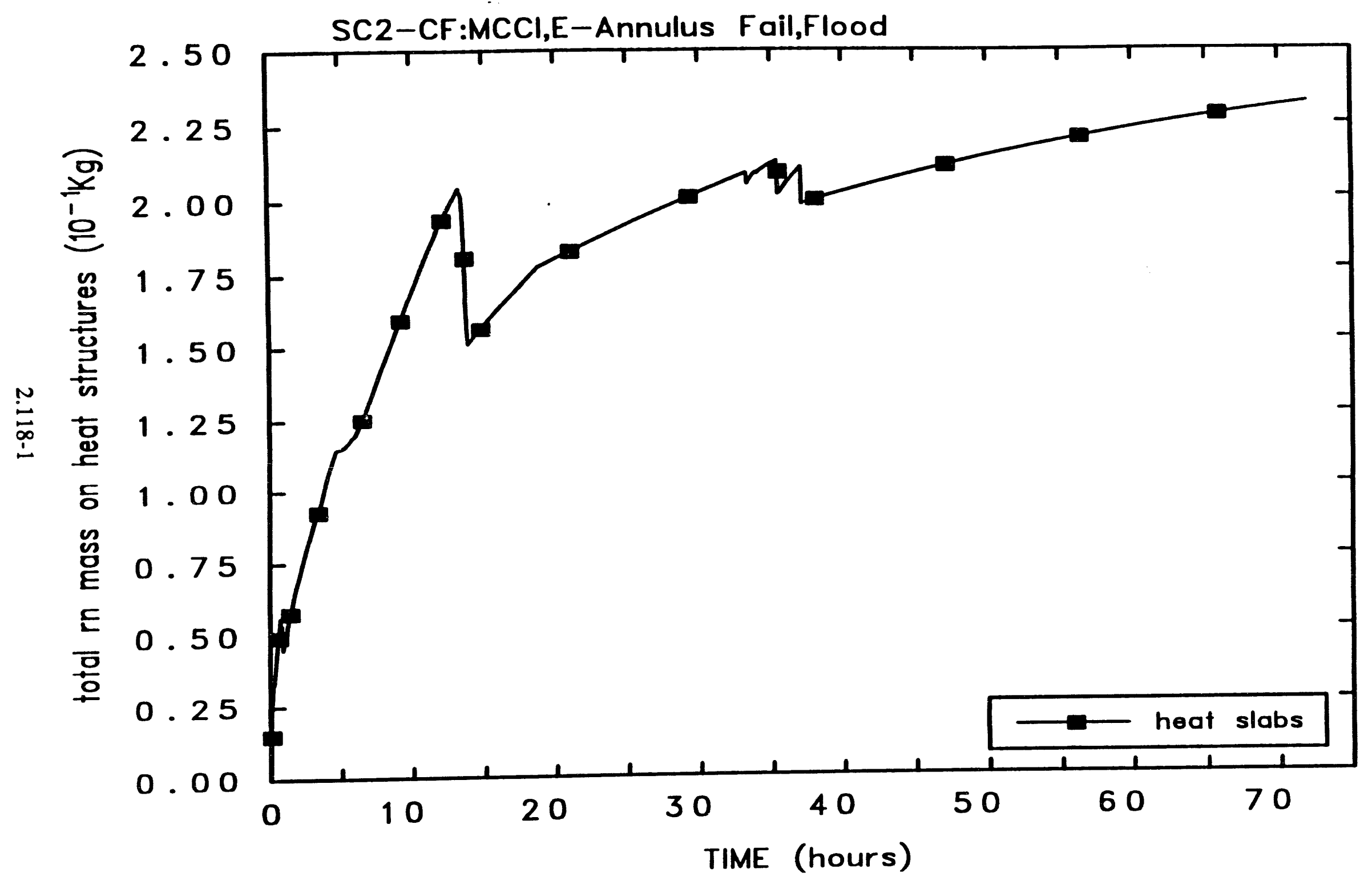

Figure 2.79-1 Variation of total radionuclide masses deposited on heat structures vs time (Case - SC2-CF) 


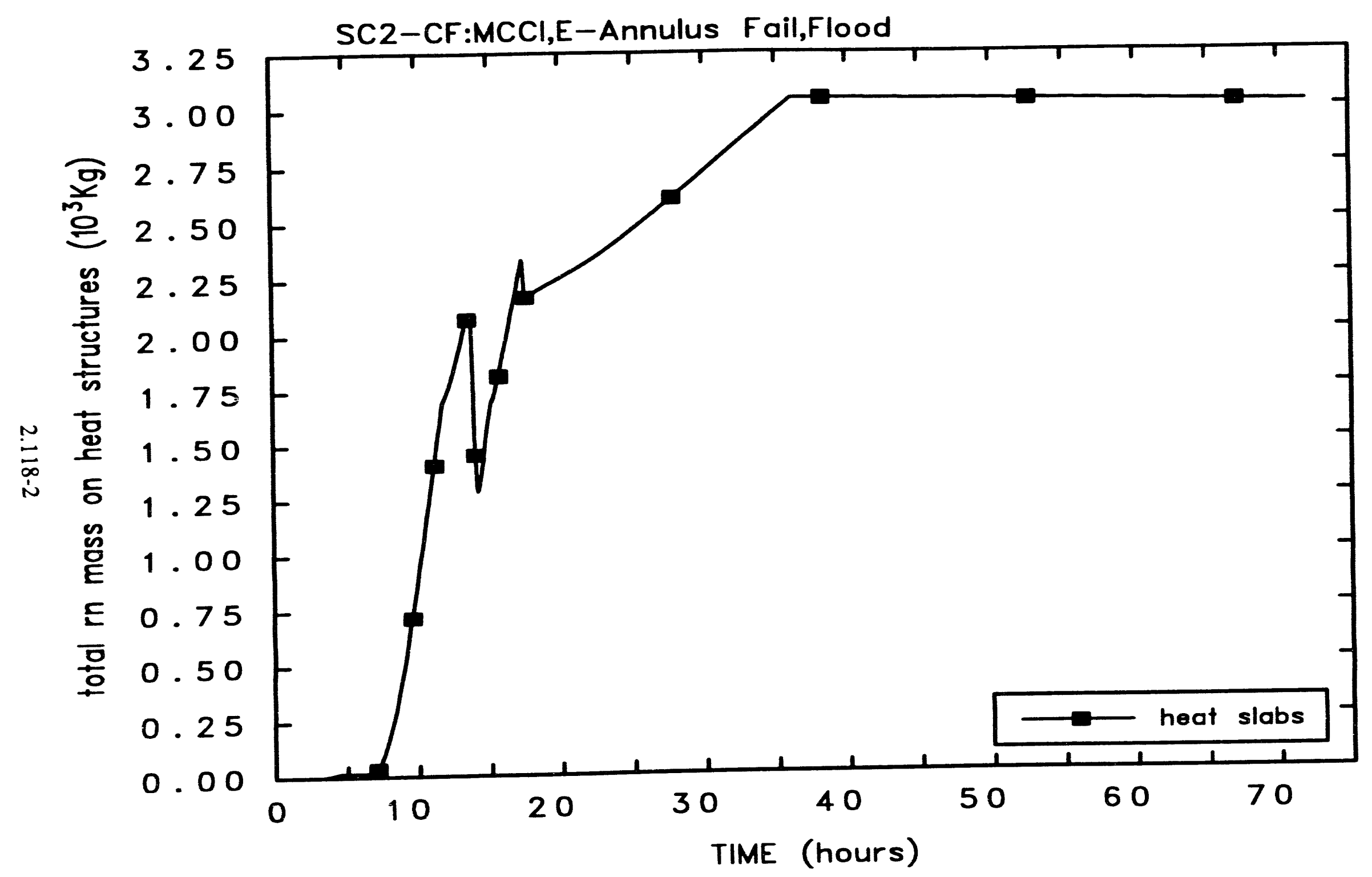

Figure 2.79-2 Variation of total radionuclide masses deposited on heat structures vs time predicted by MELCOR Mod 1.8.2 


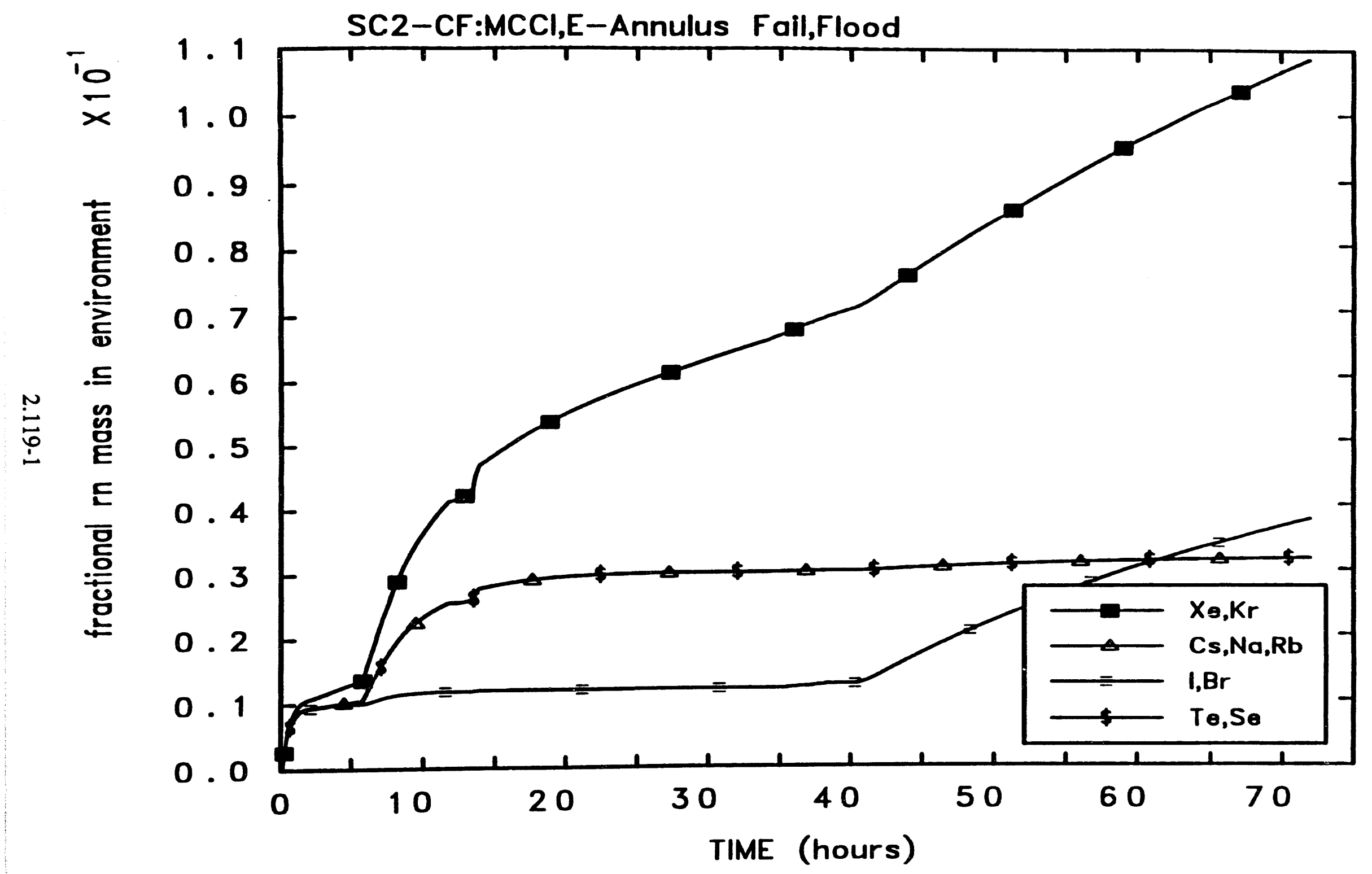

Figure 2.80-1 Variation of fractional radionuclide masses entering environment vs time (Case - SC2-CF) 
$\tau \cdot 8 \cdot 1$ pow yoJ7aw Kq paro!pasd

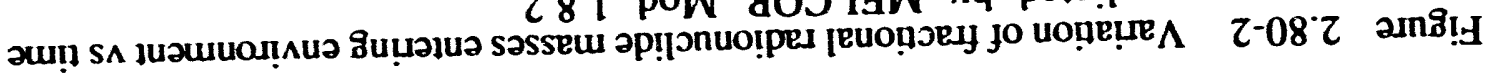

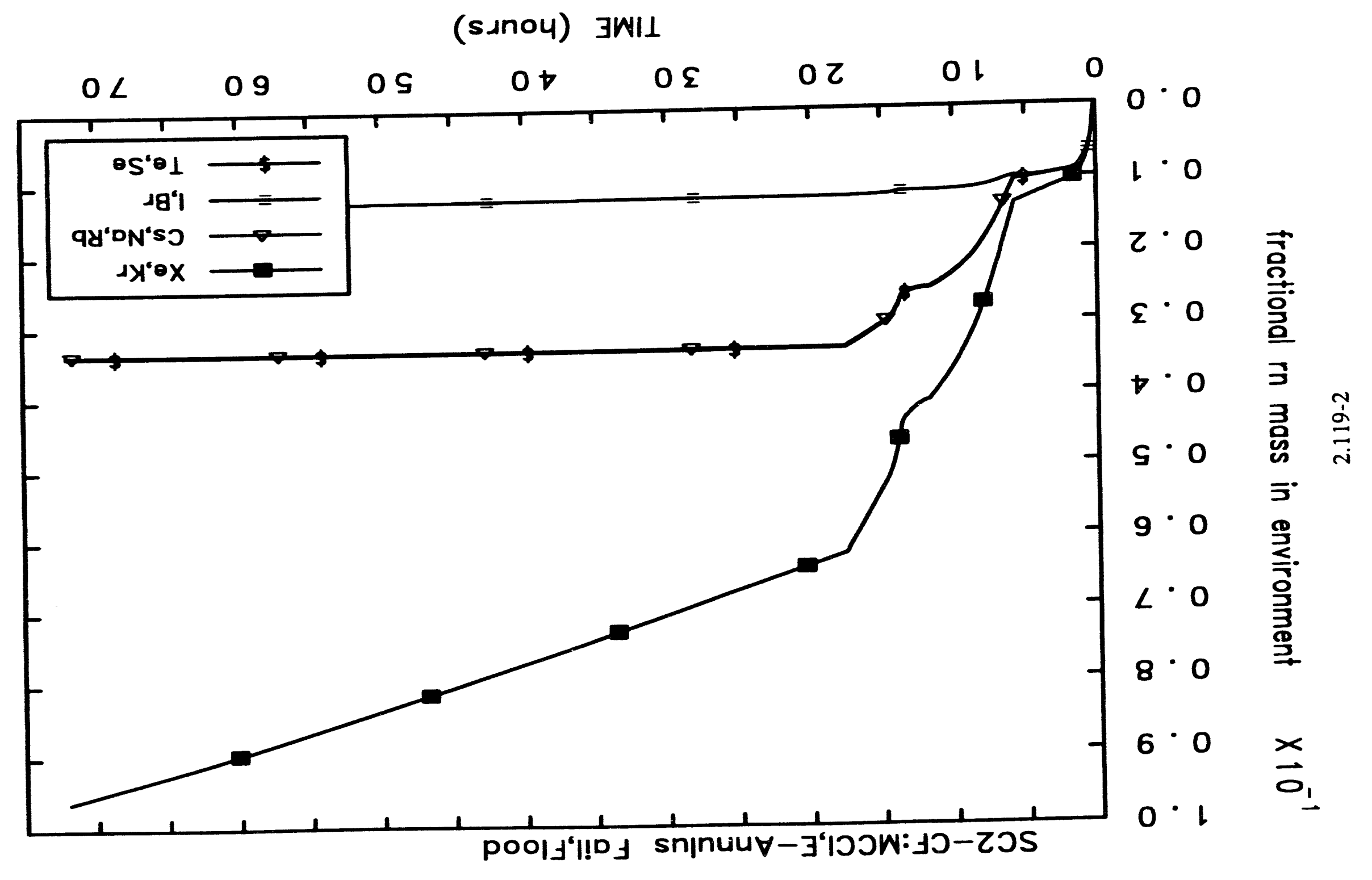




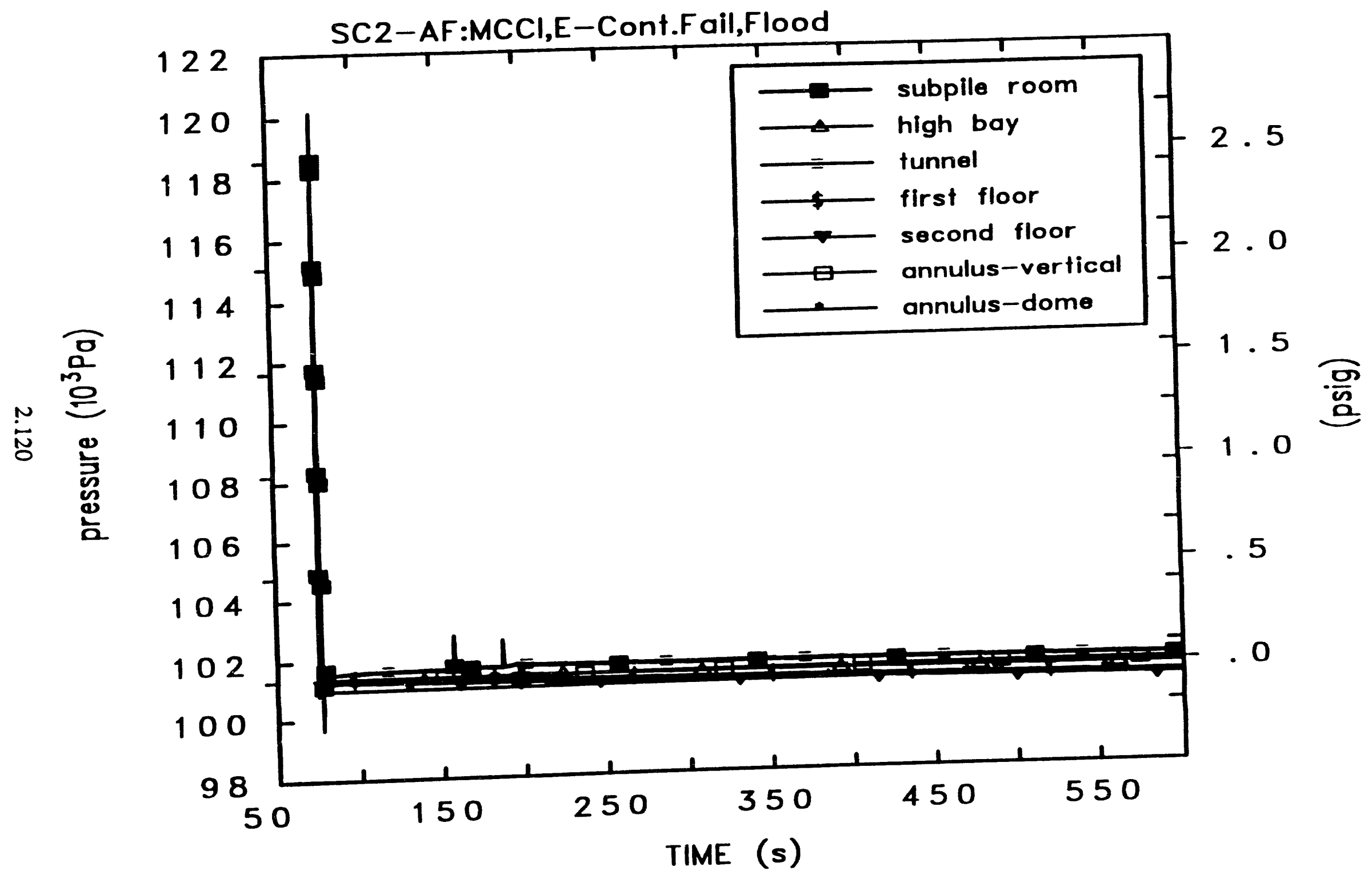

Figure 2.81a Variation of containment volume pressures vs time (Case - SC2-AF) 


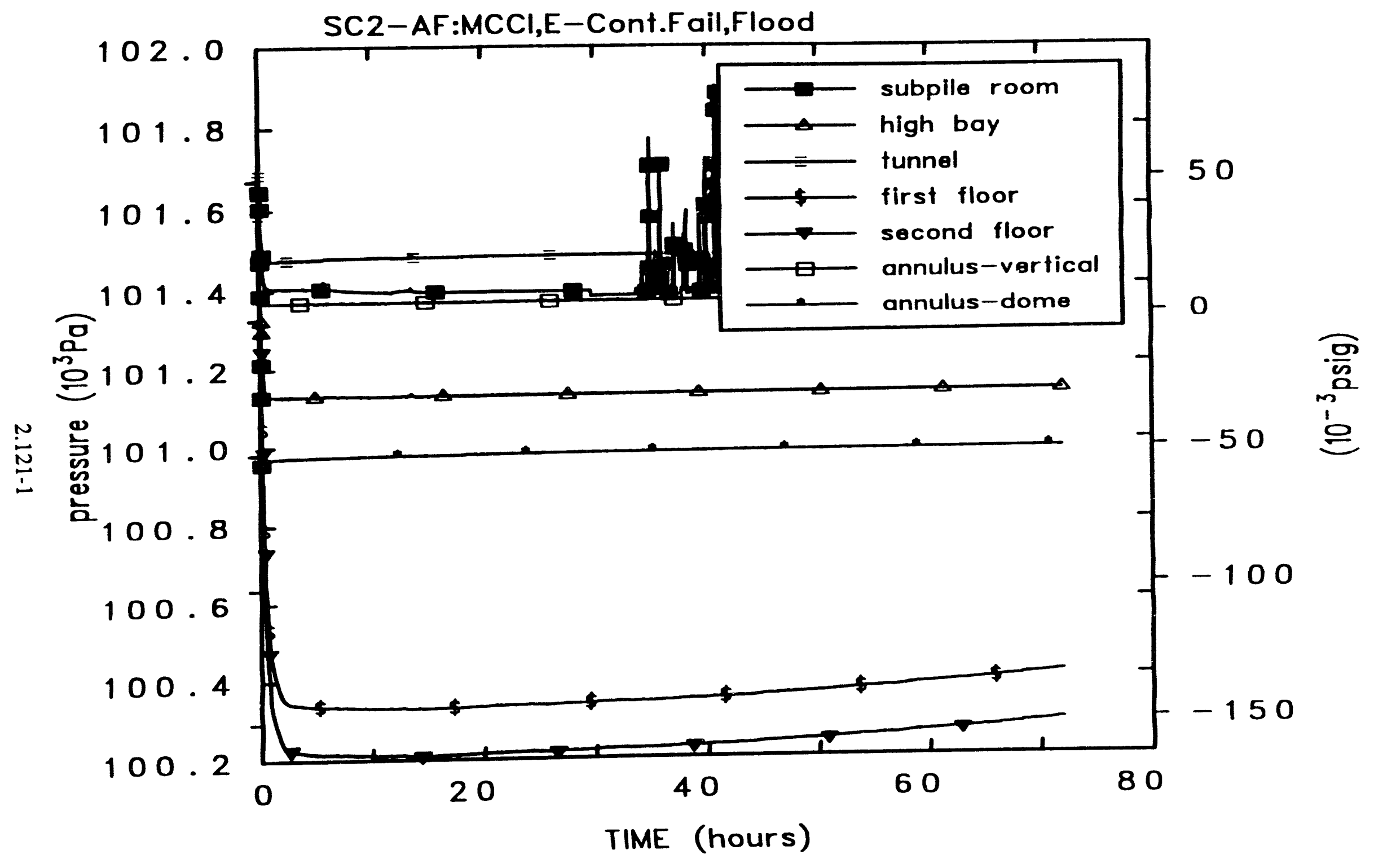

Figure 2.81b-1 Variation of containment volume pressures vs time (Case - SC2-AF) 


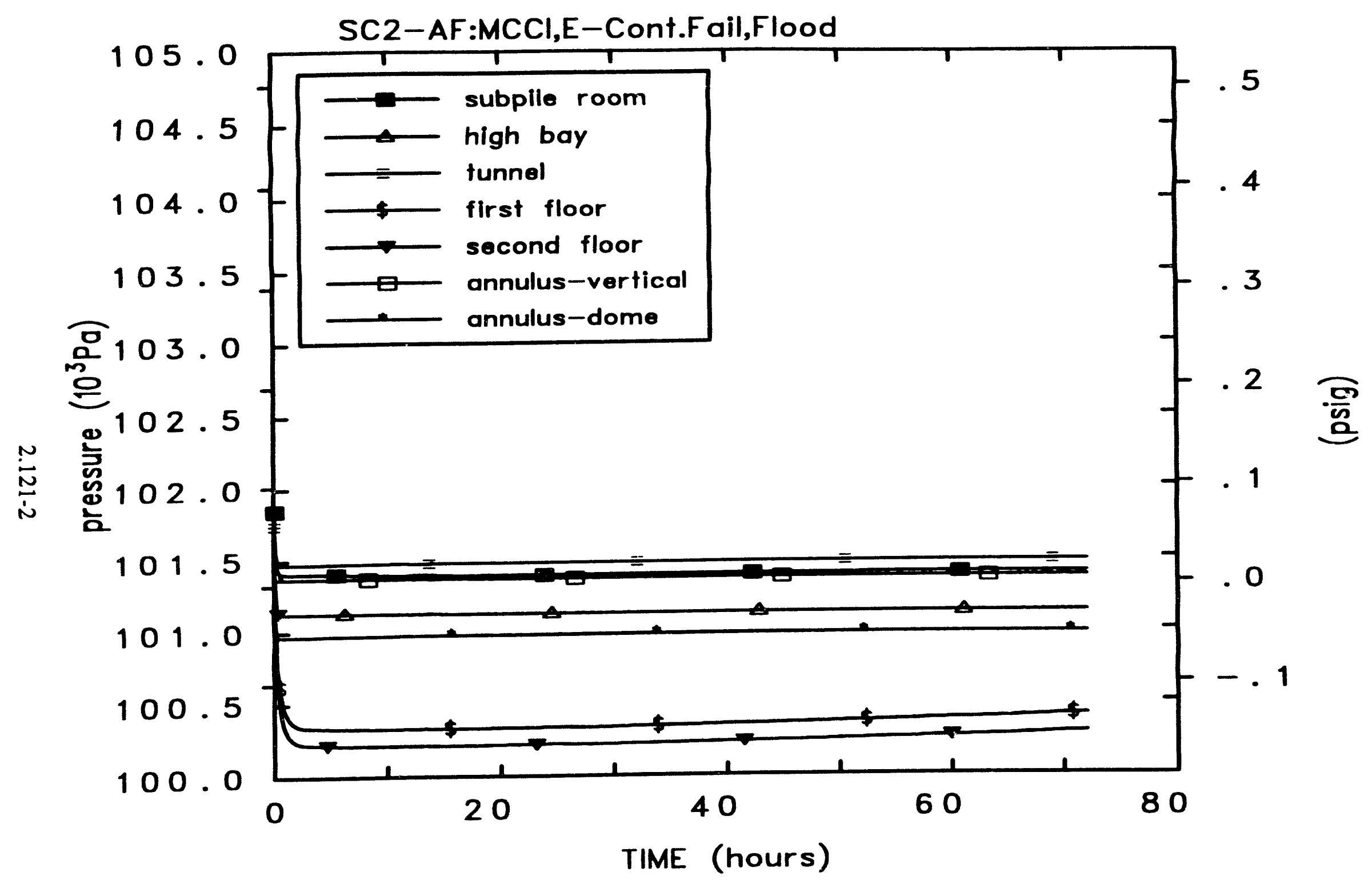

Figure 2.81b-2 Variation of containment volume pressures vs time predicted by MELCOR Mod 1.8.2 


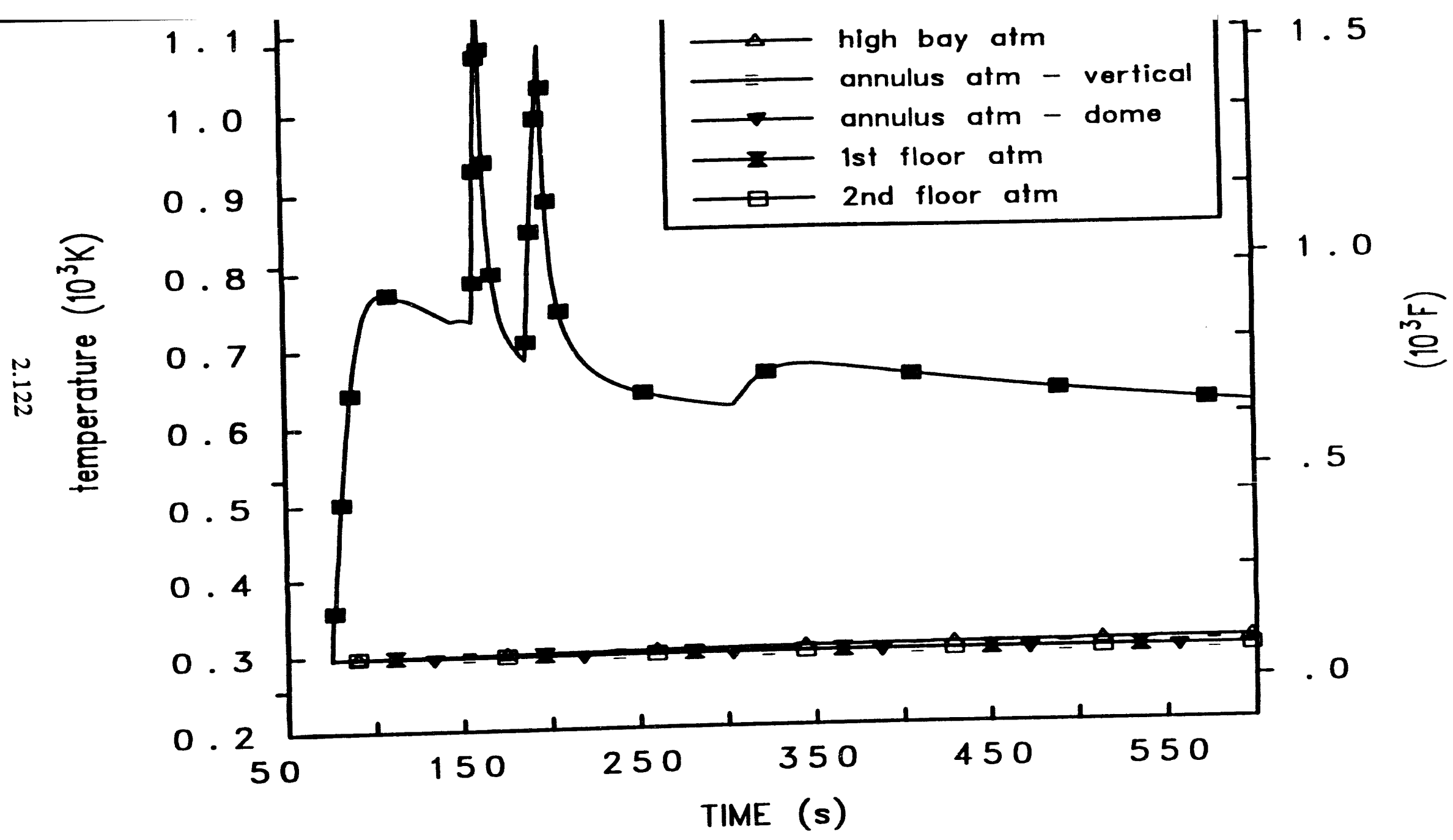

Figure 2.82a Variation of containment volume temperatures vs time (Case - SC2-AF) 


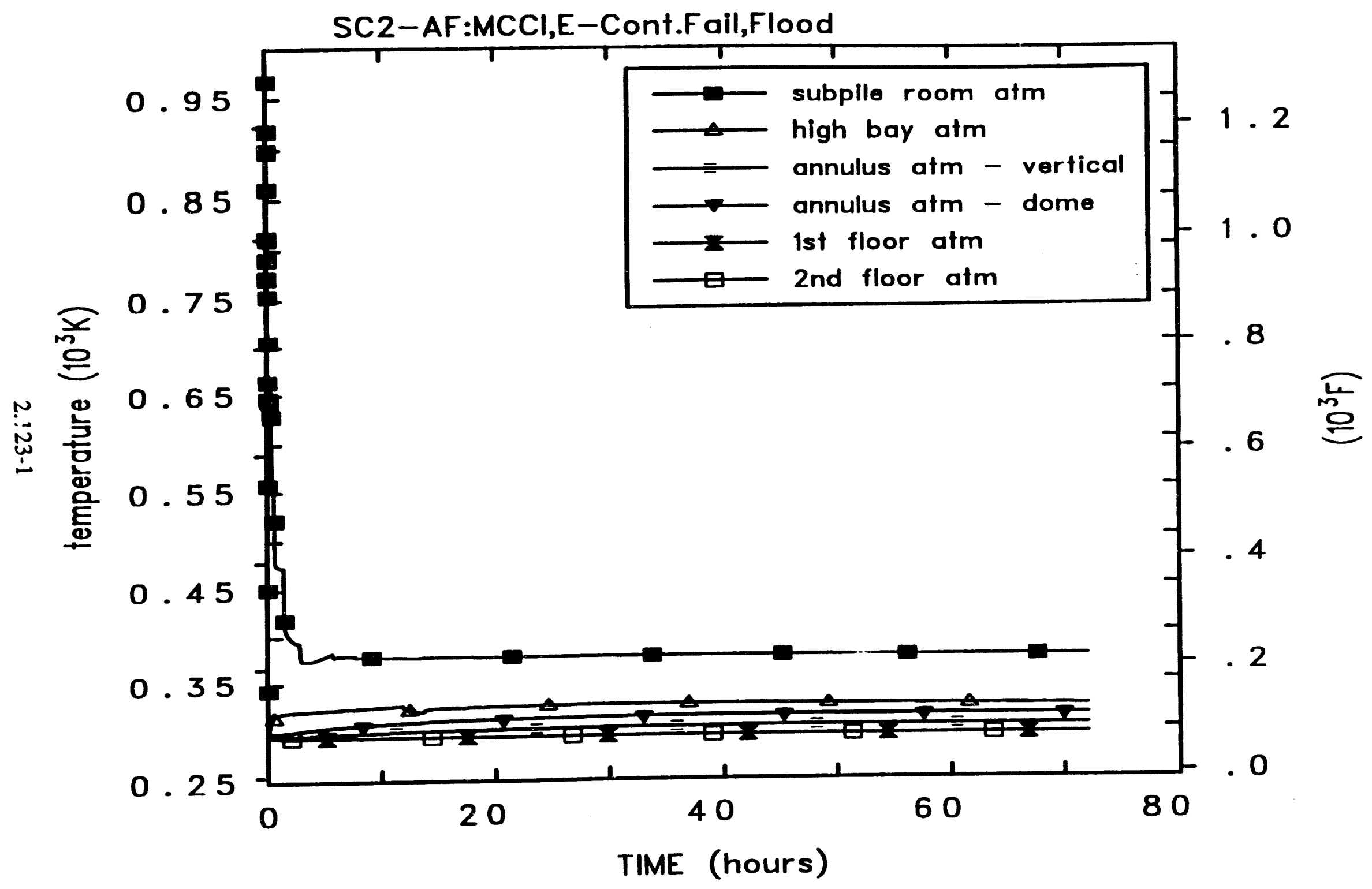

Figure $2.82 \mathrm{~b}-1$ Variation of containment volume temperatures vs time (Case - SC2-AF) 


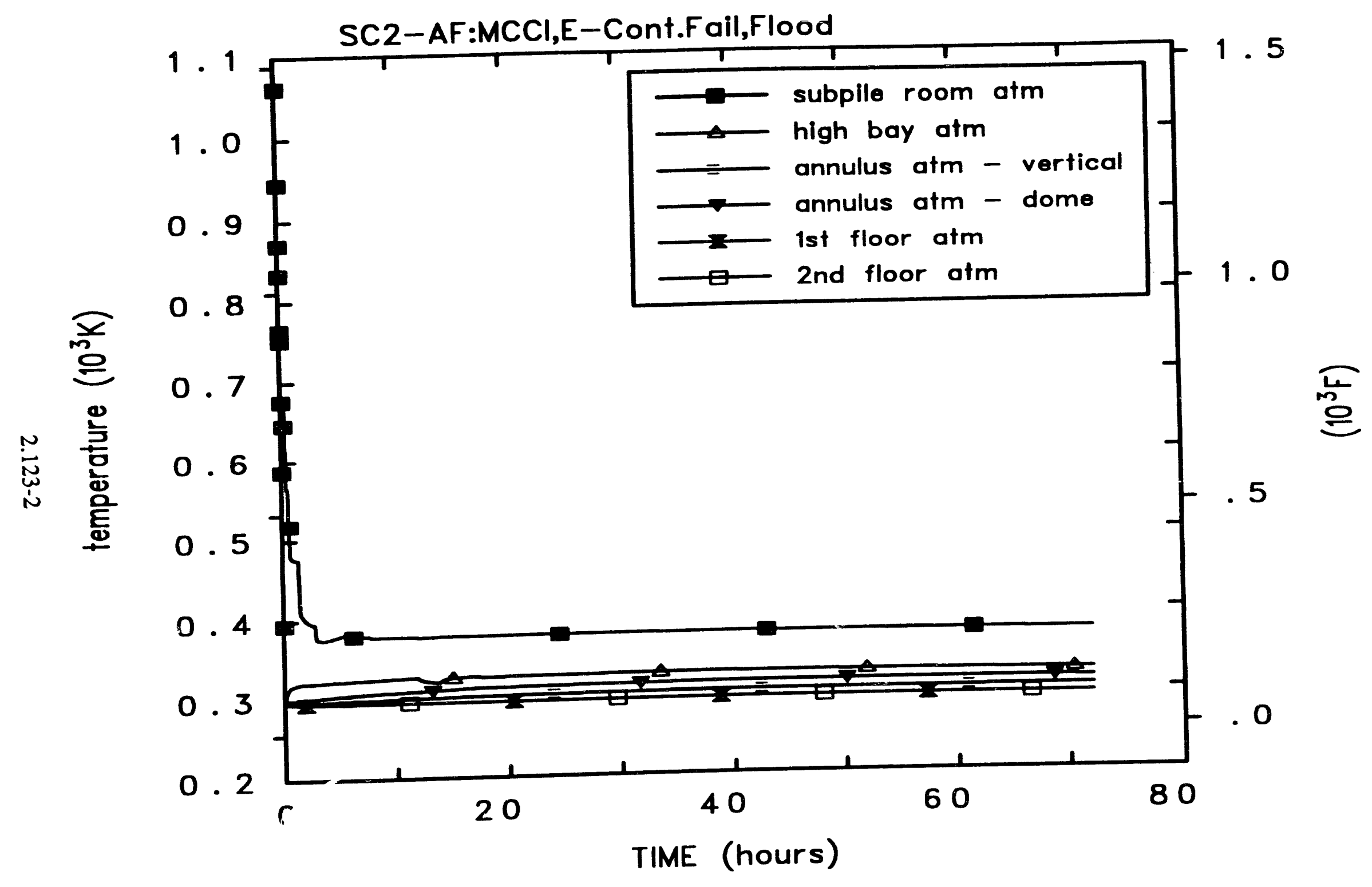

Figure $2.82 \mathrm{~b}-2$ Variation of containment volume temperatures vs time predicted by MELCOR Mod 1.8.2 


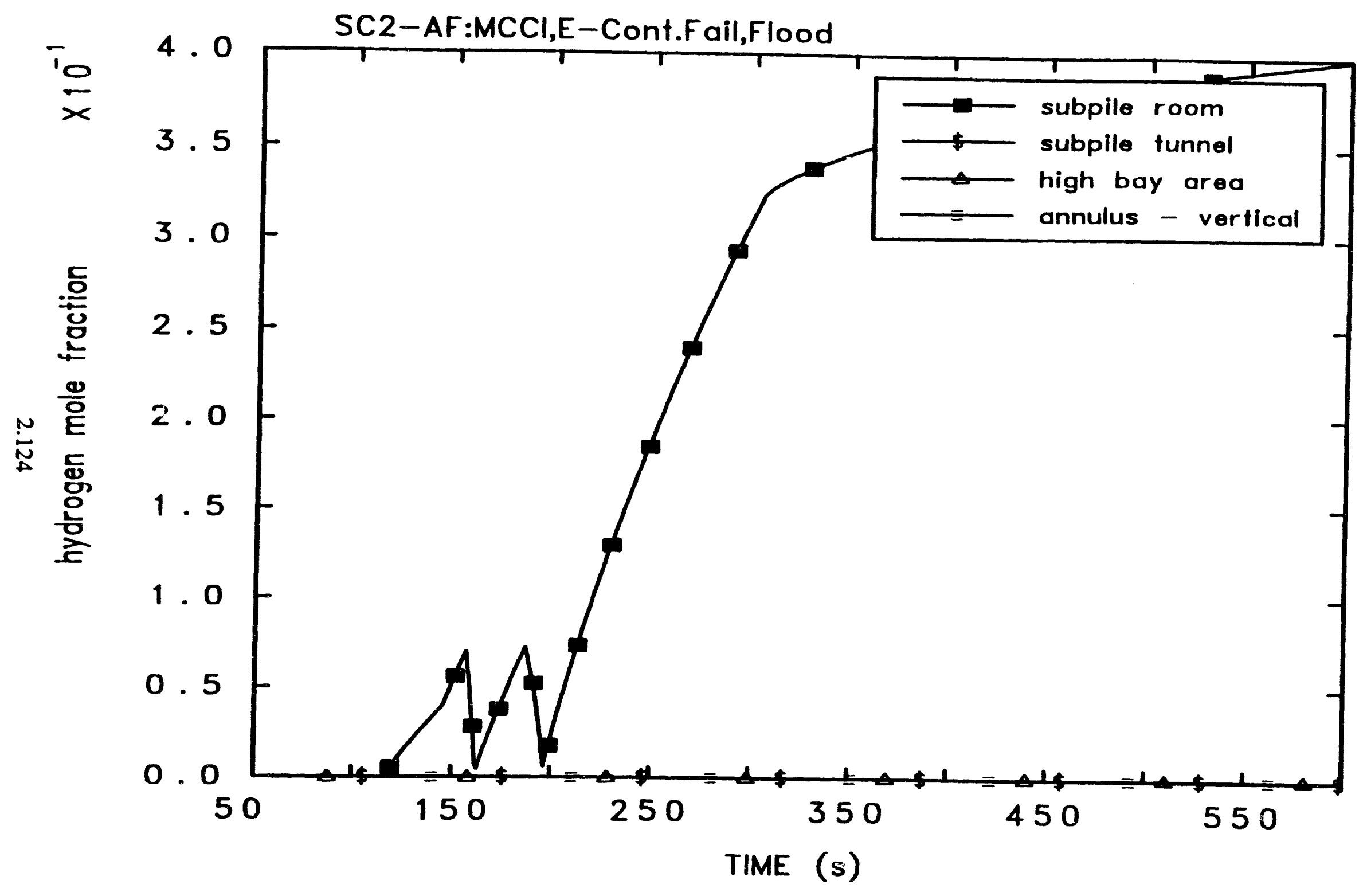

Figure 2.83a Variation of containment volume hydrogen mole fractions vs time (Case SC2-AF) 


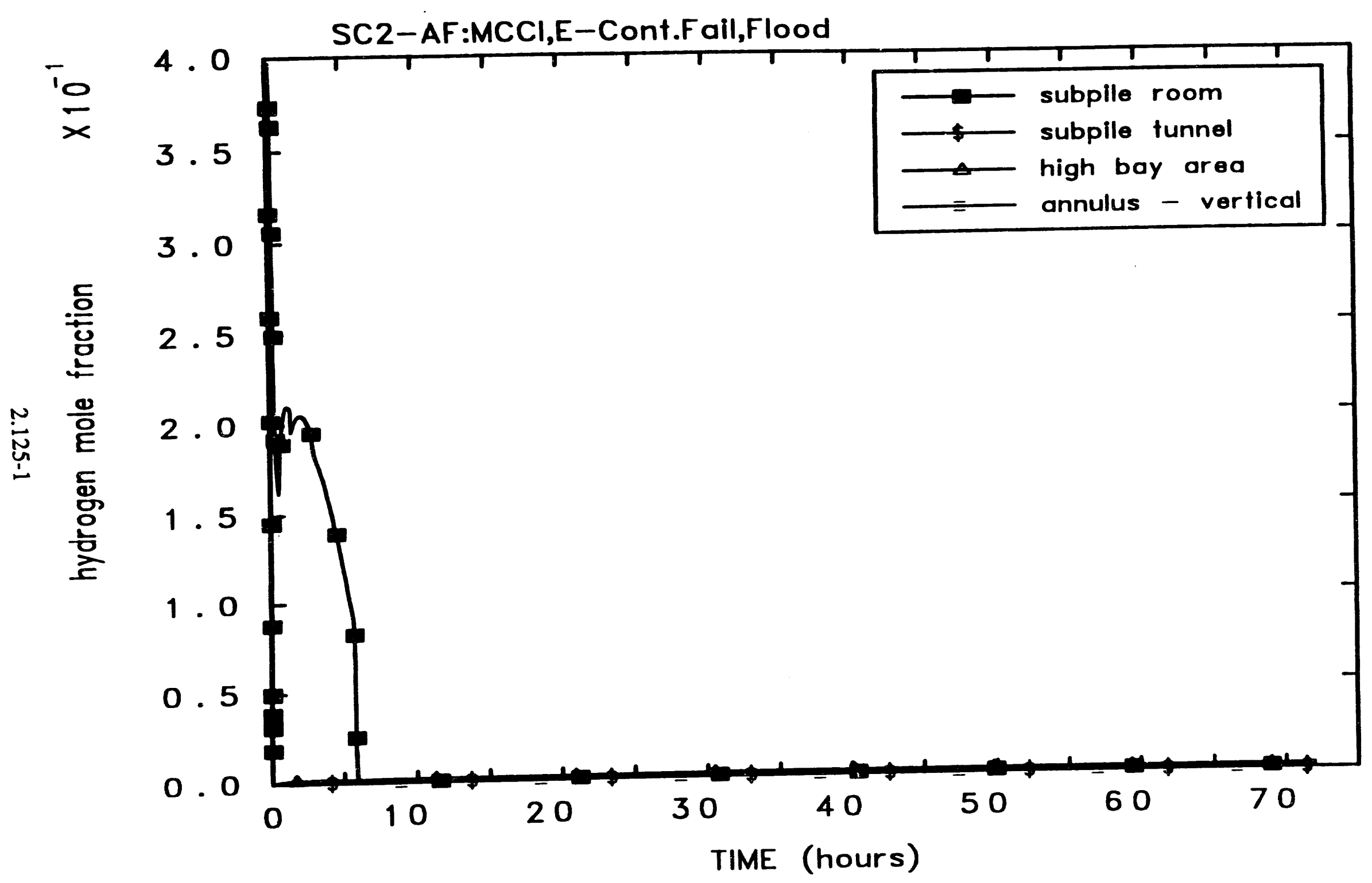

Figure 2.83b-1 Variation of containment volume hydrogen mole fractions vs time (Case - SC2-AF) 


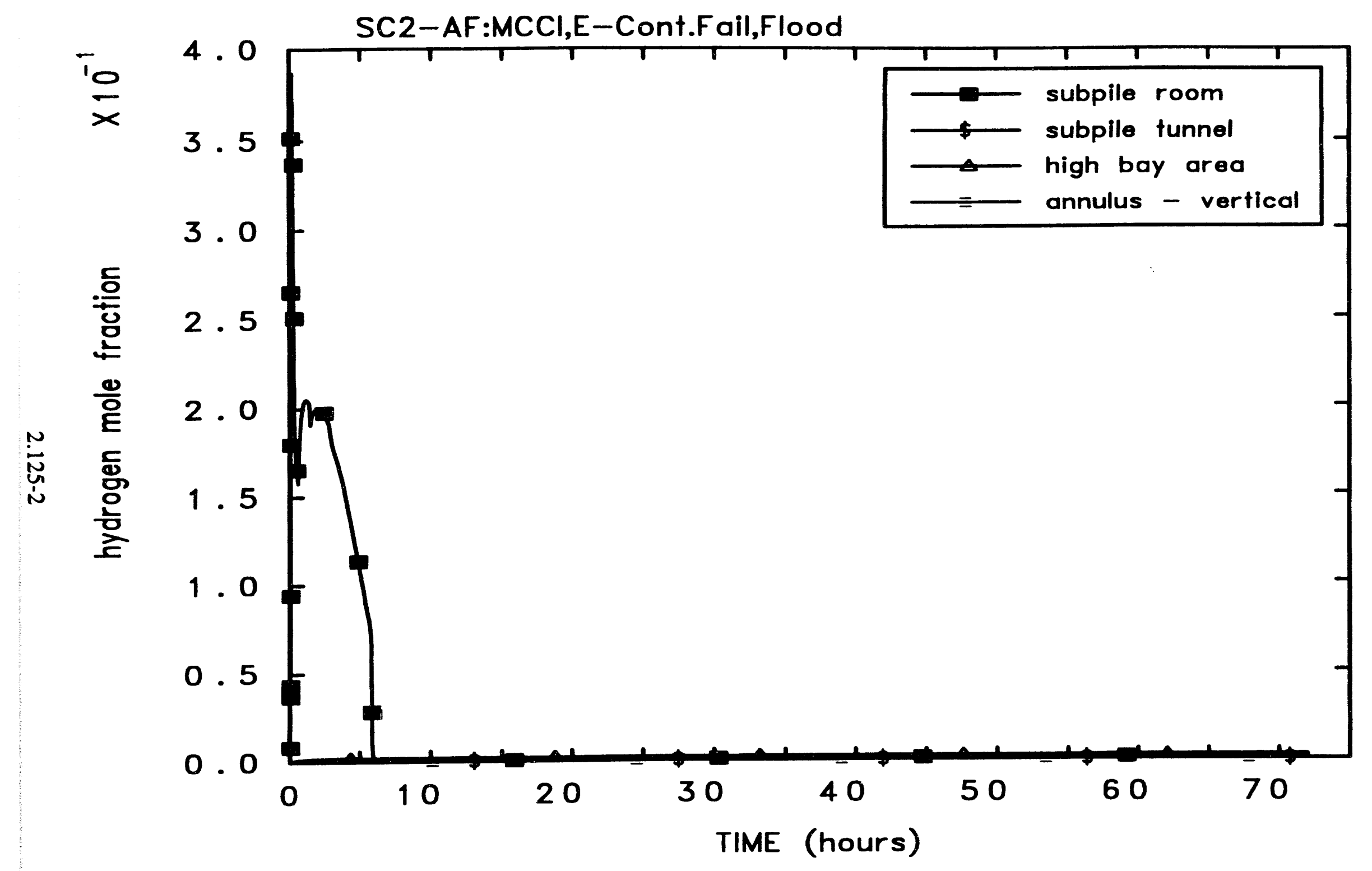

Figure $2.83 \mathrm{~b}-2$ Variation of containment volume hydrogen mole fractions vs time predicted by MELCOR Mod 1.8.2 


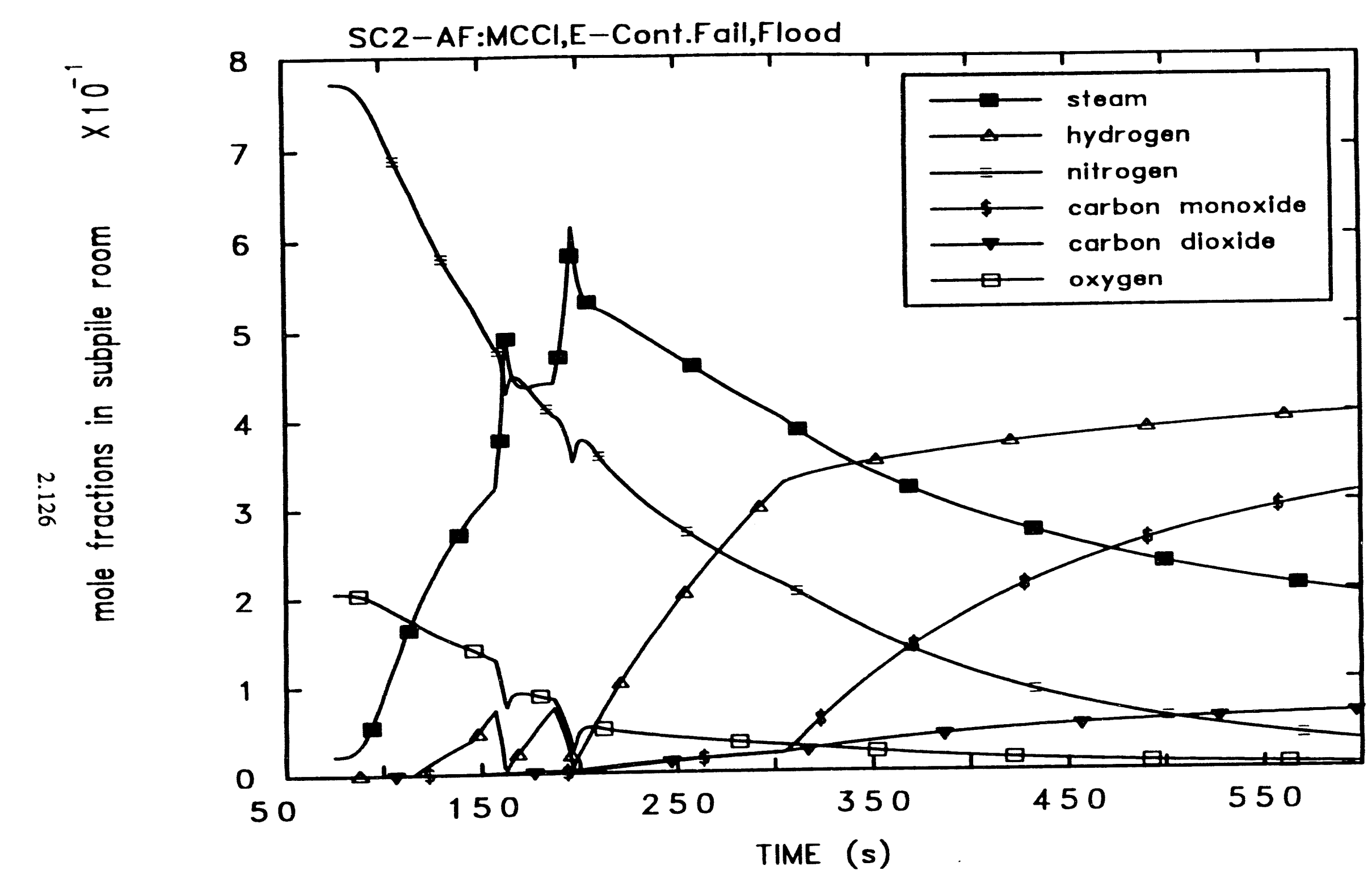

Figure 2.84 Variation of containment volume gas and steam mole fractions vs time (Case - SC2-AF) 


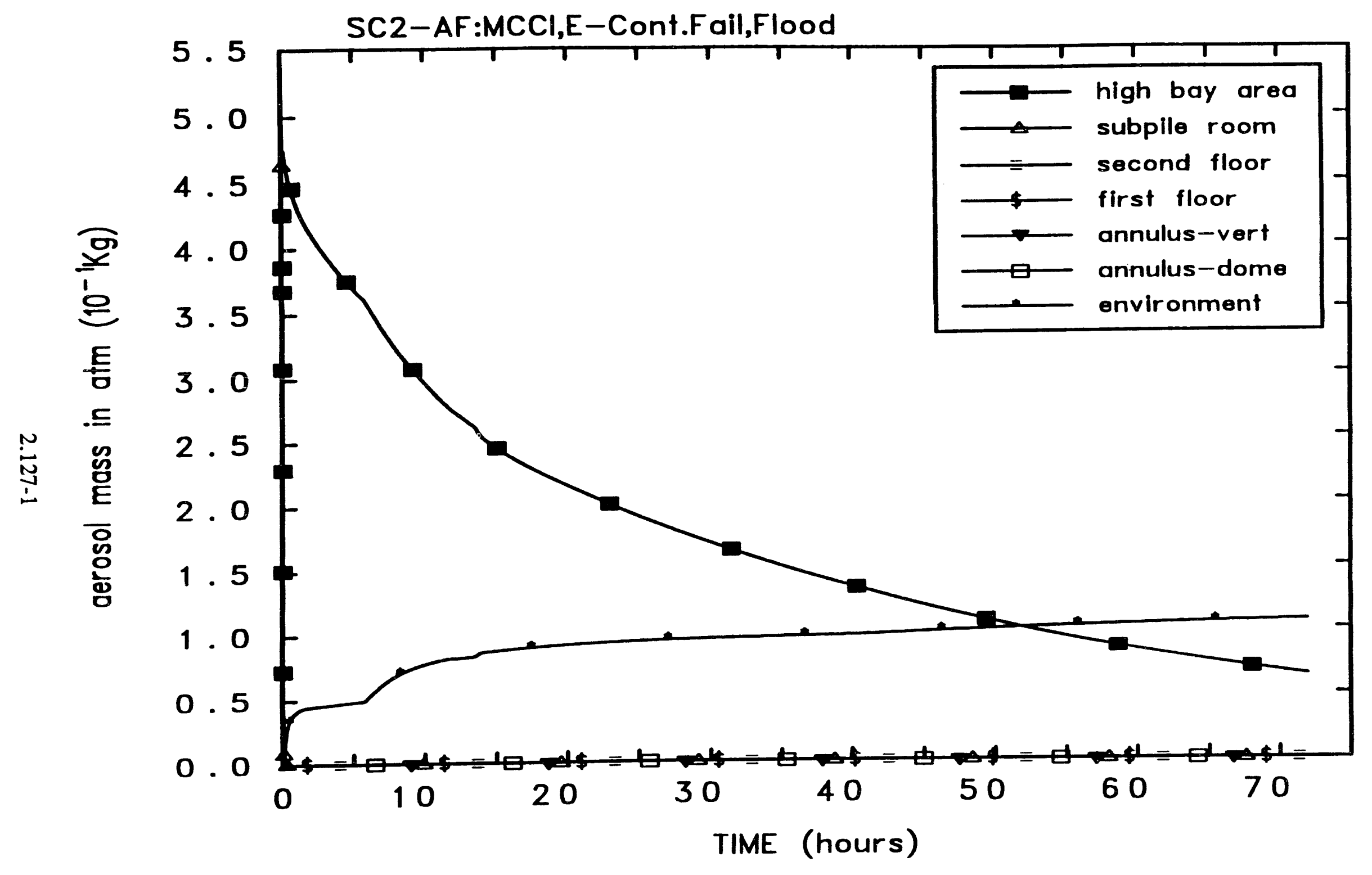

Figure 2.85-1 Variation of containment volume atmosphere aerosol mass vs time (Case - SC2-AF) 


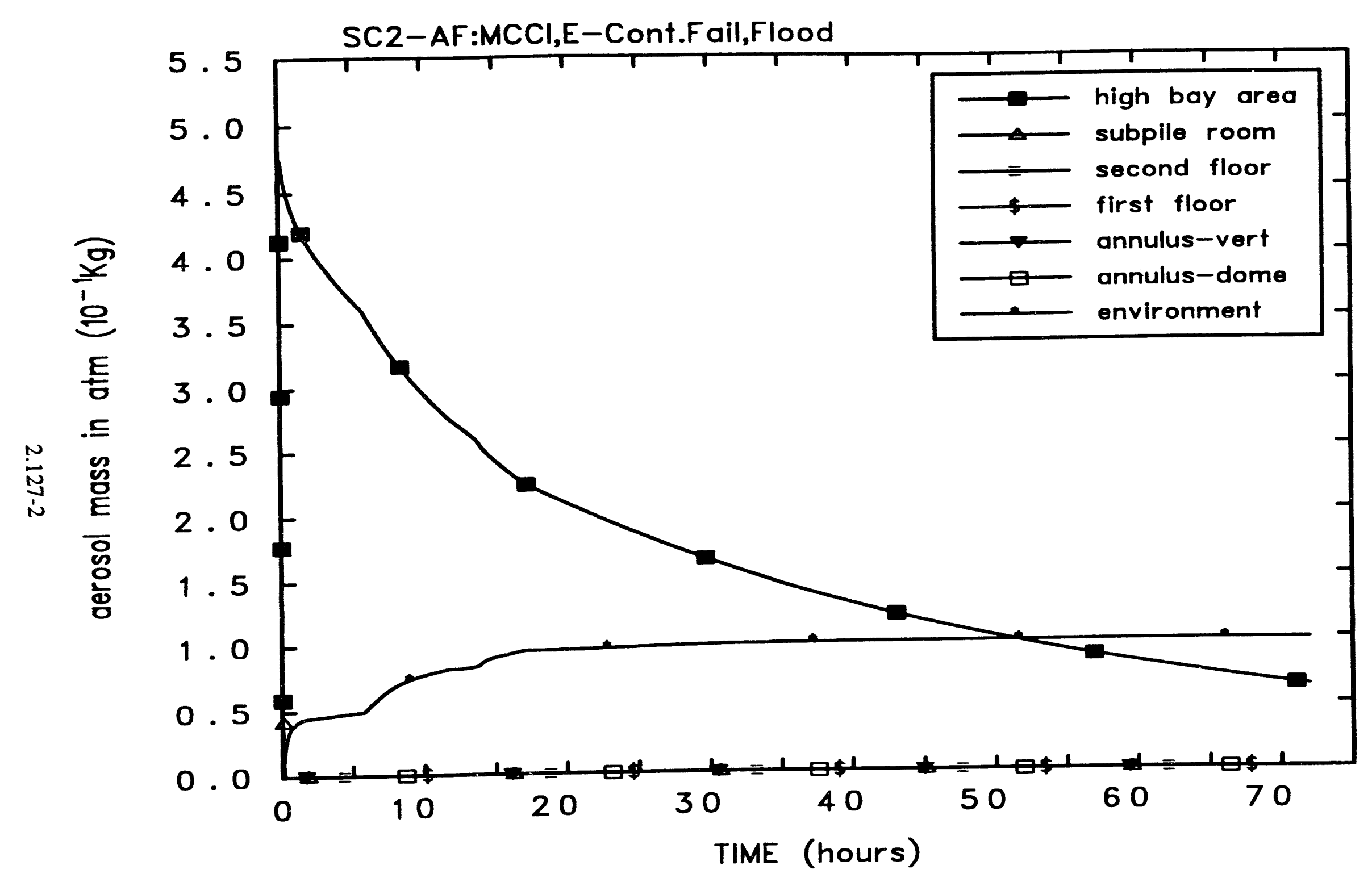

Figure 2.85-2 Variation of containment volume atmosphere aerosol mass vs time predicted by MELCOR Mod 1.8.2 


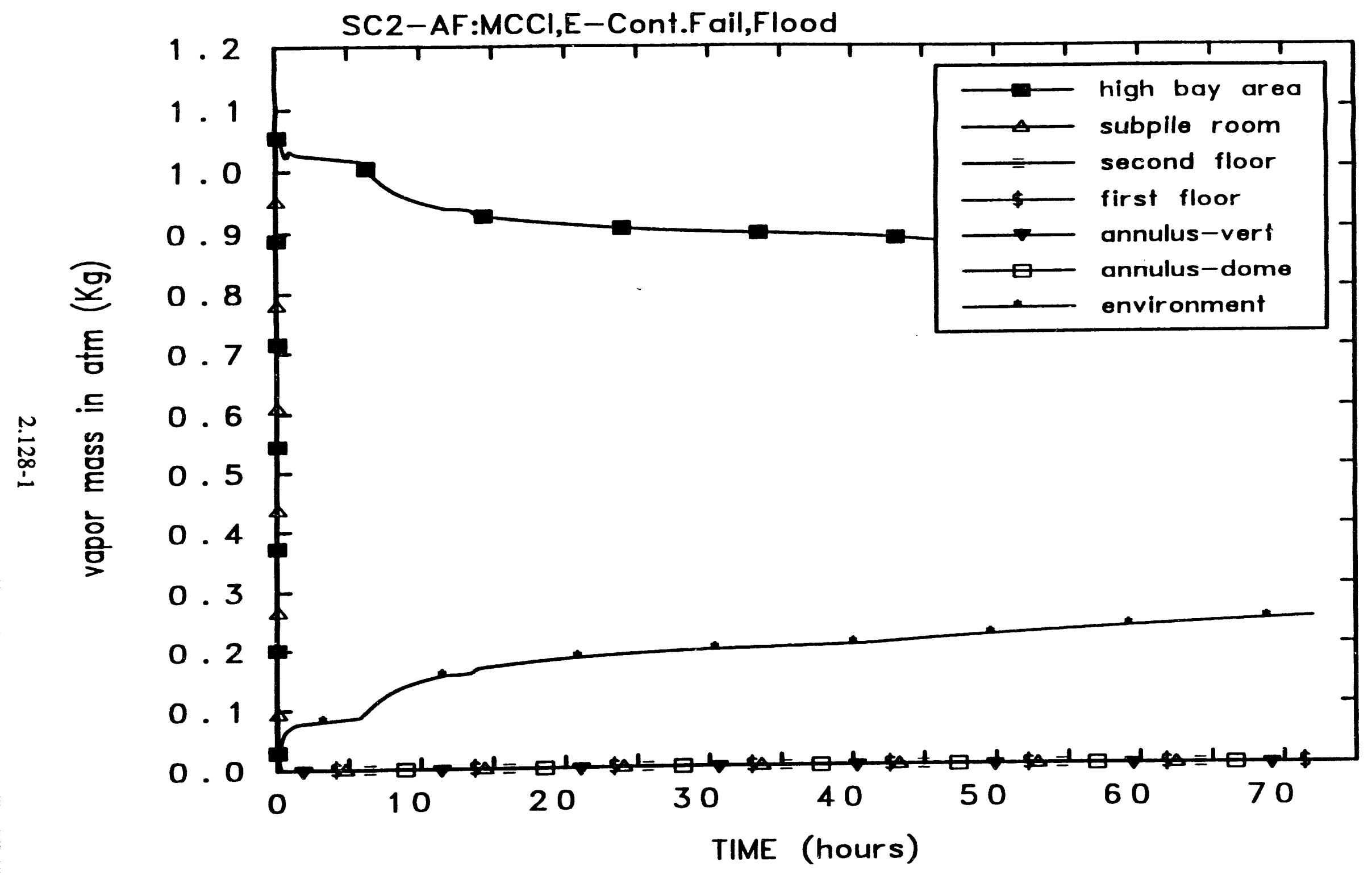

Figure 2.86-1 Variation of containment volume radionuclide vapor masses in atmosphere vs time (Case - SC2-AF) 


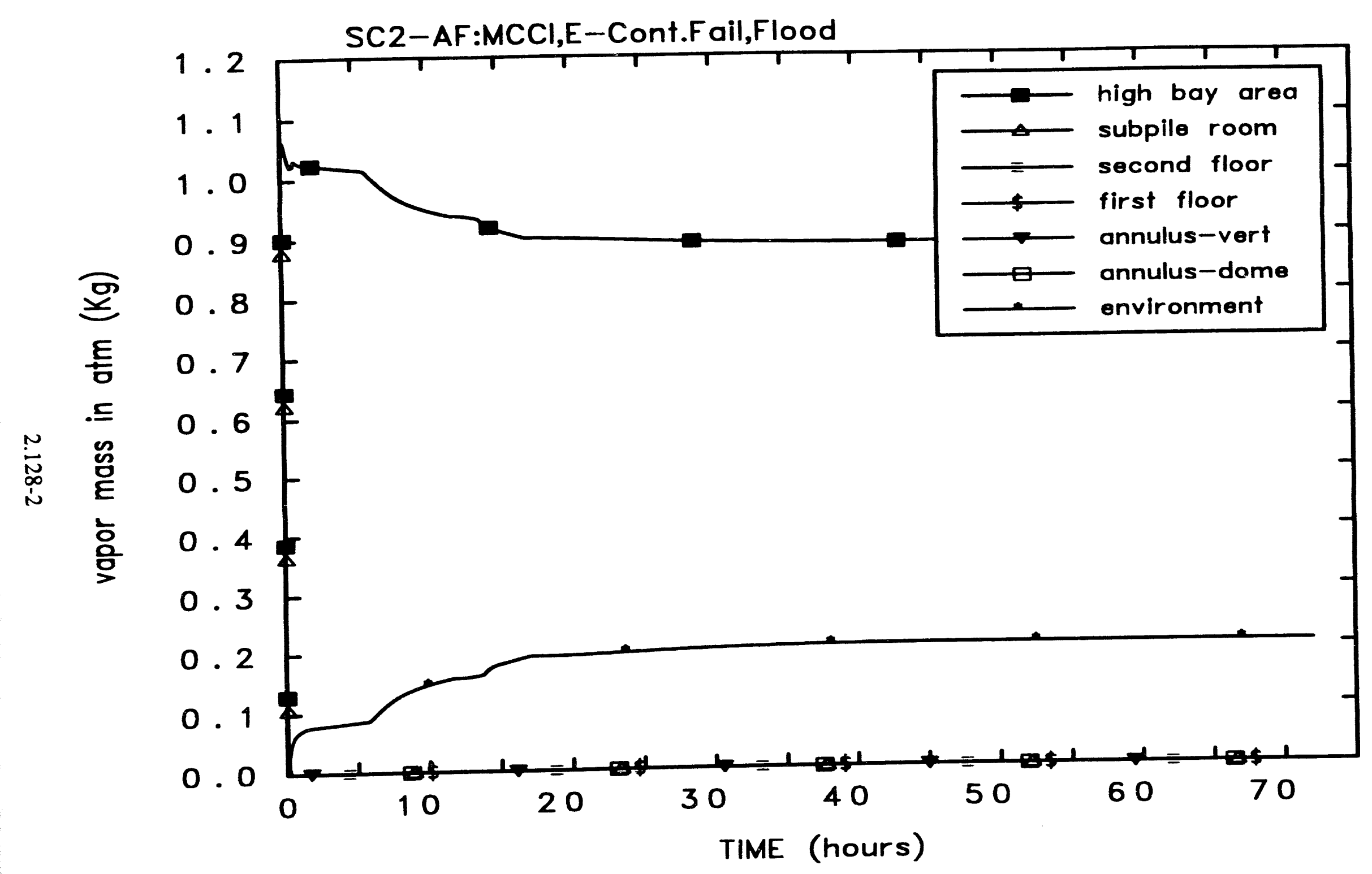

Figure 2.86-2 Variation of containment volume radionuclide vapor masses in atmosphere vs time predicted by MELCOR Mod 1.8.2 


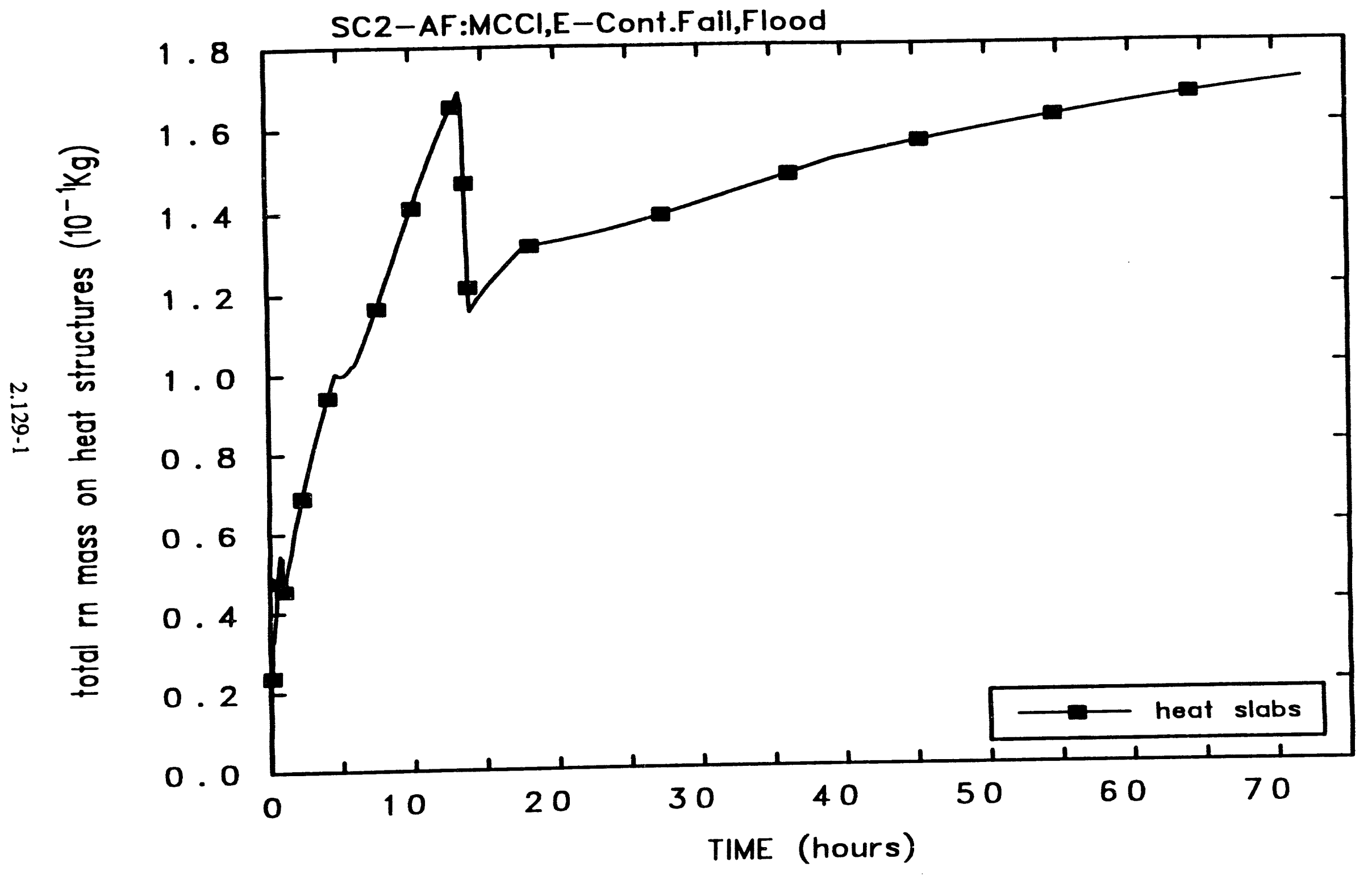

Figure 2.87-1 Variation of total radionuclide masses deposited on heat structures vs time 


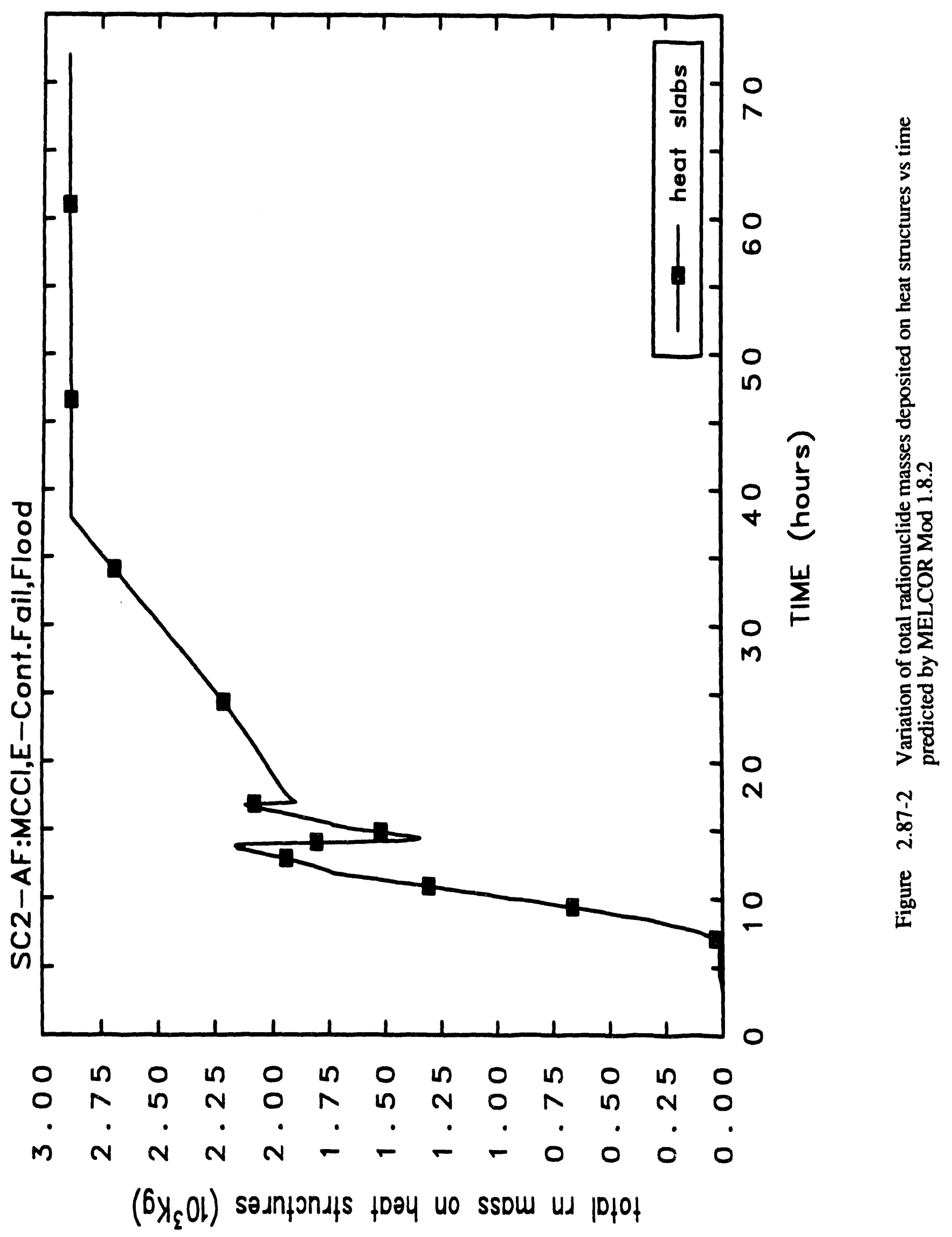




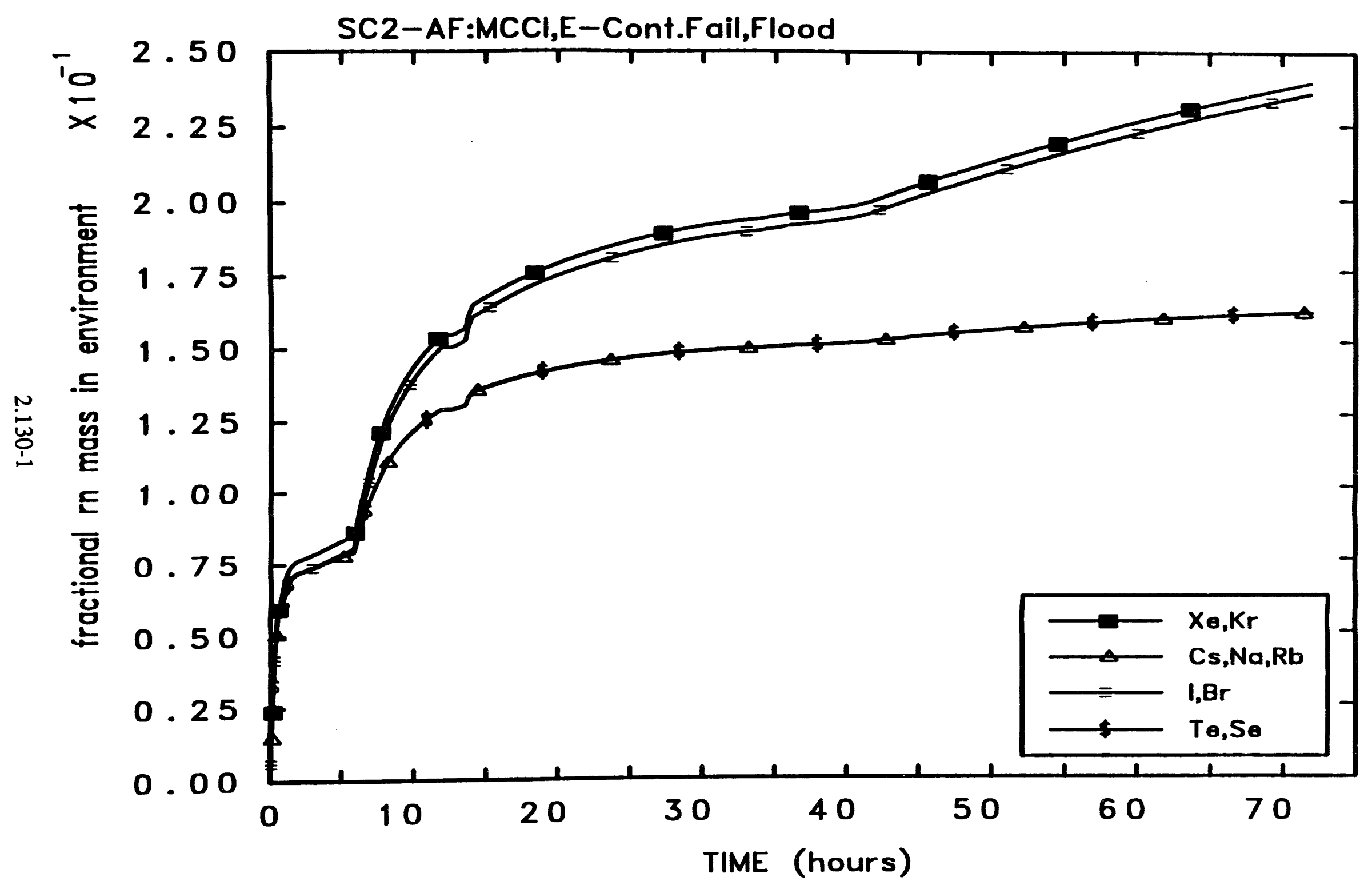

Figure 2.88-1 Variation of fractional radionuclide masses entering environment vs time (Case - SC2-AF) 


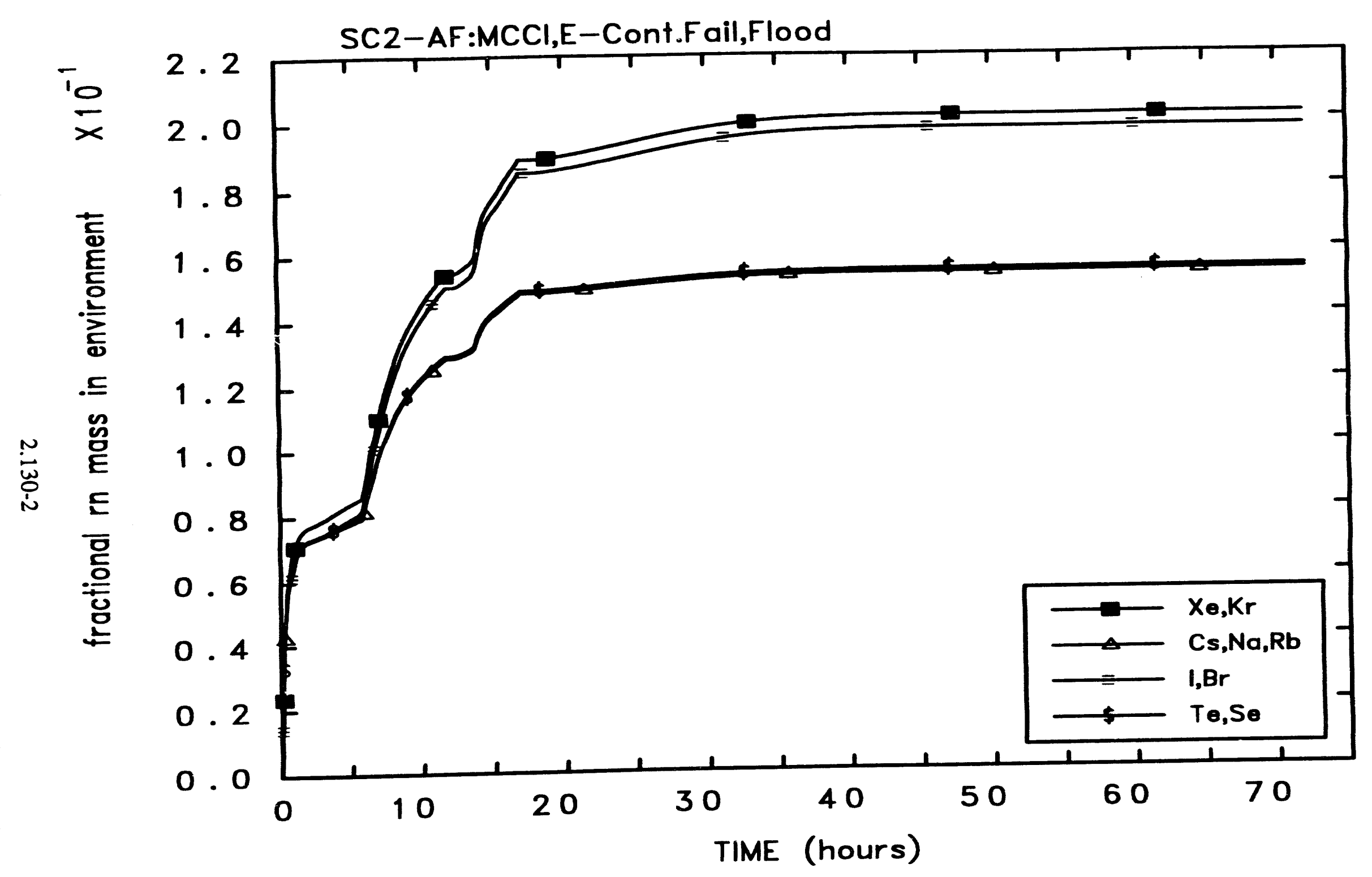

Figure 2.88-2 Variation of fractional radionuclide masses entering environment vs time predicted by MELCOR Mod 1.8.2 


\section{OFF-SITE CONSEQUENCES}

This section describes the methodology, assumptions, modeling of various features related to radiation exposure, and the health consequences resulting from source terms calculated in Chapter 2.

\subsection{MODELING METHODOLOGY OVERVIEW}

A schematic of the consequence assessment approach is presented in Fig. 3.1. The MELCOR Accident Consequence Code System (MACCS - Ver. 1.5, Chanin et al., 1990) was used for evaluating radiological impacts. The MACCS was developed to replace the Calculation of Reactor Accident Consequences (CRAC2) Code (Ritchie et al., 1984), which was developed to estimate the consequences of severe reactor accidents for the Nuclear Regulatory Commission's (NRC's) reactor safety study (NRC 1975).

The MACCS code system consists of a sequence of mathematical and statistical models which represent the radioactive material immediately after release from containment, the movement of the material as it disperses downwind of the plant, the deposition of the radioactive material onto the ground, and the effects of the airborne and deposited material on man and his environment. The consequence $\cdots$ rimated by MACCS are: early health effects, chronic (i.e., latent) health effects, and : impacts.

For the ANS CSAR, we will use the ierms presented in Chapter 2, and model the dispersion and deposition of radionuclides released from the reactor containment to the atmosphere with a straight-line Gaussian plume model in MACCS. Plume rise and dry and wet deposition will be taken into account. Downwind concentrations of radionuclides up to a distance of $80 \mathrm{~km}$ will be calculated for each directional sector around the ANS. Radiation doses to on-site and off-site populations will be calculated using the concentration of radionuclides predicted by the dispersion models. Exposure pathways to be considered for evaluating early consequences are direct radiation from the passing plume and from radioactive material deposited on the ground, and inhalation of resuspended ground contamination. It is well-known that air pathway exposures are dominant contributors to the effects of a severe accident, typically several orders of magnitude larger than from liquid pathways. Again, we have not modeled reactor coolant syster.. (RCS) response for deriving source terms. Also, the severe accident scenarios postulated already embody a significant measure of conservatism. Finally, as per the modeling done for the three accident scenarios described in Chapter 2, RCS liquid pathways will not lead to radionuclide transport to the environment and thereafter to people. Hence, we have not 
modeled radiological consequences arising from RCS liquid pathways explicitly. For assessing the long-term impact of water pathways in general (i.e., from rain, rivers, lakes), we have used values recommended as default in MACCS (generated for NUREG-1150) suitably modified to represent the environment around the ANS.

In evaluating potential radiation doses, emergency response actions will be accounted for. Short and long term actions such as evacuation, sheltering, and relocation will be considered.

\subsection{MACCS MODEL AND ASSUMPTIONS}

The proposed ANS site was chosen as the center of a polar grid. The grid was divided into 16 equally spaced sectors, with the outermost radius extending to $80 \mathrm{~km}$. Population data for the various sectors was also developed. A summary of population data around the ANS-site along with emergency response actions are given in Tables 3.1 and 3.2. A straight-line Gaussian plume model is used. Several modeling assumptions had to be made. These are given below:

1. The ANS site and surroundings is adequately represented by a polar grid consisting of 16 sectors (a fixed value built into MACCS). Each sector is further divided into 13 elements to reasonably account for the site-specific population distribution. The ANS is located at the center of the system. Each element assumes average conditions (i.e., for population, rainfall, wind speed and direction, radionuclide concentration, etc.) in that spatial region.

2. To stay conservative, shielding effects of the ANS containment and buildings are not taken credit for. All individuals in the ANS site and within the first four rings receive no shelter unless they have evacuated to the fifth ring, after which they are assumed to be relocated to a safe place and receive no radiation from the plume. For the first ring, it is assumed that all the individuals (on the ANS-site) will be uniformly distributed over the 16 sectors of the first ring, and not consciously positioned in the most unfavorable direction. While this may sound non-conservative, the effect is at least partially nullified via random sampling of the actual weather pattern over the course of one year. It should be realized that in reality, the actual gathering place would most likely be indoors, or at a normally upwind outdoor location.

3. Source terms to be used for MACCS calculations are derived from ORIGEN2 and MELCOR evaluations mentioned previously. ORIGEN2 calculations for end-of-cycle inventory of radionuclides are used (i.e., for conservatism since fission product 
buildup is greatest at end-of-cycle conditions) in conjunction with source-term information for various scenarios. In addition, MELCOR calculations are also used to specify the energy content of the generated plumes. It should be noted that of the 112 isotopic inventories listed in Table 2.2, only 52 of these are represented in the MACCS database. Therefore, in order to account for the potential health effects of the remaining isotopes, an equivalent representation of these non-MACCS isotope had to be developed in relation to the isotopes already in the MACCS database. The mechanics of this process are given in Appendix A.

4. Source terms from various accident scenarios are released at ground level. Such a prescription provides for the maximum possible contact with the radioactive cloud before dispersion begins, and as such stipulates conservative initial conditions, which may exist for certain accident conditions.

5. Building wake effects are accounted for. Building dimensions are specified to have a width of $66 \mathrm{~m}$ and height of $16 \mathrm{~m}$.

6. Due to a limitation of MACCS no credit is taken for ridges, and hills surrounding the ANS site which may block motion of the plume to off-site populated areas. Ridges and hills can also cause greater deposition of aerosol particulates. Hence, to the extent that ridges and hills act to block motion of the plume towards evacuating personnel, assuming a flat terrain is conservative. However, it should be noted that the meteorological data utilized for dispersion calculations have implicitly built into them the effect of surrounding terrain.

7. Weather data (hourly wind speed, wind direction, and atmospheric stability) taken at the HFIR site tower at $30 \mathrm{~m}$ elevation are assumed to be representative for the ANSsite. This is considered reasonable, since the ANS is located in the general vicinity of HFIR, with no intervening hills or ridges. Best available data for rainfall and mixing height were used. Rainfall data for the ANS site are assumed to be the same as that for Oak Ridge. Mixing height data (for morning and afternoon) recommended by the National Climatic Center in Asheville, NC are considered representative for the ANS site and surrounding terrain. A weather file consisting of 24 samples per day for 365 days of meteorological information is considered adequate, in conjunction with stratified random sampling of four samples per day (therefore $365 \times 4=1460$ samples are evaluáiad for atmospheric dispersion calculations).

8. Beyond $16 \mathrm{~km}$ of the ANS reactor, boundary weather conditions are applied such that the mixing height is conservatively specified as being at the lowest level (viz., $300 \mathrm{~m}$ ) from the yearly meteorological database information supplied by the National Climatic Center in Asheville, NC. Further, since actual data were not available for locations 
beyond $16 \mathrm{~km}$, we have conservatively assumed neutral stability conditions (i.e., stability class D) combined with the specification of no precipitation, and a low constant wind speed of $0.5 \mathrm{~m} / \mathrm{s}$.

9. The plume is defined as consisting of multiple sections (i.e., in time) based upon guidance received from the source term transient variation predicted from MELCOR calculations.

10. An evacuation alarm is assumed to sound ten minutes after occurrence of a severe accident. Individuals within the first four rings of each sector (i.e., within $2 \mathrm{~km}$ ) are assumed to start evacuating after a $35 \mathrm{~min}$ delay time. The $35 \mathrm{~min}$ time frame consists of two components. The first component of $30 \mathrm{~min}$ represents the mean time associated with general emergency conditions, to warning of the employees, and visitors to evacuate. This is a standard assumption used previously for similar studies (e.g., DOE/EIS-0144D, Vol. 2, Appendix J, page 15) for the New Production Reactor (NPR) EIS. The second component amounts to $5 \mathrm{~min}$ representing a reasonable delay time between wamings to evacuate, and the time people actually start to evacuate.

11. Individuals evacuating from the first four rings of the grid move to safety (i.e., to ring 5 and beyond) at a speed of $10 \mathrm{~m} / \mathrm{s}(23 \mathrm{mph})$. Sheiterees at X-10, are assumed to take 5 min to take shelter (after alarm sounds) and then stay there for six hours. After this time, these shelterees receive no more exposure. Upon passage of the plume the shelterees may move back to their original spatial element at the end of the emergency phase which is assumed to last for seven days. This is a standard assumption used previously for similar studies (e.g., DOE/EIS-0144D, Vol. 2, Appendix J, page 15) for the NPR EIS.

12. Relocation of individuals residing outside of the Immediate Notification Zone (IN) is allowed in one of three ways, viz. hot spot relocation, normal relocation, and long term relocation. Hot spot relocation occurs if the effective whole body dose equivalent to an individual exceeds $0.5 \mathrm{~Sv}$ ( $50 \mathrm{rems}$ ) during the one week emergency phase. Thereafter, individuals $i$. that ring are relocated $30 \mathrm{~min}$ after arrival of the first plume. Relocated individuals receive no further dosage during the emergency phase.

Normal relocation is activated if the effective whole body dose equivalent exceeds $0.25 \mathrm{~Sv}$ ( $25 \mathrm{rems}$ ) in the one week emergency phase. Thereafter, individuals in that ring are relocated $I \mathrm{~h}$ after the arrival of the first plume at that distance. Individuals relocated receive no further dosage during the emergency phase.

Long term relocation is activated if exposure exceeds $0.01 \mathrm{~Sv} / \mathrm{yr}(1 \mathrm{rem} / \mathrm{yr})$.

The above assumptions are based upon guidance given from default values suggested in MACCS (which were also utilized for the NUREG-1150 studies). 
13. The breathing rate of individuals is conservatively assumed to be constant, and equal to the MACCS default value of $2.66 \times 10^{-4} \mathrm{~m}^{3} / \mathrm{s}$, which is an averaged value close to the upper limit of $3.1 \times 10^{-4} \mathrm{~m}^{3} / \mathrm{s}$, as suggested by USNRC Regulatory Guides ( $\mathrm{Di}$ Nunno, et. al., 1963).

14. Other parameters that enter the calculational process such as protection factors for inhalation or skin exposure, resuspension, cloud and other shielding factors, and specific input required for deriving chronic (i.e., latent) effects are assumed to be the default values recommended in the MACCS User's Guide (Chanin, 1990).

15. Due to a limitation in MACCS, the plume transport characteristics for gases, vapors and aerosols are all required to be represented as aerosols. In order to simulate the dynamics of the various species appropriately several modeling assumptions had to be made. Noble gases-related aerosols were constrained to be not amenable to wet or dry deposition. The size bin was chose to be extremely small. Hence, noble gases are treated as aerosols of extremely small size which do not undergo dry or wet deposition, and as such always remain suspended. Halogen class aerosols are modeled as being amenable to wet deposition but not to dry deposition. This simulates vapor transport processes. Rest of the classes are treated as conventional aerosols which are amenable to wet and dry deposition.

16. For modeling off-site consequence calculations for the CFR 100 case, no evacuation or relocation is allowed. Health consequences will be reported corresponding to the 95 th percentile as prescribed by the 10 CFR 100 guidelines.

\subsection{RADIOLOGICAL CONSEQUENCE RESULTS}

In this section we present the radiological consequences arising from source terms described earlier in Chapter 2 for scenarios 1 and 2. Tables 3.3 through 3.17 summarize \% $v$ results of mean value estimates in various categories. Results were also generated conventionally as Complementary Cummulative Distribution Functions (CCDFs). Stated simply, CCDFs show variations between an event ' $\mathrm{X}$ ', and one minus the probability of this event 'Pr' occurring (i.e., $\operatorname{Pr}>\mathrm{X}$ ). These are shown in Figs. 3.2 through 3.37. For each scenario, the CCDF plots were generated for displaying probability variations (i.e., $\operatorname{Pr}>X)$ for different events $(X)$ over different distance intervals. These should be used in conjunction with health con:equence results reported in Tables 3.3 through 3.17. Note that for all cases (except the CFR 100 scenario) Tables 3.3 through 3.17 present mean values for various consequence parameters. The CCDF plots should be utilized to note important variational trends from mean value estimates for each of the three distance zones. 
Table 3.3 presents mean cumulative values for prompt and latent cancer fatality estimates as a function of distance from the ANS site. Estimates for all ten cases have been tabulated. As can be seen, prompt fatality values are a small fraction of the total number of individuals on-site, even for the $\mathrm{MCCI}$ cases with containment failure (i.e., for Scenario 2 events SC2-A, SC2-AF, and SC2-C) considering that 449 individuals are assumed to be within the ANS site boundary (i.e., within a radius of $170 \mathrm{~m}$ ). This can be attributed to the weather patterns at the ANS site, and the fact that it is unlikely that all 449 individuals would be in the direct pathway of the plume. As noted, the MCCI case provides for greater fatalities than the steaming pool case (i.e., Scenario 1). Indeed, for the CFR 100 case and all of Scenario 1 cases no prompt fatalities are predicted. This is because, for Scenario 1 several hours elapse before any significant amounts of radioactivity are released to the environment, leaving sufficient time for evacuation and sheltering of all individuals on the ANS site and within the neighboring 3 rings. For a similar reason the $\mathrm{MCCI}$ case with flooding (viz., SC2-AF) gives rise to much lower values for prompt fatality in comparison to the SC2-A case. This is despite the fact that the overall source terms (i.e., over $70 \mathrm{~h}$ ) for MCCI cases with flooding are much larger than for equivalent cases without flooding, and thus underscores the importance of providing a strategic flooding capability.

Cancer deaths and injuries are also seen to be much smaller for the CFR 100 scenario and Scenario 1 cases in comparison to those for the Scenario 2 cases. In general, for the steaming pool cases, this is attributed to the time span available for safe evacuation as mentioned previously in conjunction with prompt fatality estimates. For the CFR 100 scenario in particular, the low values of health consequences is essentially due to the leaktight nature of the ANS containment which leads to a relatively insignificant source term (and that too over a very long time). Overall cancer fatalities and injuries between the MCCI cases with and without flooding also display the same trend for individuals within the site boundary (i.e., $<1 \mathrm{~km}$ ). However, due to the overall source term being larger at later times for the $\mathrm{MCCI}$ cases with flooding cancer deaths and injuries are also larger than those for the cases without flooding, for distances $>1.0 \mathrm{~km}$. Overall, for cases where only the primary containment had failed, the mean number of cancer deaths and injuries are smaller by a factor of five to ten compared to the cases where the secondary containment had also failed. This clearly demonstrates the beneficial effect of having a dual-containment configuration. Finally, upon comparing cancer deaths and injuries caused oy containment failure versus where the containment stays intact, we note that there is a general spread of between four to five orders of magnitude. This underscores the importance of maintaining containment integrity. 
Table 3.4 presents an interesting summary of total number of individuals exceeding various levels of radiation doses, as well as a breakdown of total and individual doses to various body organs for each of the ten cases. As seen from Table 3.5, for the sitesuitability basis scenario CFR 100, no exceedance of permissible limits occurs for the three body organs. 'This is essentially due to the leak-tight nature of the dual-containment of the ANS. The same is true for all cases where the containment isolates and functions as designed (viz., cases SC1-B, SC2-B, and SC2-BF). For the cases where only the primary containment has failed, the $0.05 \mathrm{~Sv}$ ( $5 \mathrm{rem}$ ) whole body dose protective action guide limit (PAG) is exceeded. These amounts are about 10 times greater for the MCCI cases compared to the steaming-pool case SC1-C. For the cases where both the primary and secondary containment have failed, the mean number of individuals exceeding the $0.05 \mathrm{~Sv}$ (5 rem) PAG limit ranges in the several thousand. However, for the lungs and bone marrow limits given in Table 3.5 only the MCCI cases are significant.

Tables 3.5 through 3.7 present a breakdown of mean values for the total (i.e., person-sieverts) and individual doses to the thyroid, and whole body for each of the ten cases as a function of distance from the ANS site. It is important to note here that individual dose values shown in Tables 3.5 through 3.7 are not MACCS predicitions. These were evaluated separately by simply dividing total papulation dose values for a given ring by the total number of people originally in that ring. In reality, individual doses will vary with time, grid elements, wind speed, and direction also at evacuation speed, and other emergency protection measures. Internally, MACCS does account for these parameters dynamically. For all cases, the estimated average individual dose is seen to decrease rapidly away from the ANS site. As noted from Table 3.5 for the steaming pool cases, only the cases where containment failure has occurred are significant. The $0.25 \mathrm{~Sv}$ ( $25 \mathrm{rem}$ ), and $0.05 \mathrm{~Sv}$ ( $5 \mathrm{rem}$ ) PAG limits for the thyroid, and whole body dose limits are exceeded only for the SC1-A case where the primary and secondary containments have failed.

Table 3.6 presents results for the various MCCI cases without flooding. Overall trends are similar to those seen for the steaming pool cases discussed earlier. In contrast, however, for people close to the ANS site (i.e., within $2 \mathrm{~km}$ ), the SC2-A and SC2-C cases lead to dose levels which exceed the PAG limits for the whole body and thyroid. This is to be expected based upon the source terms predicted for the MCCI cases compared to the steaming pool cases.

Table 3.7 presents results for tile various $\mathrm{MCCI}$ cases with flooding. Overall trends are similar to those seen for the MCCI cases without flooding. However, due to the nature of the source terms for cases with flooding, individual doses for individuals closer 
to the ANS site are smaller. However, for greater distances the dose levels increase as the magnitude of the source terms for the cases with flooding are greater when integrated over the transient time frame.

It is realized at this stage, that a priori judgment cannot be made on whether $\mathrm{MCCI}$ situations with flooding will always lead to the trend consequences described earlier. This is because the end result relating to consequences is a function of several key assumptions made in the modeling process, which includes some large uncertainties.

Tables 3.8 through 3.17 present a summary of average individual risk (prompt and latent) from the two scenarios assuming $100 \%$ frequency of occurrence (i.e., MACCS evaluated risk values for Scenarios 1 and 2), and also accounting for the frequency of occurrence of the two scenarios (i.e., effective fatality risk) for various rings in the polar grid. Once again, as expected Scenario 2 cases dominate risk of prompt and latent cancer fatalities. It should be noted that the MACCS calculated risk for prompt and latent cancer fatality values presented in Tables 3.8 through 3.17 are not the measures of actual risk. As mentioned in the introduction portion of Chapter 1.2, in order to obtain estimates of effective risk, fatality risk estimates presented for the accident scenarios representing early containment failure should be nuultiplied by the conditional probabilities for each case as tabulated in Table 1.3. The columns under the heading "Effective Fatality Risk" reflect this aspect.

It is likely that there will be a further reduction in source terms from removal of conservatisms via best-estimate evaluations (which would then lead to lowering of fatality estimates). Based upon the results shown in Tables 3.3 through 3.17, and Figs. 3.2 through 3.37 it is seen that the ANS risk goals in individual categories shown in Table 3.18 (reproduced from ORNL/TM-11625) are met with a very wide margin for all of the ten cases analyzed, under the various assumptions mentioned earlier. It is realized that overall risk will have to consider several additional severe accidents in various release categories. However, it is expected that the risk from the other accidents will be lower than the ones highlighted in Tables 3.3 through 3.17 and in the CCDFs.

In retrospect, the margin of safety that has been demonstrated at this stage of development is a credit to the extremely low risk of core damage occurrence in the first place (i.e., ANS core damage frequency goal of less than $10^{-5}$ occurrences per year), coupled with an ANS containment failure frequency design goal of less than $10^{-2}$ per occurrence of a severe accident.

Nevertheless, the prompt fatality values evaluated for Scenario 2 cases are considered by the ANS Project to be very undesirable. Actions are being taken to prevent this from occurring. Efforts currently in place include: (1) best-estimate evaluation of core 
melt progression and fission product release and transport, and (2) the introduction of severe accident mitigative features such as, the use of alumina concrete coupled with a flooding strategy to eliminate/minimize $\mathrm{MCCl}$ occurrence, and the introduction of missile shields positioned strategically to absorb loads from generated shocks and missiles that may have the potential for causing containment failure. Such measures, when adopted, will prevent a direct path for release of radionuclides out of the containment, significantly reduce (by up to $90 \%$ ) the release of combustible gases, and most importantly may reveal a very low possibility for core debris relocation out of the RCS, or that considerable time elapses before core debris relocates onto the subpile room floor (thereby allowing sufficient time for evacuation). When these aspects are taken into account, it is expected that prompt fatalities for a Scenario 2-type event will also drop down to zero, thereby leading to an ANS which is safe both from probabilistic and deterministic standpoints (i.e., negligibly low values for risk, and also no fatalities and/or injuries given a severe accident does occur). 
Table 3.1. Population distribution and emergency response zones for MACCS calculations

\begin{tabular}{|c|c|c|c|}
\hline Ring and outer boundary designation & $\begin{array}{c}\text { Distance } \\
{[\mathbf{k m} \text { (miles)] }}\end{array}$ & Population & Emergency response \\
\hline 1. ANS site boundary fence & $0-0.177(0-0.11)$ & 449 & Evacuation to safe regions \\
\hline $\begin{array}{l}\text { 2. Exclusion area boundary (EAB) to } \\
1.6 \mathrm{~km} \text { (includes HFIR) }\end{array}$ & $0.177-1.0(0.11-0.62)$ & $\mathbf{0}$ & Evacuation to safe regions \\
\hline 3. & $1.0-1.6(0.62-1.0)$ & 285 & Evacuation to safe regions \\
\hline 4. Low population zone (LPZ) to $2 \mathrm{~km}$ & $1.6-2.0(1.0-1.25)$ & 200 & Evacuation to safe regions \\
\hline $\begin{array}{l}\text { 5. Immediate notification zone (INZ) } \\
\text { to } 3.22 \mathrm{~km} ; \mathrm{X}-10 \text { site (1) }\end{array}$ & $2.0-3.22(1.25-2.0)$ & 7006 & $\begin{array}{l}\text { Sheltering for } 6 \mathrm{~h} \text {, } \\
\text { then evacuation to safety }\end{array}$ \\
\hline 6. & $3.22-4.82(2.0-3.0)$ & 73 & Possible relocation \\
\hline 7. & $4.82-6.44(3.0-4.0)$ & 1915 & Possible relocation \\
\hline $\begin{array}{l}\text { 8. Emergency planning zone (EPZ) to } \\
8.05 \mathrm{~km} \text { ( } 5 \text { miles) }\end{array}$ & $6.44-8.05(4.0-5.0)$ & 15397 & Possible relocation \\
\hline 9. & $8.05-16.09(5.0-10.0)$ & 70640 & Possible relocation \\
\hline 10. & $16.09-32.19(10.0-20.0)$ & 241868 & Possible relocation \\
\hline 11. & $32.19-48.28(20.0-30.0)$ & 288553 & Possible relocation \\
\hline 12. & $48.28-64.37(30.0-40.0)$ & 140583 & Possible relocation \\
\hline 13. & $64.37-80.47(40.0-50.0)$ & 144776 & Possible relocation \\
\hline & Total Population $=$ & 911745 & \\
\hline
\end{tabular}

Note: The majority of the population in this ring are ORNL employees located at X-10. The 2-mile INZ distance also incompasses a handful of residents on private property in Knox County. Emergency actions for these individuals include sheltering in place, or relocation to safety. 
Table 3.2. Population Distribution Around ANS

\begin{tabular}{|c|c|c|c|c|c|c|c|c|c|c|c|c|c|c|}
\hline Ring & 1 & 2 & 3 & 4 & 5 & 6 & 7 & 8 & 9 & 10 & 11 & 12 & 13 & \\
\hline $\begin{array}{l}\text { Distance (mile) } \\
\text { Distance (km) }\end{array}$ & $\begin{array}{l}0.11 \\
0.18 \\
\end{array}$ & $\begin{array}{l}0.63 \\
1.00 \\
\end{array}$ & $\begin{array}{l}1.00 \\
1.60 \\
\end{array}$ & $\begin{array}{l}1.25 \\
2.00 \\
\end{array}$ & $\begin{array}{l}.00 \\
3.22 \\
\end{array}$ & $\begin{array}{l}3.00 \\
4.83 \\
\end{array}$ & $\begin{array}{l}4.00 \\
6.44 \\
\end{array}$ & $\begin{array}{l}5.00 \\
8.05 \\
\end{array}$ & $\begin{array}{l}10.00 \\
16.09 \\
\end{array}$ & $\begin{array}{l}20.00 \\
32.19 \\
\end{array}$ & $\begin{array}{l}30.00 \\
48.28 \\
\end{array}$ & $\begin{array}{l}40.00 \\
64.37 \\
\end{array}$ & $\begin{array}{l}50.00 \\
80.47 \\
\end{array}$ & Total \\
\hline $\mathbf{N}$ & 29 & 0 & 0 & 0 & 0 & $n$ & 0 & 4,915 & 9,159 & 2,746 & 3.461 & 3.071 & 7,961 & 31,342 \\
\hline NNE & 28 & 0 & 0 & 0 & 0 & 0 & 0 & 4,754 & 1,5613 & 6,776 & 14,492 & 16,406 & 7,625 & 65,694 \\
\hline NE & 28 & 0 & 0 & 0 & 0 & 0 & 0 & 0 & 1,740 & 17,237 & 10,575 & 6,713 & 7,673 & 43,966 \\
\hline ENE & 28 & 0 & 0 & 140 & 0 & 0 & 73 & 96 & 2,758 & 54,821 & 78,998 & 19,532 & 18.704 & 175.150 \\
\hline $\mathbf{E}$ & 28 & 0 & 0 & 0 & 0 & 4 & 60 & 141 & 7,195 & 80,539 & 80,943 & 21,434 & 19,434 & 209,778 \\
\hline ESE & 28 & 0 & 0 & 0 & 3 & 15 & 13 & 93 & 9,991 & 17,245 & 33,881 & 7,314 & 9,025 & 77,608 \\
\hline SE & 28 & 0 & 0 & 0 & 3 & 23 & 31 & 37 & 1,854 & 8,452 & 20,906 & 165 & 2,673 & 34,172 \\
\hline SSE & 28 & 0 & 0 & 0 & 3 & 12 & 158 & 302 & 4,081 & 5,004 & 4,497 & 700 & 2,922 & 17,707 \\
\hline $\mathbf{S}$ & 28 & 0 & 0 & 0 & 0 & 11 & 170 & 234 & 7,124 & 6,334 & 7,897 & 6,743 & 3,657 & 32,208 \\
\hline SSW & 28 & 0 & 0 & 0 & 0 & 8 & 96 & 183 & 1,560 & 5,738 & 11,534 & 23,474 & 13,676 & 56,297 \\
\hline SW & 28 & 0 & 0 & 0 & 8 & 0 & 0 & 23 & 1,265 & 3,317 & 3,682 & 7,276 & 9,776 & 25,375 \\
\hline WSW & 28 & 0 & 200 & 0 & 0 & 0 & 0 & 34 & 1,096 & 9,990 & 5,000 & 6,368 & 6,473 & 29,189 \\
\hline $\mathbf{W}$ & 28 & 0 & 75 & 60 & 3,495 & 0 & 0 & 3,019 & 1,400 & 13,693 & 6,490 & 8,761 & 16,299 & 53,320 \\
\hline WNW & 28 & 0 & 0 & 0 & 3,494 & 0 & $\mathbf{0}$ & 0 & 1,313 & 3,358 & 2,555 & 2,793 & 4,149 & 17,690 \\
\hline NW & 28 & $\mathbf{0}$ & 0 & 0 & 0 & 0 & 972 & 279 & 2,090 & 5,702 & 2,628 & 3,245 & 8,112 & 23,056 \\
\hline NNW & 28 & 0 & 0 & 0 & 0 & 0 & 342 & 1,287 & 2,401 & 916 & 1,014 & 6,588 & 6,617 & 19,193 \\
\hline Total & 449 & 0 & 285 & 200 & 7,006 & 73 & 1,915 & 15,397 & 70,640 & 241,868 & 288,553 & 140,583 & 144,776 & 911,745 \\
\hline
\end{tabular}

Notes: (1) ANS site boundary extends to 0.11 miles $(0.177 \mathrm{~km})$.

(2) Exclusion Area Boundary (EAB) extends to 0.625 mile $(1 \mathrm{~km})$

(3) Low Population Zone (LPZ) extends to 1.25 miles $(2 \mathrm{~km})$.

(4) Immidiate Notification Zone (INZ) extends to 2 miles $(3.2 \mathrm{~km}$ ).

(5) Emergency Planning Zone (EPZ) extends to 5 miles (8.05 km). 
Table 3.3. Mean values for health consequences for various accident scenarios

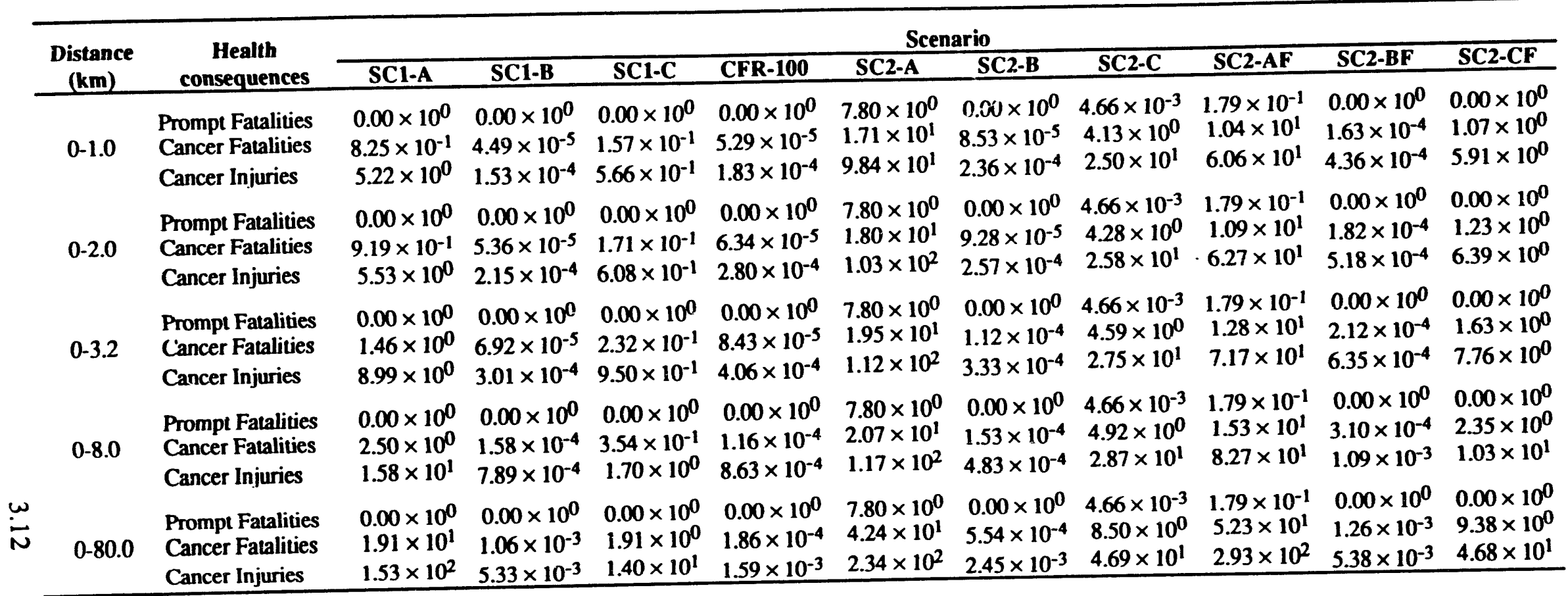

Notes: (1) Cancer injuries imply cancer of the stomach, lungs, thyroid, and skin.

(2) For CFR-100 case, 95 th percentile values are used. 
Table 3.4. Number of population exceeding specified dose of various organs for each scenario

\begin{tabular}{|c|c|c|c|c|c|c|c|c|c|c|c|}
\hline \multirow[b]{2}{*}{ Organ } & \multirow{2}{*}{$\begin{array}{c}\text { Dose } \\
\text { limits } \\
\text { (Sv) }\end{array}$} & \multicolumn{10}{|c|}{ Population exceeding dose } \\
\hline & & SC1-A & SC1-B & SCl-C & CFR-100 & SC2-A & SC2-B & $\mathrm{SC} 2-\mathrm{C}$ & SC2-AF & SC2-BF & SC2-CF \\
\hline Red marrow & $>1.5$ & $\mathbf{0}$ & $\mathbf{0}$ & $\mathbf{0}$ & $\mathbf{0}$ & 18.7 & $\mathbf{0}$ & 0.032 & 1.22 & $\mathbf{0}$ & $\mathbf{0}$ \\
\hline Lungs & $>0.5$ & $\mathbf{0}$ & $\mathbf{0}$ & 0 & $\mathbf{0}$ & 22.8 & $\mathbf{0}$ & 0.283 & 3.62 & 0 & $\mathbf{0}$ \\
\hline Whole body & $>0.05$ & 1550 & 0 & 9.9 & $\mathbf{0}$ & 3410 & $\mathbf{0}$ & 214 & 2810 & $\mathbf{0}$ & 110 \\
\hline
\end{tabular}

Notes: (1) Population exceeding dose is based on mean value (except for CFR-100 where it is based on the 95th percentile values).

(2) Population for red marrow and lungs based on acute doses.

(3) Population for whole body exposure is based on life-time dose.

(4) Red Marrow and Lung dose limits for 1.5 and $0.5 \mathrm{~Sv}$ are acute doses.

(5) Whole body dose limit of $0.05 \mathrm{~Sv}$ is based on EPA guidelines for incorporation of protective measures. Note that $0.25 \mathrm{sv}$ is the corresponding 10CFR 100 limitation. 
Table 3.5. Population and individual doses for the steaming pool accidents

\begin{tabular}{|c|c|c|c|c|c|c|c|c|c|c|}
\hline \multirow[b]{2}{*}{ Population } & \multirow[b]{2}{*}{$\begin{array}{c}\text { Distance } \\
\text { (km) }\end{array}$} & \multirow[b]{2}{*}{ Organ } & \multicolumn{2}{|c|}{ SC1-A } & \multicolumn{2}{|c|}{ SC1-B } & \multicolumn{2}{|c|}{ SC1-C } & \multicolumn{2}{|c|}{ CFR-100 } \\
\hline & & & $\begin{array}{l}\text { Total dose } \\
\text { (person-Sv) }\end{array}$ & $\begin{array}{l}\text { Individual } \\
\text { dose (Sv) }\end{array}$ & $\begin{array}{l}\text { Total dose } \\
\text { (person-Sv) }\end{array}$ & $\begin{array}{l}\begin{array}{l}\text { Individual } \\
\text { dose (Sv) }\end{array} \\
\end{array}$ & $\begin{array}{c}\text { Total dose } \\
\text { (person-Sv) }\end{array}$ & $\begin{array}{l}\text { Individual } \\
\text { dose (Sv) }\end{array}$ & $\begin{array}{c}\text { Total dose } \\
\text { (person-Sv) }\end{array}$ & $\begin{array}{l}\text { Individual } \\
\text { dose (Sv) }\end{array}$ \\
\hline $\begin{array}{l}449 \\
934\end{array}$ & $\begin{array}{l}0-1.0 \\
0-2.0\end{array}$ & $\begin{array}{l}\text { Whole body } \\
\text { Whole body }\end{array}$ & $\begin{array}{l}54.7 \\
60.5\end{array}$ & $\begin{array}{l}1.22 \times 10^{-1} \\
6.48 \times 10^{-2}\end{array}$ & $\begin{array}{l}3.03 \times 10^{-3} \\
3.90 \times 10^{-3}\end{array}$ & $\begin{array}{l}6.75 \times 10^{-6} \\
4.18 \times 10^{-6}\end{array}$ & $\begin{array}{r}9.7 \\
10.6\end{array}$ & $\begin{array}{l}2.16 \times 10^{-2} \\
1.13 \times 10^{-2}\end{array}$ & $\begin{array}{l}3.45 \times 10^{-3} \\
4.36 \times 10^{-3}\end{array}$ & $\begin{array}{l}7.68 \times 10^{-6} \\
4.67 \times 10^{-6}\end{array}$ \\
\hline 7,940 & $0-3.2$ & Whole body & 97.9 & $1.23 \times 10^{-2}$ & $5.23 \times 10^{-3}$ & $6.59 \times 10^{-7}$ & 14.7 & $1.85 \times 10^{-3}$ & $6.35 \times 10^{-3}$ & $8.00 \times 10^{-7}$ \\
\hline 25,325 & $0-8.0$ & Whole body & 172.0 & $6.79 \times 10^{-3}$ & $1.22 \times 10^{-2}$ & $4.82 \times 10^{-7}$ & 23.5 & $9.28 \times 10^{-4}$ & $1.11 \times 10^{-2}$ & $4.38 \times 10^{-7}$ \\
\hline 911.745 & $0 \_80.5$ & Whole body & 1490.0 & $1.63 \times 10^{-3}$ & $7.60 \times 10^{-2}$ & $8.34 \times 10^{-8}$ & 146.0 & $1.60 \times 10^{-4}$ & $2.04 \times 10^{-2}$ & $2.24 \times 10^{-8}$ \\
\hline $\begin{array}{l}449 \\
934\end{array}$ & $\begin{array}{l}0-1.0 \\
0-2.0\end{array}$ & $\begin{array}{l}\text { Thyroid } \\
\text { Thyroid }\end{array}$ & $\begin{array}{l}623.0 \\
645.0\end{array}$ & $\begin{array}{l}1.39 \times 10^{0} \\
6.91 \times 10^{-1}\end{array}$ & $\begin{array}{l}1.08 \times 10^{-2} \\
1.85 \times 10^{-2}\end{array}$ & $\begin{array}{l}2.41 \times 10^{-5} \\
1.98 \times 10^{-5}\end{array}$ & $\begin{array}{l}43.6 \\
46.2\end{array}$ & $\begin{array}{l}9.71 \times 10^{-2} \\
4.95 \times 10^{-2}\end{array}$ & $\begin{array}{l}1.70 \times 10^{-2} \\
3.00 \times 10^{-2}\end{array}$ & $\begin{array}{l}3.79 \times 10^{-5} \\
3.21 \times 10^{-5}\end{array}$ \\
\hline 7,940 & $0-3 .=$ & Thyroid & 1060.0 & $1.34 \times 10^{-1}$ & $2.81 \times 10^{-2}$ & $3.54 \times 10^{-6}$ & 84.4 & $1.06 \times 10^{-2}$ & $4.90 \times 10^{-2}$ & $6.17 \times 10^{-6}$ \\
\hline 25,325 & $0 \_8.0$ & Thyroid & 1880.0 & $7.42 \times 10^{-2}$ & $8.17 \times 10^{-2}$ & $3.23 \times 10^{-6}$ & 173.0 & $6.83 \times 10^{-3}$ & $1.08 \times 10^{-1}$ & $4.26 \times 10^{-6}$ \\
\hline 911.745 & $0-80.5$ & Thyroid & 20000.0 & $2.19 \times 10^{-2}$ & $5.52 \times 10^{-1}$ & $6.05 \times 10^{-7}$ & 1780.0 & $1.95 \times 10^{-3}$ & $2.06 \times 10^{-1}$ & $2.26 \times 10^{-7}$ \\
\hline
\end{tabular}

Notes: (1) Values for doses are given assuming each scenario has occurred.

(2) Emergency response actions are included for the above estimates.

(3) Dose estimates are "mean"values for all cases except for CFR-100 where they are based on the 95th percentile values. 


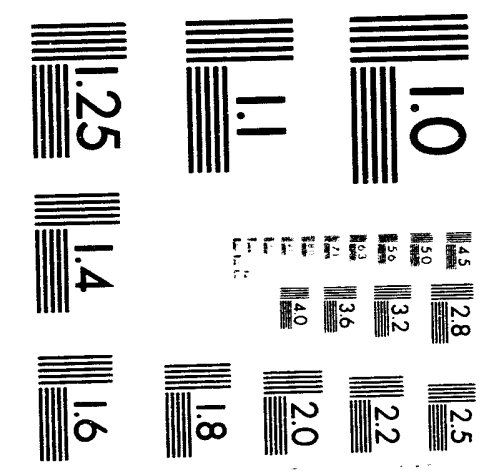



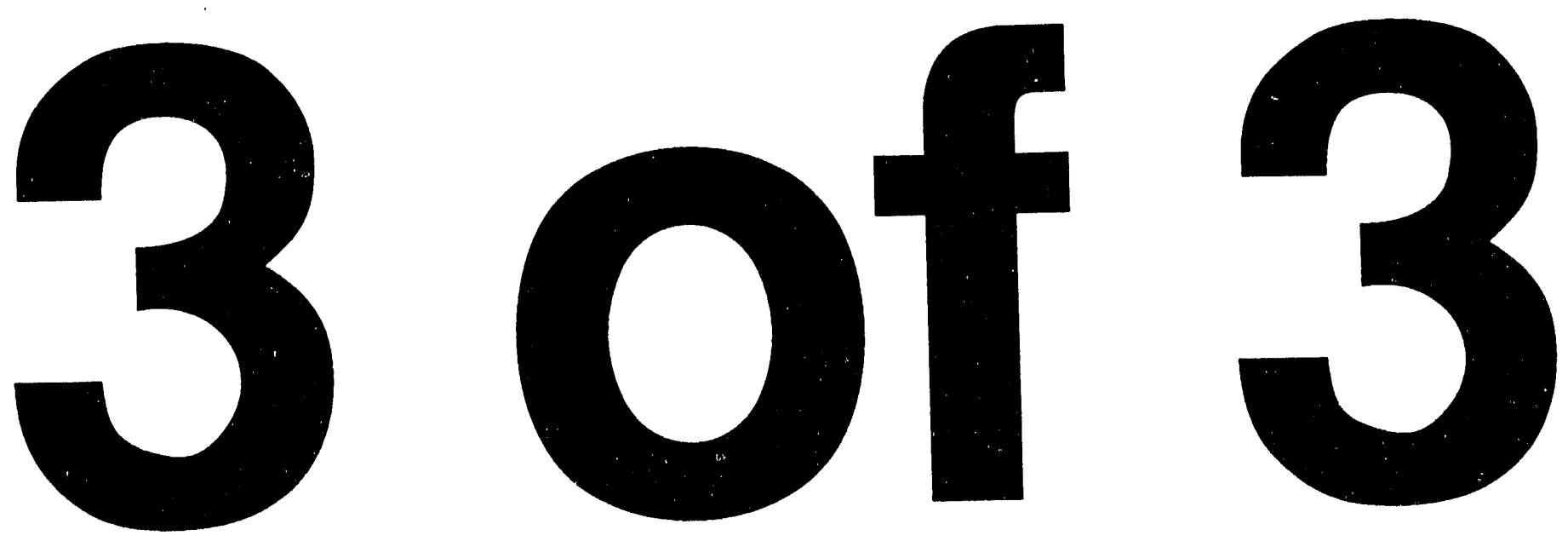
Table 3.6. Population and individual doses for the core concrete interaction cases without subpile room fooding

\begin{tabular}{|c|c|c|c|c|c|c|c|c|}
\hline \multirow[b]{2}{*}{ Population } & \multirow[b]{2}{*}{$\begin{array}{c}\text { Distance } \\
(\mathbf{k m})\end{array}$} & \multirow[b]{2}{*}{ Organ } & \multicolumn{2}{|c|}{ SC2-A } & \multicolumn{2}{|c|}{ SC2-B } & \multicolumn{2}{|c|}{ SC2-C } \\
\hline & & & $\begin{array}{l}\text { Total dose } \\
\text { (person-Sv) }\end{array}$ & $\begin{array}{c}\text { Individual } \\
\text { dose (Sv) }\end{array}$ & $\begin{array}{c}\text { Total dose } \\
\text { (person-Sv) }\end{array}$ & $\begin{array}{c}\text { Individual } \\
\text { dose (Sv) }\end{array}$ & $\begin{array}{c}\text { Total dose } \\
\text { (person-Sv) }\end{array}$ & $\begin{array}{l}\begin{array}{l}\text { Individual } \\
\text { dose (Sv) }\end{array} \\
\end{array}$ \\
\hline & $0-1.0$ & Whole body & 961 & $2.14 \times 10^{0}$ & $5.08 \times 10^{-3}$ & $1.13 \times 10^{-5}$ & 182 & $4.05 \times 10^{-1}$ \\
\hline $\begin{array}{l}449 \\
934\end{array}$ & $0-2.0$ & Whole body & $\begin{array}{r}901 \\
1000\end{array}$ & $1.07 \times 10^{0}$ & $5.54 \times 10^{-3}$ & $5.93 \times 10^{-6}$ & 191 & $2.04 \times 10^{-1}$ \\
\hline 7,940 & $0-3.2$ & Whole body & 1090 & $1.37 \times 10^{-1}$ & $6.63 \times 10^{-3}$ & $8.35:<10^{-7}$ & 209 & $2.63 \times 10^{-2}$ \\
\hline 25,325 & $0-8.0$ & Whole body & 1160 & $4.58 \times 10^{-2}$ & $8.96 \times 10^{-3}$ & $3.54 \times 10^{-7}$ & 228 & $9.00 \times 10^{-3}$ \\
\hline 911,745 & $0-80.5$ & Whole body & 2450 & $2.69 \times 10^{-3}$ & $2.95 \times 10^{-2}$ & $3.24 \times 10^{-8}$ & 438 & $4.80 \times 10^{-4}$ \\
\hline 449 & $0-1.0$ & Thyroid & 16800 & $3.74 \times 10^{-1}$ & $1.13 \times 10^{-2}$ & $2.52 \times 10^{-5}$ & 3040 & $6.77 \times 10^{0}$ \\
\hline 934 & $0-2.0$ & Thyroid & 17400 & $1.86 \times 10^{-1}$ & $1.24 \times 10^{-2}$ & $1.33 \times 10^{-5}$ & 3130 & $3.35 \times 10^{0}$ \\
\hline 7,940 & $0-3.2$ & Thyroid & 18400 & $2.32 \times 10^{0}$ & $1.89 \times 10^{-2}$ & $2.38 \times 10^{-6}$ & 3310 & $4.17 \times 10^{-1}$ \\
\hline 25,325 & $0-8.0$ & Thyroid & 18900 & $7.46 \times 10^{-1}$ & $3.10 \times 10^{-2}$ & $1.22 \times 10^{-6}$ & 3410 & $1.35 \times 10^{-1}$ \\
\hline 911,745 & $0-80.5$ & Thyroid & 31900 & $3.50 \times 10^{-2}$ & $2.38 \times 10^{-1}$ & $2.61 \times 10^{-7}$ & 5350 & $5.87 \times 10^{-3}$ \\
\hline
\end{tabular}

Notes: (1) Values for doses are given assuming each scenario has occurred.

(2) Emergency response actions are included for the above estimates.

(3) Dose estimates are "mean"values. 
Table 3.7. Population and individual doses for the core contrete interaction cases with subpile room flooding

\begin{tabular}{|c|c|c|c|c|c|c|c|c|}
\hline \multirow[b]{2}{*}{ Population } & \multirow[b]{2}{*}{$\begin{array}{c}\begin{array}{c}\text { Distance } \\
(\mathbf{k m})\end{array} \\
\end{array}$} & \multirow[b]{2}{*}{ Organ } & \multicolumn{2}{|c|}{ SC2-A } & \multicolumn{2}{|c|}{ SC2-B } & \multicolumn{2}{|c|}{ SC2-C } \\
\hline & & & $\begin{array}{l}\text { Total dose } \\
\text { (person-Sv) }\end{array}$ & $\begin{array}{l}\text { Individual } \\
\text { dose (Sv) }\end{array}$ & $\begin{array}{c}\text { Total dose } \\
\text { (person-Sv) }\end{array}$ & $\begin{array}{l}\text { Individual } \\
\text { dose (Sv) }\end{array}$ & $\begin{array}{l}\text { Total dose } \\
\text { (person-Sv) }\end{array}$ & $\begin{array}{l}\text { Individual } \\
\text { dose (Sv) }\end{array}$ \\
\hline 449 & $0-1.0$ & Whole body & 440 & $9.80 \times 10^{-1}$ & $9.98 \times 10^{-3}$ & $2.22 \times 10^{-5}$ & 60 & $1.33 \times 10^{-1}$ \\
\hline 934 & $0-2.0$ & Whole body & 469 & $5.02 \times 10^{-1}$ & $1.14 \times 10^{-2}$ & $1.22 \times 10^{-5}$ & 69 & $7.41 \times 10^{-2}$ \\
\hline 7,940 & $0-3.2$ & Whole body & 577 & $7.27 \times 10^{-2}$ & $1.35 \times 10^{-2}$ & $1.70 \times 10^{-6}$ & 93 & $1.16 \times 10^{-2}$ \\
\hline 25,325 & $0-8.0$ & Whole body & 729 & $2.88 \times 10^{-2}$ & $2.06 \times 10^{-2}$ & $8.13 \times 10^{-7}$ & 135 & $5.33 \times 10^{-3}$ \\
\hline 911,745 & $0-80.5$ & Whole body & 3060 & $3.36 \times 10^{-3}$ & $8.37 \times 10^{-2}$ & $9.18 \times 10^{-8}$ & 570 & $6.25 \times 10^{-4}$ \\
\hline 449 & $0-1.0$ & Thyroid & 7340 & $1.63 \times 10^{-1}$ & $1.89 \times 10^{-2}$ & $4.21 \times 10^{-5}$ & 666 & $1.48 \times 10^{0}$ \\
\hline 934 & $0-2.0$ & Thyroid & 7530 & $8.06 \times 10^{0}$ & $2.66 \times 1,-2$ & $2.85 \times 10^{-5}$ & 694 & $7.43 \times 10^{-1}$ \\
\hline 7,940 & $0-3.2$ & Thyroid & 8470 & $1.07 \times 10^{0}$ & $3.65 \times 10^{-2}$ & $4.60 \times 10^{-6}$ & 793 & $9.99 \times 10^{-2}$ \\
\hline 25,325 & $0-8.0$ & Thyroid & 9510 & $3.76 \times 10^{-1}$ & $8.12 \times 10^{-2}$ & $3.21 \times 10^{-6}$ & 992 & $3.92 \times 10^{-2}$ \\
\hline 911,745 & $0-80.5$ & Thyroid & 33300 & $3.65 \times 10^{-2}$ & $4.94 \times 10^{-1}$ & $5.42 \times 10^{-7}$ & 4930 & $5.41 \times 10^{-3}$ \\
\hline
\end{tabular}

Notes: (1) Values for doses are given assuming each scenario has occurred.

(2) Emergency response actions are included for the above estimates.

(3) Dose estimates are "mean" values. 
Table 3.8. Variation of average individual risk from the Scenario CFR-100

\begin{tabular}{|c|c|c|c|c|}
\hline \multirow{2}{*}{$\begin{array}{c}\text { Distance } \\
(\mathbf{k m})\end{array}$} & \multicolumn{2}{|c|}{ MACCS fataility risk estimates (1) } & \multicolumn{2}{|c|}{ Effective fatality risk (2) } \\
\hline & Prompt & Cancer & Prompt & Cancer \\
\hline $0-0.2$ & 0.0 & $9.95 \times 10^{-8}$ & 0.0 & $2.49 \times 10^{-13}$ \\
\hline $0.2-1.0$ & 0.0 & $1.12 \times 10^{-8}$ & 0.0 & $2.80 \times 10^{-14}$ \\
\hline $1.0-1.6$ & 0.0 & $3.95 \times 10^{-9}$ & 0.0 & $9.88 \times 10^{-15}$ \\
\hline $1.6-2.0$ & 0.0 & $2.51 \times 10^{-9}$ & 0.0 & $6.28 \times 10^{-15}$ \\
\hline $2.0-3.2$ & 0.0 & $1.44 \times 10^{-9}$ & 0.0 & $3.60 \times 10^{-15}$ \\
\hline $6.4-8.0$ & 0.0 & $3.29 \times 10^{-10}$ & 0.0 & $8.23 \times 10^{-16}$ \\
\hline $64.4-80.5$ & 0.0 & $1.04 \times 10^{-13}$ & 0.0 & $2.60 \times 10^{-19}$ \\
\hline
\end{tabular}

Notes: (1) Estimates under "MACCS fatality risk estimates" assume a probability of 1 for occurrence.

(2) Estimates under "Effective fatality risk" include the probability of $2.5 \times$ $10^{-6}$ for occurrence.

(3) Risk estimates are the 95 th percentile values (fatalities/yr). 
Table 3.9. Variation of average individual risk from the Scenario SC1-A

\begin{tabular}{cccccc}
\hline \multirow{2}{*}{$\begin{array}{c}\text { Distance } \\
(\mathbf{k m})\end{array}$} & \multicolumn{2}{c}{ MACCS fataility risk estimates (1) } & \multicolumn{2}{c}{ Effective fatality risk (2) } \\
\cline { 2 - 3 } \cline { 6 - 7 } & Prompt & Cancer & & Prompt & Cancer \\
\hline $0-0.2$ & 0.0 & $1.73 \times 10^{3}$ & & 0.0 & $4.33 \times 10^{-9}$ \\
$0.2-1.0$ & 0.0 & $2.40 \times 10^{4}$ & & 0.0 & $6.00 \times 10^{-10}$ \\
$1.0-1.6$ & 0.0 & $8.78 \times 10^{5}$ & 0.0 & $2.20 \times 10^{-10}$ \\
$1.6-2.0$ & 0.0 & $5.62 \times 10^{5}$ & 0.0 & $1.41 \times 10^{-10}$ \\
$2.0-3.2$ & 0.0 & $9.97 \times 10^{5}$ & & 0.0 & $2.49 \times 10^{-10}$ \\
$6.4-8.0$ & 0.0 & $8.07 \times 10^{5}$ & & 0.0 & $2.02 \times 10^{-10}$ \\
$64.4-80.5$ & 0.0 & $2.64 \times 10^{6}$ & 0.0 & $6.60 \times 10^{-12}$ \\
\hline
\end{tabular}

Notes: (1) Estimates under "MACCS fatality risk estimates" assume a probability of 1 for occurrence.

(2) Estimates under "Effective fatality risk" include the probability of $2.5 \times$ $10^{-6}$ for occurrence.

(3) Risk estimates are the 95th percentile values (fatalities/yr). 
Table 3.10. Variation of average individual risk from the Scenario SC1-B

\begin{tabular}{cccccc}
\hline \multirow{2}{*}{$\begin{array}{c}\text { Distance } \\
(\mathrm{km})\end{array}$} & \multicolumn{2}{c}{ MACCS fataility risk estimates (1) } & \multicolumn{2}{c}{ Effective fatality risk (2) } \\
\cline { 2 - 3 } \cline { 6 - 7 } Prompt & Cancer & \multicolumn{2}{c}{ Prompt } & Cancer \\
\hline $0-0.2$ & 0.0 & $8.37 \times 10^{-8}$ & 0.0 & $2.09 \times 10^{-13}$ \\
$0.2-1.0$ & 0.0 & $8.27 \times 10^{-9}$ & 0.0 & $2.07 \times 10^{-14}$ \\
$1.0-1.6$ & 0.0 & $3.02 \times 10^{-9}$ & 0.0 & $7.55 \times 10^{-15}$ \\
$1.6-2.0$ & 0.0 & $1.98 \times 10^{-9}$ & 0.0 & $4.95 \times 10^{-15}$ \\
$2.0-3.2$ & 0.0 & $1.59 \times 10^{-9}$ & 0.0 & $3.98 \times 10^{-15}$ \\
$6.4-8.0$ & 0.0 & $5.24 \times 10^{-9}$ & 0.0 & $1.31 \times 10^{-14}$ \\
$64.4-80.5$ & 0.0 & $8.85 \times 10^{-11}$ & 0.0 & $2.21 \times 10^{-16}$ \\
\hline
\end{tabular}

Notes: (1) Estimates under "MACCS fatality risk estimates" assume a probability of 1 for occurrence.

(2) Estimates under "Effective fatality risk" include the probability of $2.5 \times$ $10^{-6}$ for occurrence.

(3) Risk estimates are the 95 th percentile values (fatalities/yr). 
Table 3.11. Variation of average individual risk from the Scenario SC1-C

\begin{tabular}{|c|c|c|c|c|}
\hline \multirow{2}{*}{$\begin{array}{c}\text { Distance } \\
(\mathbf{k m})\end{array}$} & \multicolumn{2}{|c|}{ MACCS fataility risk estimates (1) } & \multicolumn{2}{|c|}{ Effective fatality risk (2) } \\
\hline & Prompt & Cancer & Prompt & Cancer \\
\hline $0-0.2$ & 0.0 & $3.32 \times 10^{-4}$ & 0.0 & $4.15 \times 10^{-10}$ \\
\hline $0.2-1.0$ & 0.0 & $3.33 \times 10^{-5}$ & 0.0 & $4.16 \times 10^{-11}$ \\
\hline $1.0-1.6$ & 0.0 & $1.25 \times 10^{-5}$ & 0.0 & $1.56 \times 10^{-11}$ \\
\hline $1.6-2.0$ & 0.0 & $8.86 \times 10^{-6}$ & 0.0 & $1.11 \times 10^{-11}$ \\
\hline $2.0-3.2$ & 0.0 & $1.16 \times 10^{-5}$ & 0.0 & $1.45 \times 10^{-11}$ \\
\hline $6.4-8.0$ & 0.0 & $8.87 \times 10^{-6}$ & 0.0 & $1.11 \times 10^{-11}$ \\
\hline $64.4-80.5$ & 0.0 & $2.32 \times 10^{-7}$ & 0.0 & $2.90 \times 10^{-13}$ \\
\hline
\end{tabular}

Notes: (1) Estimates under "MACCS fatality risk estimates" assume a probability of 1 for occurrence.

(2) Estimates under "Effective fatality risk" include the probability of $2.5 \times$ $10^{-6}$ for occurrence.

(3) Risk estimates are the 95 th percentile values (fatalities/yr). 
Table 3.12. Variation of average individual risk from the Scenario SC2-A

\begin{tabular}{cccccc}
\hline \multirow{2}{*}{$\begin{array}{c}\text { Distance } \\
(\mathrm{km})\end{array}$} & \multicolumn{2}{c}{ MACCS fataility risk estimates $(\mathbf{1})$} & \multicolumn{2}{c}{ Effective fatality risk (2) } \\
\cline { 2 - 3 } \cline { 5 - 6 } & Prompt & Cancer & & Prompt & Cancer \\
\hline $0-0.2$ & $1.74 \times 10^{-2}$ & $3.81 \times 10^{-2}$ & & $5.22 \times 10^{-9}$ & $1.14 \times 10^{-8}$ \\
$0.2-1.0$ & $1.05 \times 10^{5}$ & $3.59 \times 10^{-3}$ & & $3.15 \times 10^{-12}$ & $1.08 \times 10^{-9}$ \\
$1.0-1.6$ & 0.0 & $9.57 \times 10^{-4}$ & 0.0 & $2.87 \times 10^{-10}$ \\
$1.6-2.0$ & 0.0 & $4.99 \times 10^{-4}$ & 0.0 & $1.50 \times 10^{-10}$ \\
$2.0-3.2$ & 0.0 & $3.46 \times 10^{-4}$ & & 0.0 & $1.04 \times 10^{-10}$ \\
$6.4-8.0$ & 0.0 & $8.75 \times 10^{-5}$ & & 0.0 & $2.63 \times 10^{-11}$ \\
$64.4-80.5$ & 0.0 & $3.04 \times 10^{-6}$ & 0.0 & $9.12 \times 10^{-13}$ \\
\hline
\end{tabular}

Notes: (1) Estimates under "MACCS fatality risk estimates" assume a probability of 1 fo- occurrence.

(2) Estimates under "Effective fatality risk" include the probability of $3.0 \times$ $10^{-7}$ for occurrence.

(3) Risk estimates are the 95 th percentile values (fatalities/yr). 
Table 3.13. Variation of averate individual risk from the Scenario SC2-B

\begin{tabular}{cccccc}
\hline \multirow{2}{*}{$\begin{array}{c}\text { Distance } \\
(\mathbf{k m})\end{array}$} & \multicolumn{2}{c}{ MACCS fataility risk estimates (1) } & \multicolumn{2}{c}{ Effective fatality risk (2) } \\
\cline { 2 - 3 } \cline { 5 - 6 } & Prompt & Cancer & & Prompt & Cancer \\
\hline $0-0.2$ & 0.0 & $1.79 \times 10^{-7}$ & 0.0 & $2.24 \times 10^{-13}$ \\
$0.2-1.0$ & 0.0 & $1.49 \times 10^{-8}$ & 0.0 & $1.86 \times 10^{-14}$ \\
$1.0-1.6$ & 0.0 & $4.98 \times 10^{-9}$ & 0.0 & $6.23 \times 10^{-15}$ \\
$1.6-2.0$ & 0.0 & $3.17 \times 10^{-9}$ & 0.0 & $3.96 \times 10^{-15}$ \\
$2.0-3.2$ & 0.0 & $3.51 \times 10^{-9}$ & & 0.0 & $4.39 \times 10^{-15}$ \\
$6.4-8.0$ & 0.0 & $2.75 \times 10^{-9}$ & 0.0 & $3.44 \times 10^{-15}$ \\
$64.4-80.5$ & 0.0 & $5.73 \times 10^{-11}$ & 0.0 & $7.16 \times 10^{-17}$ \\
\hline
\end{tabular}

Notes: (1) Estimates under "MACCS fatality risk estimates" assume a probability of 1 for occurrence.

(2) Estimates under "Effective fatality risk" include the probability of $1.25 \times$ $10^{-6}$ for occurrence.

(3) Risk estimates are the 95 th percentile values (fatalities/yr). 
Table 3.14. Variation of average individual risk from the Scenario SC2-C

\begin{tabular}{cccccc}
\hline \multirow{2}{*}{$\begin{array}{c}\text { Distance } \\
(\mathrm{km})\end{array}$} & \multicolumn{2}{c}{ MACCS fataility risk estimates (1) } & \multicolumn{2}{c}{ Effective fatality risk (2) } \\
\cline { 2 - 3 } \cline { 5 - 6 } & Prompt & Cancer & & Prompt & Cancer \\
\hline $0-0.2$ & $1.03 \times 10^{-5}$ & $9.17 \times 10^{-3}$ & $6.44 \times 10^{-12}$ & $5.50 \times 10^{-9}$ \\
$0.2-1.0$ & 0.0 & $6.12 \times 10^{-4}$ & 0.0 & $3.67 \times 10^{-10}$ \\
$1.0-1.6$ & 0.0 & $1.72 \times 10^{-4}$ & 0.0 & $1.03 \times 10^{-10}$ \\
$1.6-2.0$ & 0.0 & $9.43 \times 10^{-5}$ & 0.0 & $5.66 \times 10^{-11}$ \\
$2.0-3.2$ & 0.0 & $6.75 \times 10^{-5}$ & 0.0 & $4.05 \times 10^{-11}$ \\
$6.4-8.0$ & 0.0 & $2.10 \times 10^{-5}$ & 0.0 & $1.26 \times 10^{-11}$ \\
$64.4-80.5$ & 0.0 & $4.64 \times 10^{-7}$ & 0.0 & $2.78 \times 10^{-13}$ \\
\hline
\end{tabular}

Notes: (1) Estimates under "MACCS fatality risk estimates" assume a probability of 1 for occurrence.

(2) Estimates under "Effective fatality risk" include the probability of $6.0 \times$ $10^{-7}$ for occurrence.

(3) Risk estimates are the 95 th percentile values (fatalities/yr). 
Table 3.15. Variation of average individual risk from the Scenario SC2-AF

\begin{tabular}{cccccc}
\hline \multirow{2}{*}{$\begin{array}{c}\text { Distance } \\
(\mathrm{km})\end{array}$} & \multicolumn{2}{c}{ MACCS fataility risk estimates (1) } & \multicolumn{2}{c}{ Effective fatality risk (2) } \\
\cline { 2 - 3 } \cline { 5 - 6 } & Prompt & Cancer & & Prompt & Cancer \\
\hline $0-0.2$ & 0.0 & $2.30 \times 10^{-2}$ & 0.0 & $6.90 \times 10^{-9}$ \\
$0.2-1.0$ & 0.0 & $1.66 \times 10^{-3}$ & 0.0 & $4.98 \times 10^{-10}$ \\
$1.0-1.6$ & 0.0 & $5.48 \times 10^{-4}$ & 0.0 & $1.64 \times 10^{-10}$ \\
$1.6-2.0$ & 0.0 & $3.53 \times 10^{-4}$ & 0.0 & $1.06 \times 10^{-10}$ \\
$2.0-3.2$ & 0.0 & $3.91 \times 10^{-4}$ & 0.0 & $1.17 \times 10^{-10}$ \\
$6.4-8.0$ & 0.0 & $1.77 \times 10^{-4}$ & 0.0 & $5.31 \times 10^{-11}$ \\
$64.4-80.5$ & 0.0 & $5.21 \times 10^{-6}$ & 0.0 & $1.56 \times 10^{-12}$ \\
\hline
\end{tabular}

Notes: (1) Estimates under "MACCS fatality risk estimates" assume a probability of 1 for occurrence.

(2) Estimates under "Effective fatality risk" include the probability of $3.0 \times$ $10^{-7}$ for occurrence.

(3) Risk estimates are the 95 th percentile values (fatalities/yr). 
Table 3.16. Variation of average individual risk from the Scenario SC2-BF

\begin{tabular}{|c|c|c|c|c|}
\hline \multirow{2}{*}{$\begin{array}{c}\text { Distance } \\
(\mathrm{km})\end{array}$} & \multicolumn{2}{|c|}{ MACCS fataility risk estimates (1) } & \multicolumn{2}{|c|}{ Effective fatality risk (2) } \\
\hline & Prompt & Cancer & Prompt & Cancer \\
\hline $0-0.2$ & 0.0 & $3.30 \times 10^{-7}$ & 0.0 & $4.13 \times 10^{-13}$ \\
\hline $0.2-1.0$ & 0.0 & $2.87 \times 10^{-8}$ & 0.0 & $3.59 \times 10^{-14}$ \\
\hline $1.0-1.6$ & 0.0 & $9.94 \times 10^{-9}$ & 0.0 & $1.24 \times 10^{-14}$ \\
\hline $1.6-2.0$ & 0.0 & $6.54 \times 10^{-9}$ & 0.0 & $8.18 \times 10^{-15}$ \\
\hline $2.0-3.2$ & 0.0 & $4.50 \times 10^{-9}$ & 0.0 & $4.50 \times 10^{-15}$ \\
\hline $6.4-8.0$ & 0.0 & $5.65 \times 10^{-9}$ & 0.0 & $7.06 \times 10^{-15}$ \\
\hline $64.4-80.5$ & 0.0 & $9.23 \times 10^{-11}$ & 0.0 & $1.15 \times 10^{-16}$ \\
\hline
\end{tabular}

Notes: (1) Estimates under "MACCS fatality risk estimates" assume a probability of 1 for occurrence.

(2) Estimates under "Effective fatality risk" include the probability of $1.25 \times$ $10^{-6}$ for occurrence.

(3) Risk estimates are the 95 th percentile values (fatalities/yr). 
Table 3.17. Variation of average individual risk from the Scenario SC2-CF

\begin{tabular}{|c|c|c|c|c|}
\hline \multirow{2}{*}{$\begin{array}{c}\text { Distance } \\
\text { (km) }\end{array}$} & \multicolumn{2}{|c|}{ MACCS fataility risk estimates (1) } & \multicolumn{2}{|c|}{ Effective fatality risk (2) } \\
\hline & Prompt & Cancer & Prompt & Cancer \\
\hline $0-0.2$ & 0.0 & $2.33 \times 10^{-3}$ & 0.0 & $1.40 \times 10^{-9}$ \\
\hline $0.2-1.0$ & 0.0 & $3.72 \times 10^{-4}$ & 0.0 & $2.23 \times 10^{-10}$ \\
\hline $1.0-1.6$ & 0.0 & $1.61 \times 10^{-4}$ & 0.0 & $9.66 \times 10^{-11}$ \\
\hline $1.6-2.0$ & 0.0 & $1.10 \times 10^{-4}$ & 0.0 & $6.60 \times 10^{-11}$ \\
\hline $2.0-3.2$ & 0.0 & $8.70 \times 10^{-5}$ & 0.0 & $5.22 \times 10^{-11}$ \\
\hline $6.4-8.0$ & 0.0 & $4.54 \times 10^{-5}$ & 0.0 & $2.72 \times 10^{-11}$ \\
\hline $64.4-80.5$ & 0.0 & $9.24 \times 10^{-7}$ & 0.0 & $15.54 \times 10^{-13}$ \\
\hline
\end{tabular}

Notes: (1) Estimates under "MACCS fatality risk estimates" assume a probability of 1 for occurrence.

(2) Estimates under "Effective fatality risk" include the probability of $6.0 \times$ $10^{-7}$ for occurrence.

(3) Risk estimates are the 95 th percentile values (fatalities/yr). 
Table 3.18 Radiological accident risk limitation goals for the ANS

\begin{tabular}{llc}
\hline \multicolumn{1}{c}{ Population } & $\begin{array}{c}\text { Risk } \\
\text { mode }\end{array}$ & $\begin{array}{c}\text { Risk to } \\
\text { average individual }\end{array}$ \\
\hline $\begin{array}{l}\text { Off-site residents within } 1.6 \mathrm{~km}(1 \mathrm{mile}) \text { of } \\
\text { reservation boundary }\end{array}$ & Early & $4 \times 10^{-7 / \mathrm{yr}}$ \\
$\begin{array}{l}\text { On-site workers and visitorswithin } 1.6 \mathrm{~km} \\
(1 \mathrm{mile}) \text { of the ANS facility security fence }\end{array}$ & Early & $1 \times 10^{-6 / \mathrm{yr}}$ \\
$\begin{array}{l}\text { Off-site residents within } 16 \mathrm{~km} \text { (10 miles) of } \\
\text { the reservation boundary, and on-site workers } \\
\text { and guests }\end{array}$ & Latent & $2 \times 10^{-6} / \mathrm{yr}$ \\
\hline
\end{tabular}




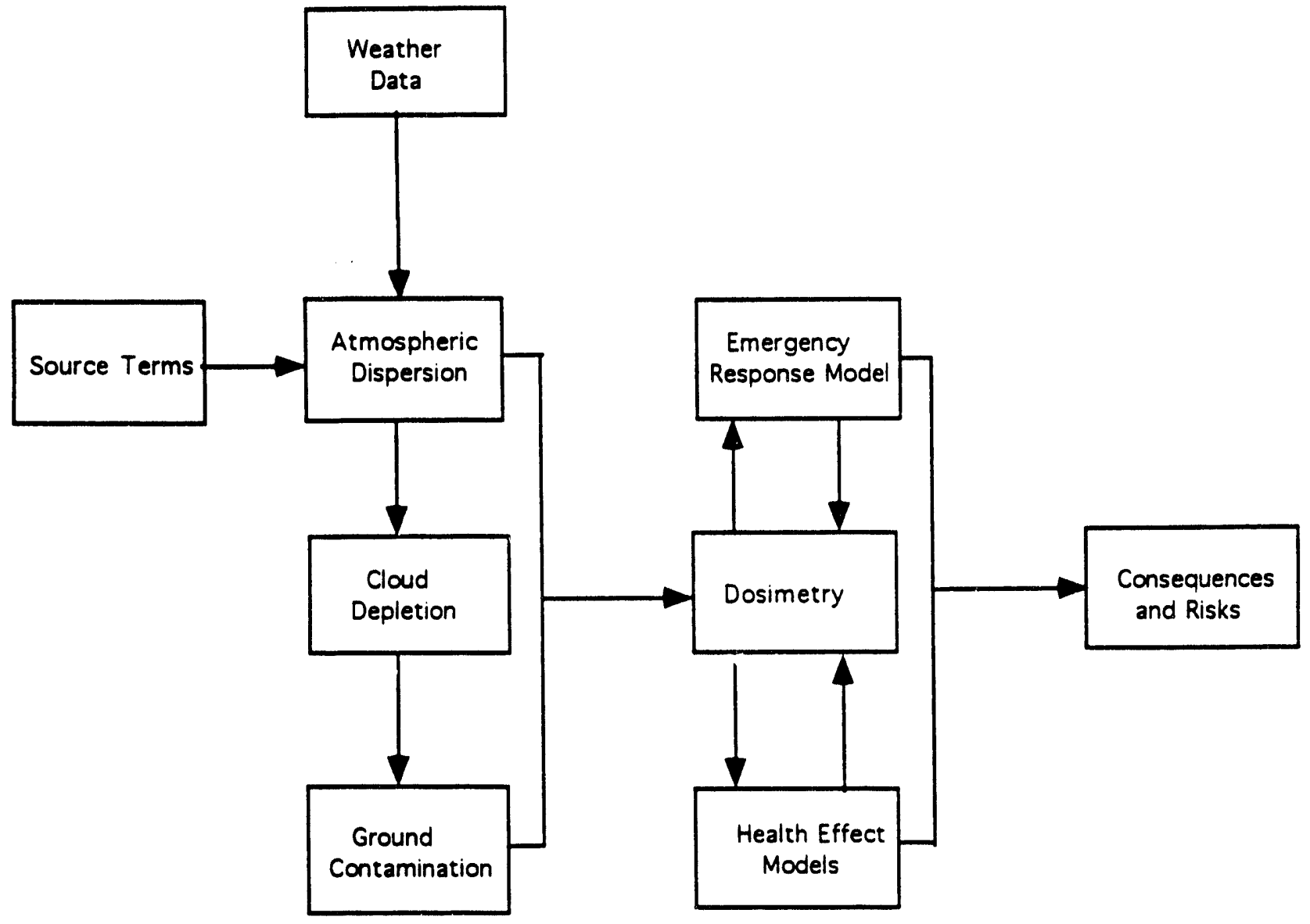

Figure 3.1 Schematic Representation for Radiological Consequences Calculations using MACCS 


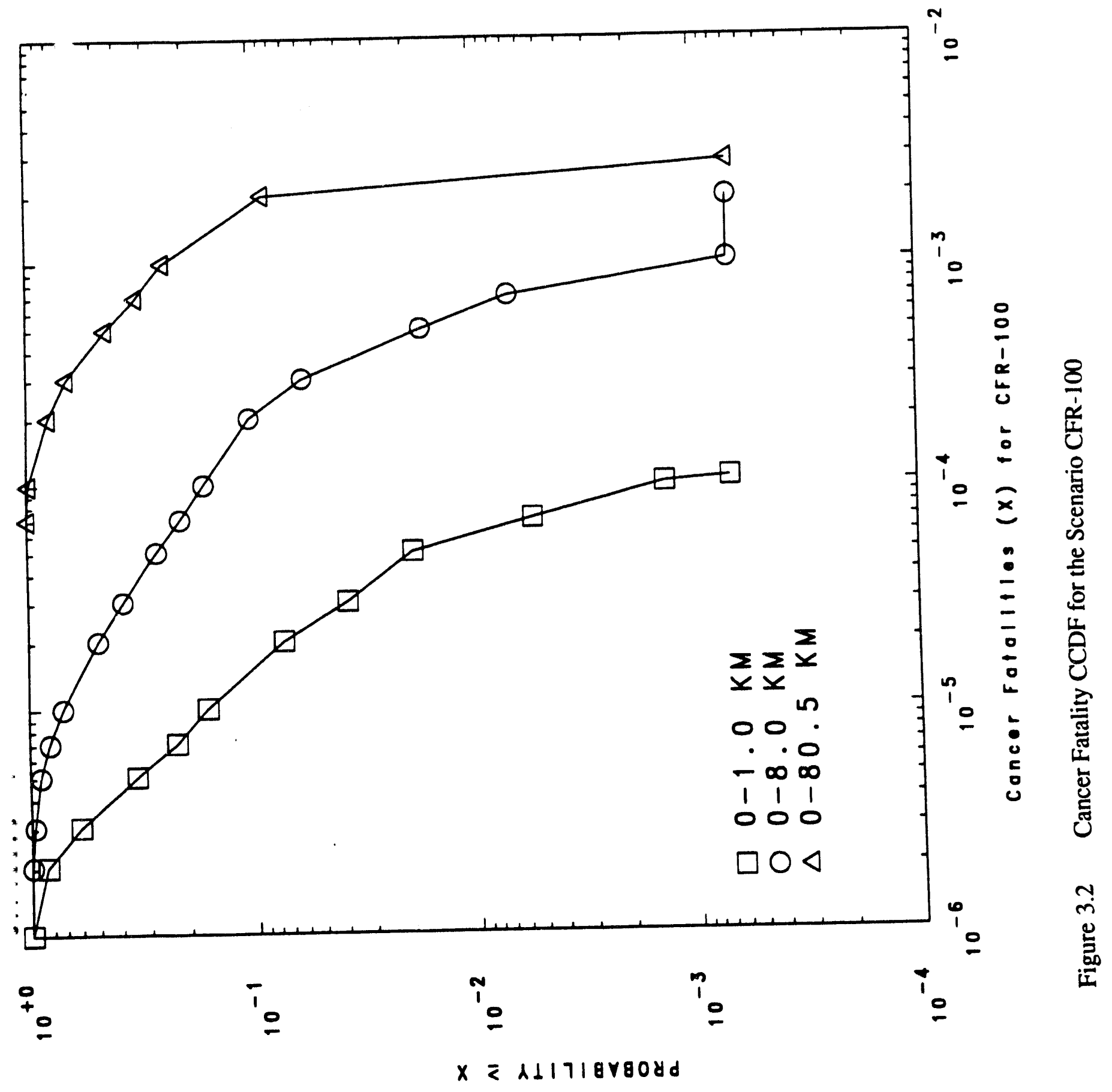


$0 \varepsilon^{\circ} \varepsilon$

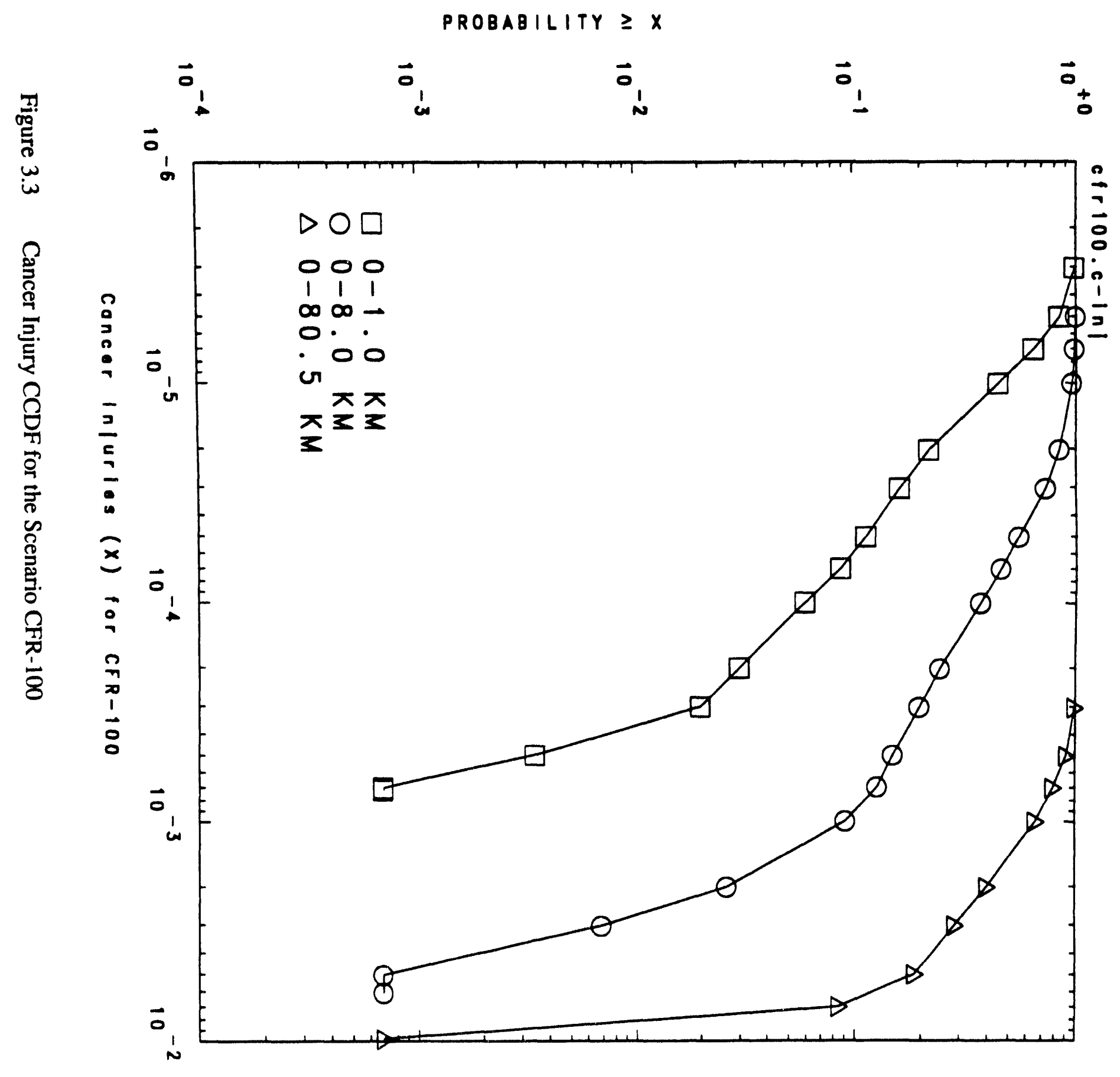




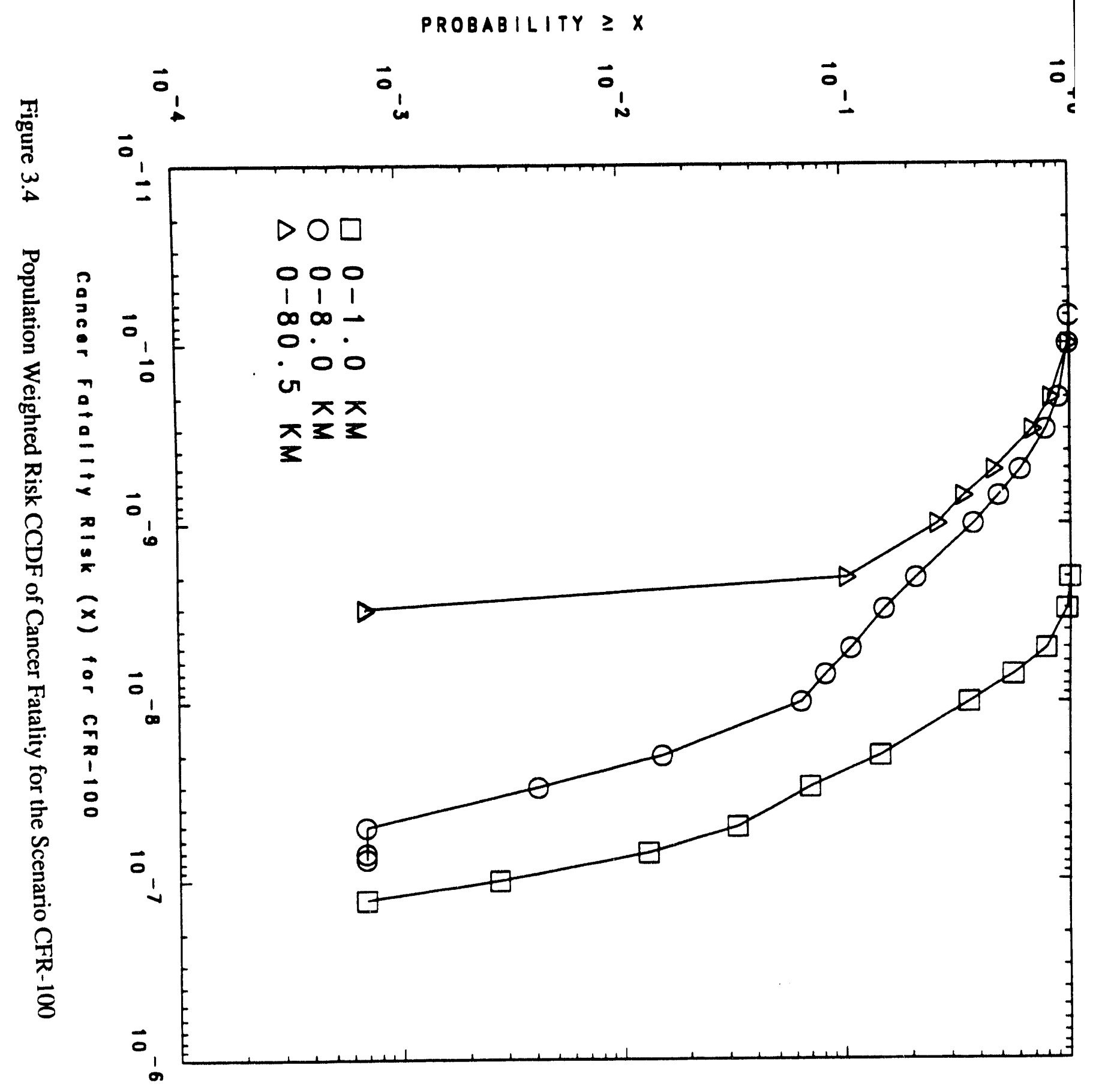




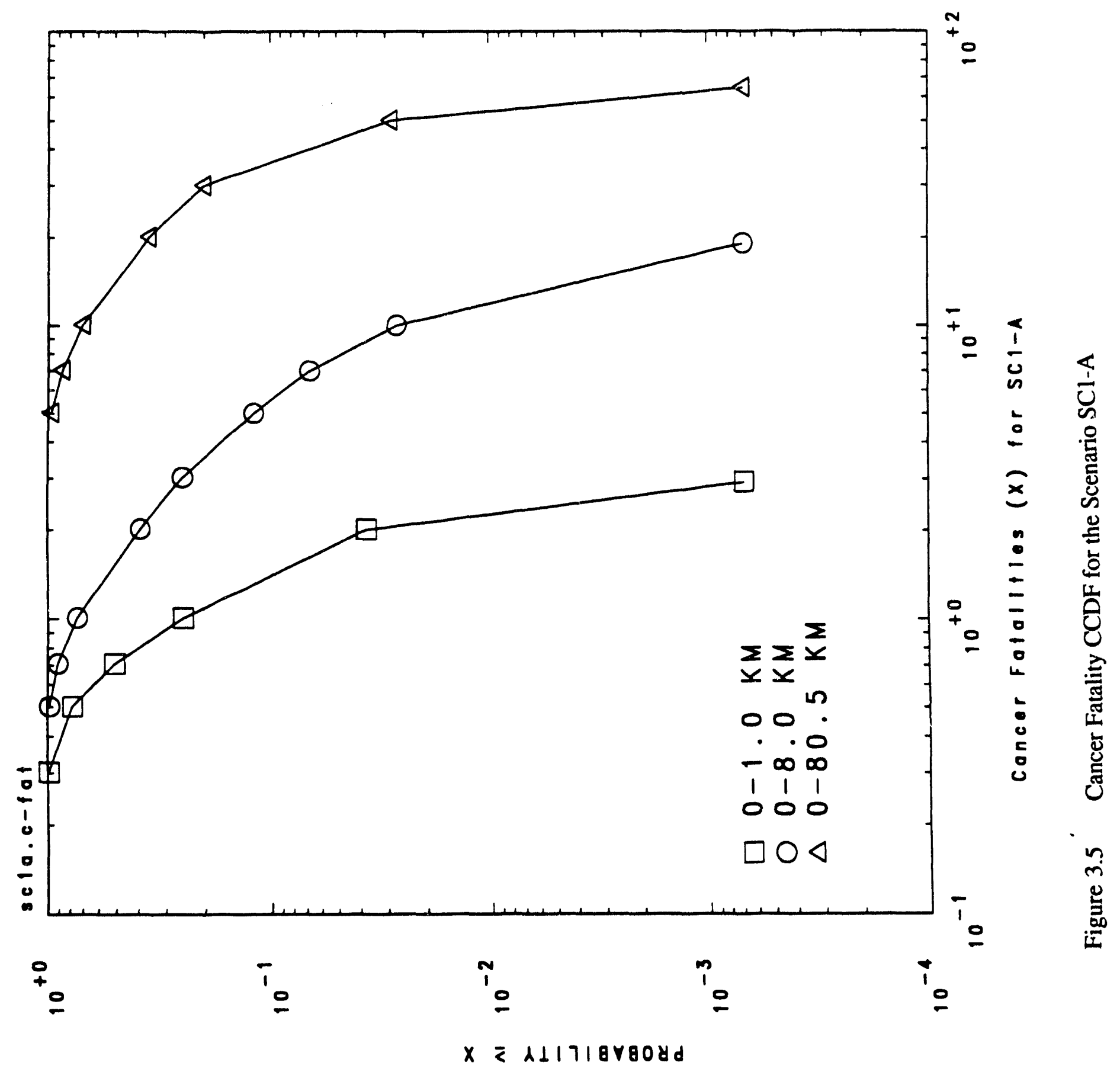




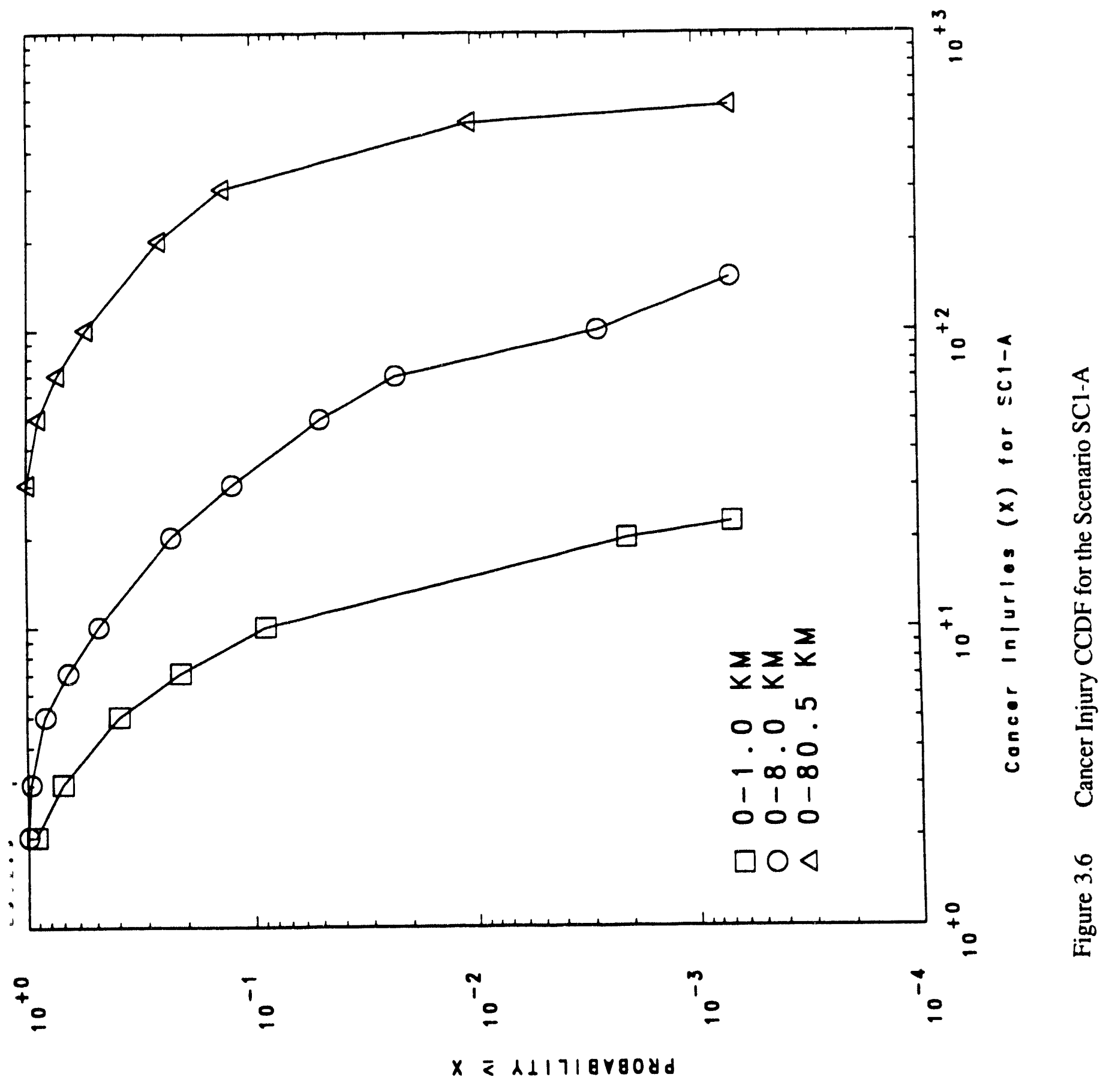




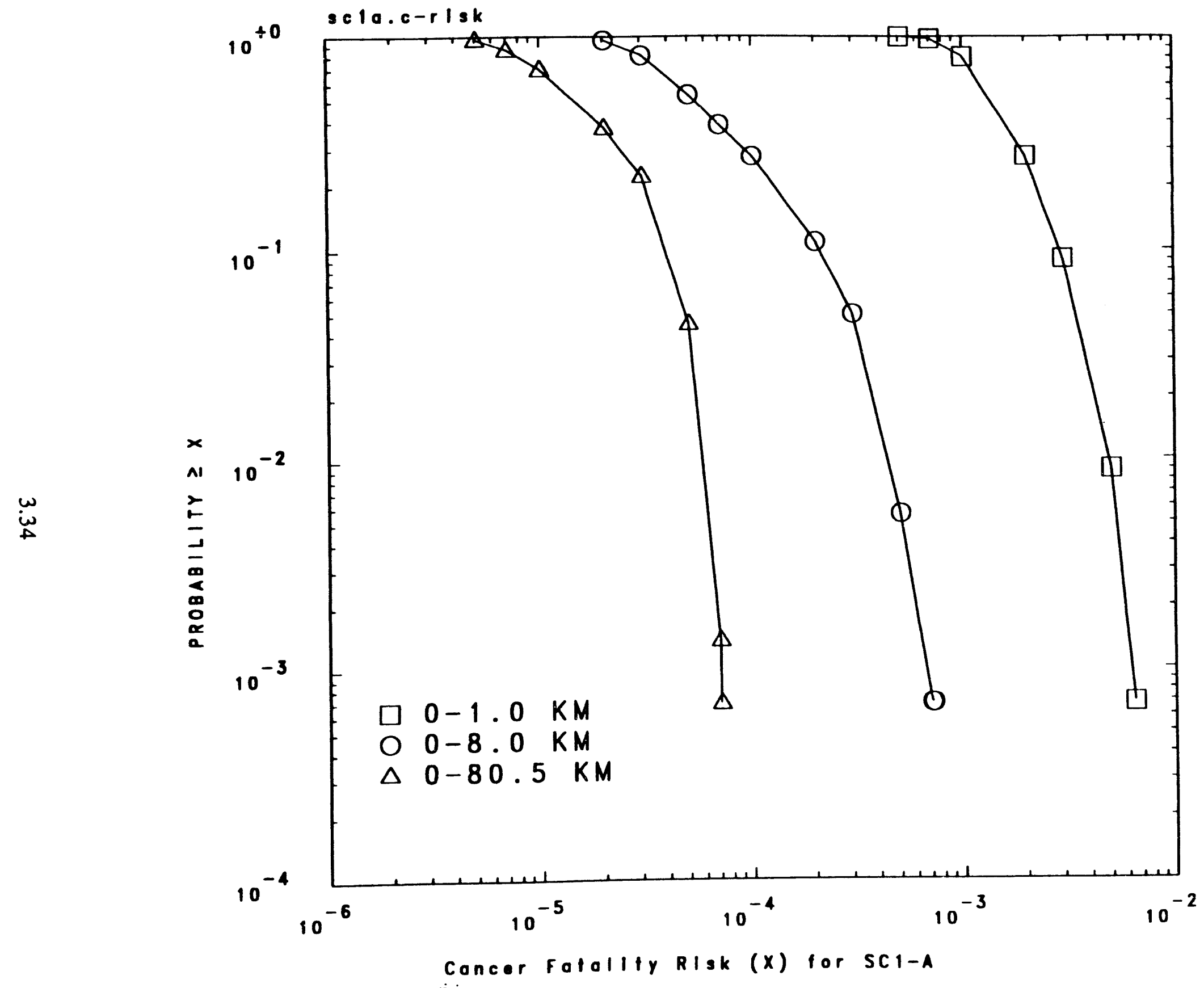

Figure 3.7 Population Weighted Risk CCDF of Cancer Fatality for the Scenario SC1-A 


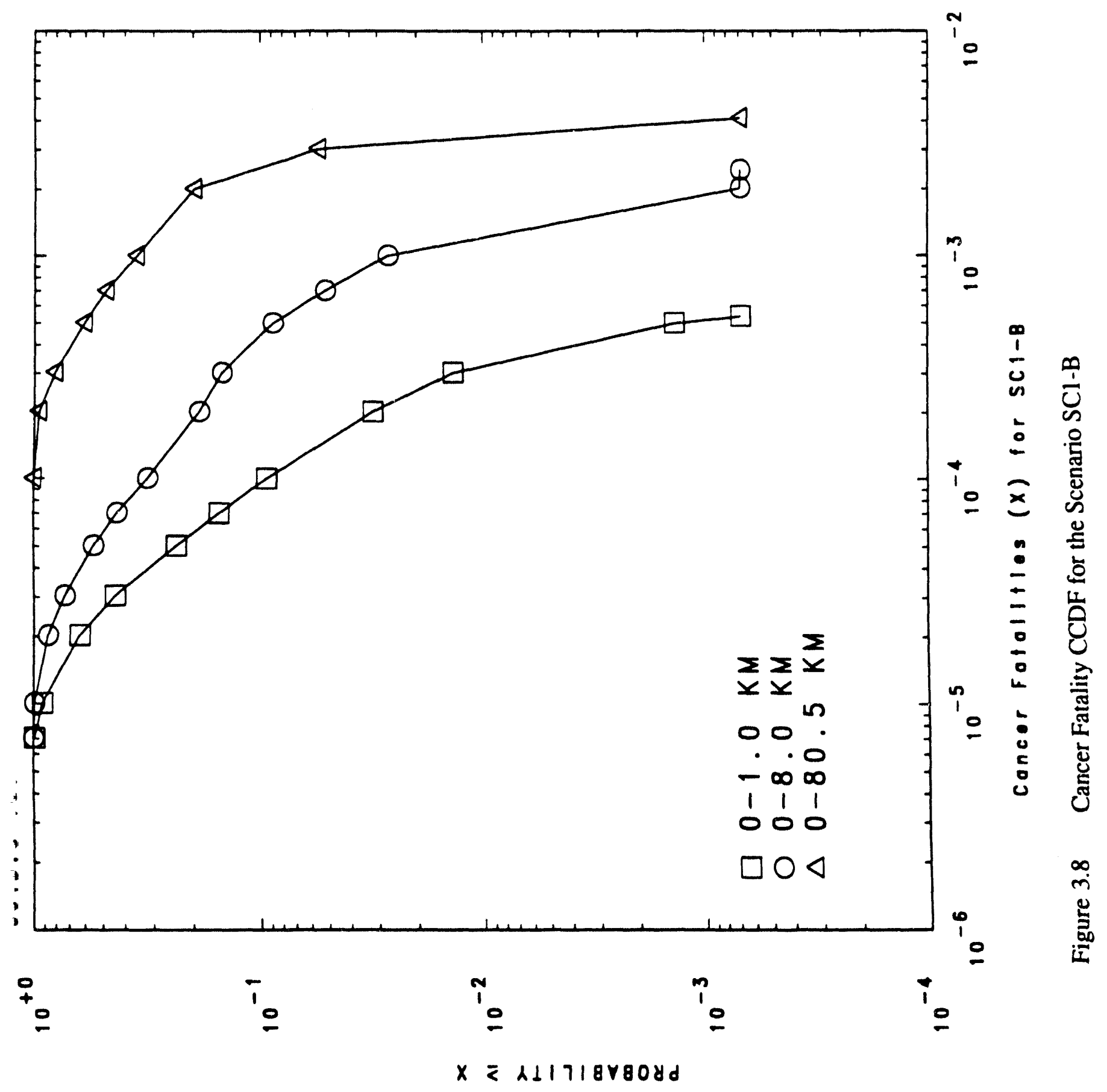




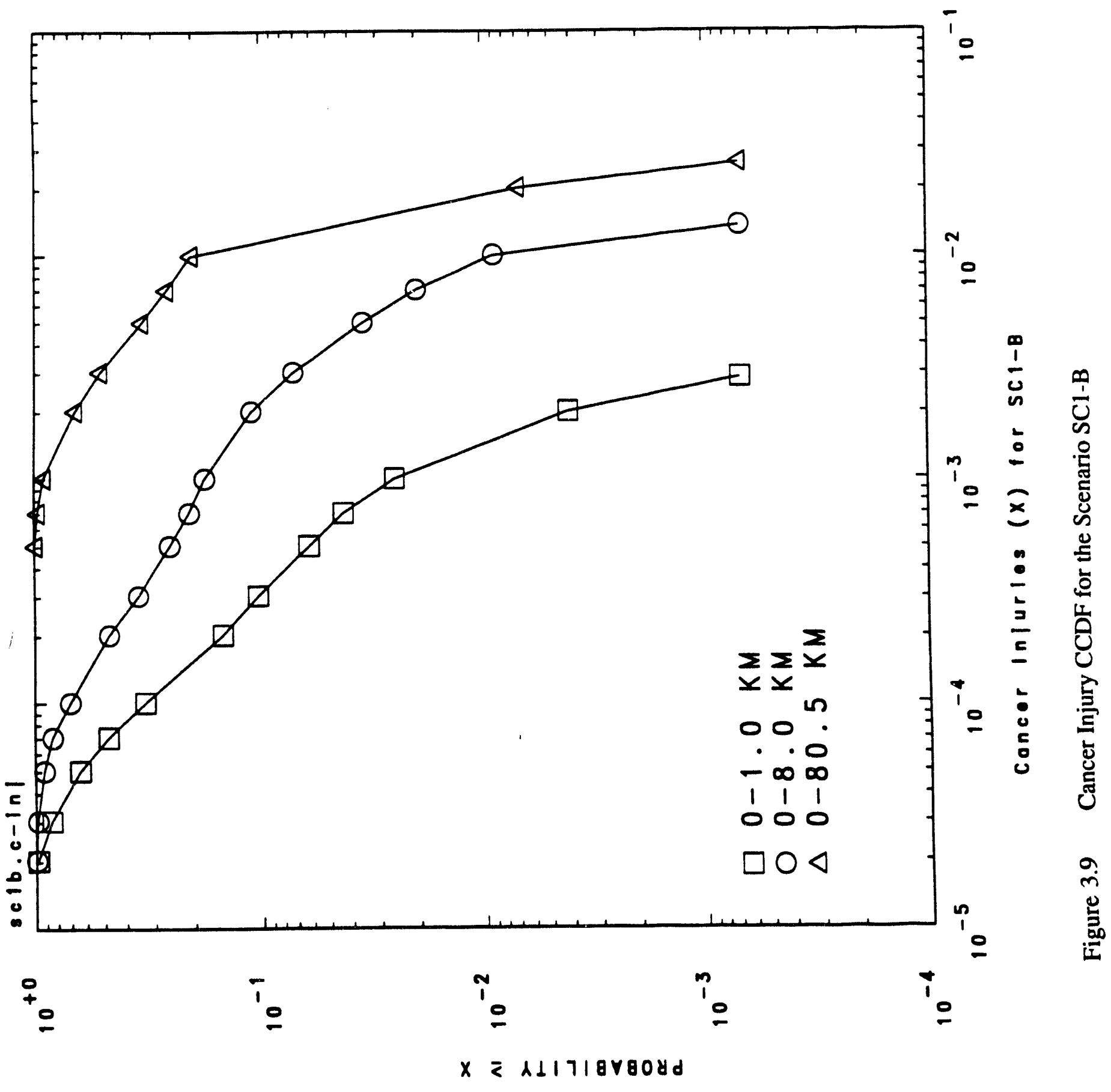




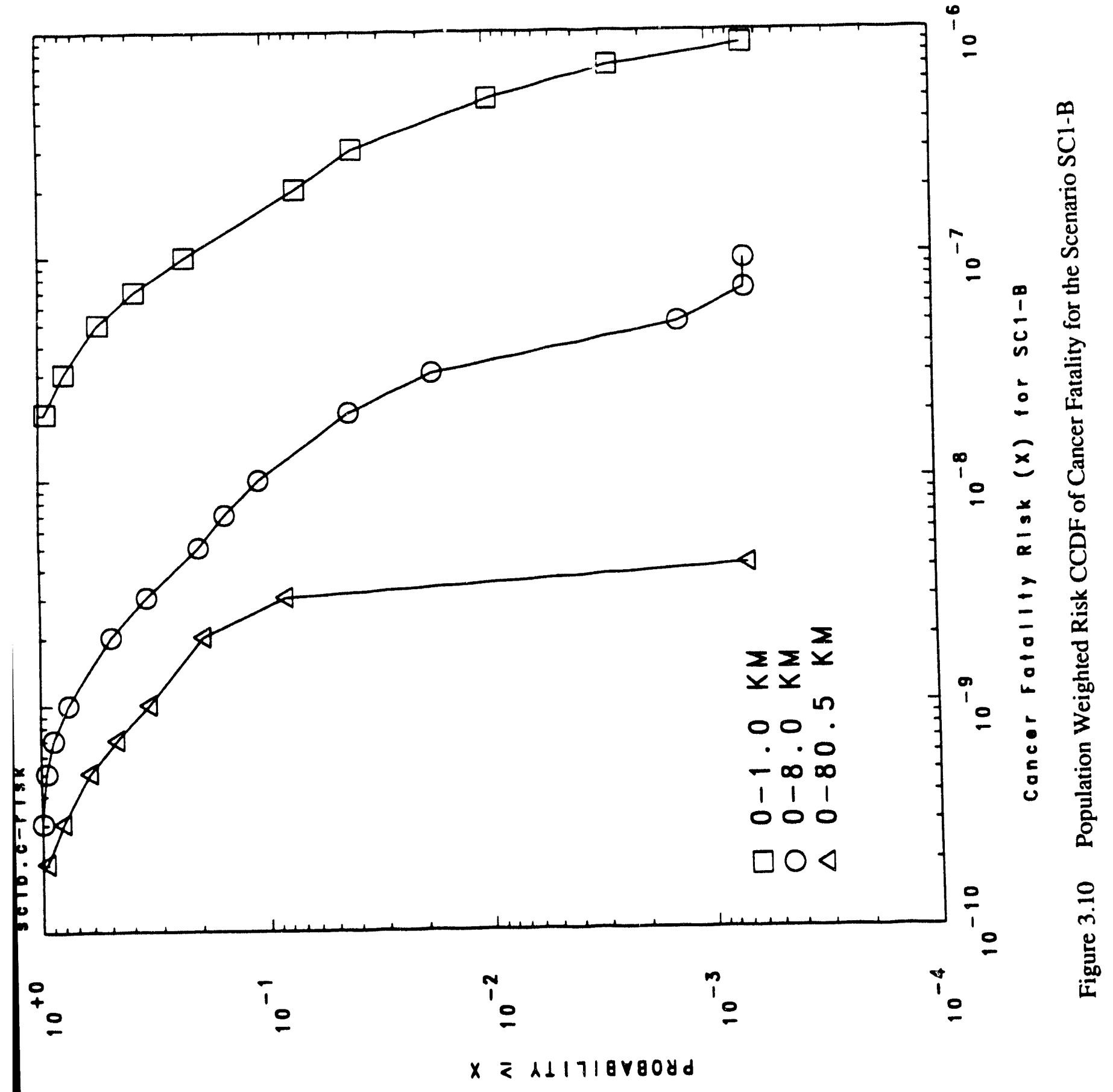




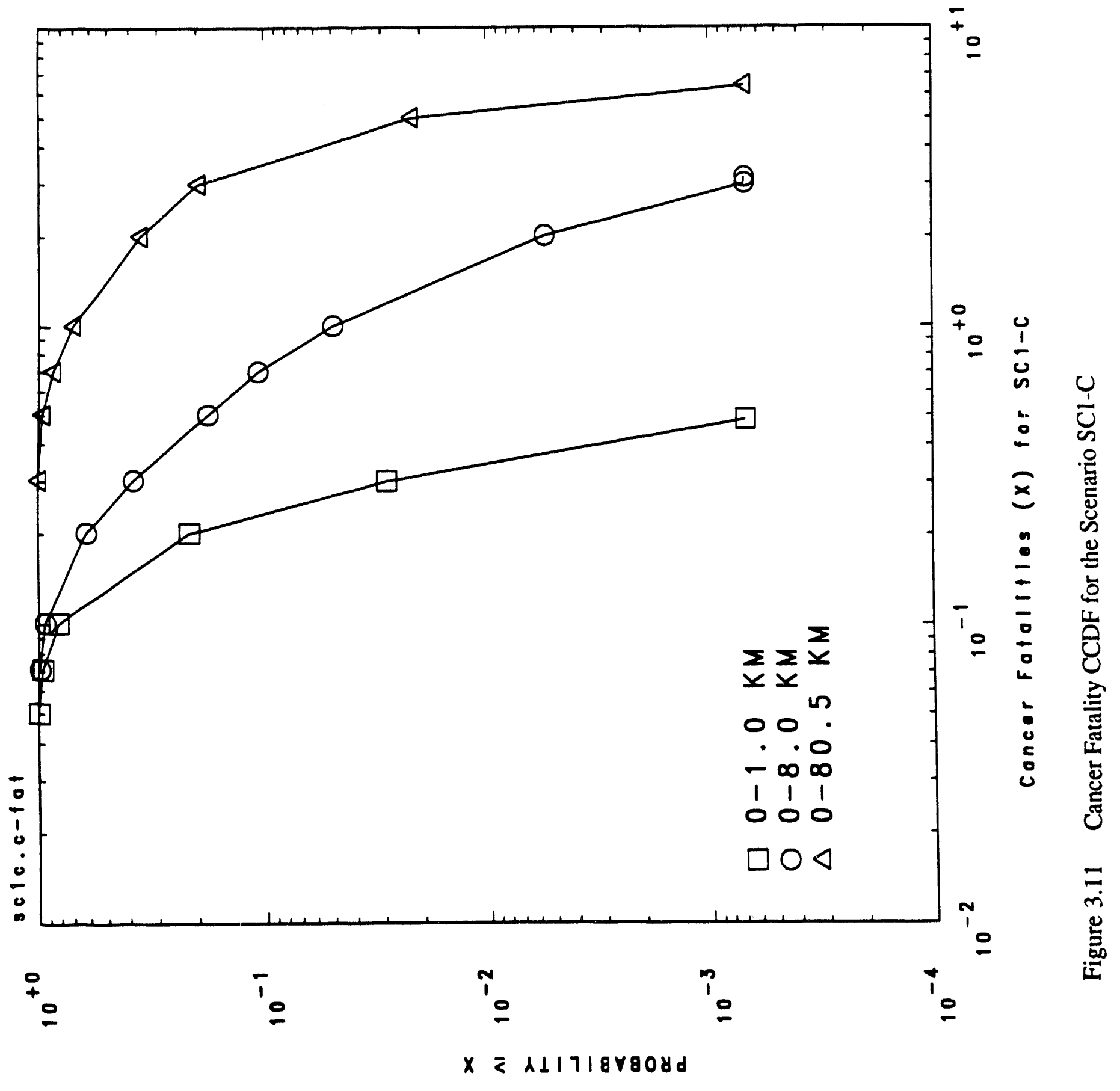




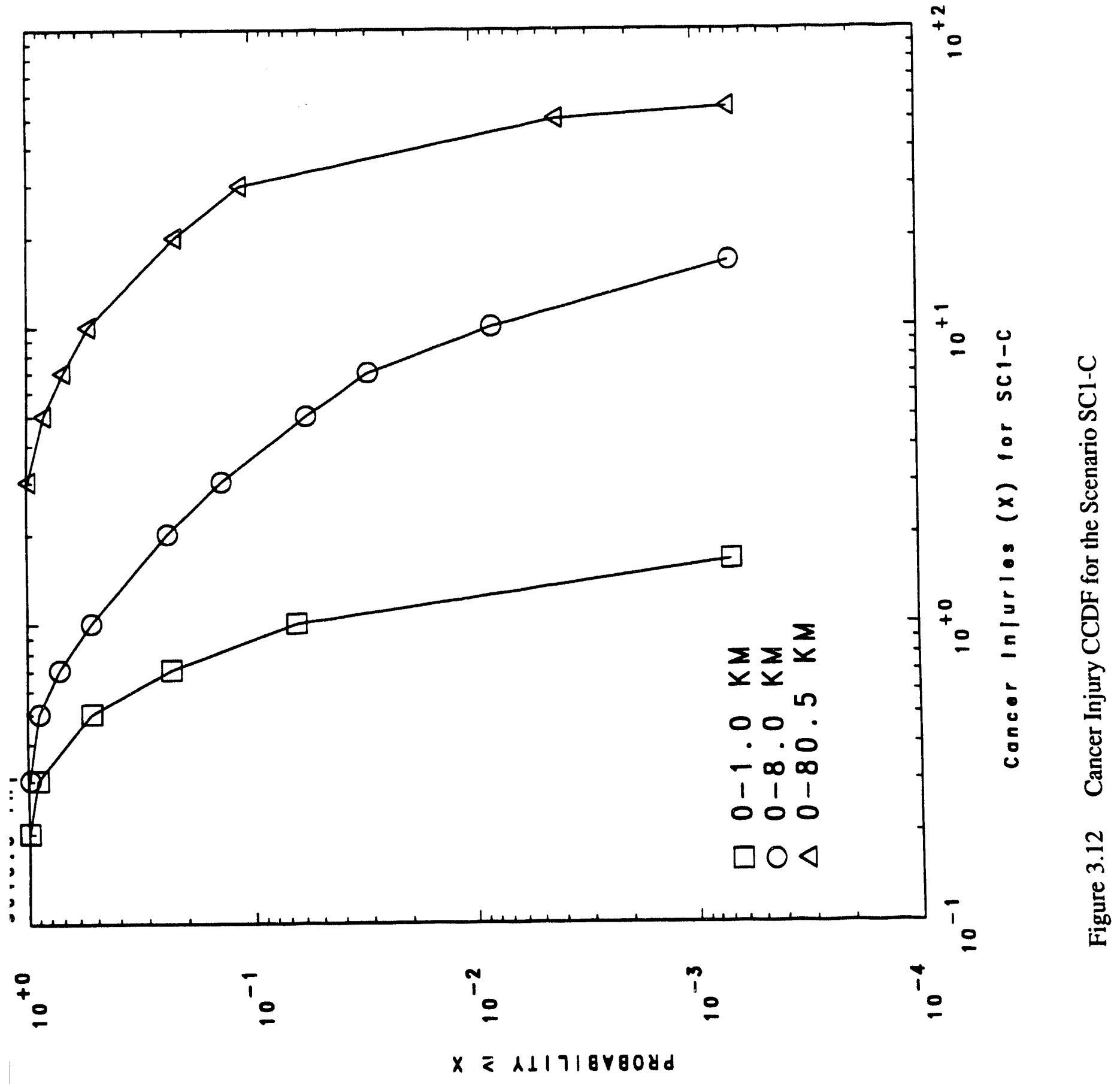

3.39 


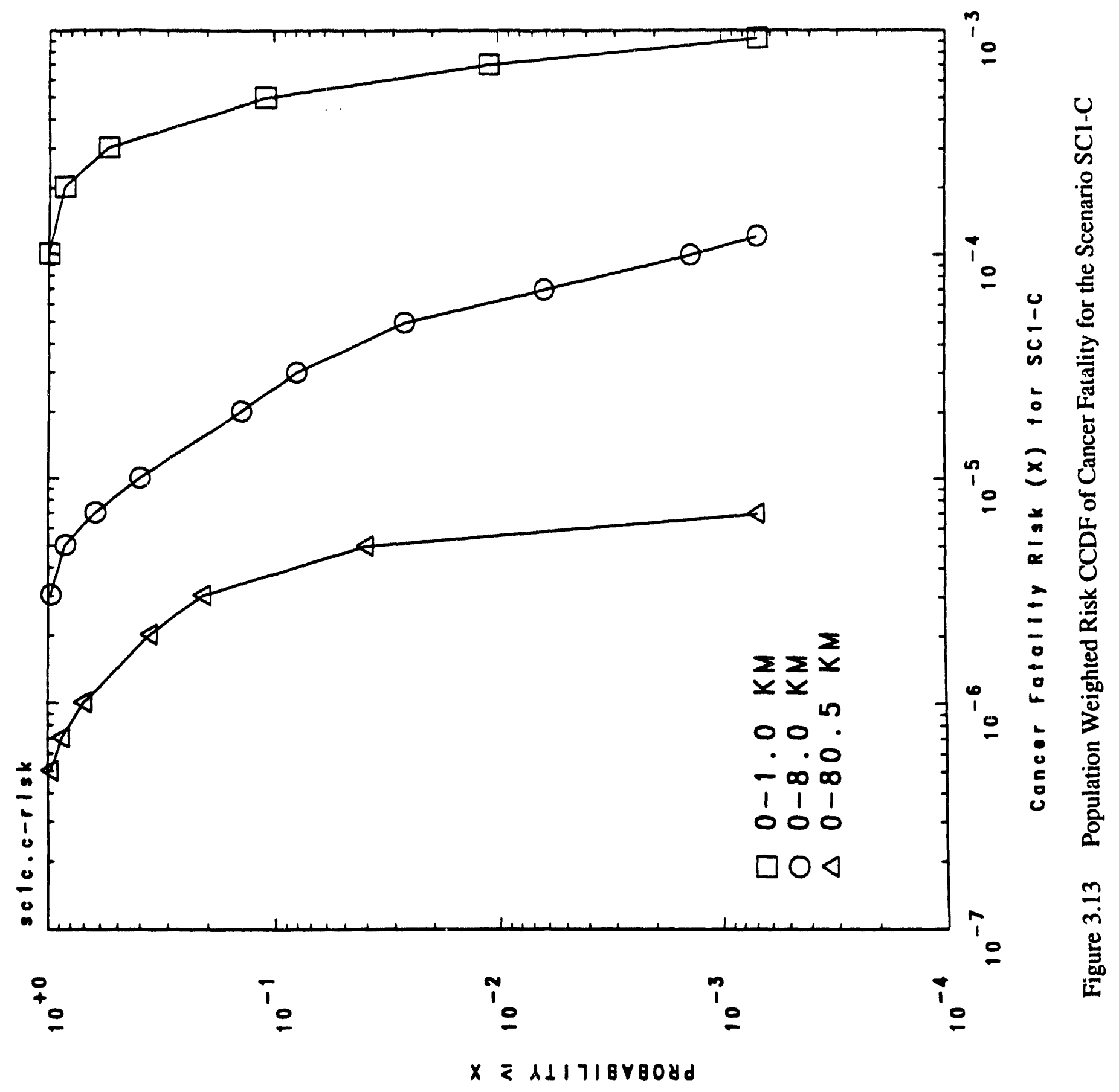




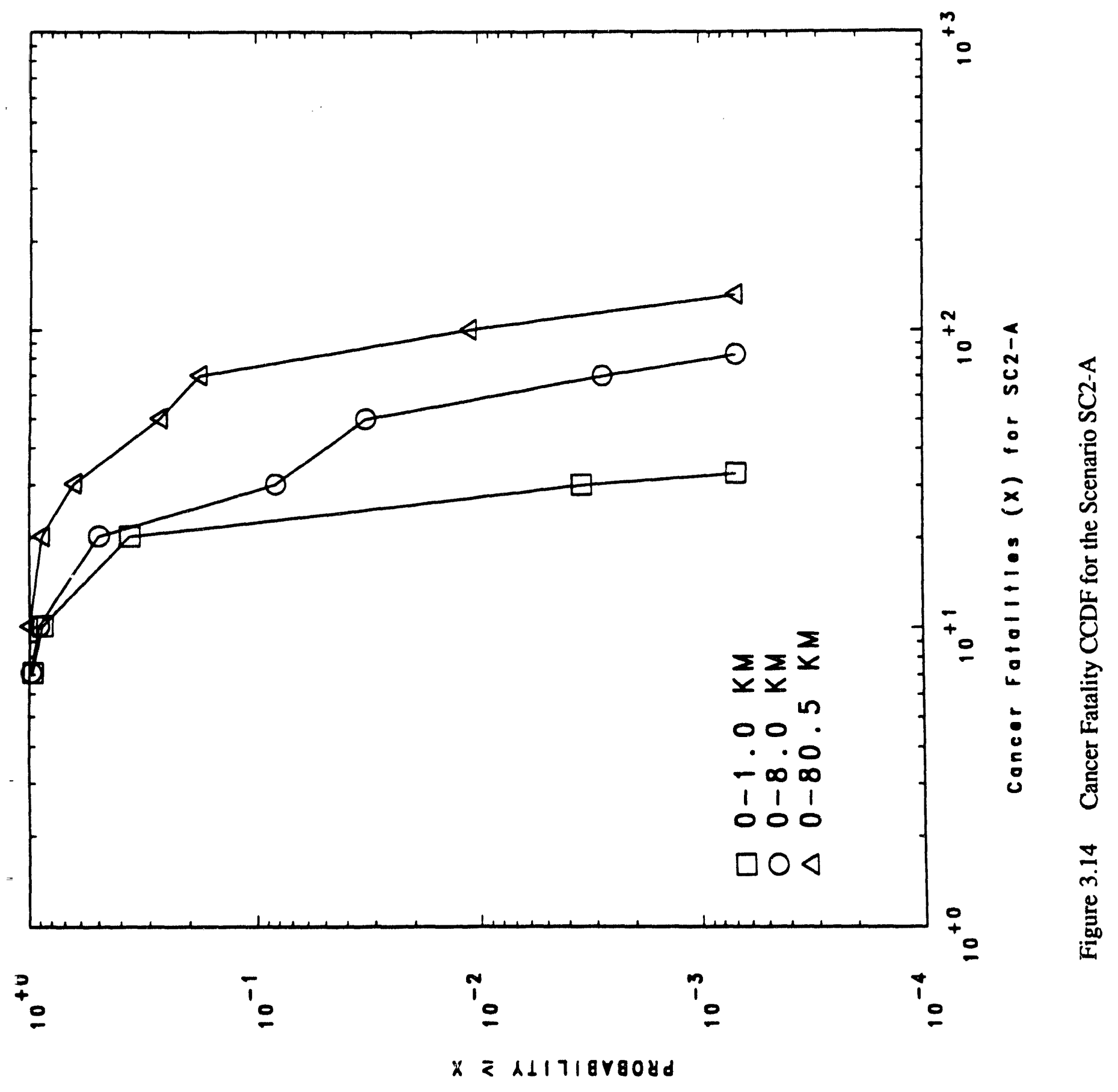




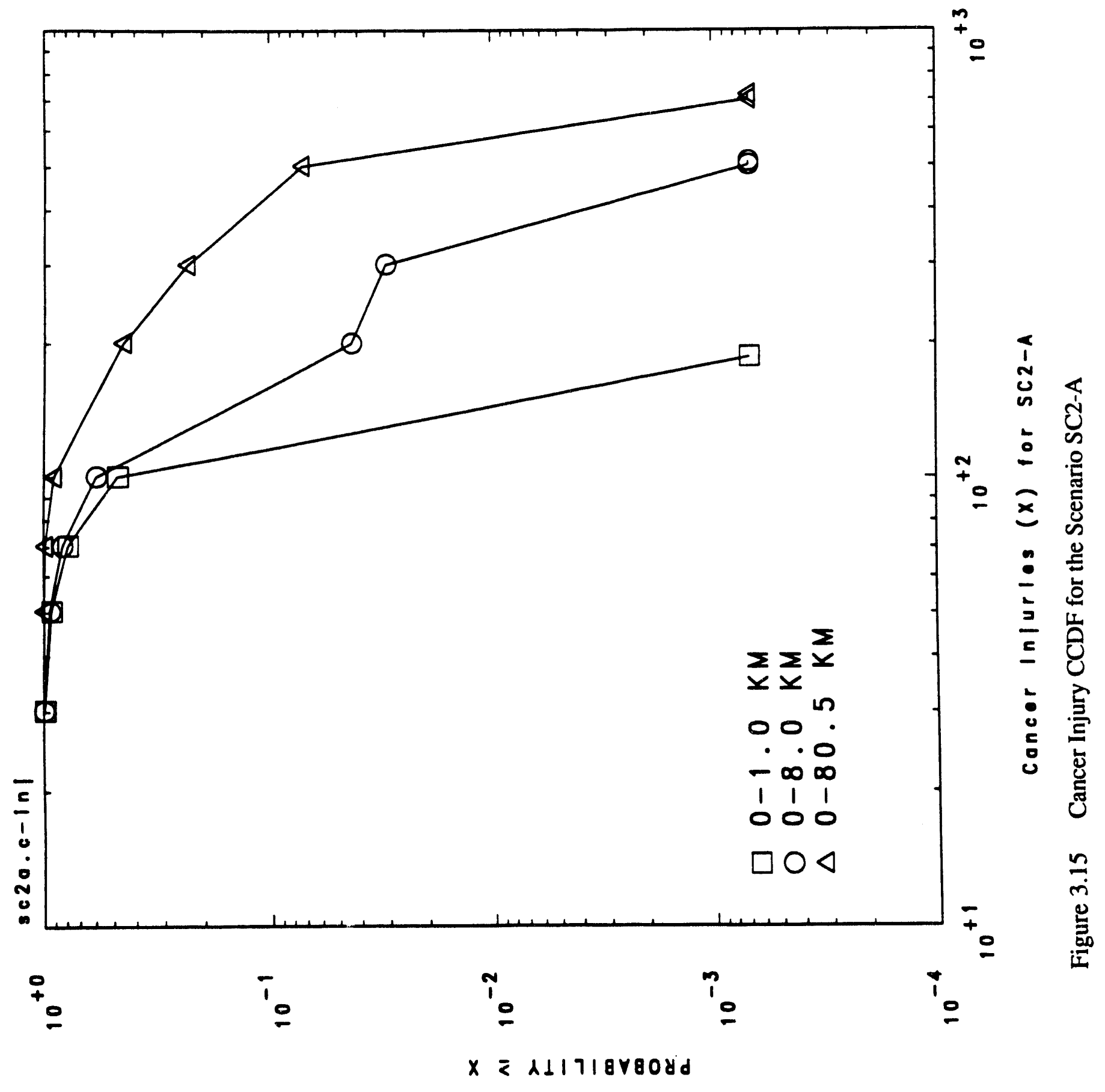




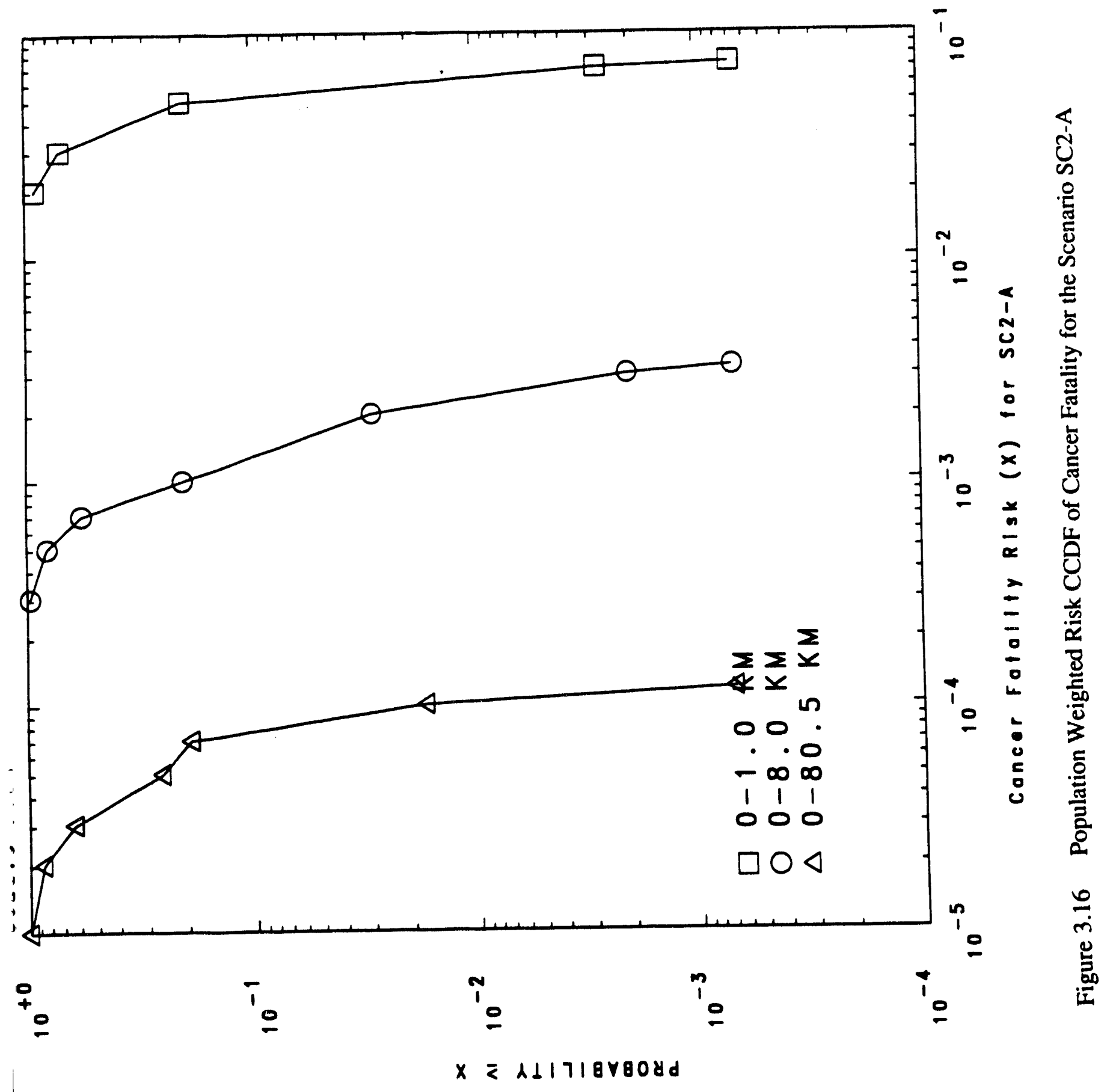




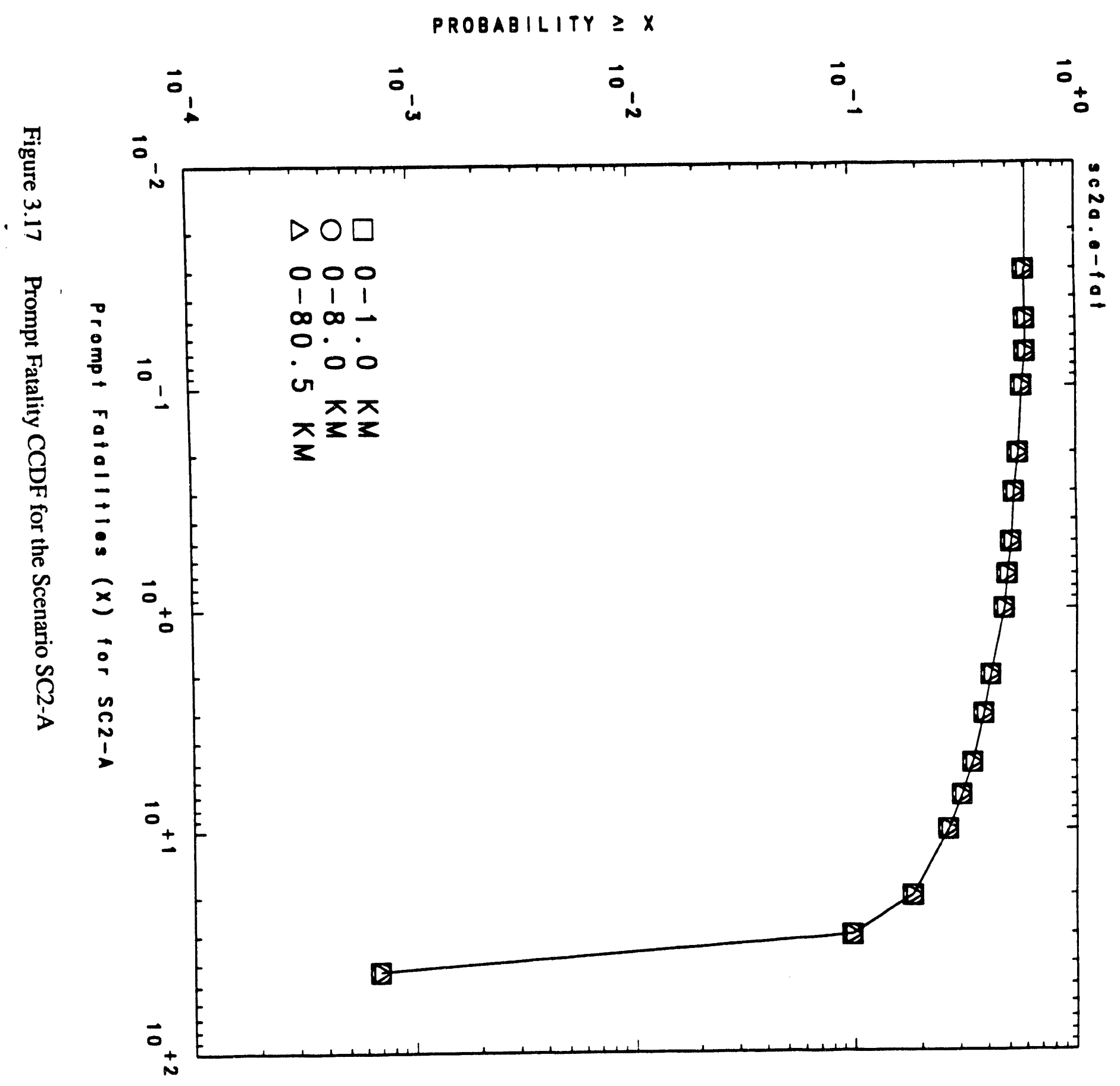




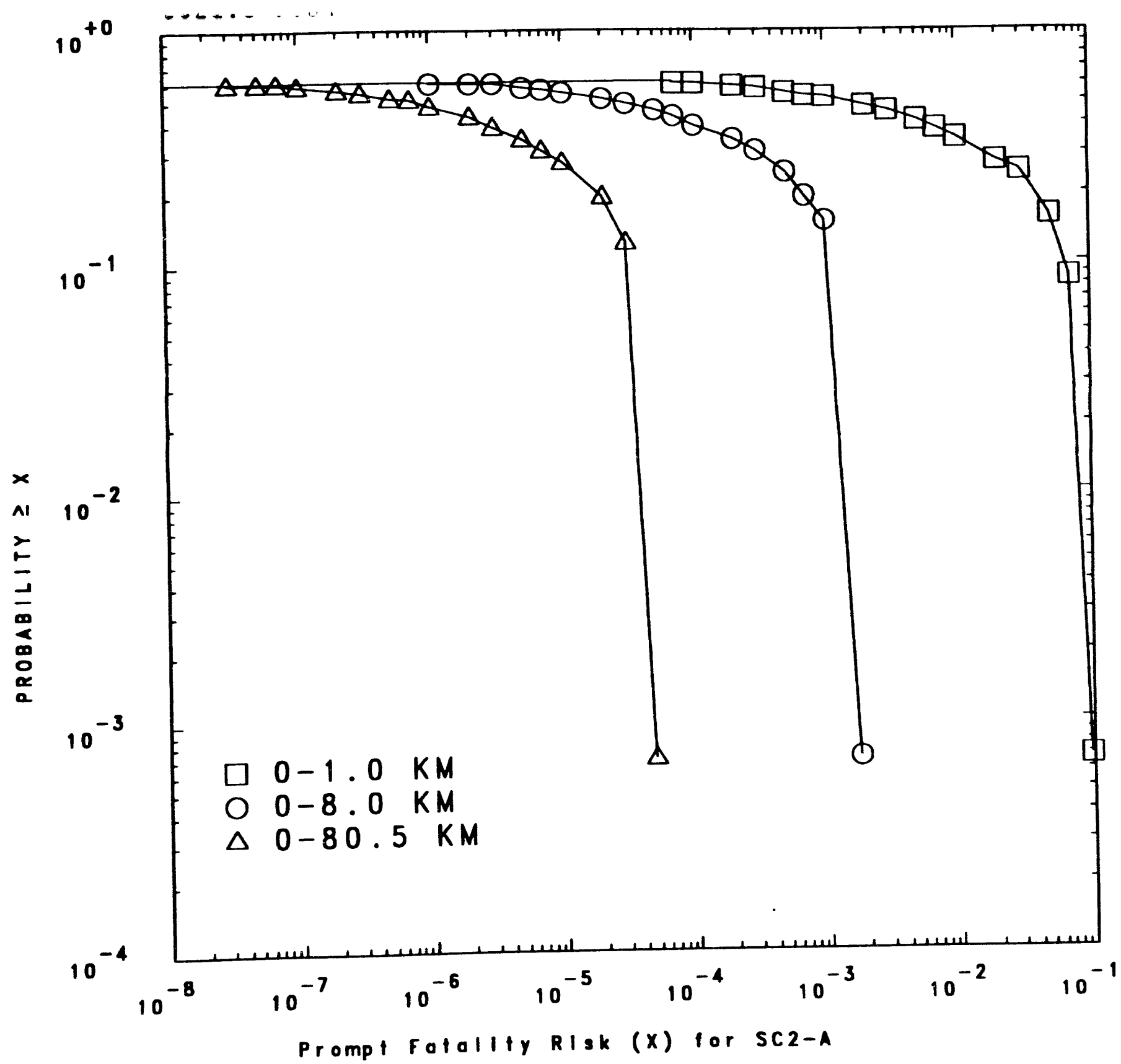

Figure 3.18 Population Weighted Risk CCDF of Prompt Fatality for the Scenario SC2-A 


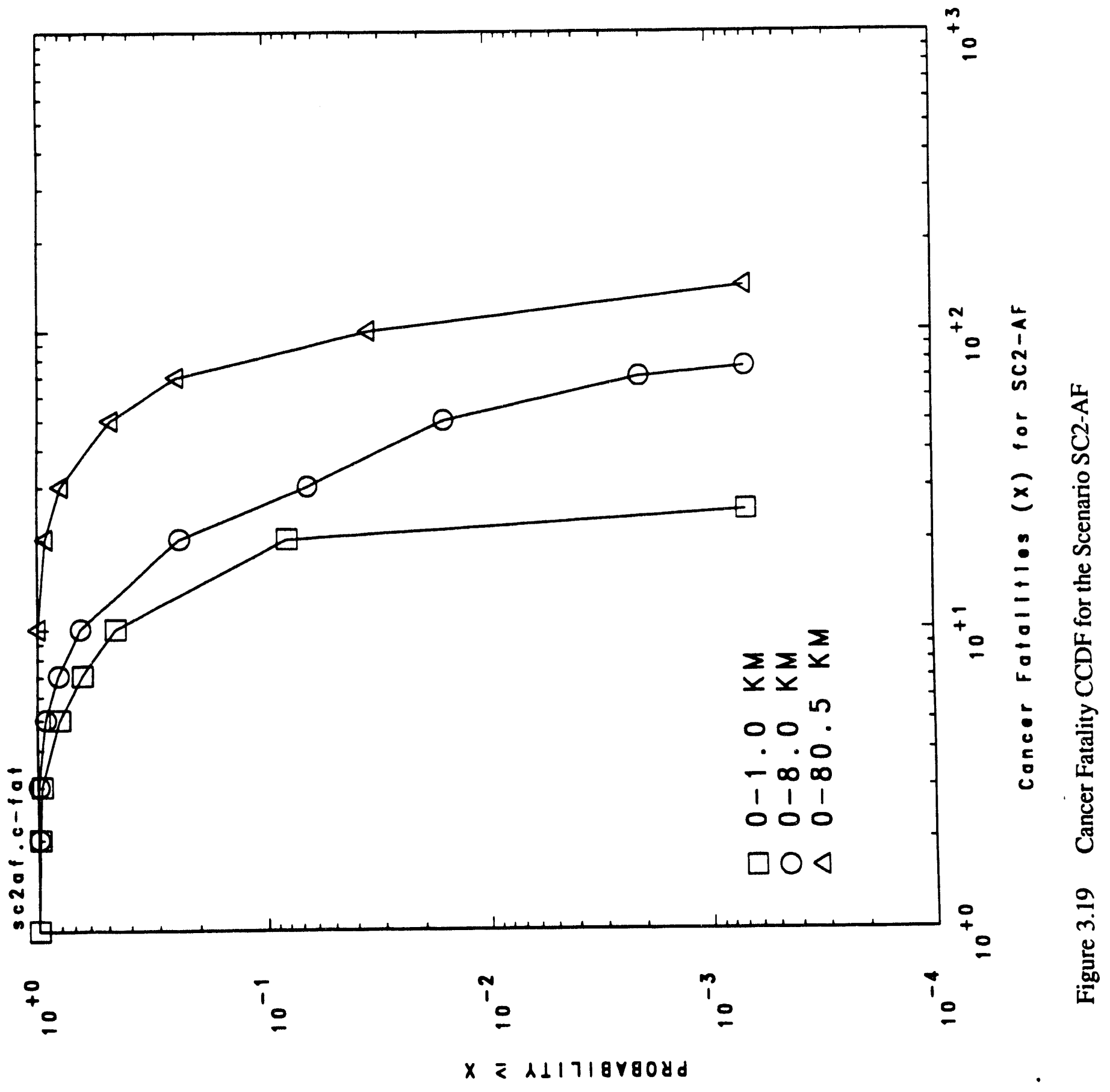




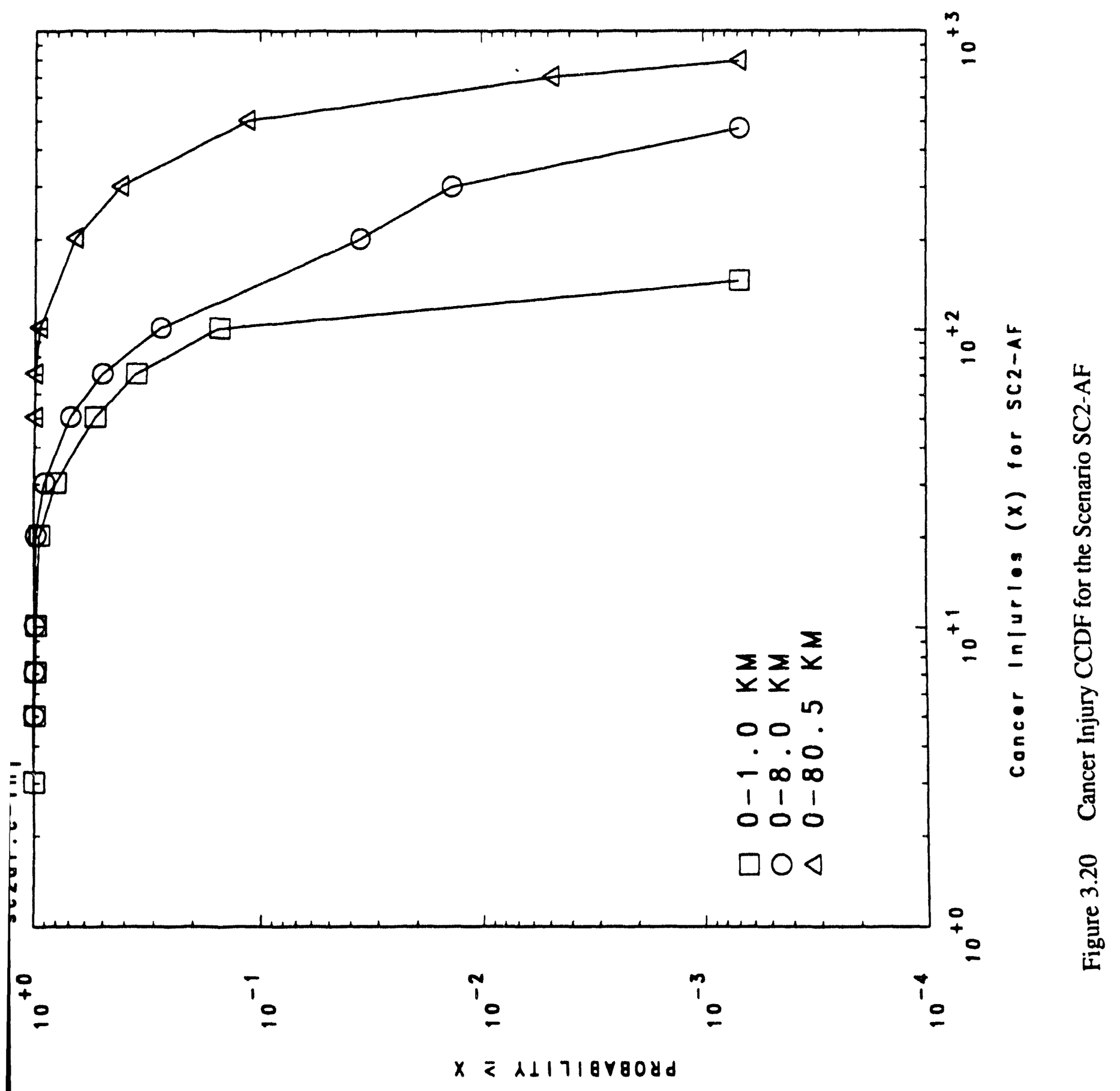




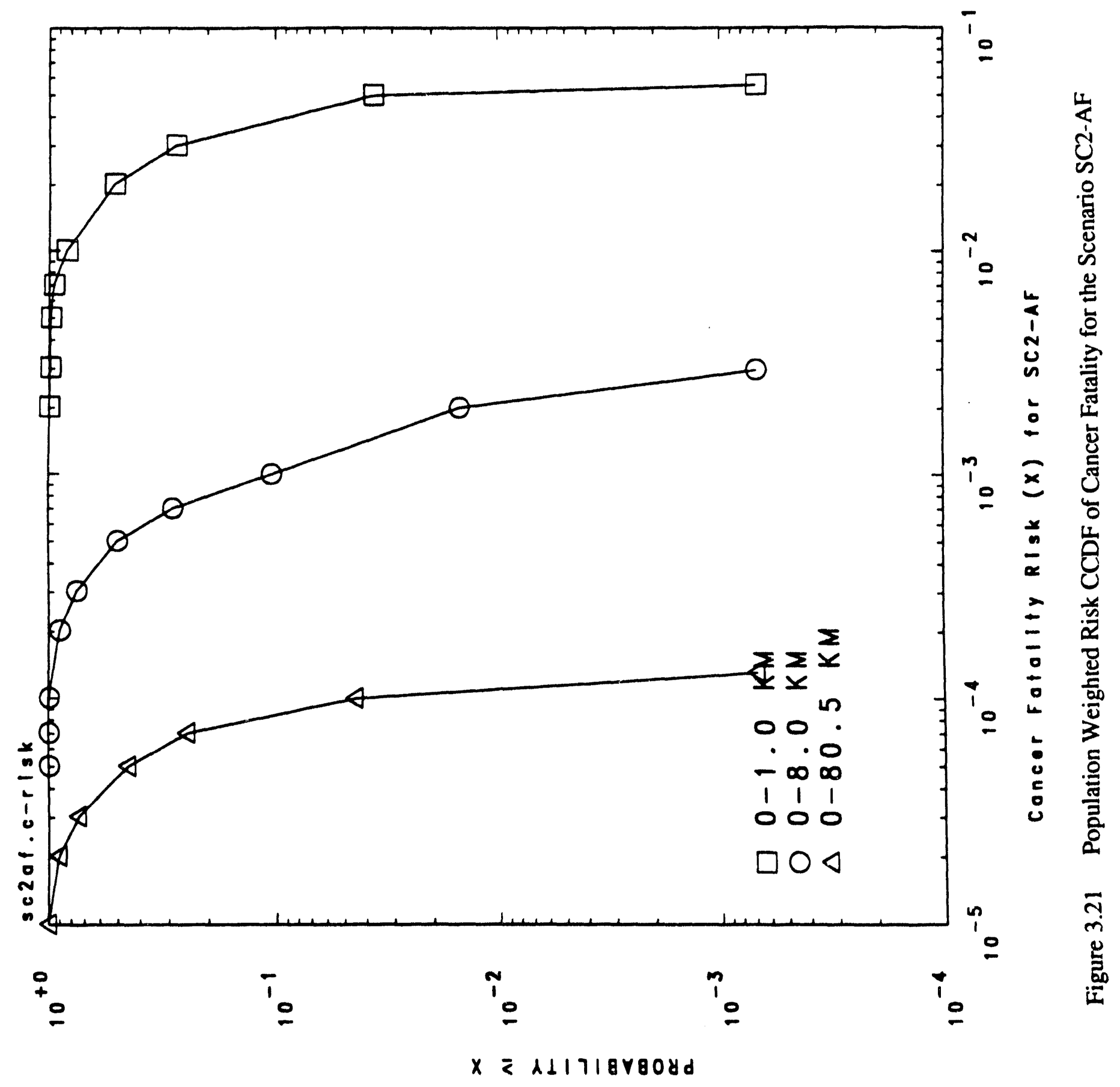




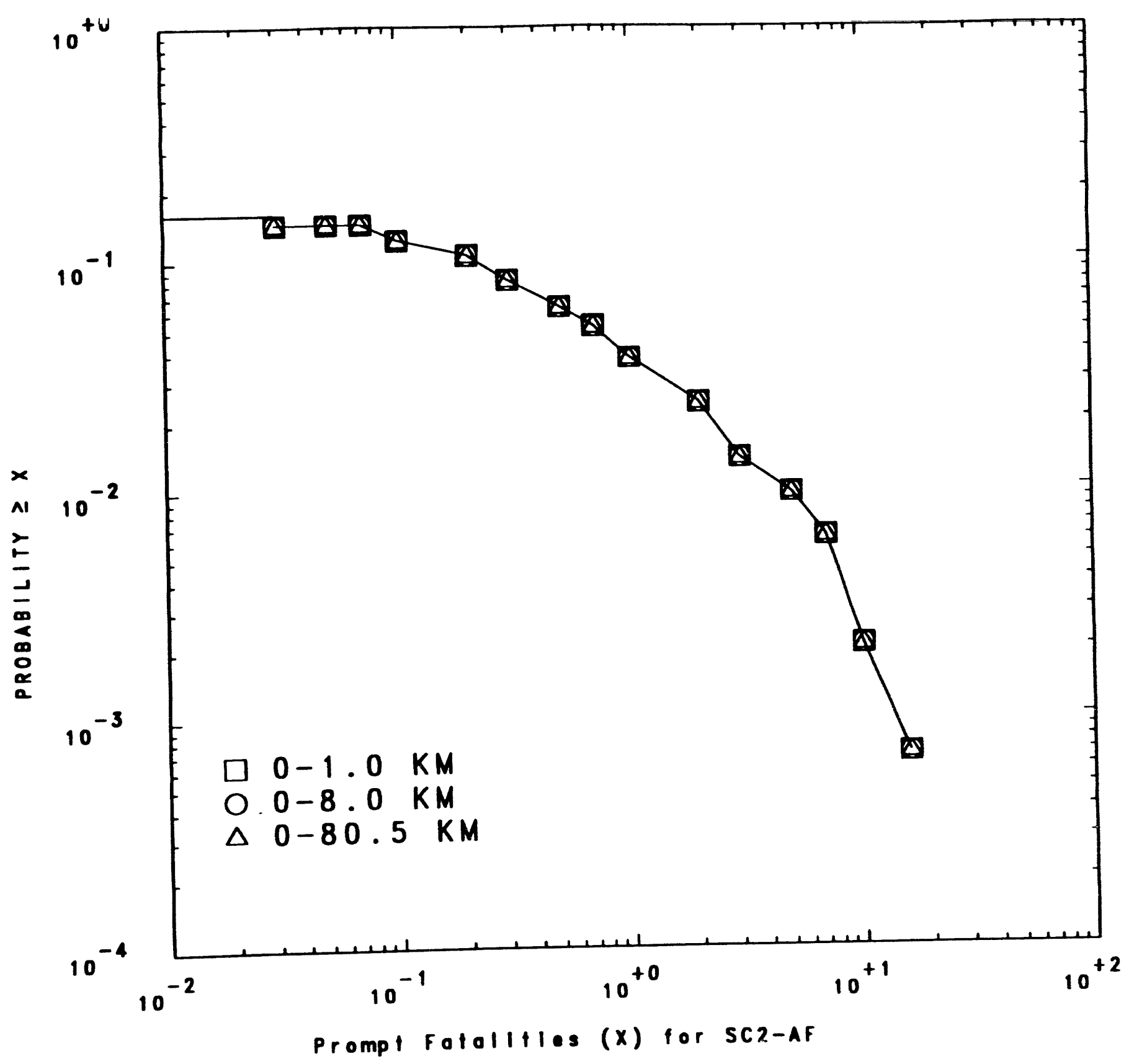

Figure 3.22 Prompt Fatality CCDF for the Scenario SC2-AF 


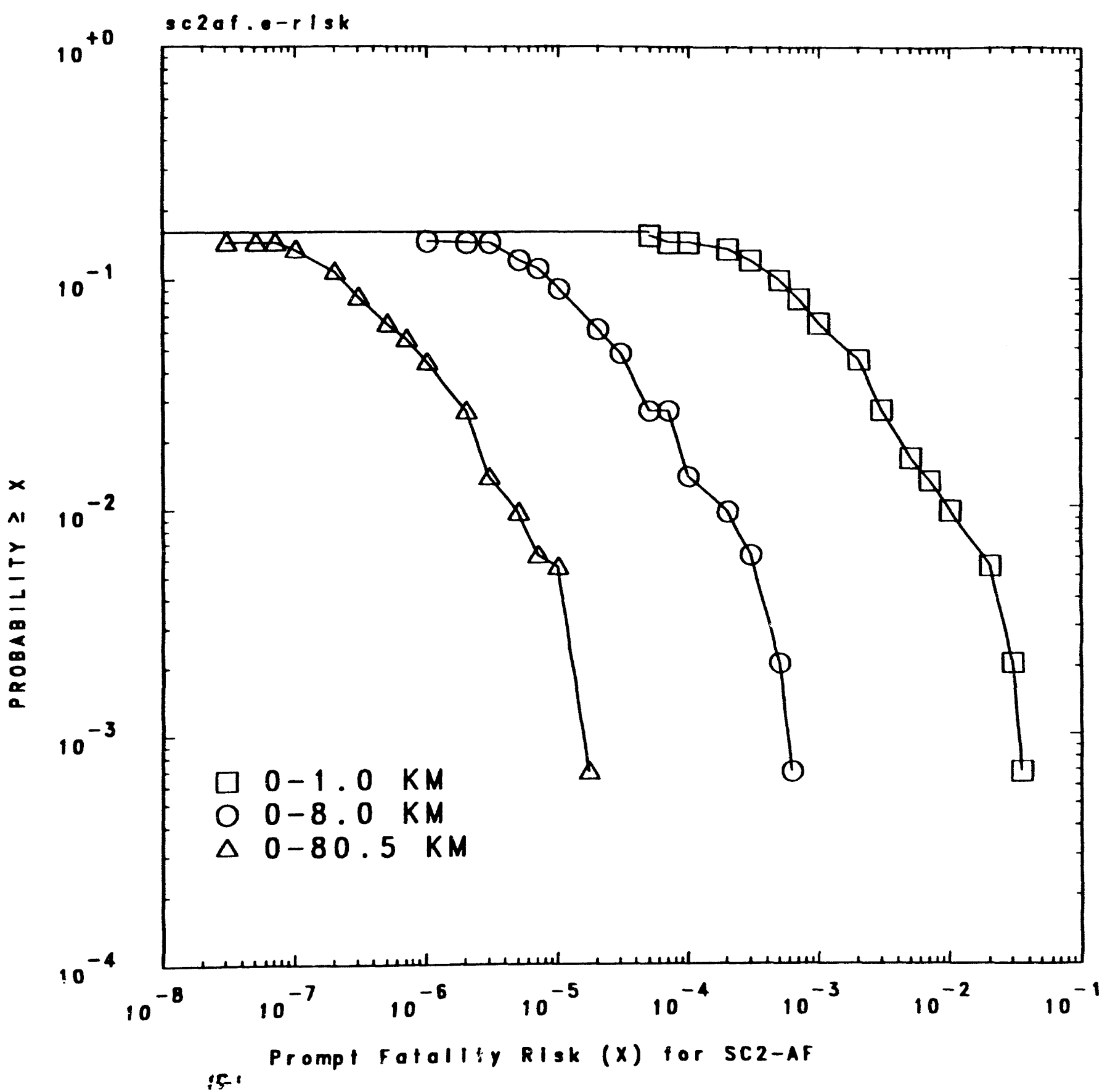

Figure 3.23 Population Weighted Risk CCDF of Prompt Fatality for the Scenario SC2-AF 


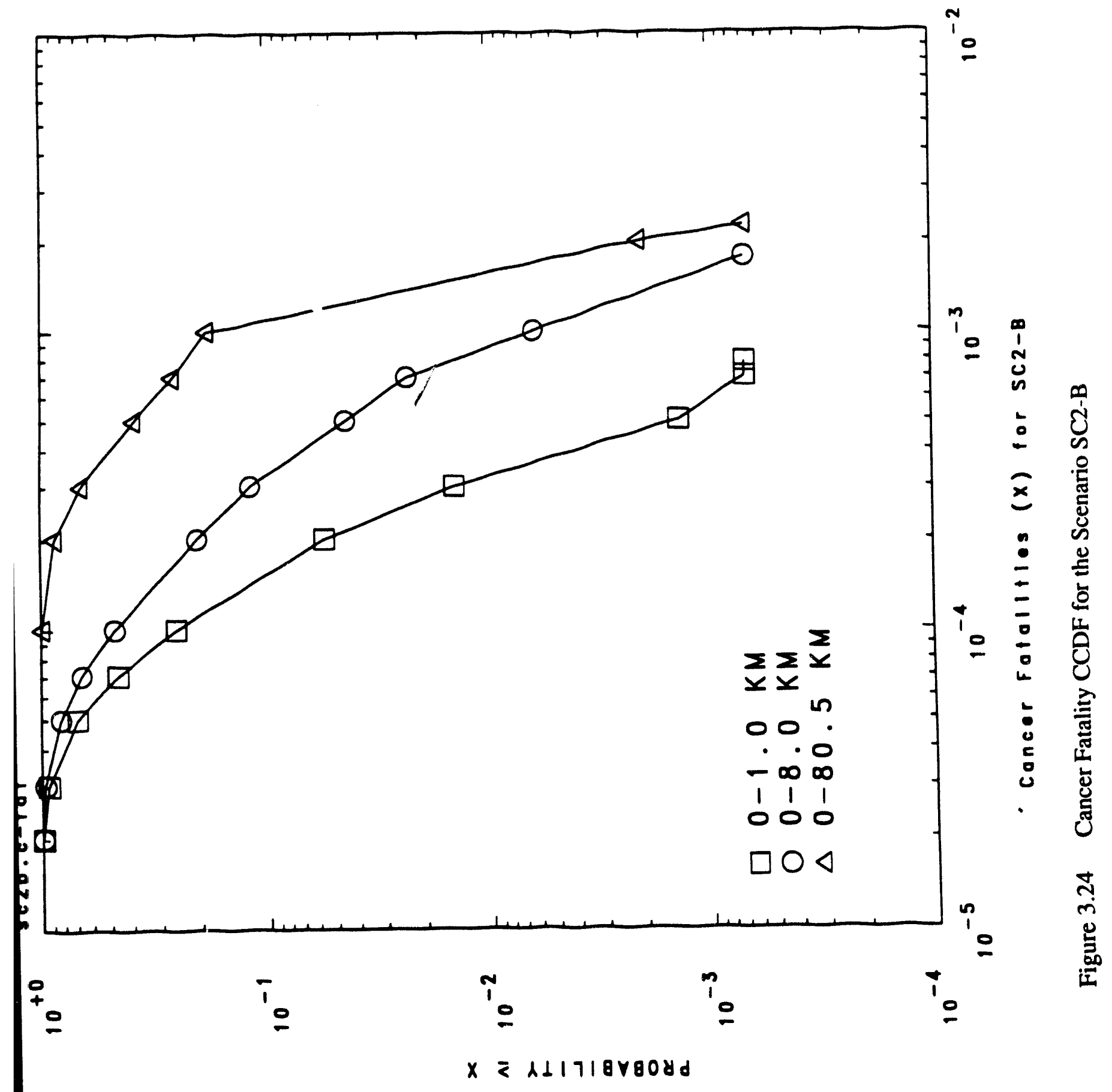




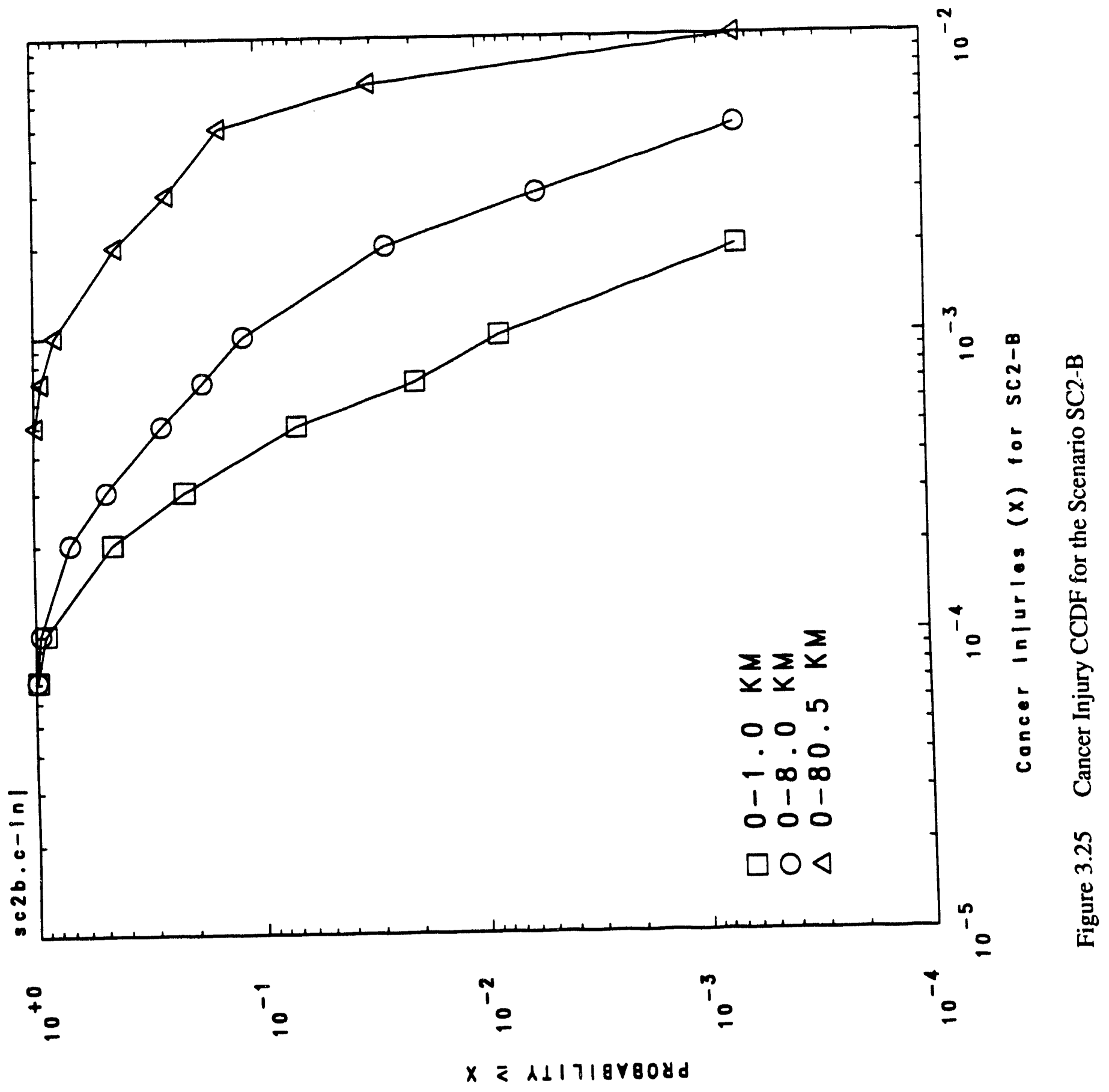

3.52 


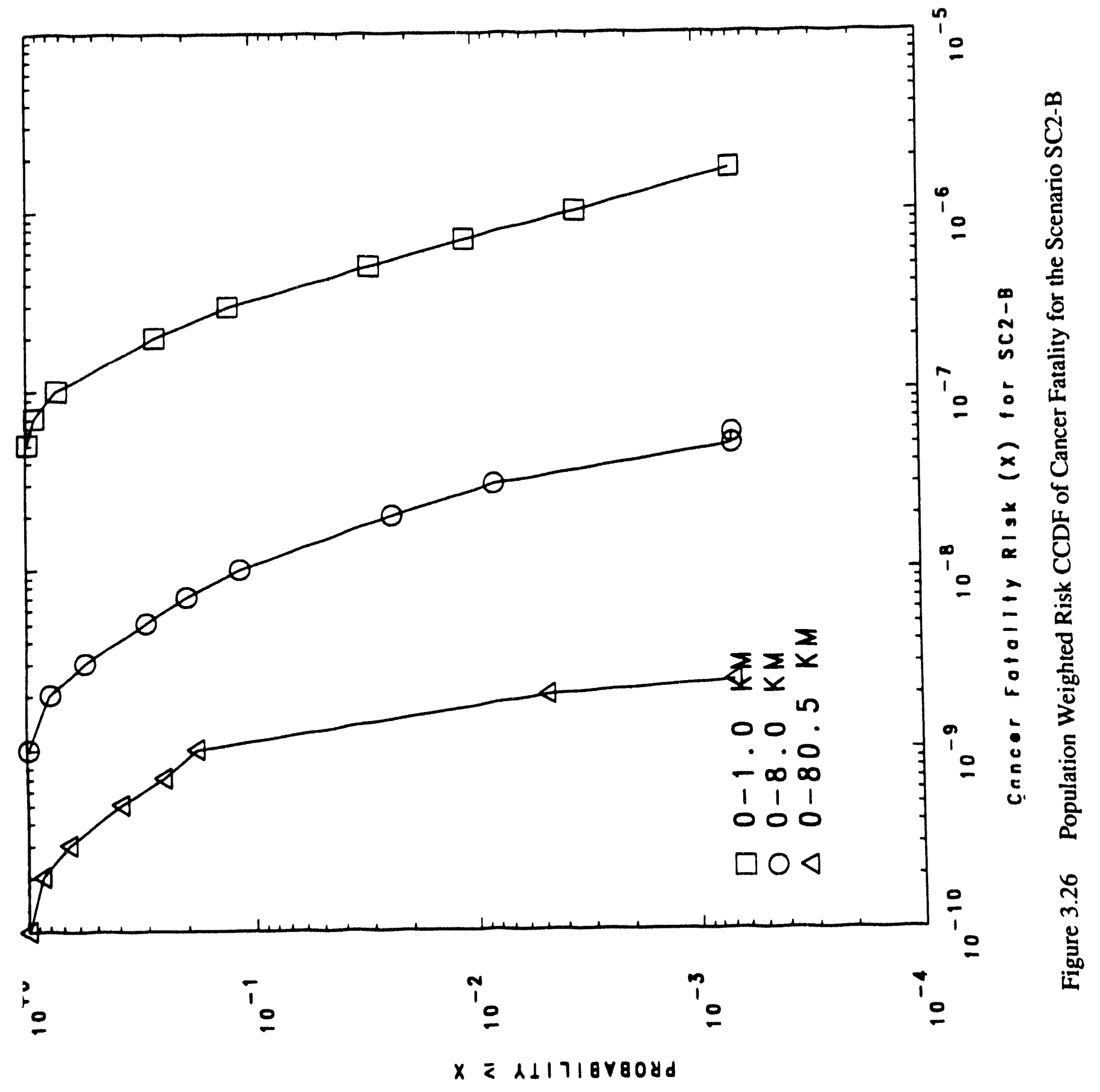




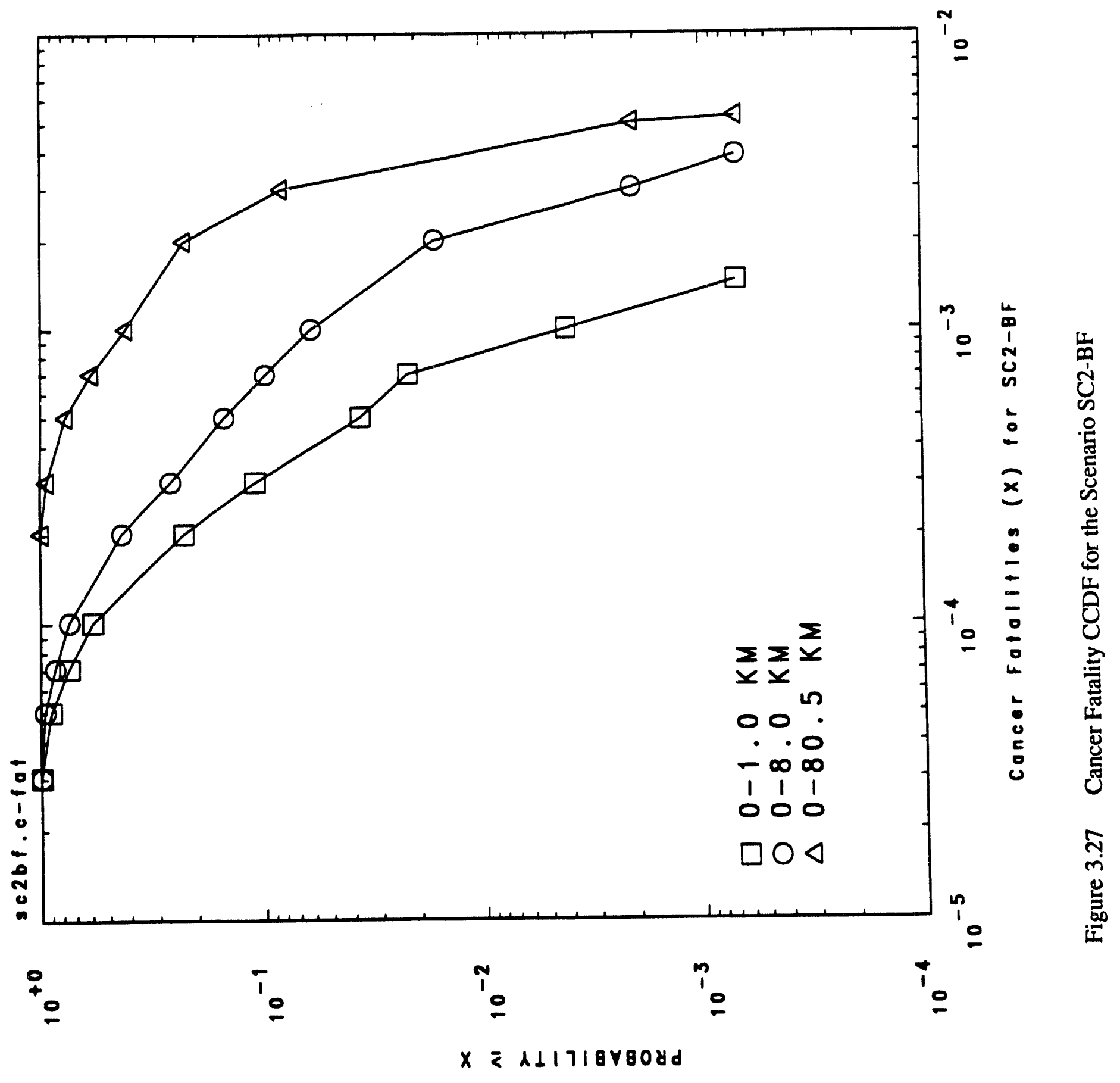




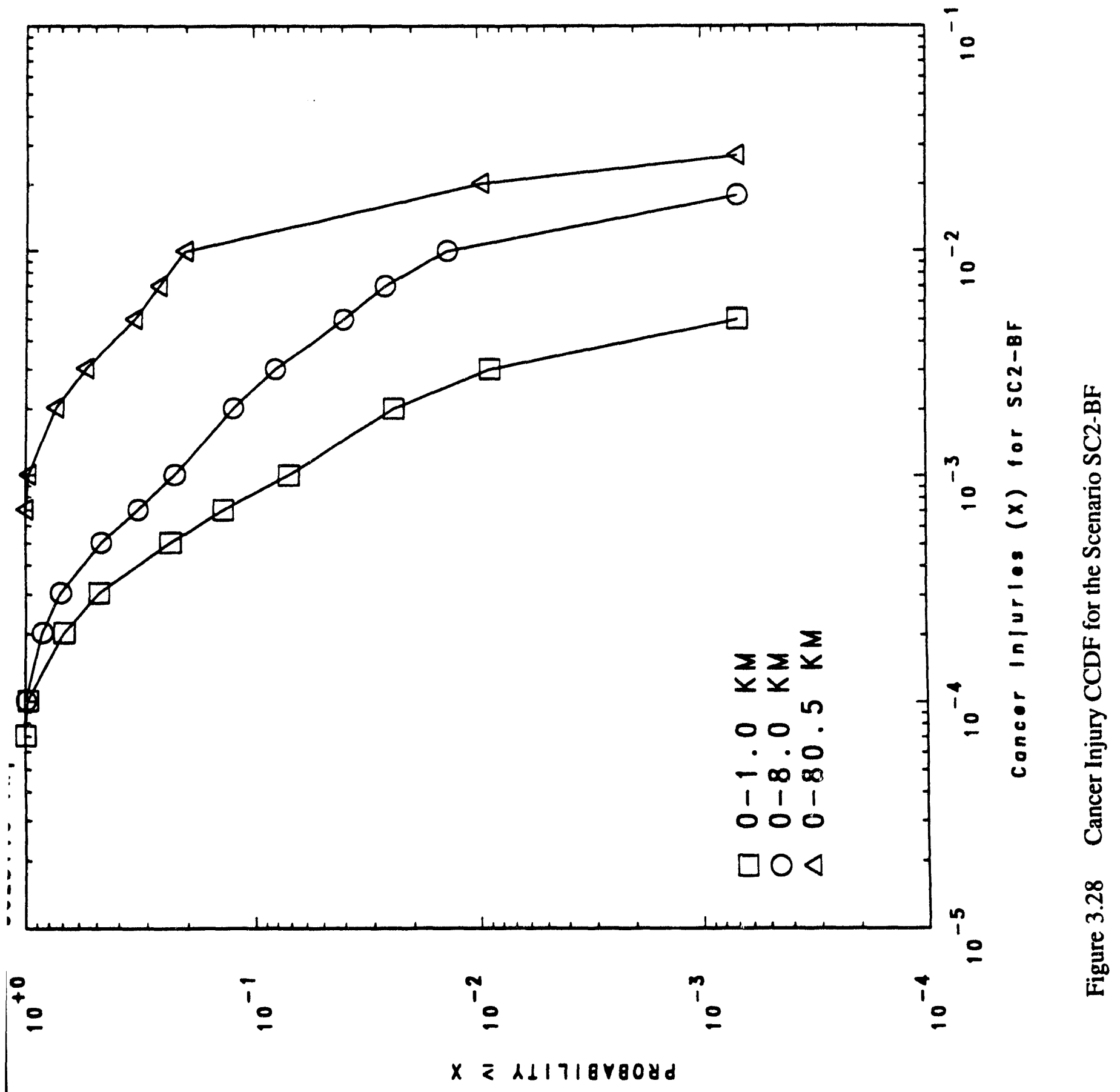




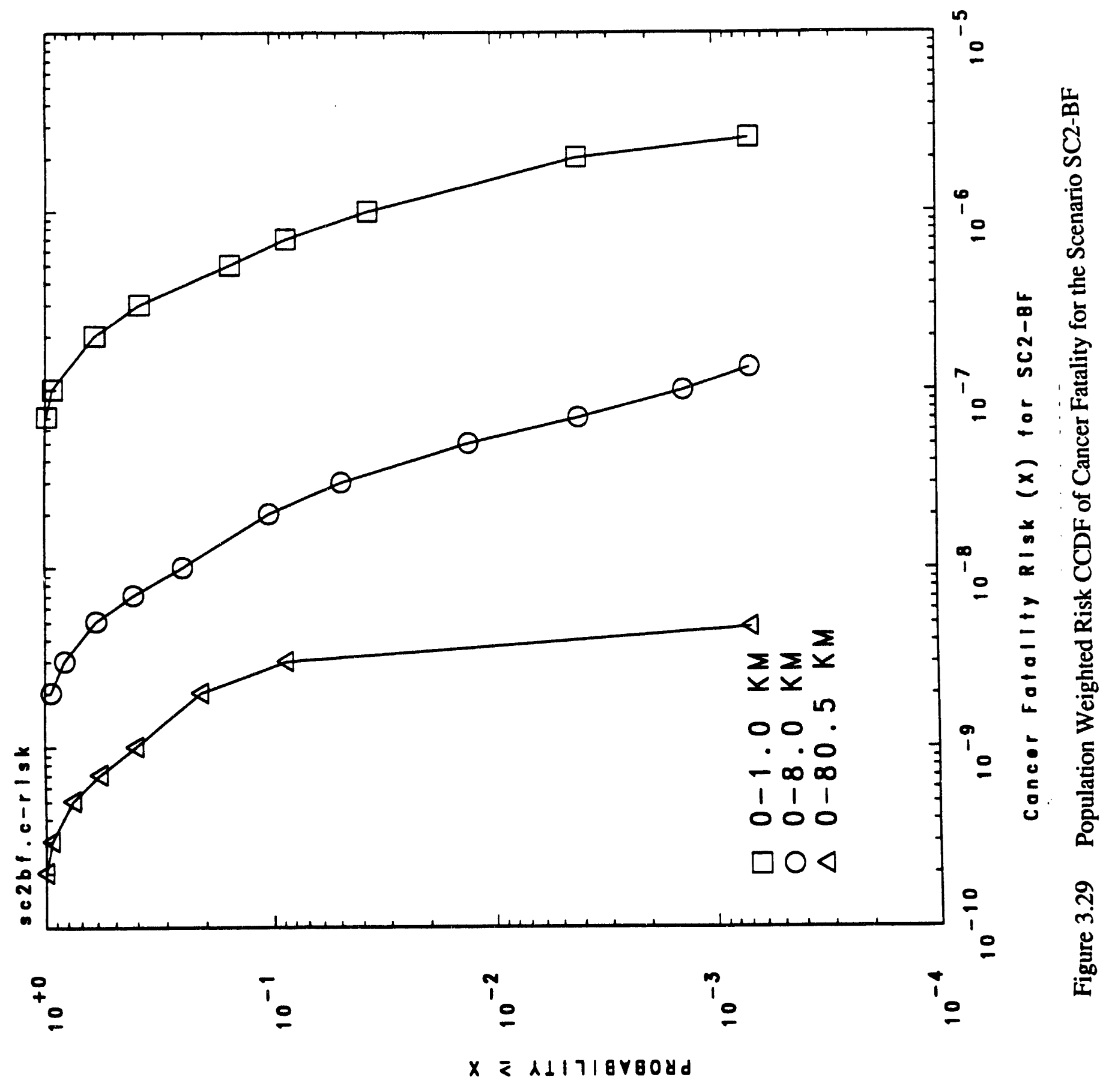




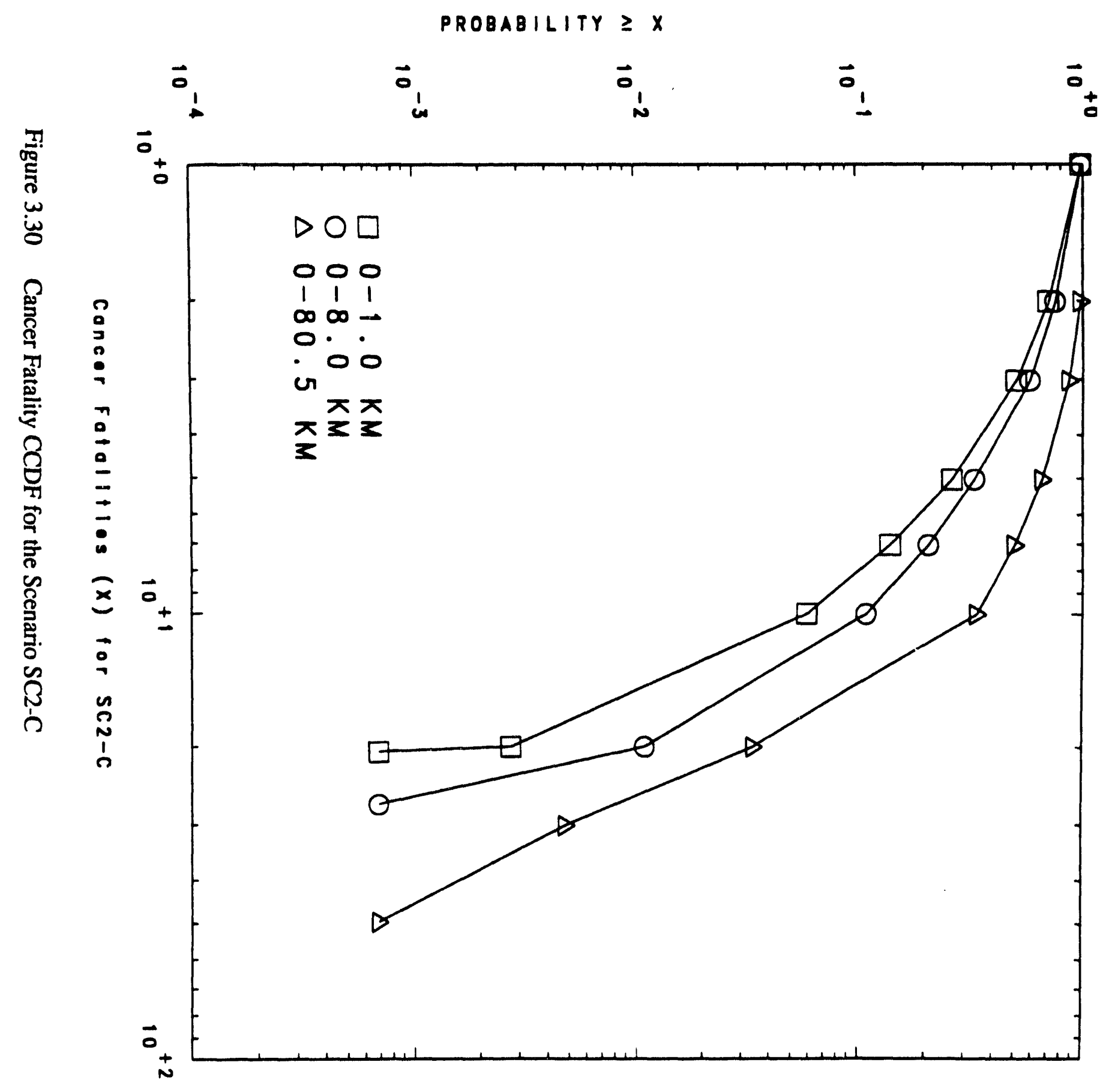




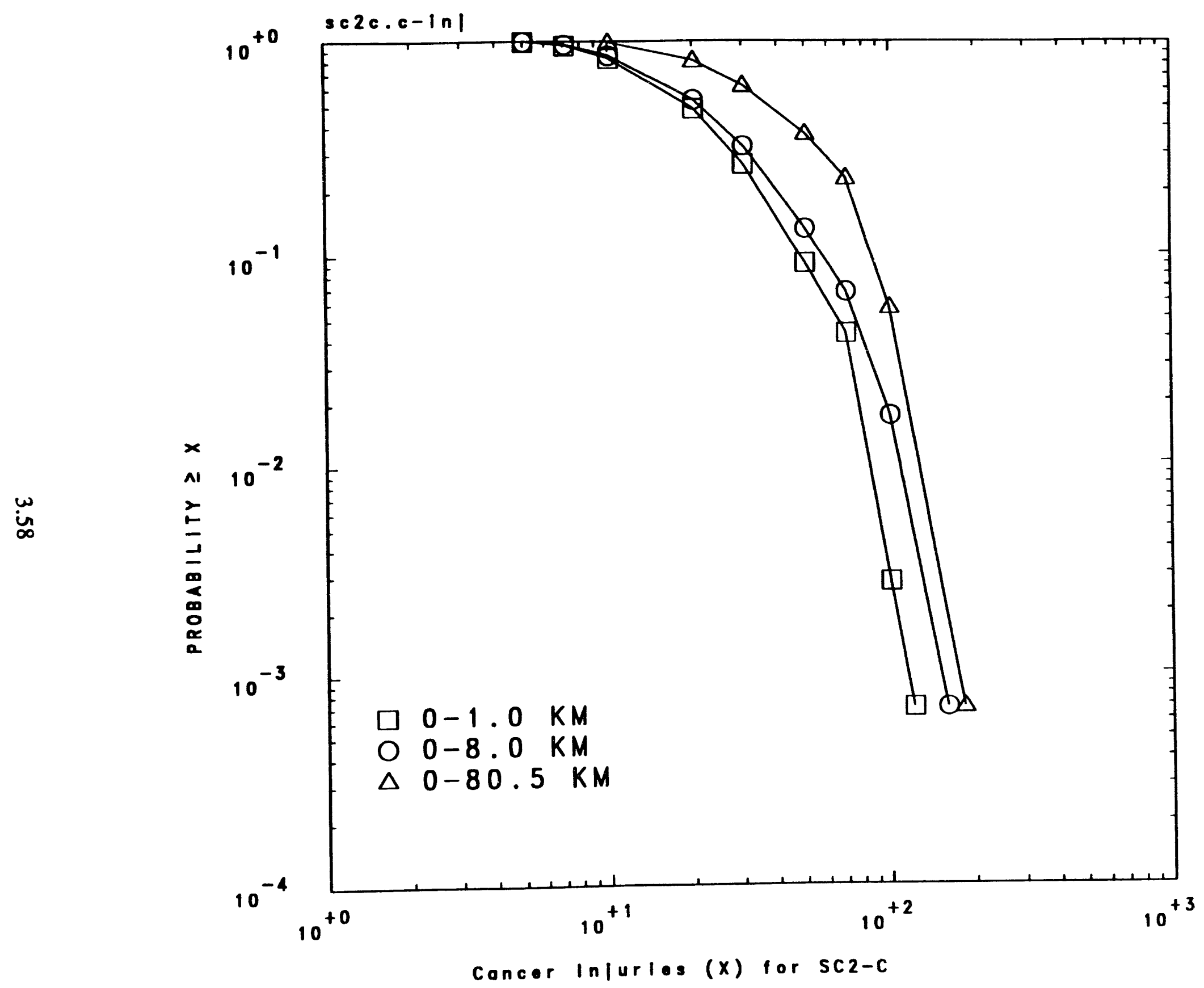

Figure 3.31 Cancer Injury CCDF for the Scenario SC2-C 


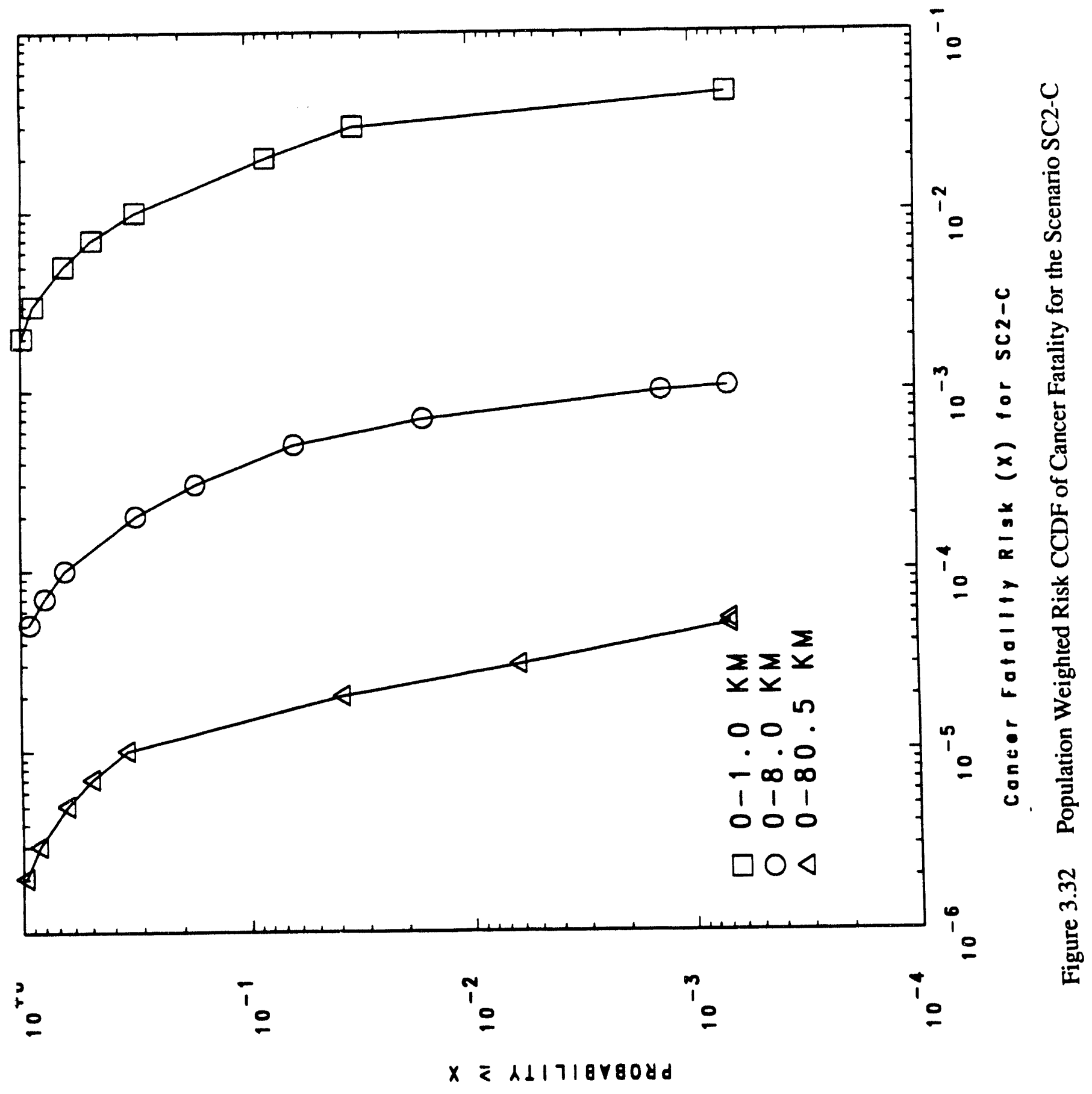




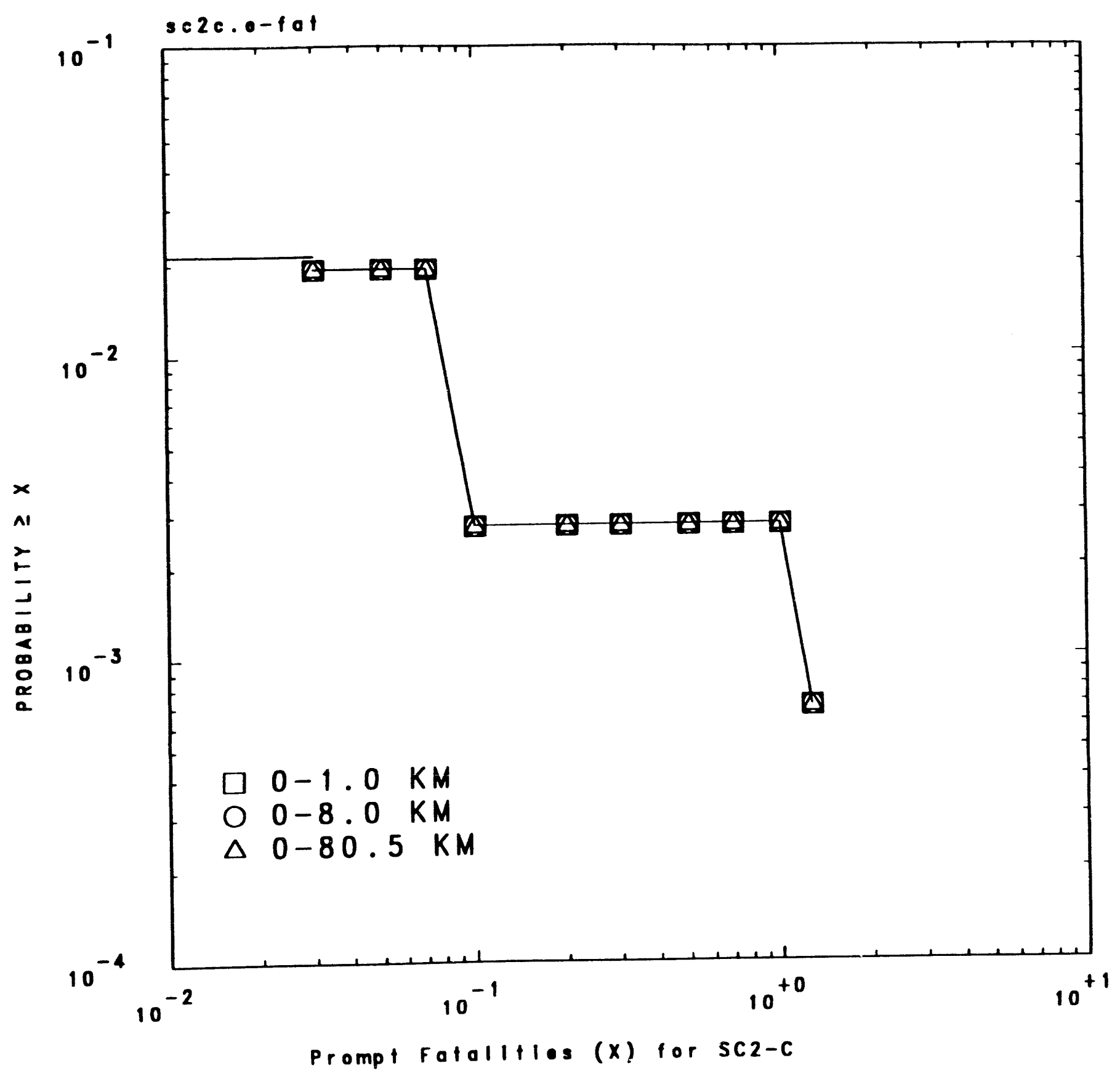

Figure 3.33 Prompt Fatality CCDF for the Scenario SC2-C 


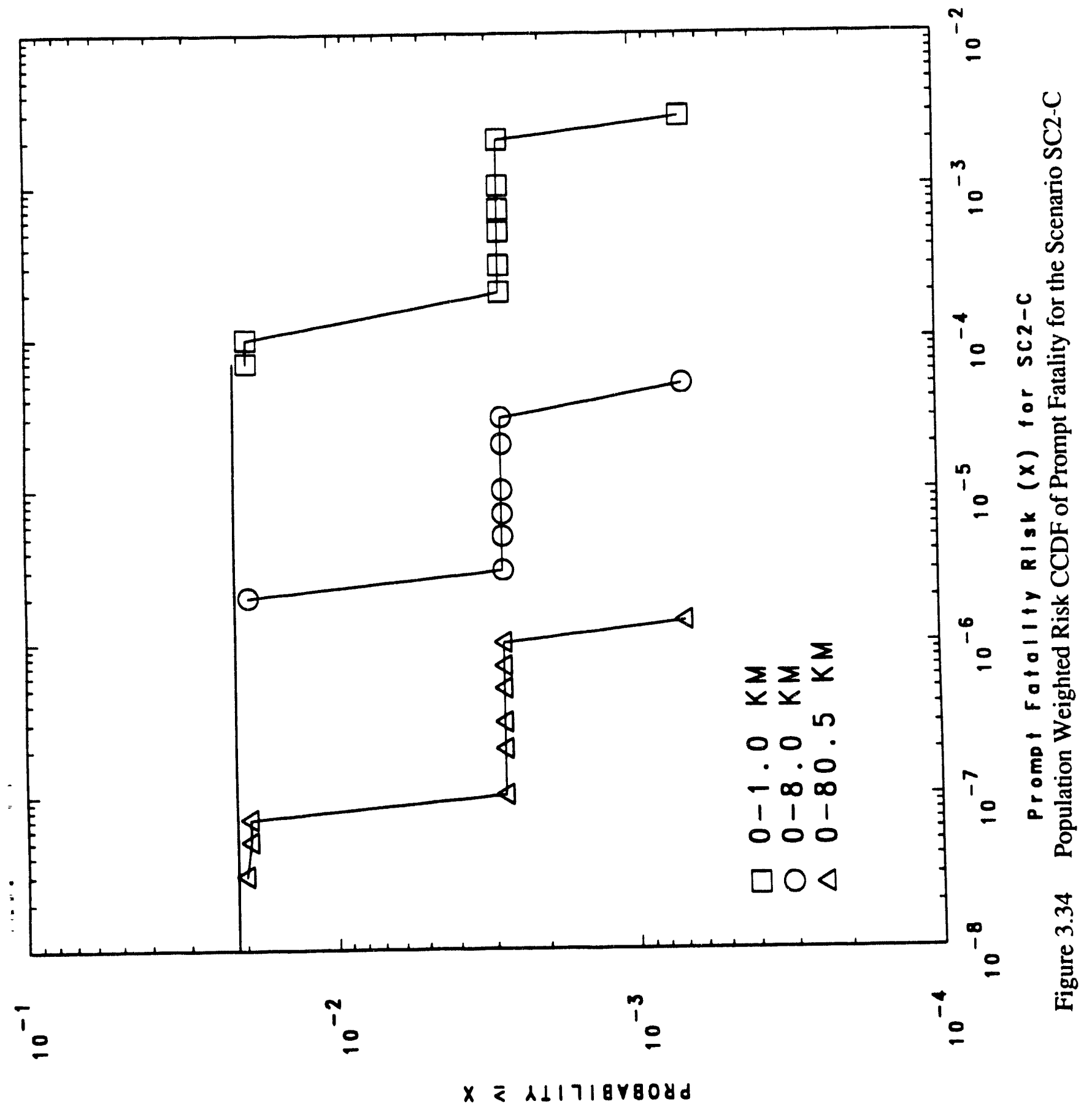




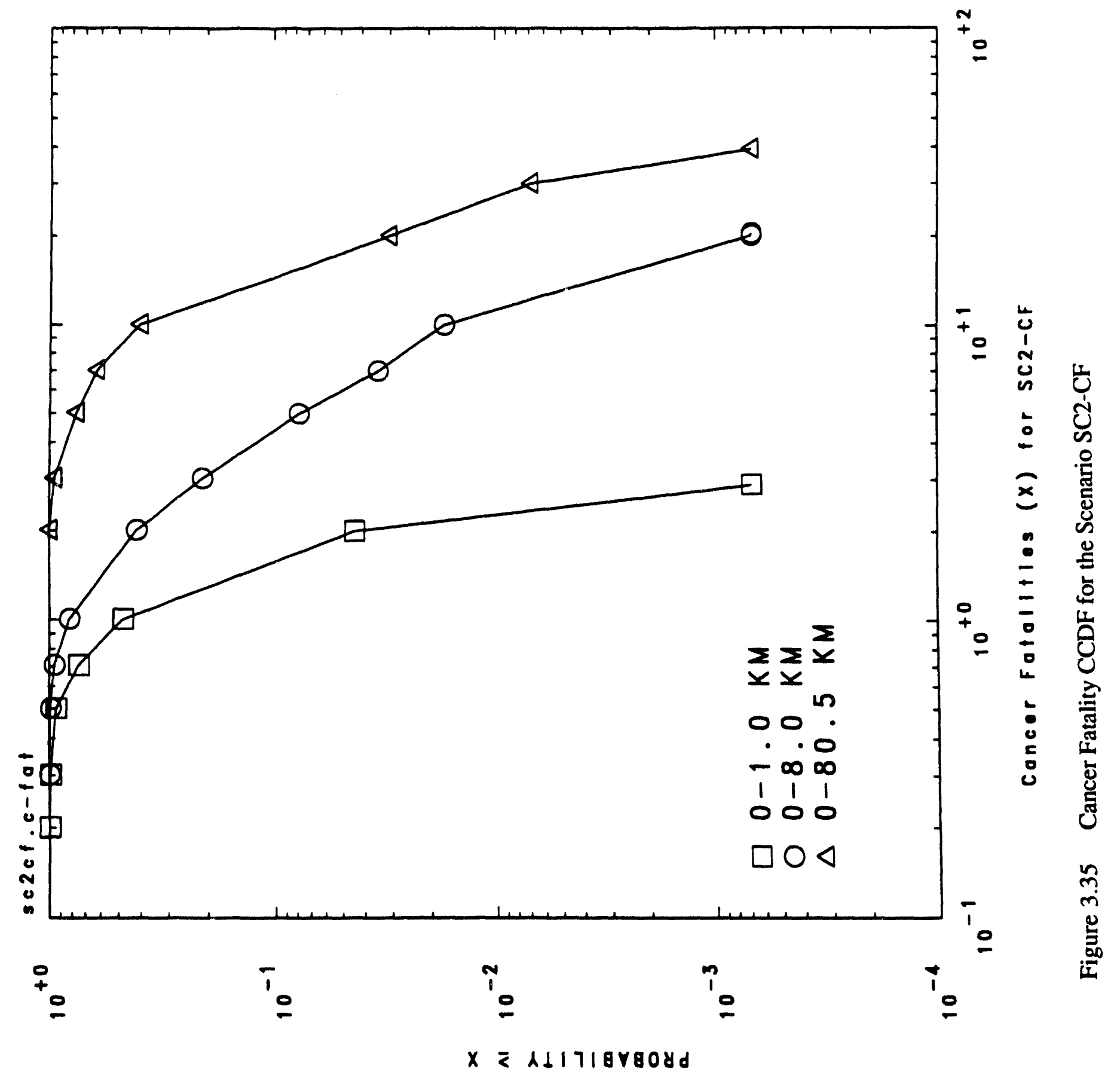




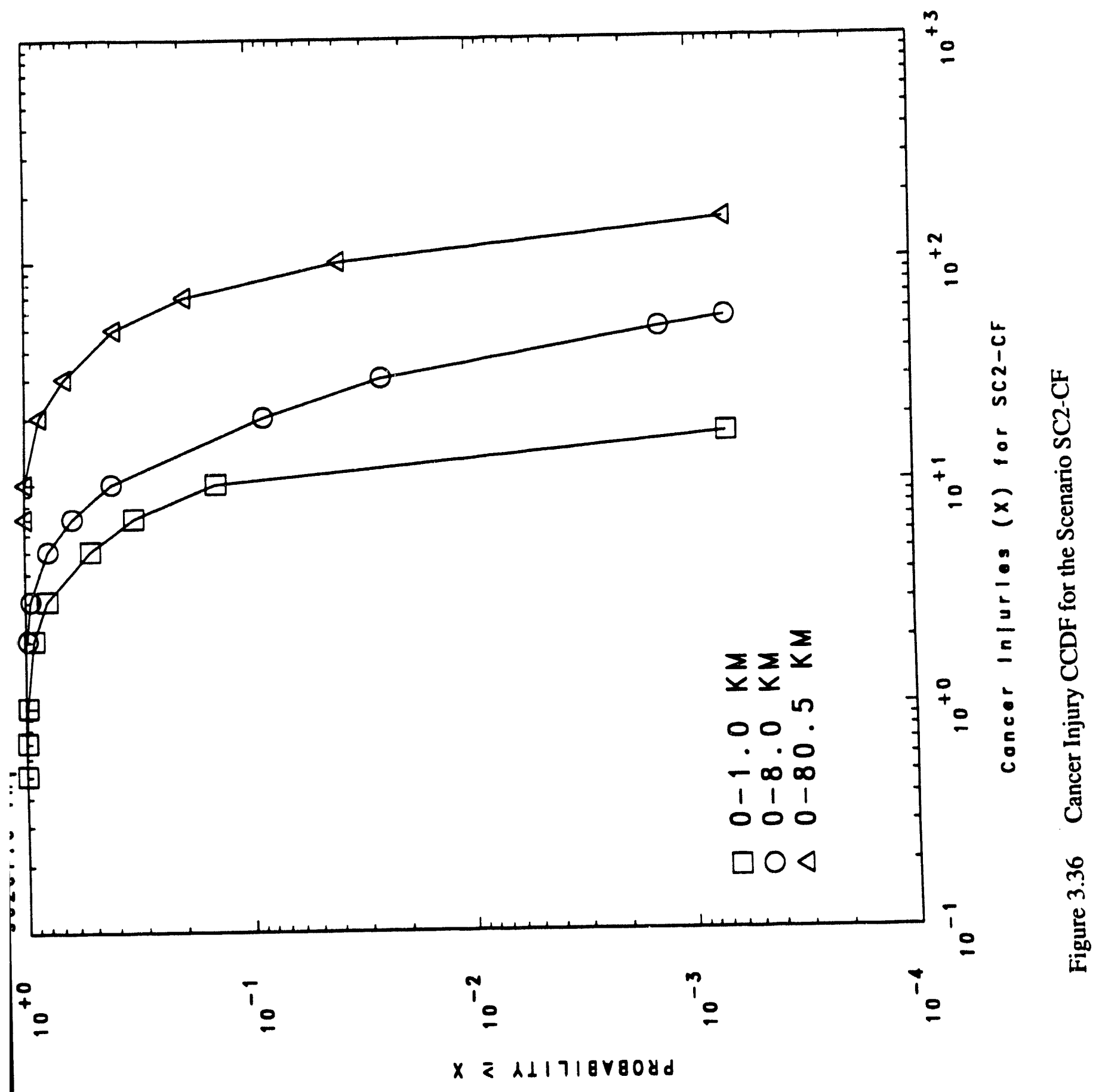




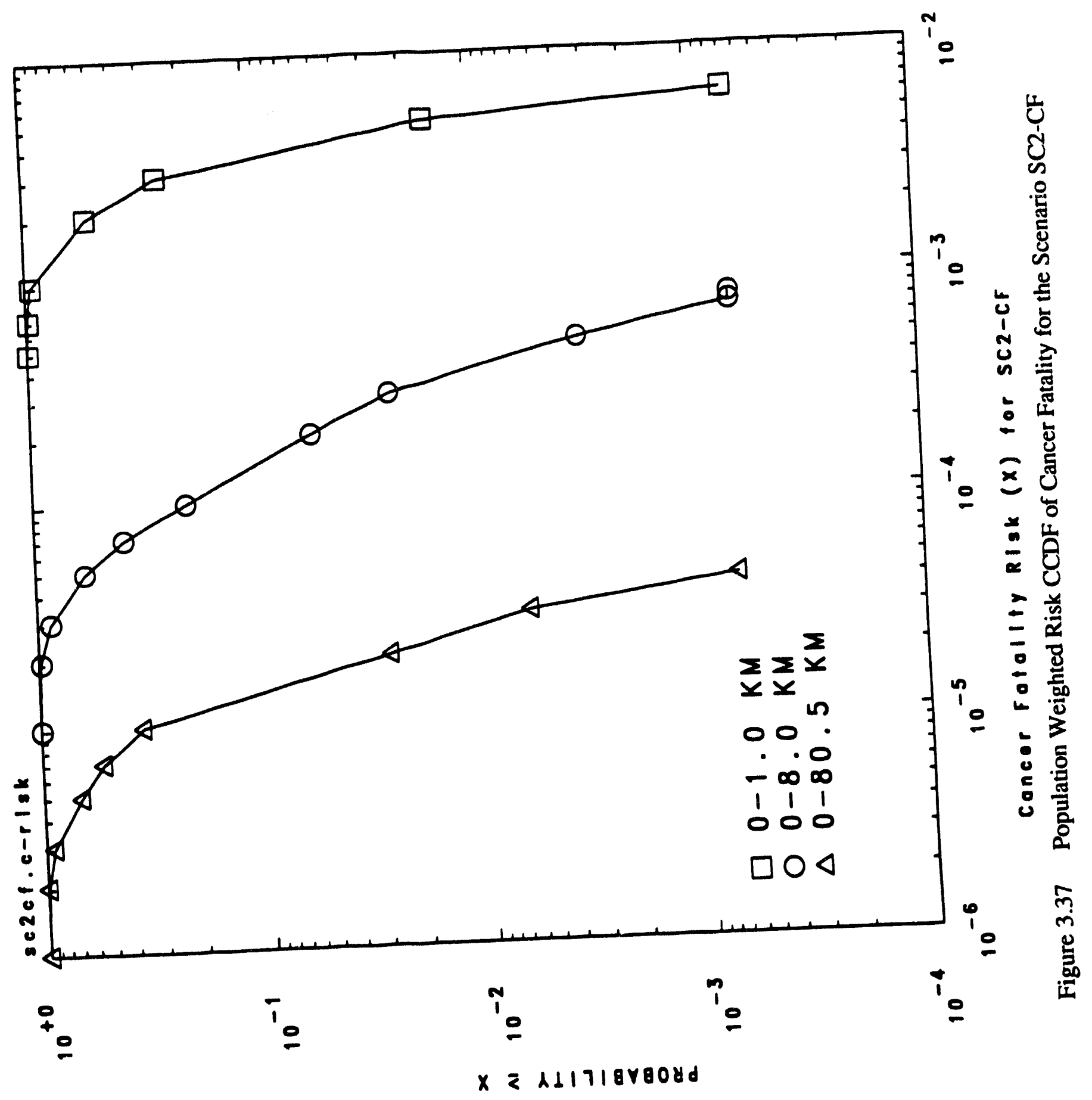




\section{SUMMARY AND CONCLUSIONS}

To summarize, the present study has provided conservatively scoped estimates of source terms arising from three different severe accident scenarios for three different containment configurations. In addition, the methodology, assumptions, modeling of various features related to radiation exposure, and radiological consequences from those source terms have been described.

The results of this study, discussed in detail in the proceeding sections, show that the conceptual design meets the radiological risk limitation goals that have been established for the ANS Project. One of the ten sequences reported in this section adopts the radionuclide source term and containment performance assumptions prescribed by 10 CFR 100 for evaluation of site suitability. The predicted consequences for this event are very small compared to the $0.25 \mathrm{~Sv}$ ( $25 \mathrm{rem}$ ) radiation exposure guidelines in $10 \mathrm{CFR} 100$; thus, the ANS design basis containment capabilities go beyond the minimum requirements of the regulations.

The calculations for six of the ten sequences investigated in this study assume partial or complete containment failure. Although the net risk attributed to these sequences is small and acceptable, the consequences would be significant, especially for personnel in the closest kilometer or two. These failures are not an inevitable consequence of the postulated core meltdown itself but rather reflect the finite possibility that containment isolation valves might not close and to a certain extent uncertainty over whether an energetic event might be able to penetrate primary and/or secondary containment with a shock wave or missile. Elimination of containment failure could yield significant risk reduction or perhaps the elimination of significant risk in a deterministic sense. This will therefore be a priority for design studies and severe accident calculations during the advanced conceptual phase planned for the ANS. 


\section{REFERENCES}

1. C. D. West, The Advanced Neutron Source: A New Reactor Based Facility for Neutron Research, Transactions of the American Nuclear Society, 61, p.375, June 1990.

2. F. J. Peretz, Advanced Neutron Source Plant Design Requirements, ORNL/TM11625, Oak Ridge National Laboratory, Oak Ridge, TN, 1991.

3. R. P. Taleyarkhan and S. H. Kim, Severe Accident Risk Minimization Studies for the Advanced Neutron Source at the Oak Ridge National Laboratory, Proceedings of the Fifth Workshop on Containment Integrity, Washington, D.C., May 1992.

4. DiNunno et al., Technical Information Document, TID-14844, U.S. Atomic Energy Commission, Washington, D.C., 1963

5. Chanin et al., MELCOR Accident Consequence Code System, NUREG/CR-4691, Washington, D.C., 1990.

6. DOE (U.S. Department of Energy) 1991. Draft Environmental Impact Statement for the Siting, Construction, and Operation of New Production Reactor Capacity, Vol. 1, DOE/EIS-01440, April

7. C. R. Hyman and R. P. Taleyarkhan, Characterization of Core Debris/Concrete Interactions for the Advanced Neutron Source, ORNL/TM-11761, Oak Ridge National Laboratory, Oak Ridge, Tenn., 1991.

8. NRC (U.S. Nuclear Regulatory Commission) 1975. Reactor Safety Study, NUREG/75-0114, Washington, D. C.

9. Ritchie et al., Calculation of Reactor Accident Consequences, Version 2, USNRC Report NUREG/CR-2324, Sandia National Laboratories, Albuquerque, New Mexico, 1981.

10. Saito et al., "Further Data of Silicide Fuel for the LEU Conversion of JMTR," Proceedings of the International Symposium on Research Reactor Safety, Operations and Modifications, IAEA-SM-310/59P, Vienna, 1989.

11. Summers et al., MELCOR 1.8.0: A Computer Code for Nuclear Reactor Severe Accident Source Term and Risk Assessment Analyses, NUREG/CR-5531, Washington, D.C., 1991.

12. Taleyarkhan, R. P. Analysis and Modeling of Fission Product Release from Heated Uranium - Aluminum Plate-Type Reactor Fuels, Nuclear Safety, Vol. 33-1, 6-22, January - March 1992.

13. Croff, A. G., A User's Manual for the ORIGEN2 Computer Code, ORNL/TM7175, July 1980 . 


\section{Appendix A}

\section{Determination of Equivalent Activities for MACCS Calculations}

This appendix provides a brief description of the method used for arriving at equivalent activities of isotopes in order to conduct MACCS calculations for off-site radiological consequences.

As mentioned previously in Chapter 3, not all of the isotopes from ORIGEN code depletion calculations are represented in the MACCS health effects database. This database was developed primarily for conducting radiological consequence calculations for power reactor severe accidents. As such, the database consists of information on about 60 isotopes only. From the ORIGEN calculations for End-Of-Cycle (EOC) conditions, 112 isotopes were evaluated as contributing to the top $99.9 \%$ of decay power. These isotopes are listed in Table A.1. Unfortunately, as mentioned above, not all of these isotopes are represented in the MACCS database. In order to account for the health effects of the non-MACCS isotopes, a simple transformation criterion was developed utilizing the following equation

$$
B_{a m, i}=B_{m, i}+B_{m, j} \frac{D_{m, i}}{D_{m, j}}
$$

where,

$$
\begin{aligned}
& B_{e m, i}=\text { Equivalent activity level for a MACCS isotope, } i \\
& B_{m, i}=\text { Activity level of MACCS isotope, } i, \text { calculated with ORIGEN, } \\
& B_{m, j}=\text { Activity level of a non-MACCS isotope, } j, \text { calculated with ORIGEN, } \\
& D_{m, j}=\text { Dose conversion factor for the non-MACCS isotope, } j, \text { and } \\
& D_{m, j}=\text { Dose conversion factor for the MACCS isotope, } i .
\end{aligned}
$$

Utilizing the above formula of Eq. (A.1) requires knowledge of dose conversion factors which have the units of Sv/Bq for internal exposure. Appropriate dose conversion factors were derived utilizing computer codes DFINT (for internal exposures) and DFEXT (for external exposure) developed at Oak Ridge National Laboratory (ORNL) by Keith Eckermian. These codes were obtained via personal communication. Upon developing information dose conversion factors, Eq. (A.1) was used to arrive at the appropriate equivalent activity levels for MACCS isotopes. The mechanics of this process are shown in Table A.2. It should be noted that dose conversion factors listed in Table A.2 are for internal doses which were obtained for most isotopes except for noble 
gases. For noble gases, appropriate ratios of isotope effects for external exposure were developed using DFEXT. The last column of Table A.2 indicates whether an isotope, $i$, is represented in the MACCS database, and what isotopes, $\mathrm{j}$, were transformed to this isotope, $\mathrm{i}$. Assumptions made during this process, necessitated by the fact that for some isotopes such as $\mathrm{Rh}-105 \mathrm{~m}$ no dose conversion factors were available, even from DFINT. 
Table A.1. Activity Levels for Important Radionuclides at End-of-Cycle for ANS Core

\begin{tabular}{|c|c|c|c|c|c|}
\hline Nuclide & $\begin{array}{c}\text { Activity } \\
\text { (Bq) }\end{array}$ & $\begin{array}{c}\text { Activity } \\
\text { (Ci) }\end{array}$ & Nuclide & $\begin{array}{c}\text { Activity } \\
\text { (Bq) }\end{array}$ & $\begin{array}{c}\text { Activity } \\
\text { (Ci) }\end{array}$ \\
\hline$m n-56$ & $1.56 \times 10^{16}$ & $4.23 \times 10^{5}$ & $\mathrm{i}-131$ & $2.22 \times 10^{17}$ & $5.99 \times 10^{6}$ \\
\hline co-58 & $0.00 \times 100$ & $0.00 \times 10^{0}$ & te- 132 & $4.46 \times 10^{17}$ & $1.20 \times 10^{7}$ \\
\hline co-60 & $0.00 \times 10^{0}$ & $0.00 \times 10^{0}$ & $\mathrm{i}-132$ & $4.58 \times 10^{17}$ & $1.23 \times 10^{7}$ \\
\hline br-83 & $4.78 \times 10^{16}$ & $1.29 \times 10^{6}$ & te-133 & $7.44 \times 10^{16}$ & $2.01 \times 10^{6}$ \\
\hline$k r-83 m$ & $5.44 \times 10^{16}$ & $1.46 \times 10^{6}$ & te- $133 \mathrm{~m}$ & $1.83 \times 10^{17}$ & $4.95 \times 10^{6}$ \\
\hline br- 84 & $4.82 \times 10^{16}$ & $1.30 \times 10^{6}$ & $\mathrm{i}-133$ & $7.12 \times 10^{17}$ & $1.92 \times 10^{7}$ \\
\hline$k r-85$ & $7.34 \times 10^{13}$ & $1.98 \times 10^{3}$ & $x e-133$ & $5.22 \times 10^{17}$ & $1.41 \times 10^{7}$ \\
\hline $\mathrm{kr}-85 \mathrm{~m}$ & $1.19 \times 10^{17}$ & $3.22 \times 10^{6}$ & $x e-133 m$ & $2.15 \times 10^{16}$ & $5.80 \times 10^{5}$ \\
\hline$k r-87$ & $1.84 \times 10^{17}$ & $4.97 \times 10^{6}$ & te- 134 & $3.56 \times 10^{17}$ & $9.62 \times 10^{6}$ \\
\hline$k r-88$ & $3.18 \times 10^{17}$ & $8.60 \times 10^{6}$ & cs-134 & $2.88 \times 10^{14}$ & $7.78 \times 10^{3}$ \\
\hline $\mathrm{rb}-86$ & $1.31 \times 10^{14}$ & $3.54 \times 10^{3}$ & $\mathrm{i}-134$ & $6.67 \times 10^{17}$ & $1.80 \times 10^{7}$ \\
\hline $\mathrm{rb}-88$ & $3.47 \times 10^{17}$ & $9.37 \times 10^{6}$ & $i-135$ & $6.15 \times 10^{17}$ & $1.66 \times 10^{7}$ \\
\hline rb-89 & $9.91 \times 10^{16}$ & $2.68 \times 10^{6}$ & $x e-135$ & $5.29 \times 10^{16}$ & $1.42 \times 10^{6}$ \\
\hline sr-89 & $9.28 \times 10^{16}$ & $2.51 \times 10^{6}$ & $x e-135 m$ & $1.00 \times 10^{17}$ & $2.72 \times 10^{6}$ \\
\hline sr-90 & $5.79 \times 10^{14}$ & $1.56 \times 10^{4}$ & cs-136 & $8.62 \times 10^{14}$ & $2.33 \times 10^{4}$ \\
\hline st -91 & $5.86 \times 10^{17}$ & $1.58 \times 10^{7}$ & cs- 137 & $6.04 \times 10^{14}$ & $1.63 \times 10^{4}$ \\
\hline$y-90$ & $5.32 \times 10^{14}$ & $1.43 \times 10^{4}$ & xe-138 & $9.10 \times 10^{16}$ & $2.46 \times 10^{6}$ \\
\hline$y-91$ & $9.71 \times 10^{16}$ & $2.63 \times 10^{6}$ & cs-138 & $4.36 \times 10^{17}$ & $1.17 \times 10^{7}$ \\
\hline$y-91 m$ & $3.53 \times 10^{17}$ & $9.55 \times 10^{6}$ & cs-139 & $3.65 \times 10^{16}$ & $9.86 \times 10^{5}$ \\
\hline st-92 & $5.18 \times 10^{17}$ & $1.40 \times 10^{7}$ & ba-139 & $5.35 \times 10^{17}$ & $1.44 \times 10^{7}$ \\
\hline$y-92$ & $6.11 \times 10^{17}$ & $1.65 \times 10^{7}$ & ba- 140 & $3.65 \times 10^{17}$ & $9.86 \times 10^{6}$ \\
\hline sT -93 & $1.63 \times 10^{16}$ & $4.41 \times 10^{5}$ & la-140 & $3.31 \times 10^{17}$ & $8.94 \times 10^{6}$ \\
\hline$y-93$ & $6.56 \times 10^{17}$ & $1.77 \times 10^{7}$ & ba-141 & $1.36 \times 10^{17}$ & $3.68 \times 10^{6}$ \\
\hline$y-94$ & $1.60 \times 10^{17}$ & $4.32 \times 10^{6}$ & la-141 & $5.82 \times 10^{17}$ & $1.57 \times 10^{7}$ \\
\hline$y-95$ & $4.85 \times 10^{16}$ & $1.31 \times 10^{6}$ & ce- 141 & $1.64 \times 10^{17}$ & $4.42 \times 10^{6}$ \\
\hline$z \pi-95$ & $1.00 \times 10^{17}$ & $2.71 \times 10^{6}$ & ba- 142 & $4.46 \times 10^{16}$ & $1.20 \times 10^{6}$ \\
\hline nb-95 & $1.29 \times 10^{16}$ & $3.50 \times 10^{5}$ & $1 a-142$ & $5.00 \times 10^{17}$ & $1.35 \times 10^{7}$ \\
\hline zr-97 & $6.12 \times 10^{17}$ & $1.65 \times 10^{7}$ & la- 143 & $8.47 \times 10^{16}$ & $2.29 \times 10^{6}$ \\
\hline
\end{tabular}


Table A.1. (continued)

\begin{tabular}{|c|c|c|c|c|c|}
\hline Nuclide & $\begin{array}{c}\text { Activity } \\
\text { (Bq) }\end{array}$ & $\begin{array}{c}\text { Activity } \\
\text { (Ci) }\end{array}$ & Nuclide & $\begin{array}{c}\text { Activity } \\
\text { (Bq) }\end{array}$ & $\begin{array}{c}\text { Activity } \\
\text { (Ci) }\end{array}$ \\
\hline nb-97 & $6.28 \times 10^{17}$ & $1.70 \times 10^{7}$ & ce-143 & $6.31 \times 10^{17}$ & $1.71 \times 10^{7}$ \\
\hline nb-97m & $5.80 \times 10^{17}$ & $1.56 \times 10^{7}$ & $\mathrm{pr}-143$ & $2.74 \times 10^{17}$ & $7.41 \times 10^{6}$ \\
\hline mo-99 & $6.35 \times 10^{17}$ & $1.71 \times 10^{7}$ & ce-1 144 & $2.03 \times 10^{16}$ & $5.48 \times 10^{5}$ \\
\hline tc- $99 \mathrm{~m}$ & $5.60 \times 10^{17}$ & $1.51 \times 10^{7}$ & pr-144 & $4.04 \times 10^{16}$ & $1.09 \times 10^{6}$ \\
\hline mo-101 & $8.00 \times 10^{16}$ & $2.16 \times 10^{6}$ & pr-145 & $3.83 \times 10^{17}$ & $1.03 \times 10^{7}$ \\
\hline tc- 101 & $2.27 \times 10^{17}$ & $6.13 \times 10^{6}$ & ce-146 & $4.37 \times 10^{16}$ & $1.18 \times 10^{6}$ \\
\hline mo-102 & $3.70 \times 10^{16}$ & $9.99 \times 10^{5}$ & $\mathrm{pr}-146$ & $1.74 \times 10^{17}$ & $4.71 \times 10^{6}$ \\
\hline tc-102 & $3.73 \times 10^{16}$ & $1.00 \times 10^{6}$ & $\mathrm{pr}-147$ & $2.59 \times 10^{16}$ & $7.01 \times 10^{5}$ \\
\hline ru-103 & $7.57 \times 10^{16}$ & $2.04 \times 10^{6}$ & nd-147 & $1.26 \times 10^{17}$ & $3.41 \times 10^{6}$ \\
\hline rh-103m & $6.83 \times 10^{16}$ & $1.84 \times 10^{6}$ & nd-149 & $9.12 \times 10^{16}$ & $2.46 \times 10^{6}$ \\
\hline tc- 104 & $4.79 \times 10^{16}$ & $1.29 \times 10^{6}$ & pm-149 & $1.13 \times 10^{17}$ & $3.07 \times 10^{6}$ \\
\hline ru-105 & $1.06 \times 10^{17}$ & $2.87 \times 10^{6}$ & $\mathrm{pm}-150$ & $6.42 \times 10^{16}$ & $1.73 \times 10^{6}$ \\
\hline rh-105 & $1.84 \times 10^{16}$ & $4.97 \times 10^{5}$ & $\mathrm{pm}-151$ & $3.65 \times 10^{16}$ & $9.87 \times 10^{5}$ \\
\hline rh-105m & $2.98 \times 10^{16}$ & $8.06 \times 10^{5}$ & sm- 153 & $6.11 \times 10^{16}$ & $1.65 \times 10^{6}$ \\
\hline ru-106 & $1.28 \times 10^{15}$ & $3.46 \times 10^{4}$ & u-237 & $1.51 \times 10^{17}$ & $4.09 \times 10^{6}$ \\
\hline rh-106m & $2.27 \times 10^{16}$ & $6.14 \times 10^{5}$ & pu-238 & $7.69 \times 10^{11}$ & $2.08 \times 10^{1}$ \\
\hline sb- 127 & $1.63 \times 10^{16}$ & $4.42 \times 10^{5}$ & $n p-238$ & $1.24 \times 10^{16}$ & $3.35 \times 10^{5}$ \\
\hline te- 127 & $1.42 \times 10^{16}$ & $3.84 \times 10^{5}$ & u-239 & $2.35 \times 10^{17}$ & $6.35 \times 10^{6}$ \\
\hline te- $127 \mathrm{~m}$ & $1.35 \times 10^{14}$ & $3.65 \times 10^{3}$ & np-239 & $2.04 \times 10^{17}$ & $5.52 \times 10^{6}$ \\
\hline sn-128 & $2.42 \times 10^{16}$ & $6.53 \times 10^{5}$ & pu-239 & $5.66 \times 10^{10}$ & $1.53 \times 10^{0}$ \\
\hline sb- $128 \mathrm{~m}$ & $2.88 \times 10^{16}$ & $7.79 \times 10^{5}$ & $n p-240$ & $1.24 \times 10^{16}$ & $3.35 \times 10^{5}$ \\
\hline sb-129 & $6.57 \times 10^{16}$ & $1.77 \times 10^{6}$ & $n p-240 m$ & $3.07 \times 10^{15}$ & $8.30 \times 10^{4}$ \\
\hline te-129 & $6.47 \times 10^{16}$ & $1.75 \times 10^{6}$ & pu-240 & $9.25 \times 10^{10}$ & $2.50 \times 10^{0}$ \\
\hline te- $129 \mathrm{~m}$ & $2.82 \times 10^{15}$ & $7.62 \times 10^{4}$ & $u-240$ & $3.11 \times 10^{13}$ & $8.41 \times 10^{2}$ \\
\hline sb-131 & $8.10 \times 10^{16}$ & $2.19 \times 10^{6}$ & am-241 & $1.88 \times 1008$ & $5.08 \times 10^{3}$ \\
\hline te- 131 & $1.83 \times 10^{17}$ & $4.93 \times 10^{6}$ & pu-241 & $1.71 \times 10^{13}$ & $4.62 \times 10^{2}$ \\
\hline \multirow[t]{3}{*}{ te- $131 \mathrm{~m}$} & $3.93 \times 10^{16}$ & $1.06 \times 10^{6}$ & $\mathrm{~cm}-242$ & $4.54 \times 10^{10}$ & $1.23 \times 10^{0}$ \\
\hline & & & pu-243 & $1.12 \times 10^{15}$ & $3.03 \times 10^{4}$ \\
\hline & & & $\mathrm{cm}-244$ & $4.09 \times 10^{10}$ & $1.11 \times 10^{0}$ \\
\hline
\end{tabular}


Table A.2. Deriving Equivalent Activity Levels for MACCS Radionuclides at End-of-Cycle for ANS

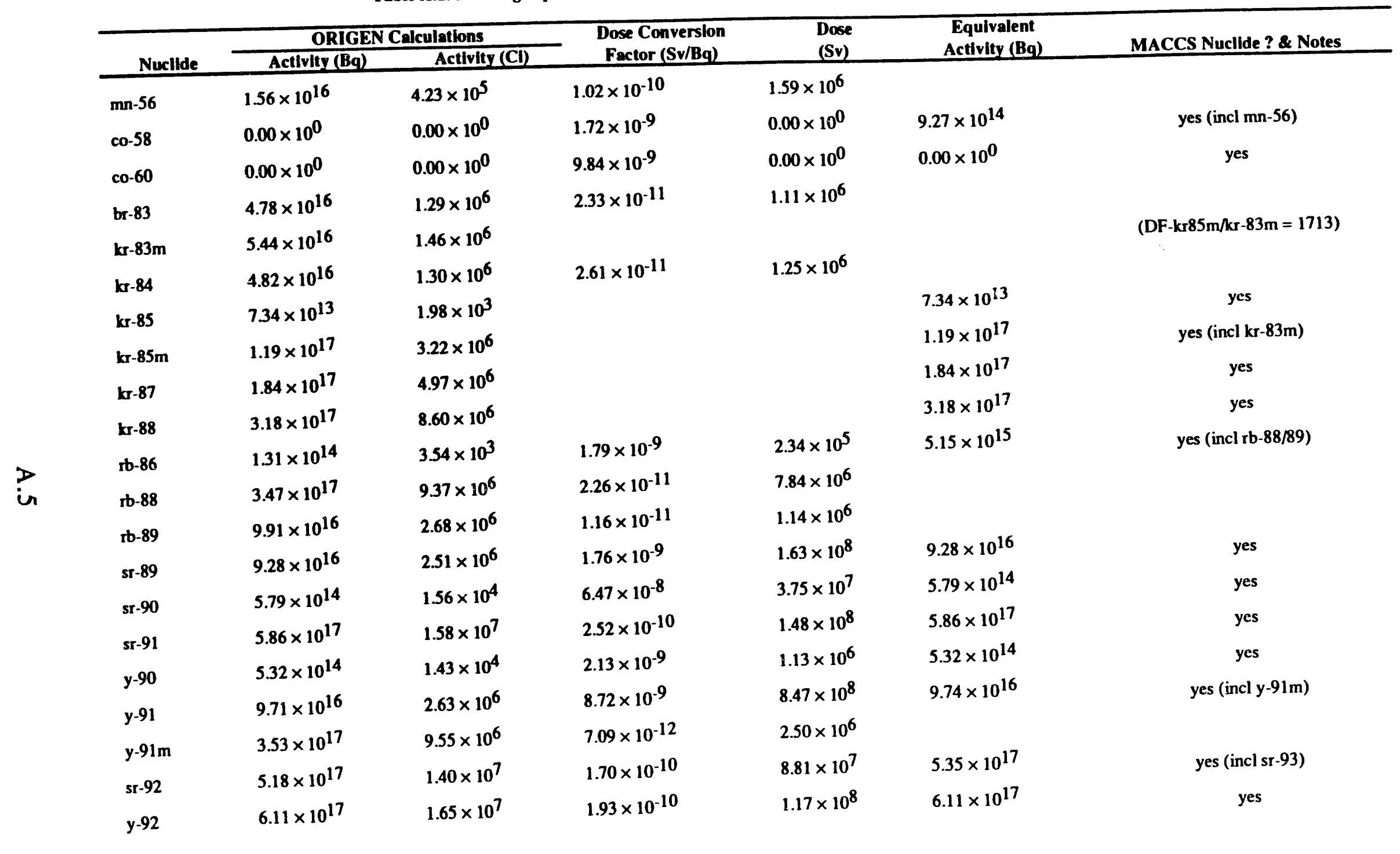




\begin{tabular}{|c|c|c|c|c|c|c|}
\hline Nuclide & \multicolumn{2}{|c|}{ ORIGEN Calculattons } & $\begin{array}{c}\text { Dose Conversion } \\
\text { Factor (Sv/Bq) } \\
\end{array}$ & $\begin{array}{l}\text { Dose } \\
\text { (Sv) }\end{array}$ & $\begin{array}{c}\text { Equivalent } \\
\text { Activity (Bq) } \\
\end{array}$ & MACCS Nucllde? \& Notes \\
\hline sr-93 & $1.63 \times 10^{16}$ & $4.41 \times 10^{5}$ & $1.70 \times 10^{-10}$ & $2.77 \times 10^{6}$ & & (st-92 DR assumed) \\
\hline$y-93$ & $6.56 \times 10^{17}$ & $1.77 \times 10^{7}$ & $5.29 \times 10^{-10}$ & $3.47 \times 10^{8}$ & $6.62 \times 10^{17}$ & yes (incl y-94/95) \\
\hline$y-94$ & $1.60 \times 10^{17}$ & $4.32 \times 10^{6}$ & $1.78 \times 10^{-11}$ & $2.84 \times 10^{6}$ & & \\
\hline y-95 & $4.85 \times 10^{16}$ & $1.31 \times 10^{6}$ & $9.59 \times 10^{-12}$ & $4.65 \times 10^{5}$ & & \\
\hline$z r-95$ & $1.00 \times 10^{17}$ & $2.71 \times 10^{6}$ & $6.39 \times 10^{-9}$ & $6.40 \times 10^{8}$ & $1.00 \times 10^{17}$ & yes \\
\hline nb-95 & $1.29 \times 10^{16}$ & $3.50 \times 10^{5}$ & $1.29 \times 10^{-9}$ & $1.67 \times 10^{7}$ & $3.24 \times 10^{16}$ & yes (incl nb-97/97m) \\
\hline$z x-97$ & $6.12 \times 10^{17}$ & $1.65 \times 10^{7}$ & $7.37 \times 10^{-10}$ & $4.51 \times 10^{8}$ & $6.12 \times 10^{17}$ & yes \\
\hline nb-97 & $6.28 \times 10^{17}$ & $1.70 \times 10^{7}$ & $2.08 \times 10^{-11}$ & $1.30 \times 10^{7}$ & & \\
\hline nb-97m & $5.80 \times 10^{17}$ & $1.56 \times 10^{7}$ & $2.08 \times 10^{-11}$ & $1.20 \times 10^{7}$ & & (nb-97 DF assumed) \\
\hline mo-99 & $6.35 \times 10^{17}$ & $1.71 \times 10^{7}$ & $5.42 \times 10^{-10}$ & $3.44 \times 10^{8}$ & $6.37 \times 10^{17}$ & yes (incl mo-101/102) \\
\hline tc-99m & $5.60 \times 10^{17}$ & $1.51 \times 10^{6}$ & $8.80 \times 10^{-12}$ & $4.93 \times 10^{6}$ & $8.26 \times 10^{17}$ & yes (incl tc-101/102/104) \\
\hline mo-101 & $8.00 \times 10^{16}$ & $2.16 \times 10^{6}$ & $1.12 \times 10^{-11}$ & $8.96 \times 10^{5}$ & & \\
\hline tc-101 & $2.27 \times 10^{17}$ & $6.13 \times 10^{6}$ & $4.84 \times 10^{-12}$ & $1.09 \times 10^{6}$ & & \\
\hline mo-102 & $3.70 \times 10^{16}$ & $9.99 \times 10^{5}$ & $1.12 \times 10^{-11}$ & $4.14 \times 10^{5}$ & & (mo-101 DF assumed) \\
\hline tc-102 & $3.73 \times 10^{16}$ & $1.00 \times 10^{6}$ & $4.84 \times 10^{-12}$ & $1.80 \times 10^{5}$ & & (Ic-101 DF assumed) \\
\hline ru-03 & $7.57 \times 10^{16}$ & $2.04 \times 10^{6}$ & $8.24 \times 10^{-10}$ & $6.24 \times 10^{7}$ & $7.57 \times 10^{6}$ & yes \\
\hline rh-103m & $6.83 \times 10^{16}$ & $1.84 \times 10^{6}$ & $1.38 \times 10^{-12}$ & $9.42 \times 10^{4}$ & & \\
\hline Ic-104 & $4.79 \times 10^{16}$ & $1.29 \times 10^{6}$ & $2.22 \times 10^{-11}$ & $1.06 \times 10^{6}$ & & \\
\hline n-105 & $1.06 \times 10^{17}$ & $2.87 \times 10^{6}$ & $9.84 \times 10^{-11}$ & $1.04 \times 10^{7}$ & $1.06 \times 10^{17}$ & yes \\
\hline rh-105 & $1.84 \times 10^{16}$ & $4.97 \times 10^{5}$ & $1.28 \times 10^{-10}$ & $2.36 \times 10^{6}$ & $2.97 \times 10^{16}$ & yes (incl rh-103m/105m/106m) \\
\hline m-105m & $2.98 \times 10^{16}$ & $8.06 \times 10^{5}$ & $1.38 \times 10^{-12}$ & $4.12 \times 10^{4}$ & & (rh-103m DF assumed) \\
\hline
\end{tabular}




\begin{tabular}{|c|c|c|c|}
\hline Nuclide & \multicolumn{2}{|c|}{ ORIGEN Calculations } & $\begin{array}{l}\text { Dose Conversto } \\
\text { Factor (Sv/Bg }\end{array}$ \\
\hline $\mathrm{ru}-106$ & $1.28 \times 10^{15}$ & $3.46 \times 10^{4}$ & $1.52 \times 10^{-8}$ \\
\hline th-106m & $2.27 \times 10^{16}$ & $6.14 \times 10^{5}$ & $5.77 \times 10^{-11}$ \\
\hline$s b-127$ & $1.63 \times 10^{16}$ & $4.42 \times 10^{5}$ & $6.55 \times 10^{-10}$ \\
\hline te- 127 & $1.42 \times 10^{16}$ & $3.84 \times 10^{5}$ & $6.74 \times 10^{-11}$ \\
\hline te- $127 \mathrm{~m}$ & $1.35 \times 10^{14}$ & $3.65 \times 10^{3}$ & $3.64 \times 10^{-9}$ \\
\hline sn-128 & $2.42 \times 10^{16}$ & $6.53 \times 10^{5}$ & $5.83 \times 10^{-11}$ \\
\hline sb-128m & $2.88 \times 10^{16}$ & $7.79 \times 10^{5}$ & $1.64 \times 10^{-10}$ \\
\hline$s b-129$ & $6.57 \times 10^{16}$ & $1.77 \times 10^{6}$ & $1.64 \times 10^{-10}$ \\
\hline te-129 & $6.47 \times 10^{16}$ & $1.75 \times 10^{6}$ & $2.42 \times 10^{-11}$ \\
\hline te- $129 m$ & $2.82 \times 10^{15}$ & $7.62 \times 10^{4}$ & $2.53 \times 10^{-9}$ \\
\hline sb-131 & $8.10 \times 10^{16}$ & $2.19 \times 10^{6}$ & $3.88 \times 10^{-11}$ \\
\hline te-131 & $1.83 \times 10^{17}$ & $4.93 \times 10^{6}$ & $1.29 \times 10^{-10}$ \\
\hline te-131m & $3.93 \times 10^{16}$ & $1.06 \times 10^{6}$ & $1.38 \times 10^{-9}$ \\
\hline $\mathrm{i}-131$ & $2.22 \times 10^{17}$ & $5.99 \times 10^{6}$ & $8.89 \times 10^{-9}$ \\
\hline te-132 & $4.46 \times 10^{17}$ & $1.20 \times 10^{7}$ & $2.26 \times 10^{-9}$ \\
\hline $\mathrm{i}-132$ & $4.58 \times 10^{17}$ & $1.23 \times 10^{7}$ & $1.03 \times 10^{-10}$ \\
\hline te- 133 & $7.44 \times 10^{16}$ & $2.01 \times 10^{6}$ & $2.49 \times 10^{-11}$ \\
\hline te-133m & $1.83 \times 10^{17}$ & $4.95 \times 10^{6}$ & $1.17 \times 10^{-10}$ \\
\hline $\mathrm{i}-133$ & $7.12 \times 10^{17}$ & $1.92 \times 10^{7}$ & $1.58 \times 10^{-9}$ \\
\hline xe-133 & $5.22 \times 10^{17}$ & $1.41 \times 10^{7}$ & \\
\hline xe-133m & $2.15 \times 10^{16}$ & $5.80 \times 10^{5}$ & \\
\hline
\end{tabular}

$1.95 \times 10^{7}$

$1.28 \times 10^{15}$

$1.31 \times 10^{6}$

$1.07 \times 10^{7}$

$1.63 \times 10^{16}$

yes

$9.58 \times 10^{5}$

$1.42 \times 10^{16}$

yes

$4.91 \times 10^{5}$

$1.35 \times 10^{14}$

yes

$1.40 \times 10^{6}$

$4.73 \times 10^{6}$

$1.07 \times 10^{7}$

$1.22 \times 10^{17}$

$1.56 \times 10^{6}$

$6.47 \times 10^{16}$

$7.13 \times 10^{6}$

$2.82 \times 10^{15}$

(sb-129 DF assumed)

$3.14 \times 10^{6}$

$2.35 \times 10^{7}$

$5.42 \times 10^{7}$

$7.19 \times 10^{16}$

$1.97 \times 10^{9}$

$2.22 \times 10^{17}$

$1.00 \times 10^{9}$

$4.52 \times 10^{17}$

$4.72 \times 10^{7}$

$4.81 \times 10^{17}$

$1.85 \times 10^{6}$

$2.14 \times 10^{7}$

$1.12 \times 10^{9}$

$7.12 \times 10^{17}$

yes

$5.40 \times 10^{17}$

yes (incl sn-128, sb-128m/131)

yes

yes

yes (incl te-131/133m)

yes

yes (incl te-133/134)

yes (incl br-83/84)

yes (incl xe-133m)

(DF-xe-133/xe-133m=1.8) 


\begin{tabular}{|c|c|c|c|c|c|c|}
\hline Nucllde & \multicolumn{2}{|c|}{ ORIGEN Calculations } & $\begin{array}{c}\text { Dose Conversion } \\
\text { Factor (Sv/Bq) } \\
\end{array}$ & $\begin{array}{l}\text { Dose } \\
\text { (Sv) }\end{array}$ & $\begin{array}{c}\text { Equivalent } \\
\text { Activity (Bq) } \\
\end{array}$ & MACCS Nucllide? \& Notes \\
\hline te-134 & $3.56 \times 10^{17}$ & $9.62 \times 10^{6}$ & $3.44 \times 10^{-11}$ & $1.22 \times 10^{7}$ & & \\
\hline cs-134 & $2.88 \times 10^{14}$ & $7.78 \times 10^{3}$ & $1.25 \times 10^{-8}$ & $3.60 \times 10^{6}$ & $2.88 \times 10^{14}$ & yes \\
\hline $\mathrm{i}-134$ & $6.67 \times 10^{17}$ & $1.80 \times 10^{7}$ & $3.55 \times 10^{-11}$ & $2.37 \times 10^{7}$ & $6.67 \times 10^{17}$ & $\begin{array}{l}\text { yes } \\
\text { yes }\end{array}$ \\
\hline$i-135$ & $6.15 \times 10^{17}$ & $1.66 \times 10^{7}$ & $3.32 \times 10^{-10}$ & $2.04 \times 10^{8}$ & $6.15 \times 10^{17}$ & $\begin{array}{l}\text { yes } \\
\text { yes }\end{array}$ \\
\hline xe-135 & $5.29 \times 10^{16}$ & $1.42 \times 10^{6}$ & & & & $\begin{array}{c}\text { yes } \\
\text { yes (incl xe-135m/138) }\end{array}$ \\
\hline$x e-135 m$ & $1.00 \times 10^{17}$ & $2.72 \times 10^{6}$ & & & & $\begin{array}{c}\text { yes (incl xe-135m/138) } \\
\text { (DF-xe-135/xe-135m }=0.58)\end{array}$ \\
\hline cs- 136 & $8.62 \times 10^{14}$ & $2.33 \times 10^{4}$ & $1.98 \times 10^{-9}$ & $1.70 \times 10^{6}$ & $8.62 \times 10^{14}$ & $\begin{array}{c}(D F-x e-135 / x e-135 m=0.58) \\
\text { yes }\end{array}$ \\
\hline cs-137 & $6.04 \times 10^{14}$ & $1.63 \times 10^{4}$ & $8.63 \times 10^{-9}$ & $5.21 \times 10^{6}$ & $2.10 \times 10^{15}$ & $\begin{array}{c}\text { yes } \\
\text { yes (incl cs-138/139) }\end{array}$ \\
\hline$x e-138$ & $9.10 \times 10^{16}$ & $2.46 \times 10^{6}$ & & & & $\begin{array}{c}\text { yes }(\text { incl cs-138/139) } \\
(\text { DF-xe-135/xe-138 = 0.2) }\end{array}$ \\
\hline cs-138 & $4.36 \times 10^{17}$ & $1.17 \times 10^{7}$ & $2.74 \times 10^{-11}$ & $1.19 \times 10^{7}$ & & $(D F-x e-135 / x e-138=0.2)$ \\
\hline cs-139 & $3.65 \times 10^{16}$ & $9.86 \times 10^{5}$ & $2.74 \times 10^{-11}$ & $1.00 \times 10^{6}$ & & \\
\hline ba-139 & $5.35 \times 10^{17}$ & $1.44 \times 10^{7}$ & $4.64 \times 10^{-11}$ & $2.48 \times 10^{7}$ & $5.35 \times 10^{17}$ & $\begin{array}{c}\text { (cs-138 DF assumed) } \\
\text { yes }\end{array}$ \\
\hline ba- 140 & $3.65 \times 10^{17}$ & $9.86 \times 10^{6}$ & $1.01 \times 10^{-9}$ & $3.68 \times 10^{8}$ & $3.68 \times 10^{17}$ & $\begin{array}{c}\text { yes } \\
\text { yes (incl ba-141/142) }\end{array}$ \\
\hline la- 140 & $3.31 \times 10^{17}$ & $8.94 \times 10^{6}$ & $9.33 \times 10^{-10}$ & $3.09 \times 10^{8}$ & $3.31 \times 10^{17}$ & $\begin{array}{c}\text { yes (incl ba-141/142) } \\
\text { yes }\end{array}$ \\
\hline ba- 141 & $1.36 \times 10^{17}$ & $3.68 \times 10^{6}$ & $2.18 \times 10^{-11}$ & $2.97 \times 10^{6}$ & & \\
\hline$|1-14|$ & $5.82 \times 10^{17}$ & $1.57 \times 10^{7}$ & $1.57 \times 10^{-10}$ & $9.14 \times 10^{7}$ & $5.82 \times 10^{17}$ & yes \\
\hline ce-141 & $1.64 \times 10^{17}$ & $4.42 \times 10^{6}$ & $2.25 \times 10^{-9}$ & $3.68 \times 10^{8}$ & $1.64 \times 10^{17}$ & $\begin{array}{l}\text { yes } \\
\text { yes }\end{array}$ \\
\hline ba- 142 & $4.46 \times 10^{16}$ & $1.20 \times 10^{6}$ & $1.11 \times 10^{-11}$ & $4.95 \times 10^{5}$ & & \\
\hline la- 142 & $5.00 \times 10^{17}$ & $1.35 \times 10^{7}$ & $6.84 \times 10^{-11}$ & $3.42 \times 10^{7}$ & $5.20 \times 10^{17}$ & yes (incl la-143) \\
\hline la-143 & $8.47 \times 10^{16}$ & $2.29 \times 10^{6}$ & $1.58 \times 10^{-11}$ & $1.33 \times 10^{6}$ & & \\
\hline & & & & & & \\
\hline
\end{tabular}




\begin{tabular}{|c|c|c|c|c|c|c|c|}
\hline & Nuclide & $\begin{array}{c}\text { ORIGES } \\
\text { Activity }(\mathrm{Bq}) \\
\end{array}$ & ORIGEN Calculations & $\begin{array}{c}\text { Dose Conversion } \\
\text { Factor (Sv/Bq) }\end{array}$ & $\begin{array}{l}\text { Dose } \\
\text { (Sv) }\end{array}$ & $\begin{array}{c}\text { Equivalent } \\
\text { Activity (Bq) } \\
\end{array}$ & MACCS Nuclide? \& Notes \\
\hline & ce-143 & $6.31 \times 10^{17}$ & $1.71 \times 10^{7}$ & $8.66 \times 10^{-10}$ & $5.47 \times 10^{8}$ & $6.31 \times 10^{17}$ & yes \\
\hline & pr-143 & $2.74 \times 10^{17}$ & $7.41 \times 10^{6}$ & $2.04 \times 10^{-9}$ & $5.60 \times 10^{8}$ & $3.20 \times 10^{17}$ & yes (incl pr-144/145/146/147) \\
\hline & ce-144 & $2.03 \times 10^{16}$ & $5.48 \times 10^{5}$ & $5.84 \times 10^{-8}$ & $1.18 \times 10^{9}$ & $6.40 \times 10^{16}$ & yes (incl ce-146) \\
\hline & pr-144 & $4.04 \times 10^{16}$ & $1.09 \times 10^{6}$ & $1.10 \times 10^{-11}$ & $4.45 \times 10^{5}$ & & \\
\hline & $p r-145$ & $3.83 \times 10^{17}$ & $1.03 \times 10^{7}$ & $1.65 \times 10^{-10}$ & $6.32 \times 10^{7}$ & & \\
\hline & ce-146 & $4.37 \times 10^{16}$ & $1.18 \times 10^{6}$ & $5.84 \times 10^{-8}$ & $2.55 \times 10^{9}$ & & (ce-144 DF assumed) \\
\hline & pr-146 & $1.74 \times 10^{17}$ & $4.71 \times 10^{6}$ & $1.65 \times 10^{-10}$ & $2.88 \times 10^{7}$ & & (pr-145 DF assumed) \\
\hline & $\begin{array}{l}\text { pr-147 } \\
\text { nd-147 }\end{array}$ & $2.59 \times 10^{16}$ & $7.01 \times 10^{5}$ & $7.72 \times 10^{-12}$ & $2.00 \times 10^{5}$ & & \\
\hline & $\begin{array}{l}\text { nd-147 } \\
\text { nd-149 }\end{array}$ & $\begin{array}{l}1.26 \times 10^{17} \\
9.12 \times 10^{16}\end{array}$ & $\begin{array}{l}3.41 \times 10^{6} \\
2.46 \times 10^{6}\end{array}$ & $\begin{array}{l}1.72 \times 10^{-9} \\
558 \times 10^{-11}\end{array}$ & $\begin{array}{l}2.17 \times 10^{8} \\
5.09 \times 10^{6}\end{array}$ & $2.06 \times 10^{17}$ & yes (incl nd-149, pm-149/150/151, sm-153 \\
\hline & $\mathrm{pm}-149$ & $\begin{array}{l}9.12 \times 10^{10} \\
1.13 \times 10^{17}\end{array}$ & $\begin{array}{l}2.46 \times 10^{6} \\
3.07 \times 10^{6}\end{array}$ & $\begin{array}{l}5.58 \times 10^{-11} \\
7.44 \times 10^{-10}\end{array}$ & $\begin{array}{l}5.09 \times 10^{6} \\
8.44 \times 10^{7}\end{array}$ & & \\
\hline & pm-150 & $6.42 \times 10^{16}$ & $\begin{array}{l}3.07 \times 10^{6} \\
1.73 \times 10^{6}\end{array}$ & $\begin{array}{l}7.44 \times 10^{-20} \\
8.85 \times 10^{-11}\end{array}$ & $\begin{array}{l}8.44 \times 10^{7} \\
5.68 \times 10^{6}\end{array}$ & & \\
\hline & $\mathrm{pm}-151$ & $3.65 \times 10^{16}$ & $9.87 \times 10^{5}$ & $4.38 \times 10^{-10}$ & $1.60 \times 10^{7}$ & & \\
\hline b & $\mathrm{sm}-153$ & $6.11 \times 10^{16}$ & $1.65 \times 10^{6}$ & $5.31 \times 10^{-10}$ & $3.24 \times 10^{7}$ & & \\
\hline & $u-237$ & $1.51 \times 10^{17}$ & $4.09 \times 10^{6}$ & $5.32 \times 10^{-10}$ & $8.05 \times 10^{7}$ & & \\
\hline & pu-238 & $7.69 \times 10^{11}$ & $2.08 \times 10^{1}$ & $1.06 \times 10^{-4}$ & $8.15 \times 10^{7}$ & $1.54 \times 10^{12}$ & \\
\hline & $n p-238$ & $1.24 \times 10^{16}$ & $3.35 \times 10^{5}$ & $1.00 \times 10^{-8}$ & $1.24 \times 10^{8}$ & & yes (incl u237/239) \\
\hline & $\begin{array}{l}\text { np-239 } \\
\text { pu-239 }\end{array}$ & $\begin{array}{l}2.04 \times 10^{17} \\
5.66 \times 10^{10}\end{array}$ & $\begin{array}{l}5.52 \times 10^{6} \\
1.53 \times 10^{0}\end{array}$ & $6.78 \times 10^{-10}$ & $1.38 \times 10^{8}$ & $5.91 \times 10^{17}$ & yes (incl np-238/239/240m) \\
\hline & pu-239 & & $1.53 \times 10^{0}$ & $1.16 \times 10^{-4}$ & $6.57 \times 10^{6}$ & $5.66 \times 10^{10}$ & 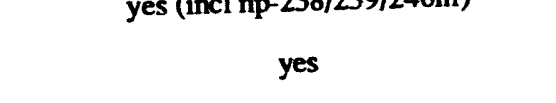 \\
\hline
\end{tabular}




\begin{tabular}{|c|c|c|c|c|c|c|}
\hline np-240 & $1.24 \times 10^{16}$ & $3.35 \times 10^{5}$ & $2.20 \times 10^{-11}$ & $2.73 \times 10^{5}$ & & \\
\hline $\mathrm{np}-240 \mathrm{~m}$ & $3.07 \times 10^{15}$ & $8.30 \times 10^{4}$ & $2.20 \times 10^{-11}$ & $6.75 \times 10^{4}$ & & (np-240 DF assumed) \\
\hline $\mathrm{pu}-240$ & $9.25 \times 10^{10}$ & $2.50 \times 10^{0}$ & $1.16 \times 10^{-4}$ & $1.07 \times 10^{7}$ & $9.26 \times 10^{10}$ & yes (incl $u-240$ ) \\
\hline$u-240$ & $3.11 \times 10^{13}$ & $8.41 \times 10^{2}$ & $4.21 \times 10^{-10}$ & $1.30 \times 10^{4}$ & & \\
\hline am-241 & $1.88 \times 10^{8}$ & $5.08 \times 10^{3}$ & $1.20 \times 10^{-4}$ & $2.26 \times 10^{4}$ & $1.88 \times 10^{8}$ & yes \\
\hline pu-241 & $1.71 \times 10^{13}$ & $4.62 \times 10^{2}$ & $2.23 \times 10^{-6}$ & $3.81 \times 10^{7}$ & $1.71 \times 10^{13}$ & yes (incl pu-243) \\
\hline $\mathrm{cm}-242$ & $4.54 \times 10^{10}$ & $1.23 \times 10^{0}$ & $4.67 \times 10^{-6}$ & $2.12 \times 10^{5}$ & $4.54 \times 10^{10}$ & yes \\
\hline pu-243 & $1.12 \times 10^{15}$ & $3.03 \times 10^{4}$ & $4.44 \times 10^{-11}$ & $4.97 \times 10^{4}$ & & \\
\hline $\mathrm{cm}-244$ & $4.09 \times 10^{10}$ & $1.11 \times 10^{0}$ & $6.70 \times 10^{-5}$ & $2.74 \times 10^{6}$ & $4.09 \times 10^{10}$ & yes \\
\hline
\end{tabular}


Internal Distribution List

1. W. G. Craddick

2. V. Georgevich

3. R. M. Harrington

4. J. E. Jones Jr.

5.-6. S. H. Kim

7. T. S. Kress

8. D. L. Moses

9. D. L. Selby
10. R. P. Taleyarkhan

11. S. Valenti

12. C. D. West

13. ORNL Patent Section

14. Central Research Library

15.-16.Laboratory Records

Department

17. Laboratory Records (RC)

\section{External Distribution}

18. F. Eltawila, USNRC, Division of Systems Research, Office of Regulatory Research, Washington, D.C., 20555

19. R. Wright, USNRC, Division of Systems of Research, Office of Regulatory Research, Washington, D.C., 20555

20.-21. DOE, Office of Scientific and Technical Information, P.O. Box 62, Oak Ridge, Tennessee 37831

22. AMERD, U.S. Department of Energy, Oak Ridge Operations Office, P.O. Box 2001, Oak Ridge, Tennessee 37831-8600

23. Hee-Dong Kim, Severe Accident Analysis Department, Nuclear Safety Research Division, Korea Atomic Energy Research Institute, P.O. Box 7, Daeduk-Danji, Daejon, South Korea

24. Jong-In Lee, Safety Engineering Division, Severe Accident Assessment Department, Korea Institute of Nuclear Safety, P.O. Box 16, Daeduk-Danji, Daejon, South Korea

25. D. H. Cho, Reactor Engineering Division, Argonne National Laboratory, 9700 South Cass Avenue, Argonne, Illinois 60439

26. Dr. Fujishiro, Deputy Director, Department of Reactor Safety Research, Tokai Research Establishment, Japan Atomic Energy Research Institute, Tokai-Mura, Naka-Gun, IbarakiKen 319-11, JAPAN

27. S. L. Thompson, MS-6418, Sandia National Laboratory, Albuquerque, New Mexico 87185 

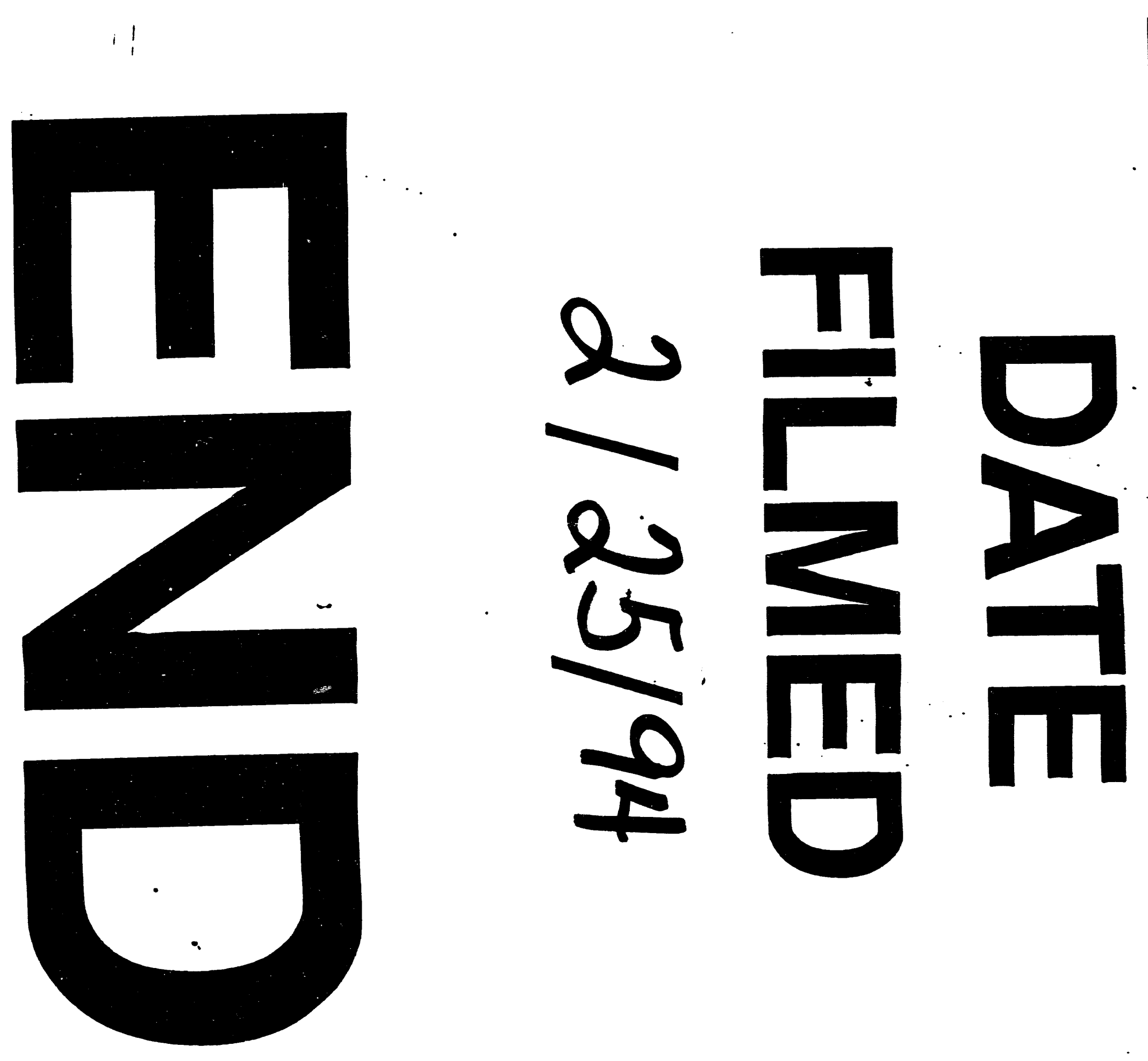
